\title{
BATTELLE ENERGY ALLIANCE, LLC (BEA) 2014 ANNUAL REPORT FOR IDAHO NATIONAL LABORATORY (INL)
}

\author{
Juan Alvarez and Todd Allen
}

October 2014

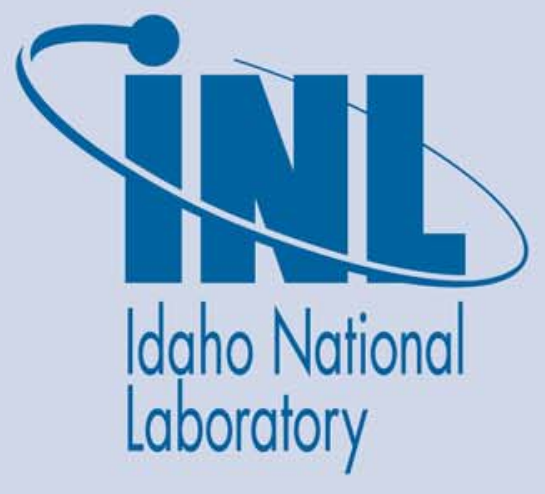

The INL is a U.S. Department of Energy National Laboratory operated by Battelle Energy Alliance 
INL/EXT-14-33245

\title{
BATTELLE ENERGY ALLIANCE, LLC (BEA) 2014 ANNUAL REPORT FOR IDAHO NATIONAL LABORATORY (INL)
}

\author{
Juan Alvarez and Todd Allen
}

October 2014

\author{
Idaho National Laboratory \\ Idaho Falls, Idaho 83415
}

http://www.inl.gov

Prepared for the

U.S. Department of Energy

Office of Nuclear Energy

Under DOE Idaho Operations Office

Contract DE-AC07-05ID14517 


\section{Self-Assessment Report}

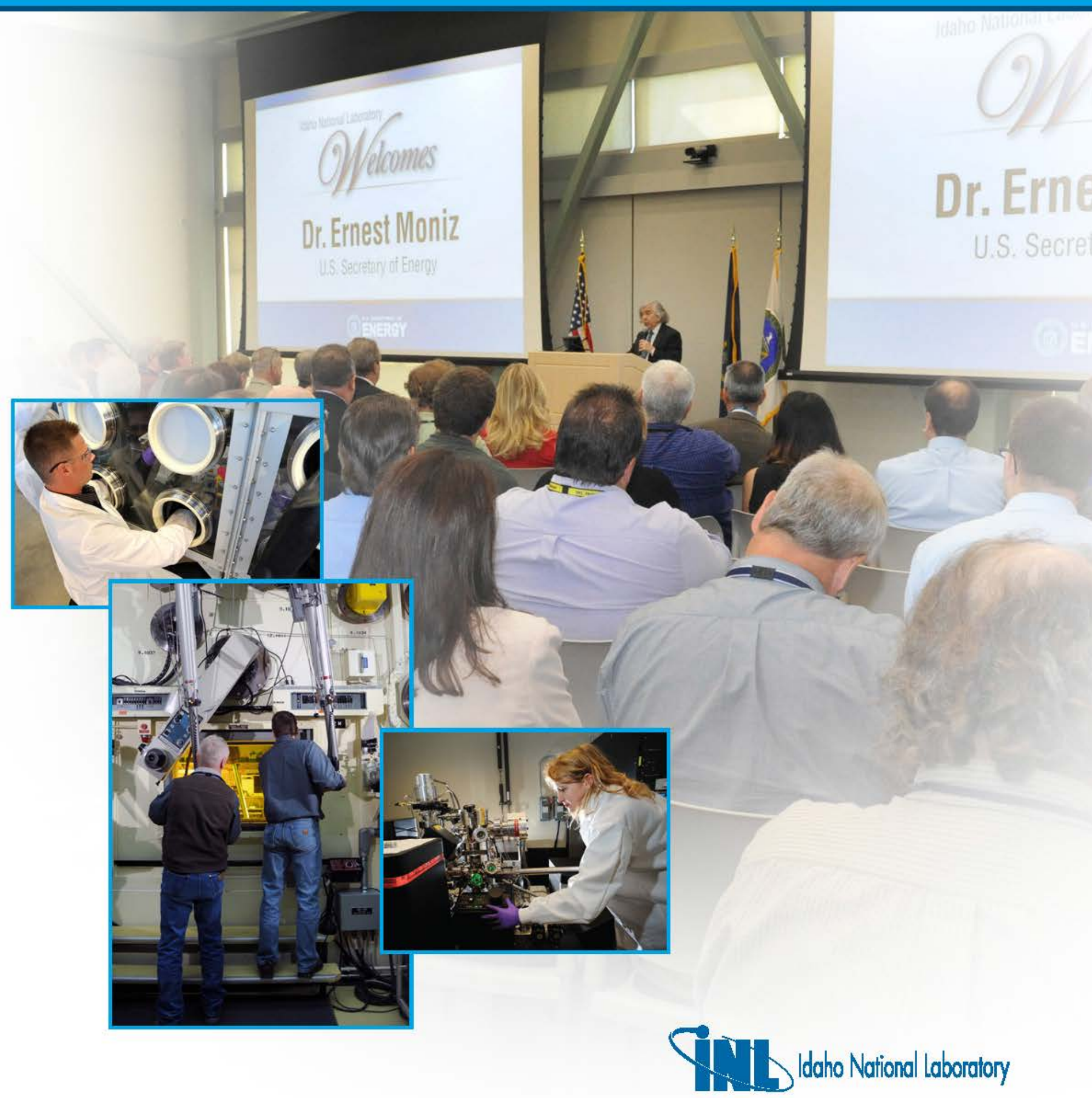




\section{On the front cover:}

Dr. Ernest Moniz, Visit to INL August 19-20, 2014

Steven Cook - Radiological Spark Plasma Sintering Researcher

Kent Dale and Brian Frickey - Hot Cell Operators

Melissa Teague - Materials Scientist

On the back cover (clockwise from top):

Megan Petti - INL Student Intern

Brad Anderson - INL Power Grid Researcher

INL Human System's Simulation Laboratory

Elliott Rolle - Hot Cell Operator

Lower left: Peter Zalupski - Aqueous Separations Researcher

Upper left: Aaron Wilson - Award Winning Chemist

\section{DISCLAIMER}

This information was prepared as an account of work sponsored by an agency of the U.S. Government. Neither the U.S. Government nor any agency thereof, nor any of their employees, makes any warranty, expressed or implied, or assumes any legal liability or responsibility for the accuracy, completeness, or usefulness, of any information, apparatus, product, or process disclosed, or represents that its use would not infringe privately owned rights. References herein to any specific commercial product, process, or service by trade name, trade mark, manufacturer, or otherwise, does not necessarily constitute or imply its endorsement, recommendation, or favoring by the U.S. Government or any agency thereof. The views and opinions of authors expressed herein do not necessarily state or reflect those of the U.S. Government or any agency thereof. 


\section{CONTENTS}

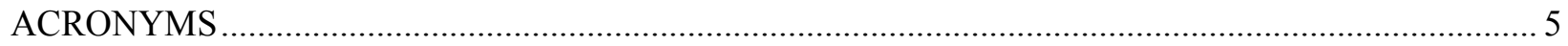

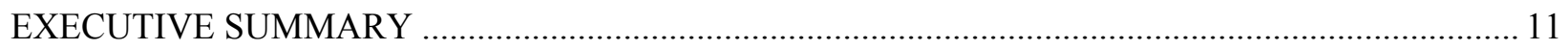

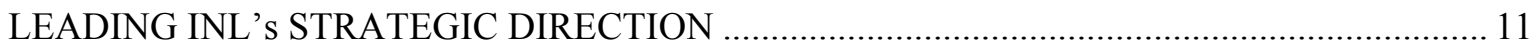

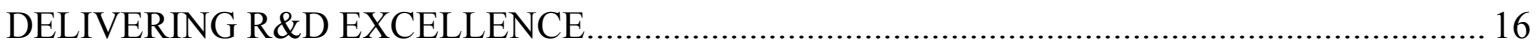

FIGURES

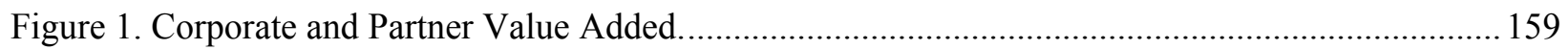

\section{ATTACHMENTS}

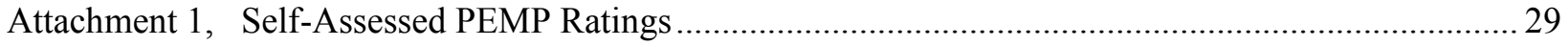

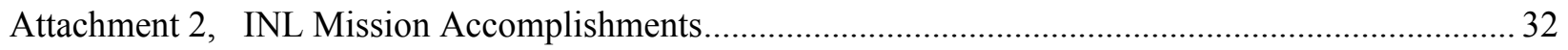

Attachment 3, Battelle Energy Alliance, LLC, Contributions to INL Success.................................... 159

Attachment 4, FY 2014 Awards, Recognition, Professional Roles and Certifications......................... 169

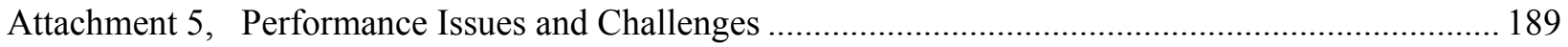




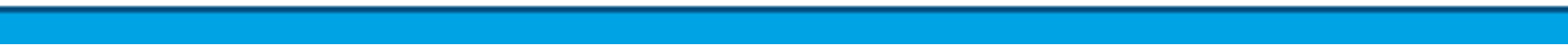




\section{ACRONYMS}

ACEP Alaska Center for Energy and Power

AEM Advanced Electrolyte Model

AFCI Advance Fuel Cycle Initiative

AL Analytical Laboratory

ALARA As Low As Reasonably Achievable

ANS American Nuclear Society

APS Arizona Public Service

ASME American Society of Mechanical Engineers

ASSET Aviation Security System Evaluation Tool

ATAC Attack Technology, Analysis, and Characterization

ATR Advanced Test Reactor

AVTA Advanced Vehicle Test Activity

B\&W Babcock and Wilcox

BEA Battelle Energy Alliance, LLC

BFNUF Biomass Feedstock National User Facility

BUMED Bureau of Medicine and Surgery

BWR Boiling Water Reactor

CAES Center for Advanced Energy Studies

CAP Corrective Action Plan

CFA Central Facilities Area

CMI Critical Materials Institute

COO Chief Operating Officer

$\mathrm{CoP} \quad$ Communities of Practice

CoR Conduct of Research

CRADA Cooperative Research and Development Agreement

CSCC Contractor Supply Chain Council

CSET Cyber Security Evaluation Tool

CWI CH2M-WG Idaho, LLC

D\&D Decontamination and Decommissioning

DHS Department of Homeland Security 
DOD Department of Defense

DOE Department of Energy

DOE-BES Department of Energy Basic Energy Sciences

DOE-EM Department of Energy Office of Environmental Management

DOEHRS Defense Occupational \& Environmental Health Readiness System

DOE-ID Department of Energy Idaho Operations Office

DOELAP Department of Energy Laboratory Accreditation Program

DOE-NE Department of Energy Office of Nuclear Energy

DOE-SC Department of Energy Office of Science

ECP Element Contact Profilometer

EdF Electricity de France

EERE Energy Efficiency and Renewable Energy

EFCOG Energy Facility Contractors Group

EFF Experimental Fuels Facility

EIL Energy Innovation Laboratory

EMI SIG Emergency Management Issues Special Interest Group

EPMA Electron Probe Micro-Analyzer

EPRI Electric Power Research Institute

ES\&H Environment, Safety, and Health

ESH\&Q Environment, Safety, Health \& Quality

ESTEC Energy System Technology and Education Center

$\mathrm{EV}$

Electric Vehicle

FCF Fuel Conditioning Facility

FCRD Fuel Cycle Research and Development

FIB Focused Ion Beam

FLC Federal Laboratory Consortium

FTE Full-Time Equivalent

FY Fiscal Year

G\&A General and Administrative

GASR Gas Assay, Sample, and Recharge

GE

General Electric

GEMS Generalized Environment for Modeling Systems $(\mathrm{C}$ 


\begin{tabular}{|c|c|}
\hline GHG & Greenhouse Gas \\
\hline GTRI & Global Threat Reduction Initiative \\
\hline HEU & Highly Enriched Uranium \\
\hline HFEF & Hot Fuel Examination Facility \\
\hline HPC & High Performance Computing \\
\hline HQ & Headquarters \\
\hline HSS & Health, Safety, and Security \\
\hline I2SL & International Institute for Sustainable Laboratories \\
\hline IAEA & International Atomic Energy Agency \\
\hline IASCC & Irradiation-Assisted Stress Corrosion Cracking \\
\hline ICS-CERT & Industrial Control Systems Cyber Emergency Response Team \\
\hline IEEE & Institute of Electrical and Electronics Engineers \\
\hline IFNEC & International Framework for Nuclear Energy Cooperation \\
\hline IMCL & Irradiated Materials Characterization Laboratory \\
\hline IMOM & Integrated Many-on-Many \\
\hline INL & Idaho National Laboratory \\
\hline INMM & Institute of Nuclear Materials Management \\
\hline INPO & Institute of Nuclear Power Operations \\
\hline INTEC & Idaho Nuclear Technology and Engineering Center \\
\hline IRT & Integrated Recycle Test \\
\hline ISMS & Integrated Safety Management System \\
\hline ISSM & Integrated Safeguards and Security Management \\
\hline i-STEM & Idaho STEM \\
\hline ISU & Idaho State University \\
\hline ITER & U.S. International Thermonuclear Experimental Reactor \\
\hline IUC & Idaho University Consortium \\
\hline JUICE & Joint Users Interoperability Communications Exercise \\
\hline LINE & Leadership in Nuclear Energy \\
\hline LOLA & Laboratory Operations Leadership Academy \\
\hline LTO & Long Term Operations \\
\hline LWR & Light Water Reactor \\
\hline LWRS & Light Water Reactor Sustainability \\
\hline
\end{tabular}


MAAP Modular Accident Analysis Program

MaCS Materials and Characterization Suite

MFC Materials and Fuels Complex

MIT Massachusetts Institute of Technology

MITR Massachusetts Institute of Technology Reactor

MOOSE Multiphysics Object Oriented Simulation Environment

MP Mini Plate

MSC Mission Support Center

N\&HS National and Homeland Security

NCCIC National Cybersecurity and Communications Integration Center

NCNR NIST Centre for Neutron Research

NEA Nuclear Energy Agency

NEAC Nuclear Energy Advisory Committee

NEAMS Nuclear Energy Advanced Modeling and Simulation

NEI Nuclear Energy Institute

NEPA National Environmental Policy Act

NEUP Nuclear Energy University Program

NFIR Nuclear Fuels Industry Research

NIST National Institute of Standards and Technology

NLCCO National Laboratory Chief Communication Officers

NLCIO National Laboratory Chief Information Officers

NNSA National Nuclear Security Administration

NPAS Nuclear Power Assessment Study

NPC Nuclear Power Council

NPI Nuclear Power Institute

NPSTC National Public Safety Telecommunications Council

NR Naval Reactors

NRAD Neutron Radiography Reactor

NREL National Renewable Energy Laboratory

NS\&T Nuclear Science \& Technology

NSF National Science Foundation

NSUF National Scientific User Facility 
NTC National Training Center

NUC National University Consortium

NWRCS National Wireless Research Collaboration Symposium

OECD-NEA Organization for Economic Co-operation and Development-Nuclear Energy Agency

OFR Operational and Functional Resilience

OMB Office of Management and Budget

ORNL Oak Ridge National Laboratory

ORPS Occurrence Reporting and Processing System

ORR Operational Readiness Review

PEMP Performance Evaluation and Measurement Plan

PFCN Private Facility Control Network

PIE Post-irradiation examination

PISA Potentially Inadequate Safety Analysis

PNNL Pacific Northwest National Laboratory

QA Quality Assurance

R\&D Research and Development

RAL Remote Analytical Laboratory

RAP Radiological Assistance Program

RDD\&D Research Development, Demonstration, and Deployment

ReACT Response Analysis Characterization Tool

ReSia Resilience and Security for Industrial Applications

RISMC Risk-Informed Safety Management Characterization

RMSS Radiological Monitoring and Seal System

RRAP Regional Resilience Assessment Program

RWP Radiological Work Permit

S\&T Science and Technology

SAE Society of Automotive Engineers

SAR Safety Analysis Report

SCiDAC Scientific Study through Advanced Computing

SLTTGCC State, Local, Tribal, and Territorial Government Coordinating Council

SMC Specific Manufacturing Capability

SNM Special Nuclear Material 
SPS-FO Switchable Polarity Solvent - Forward Osmosis

SSPA Shielded Sample Preparation Area

STEM Science, Technology, Engineering, and Math

SWAN Smart Water Networks

TEM Transmission Electron Microscope

TIO Technical Integration Office

TIP Top Industry Practice

TISP The Infrastructure Security Partnership

TMS The Minerals, Metals, and Materials Society

TREAT Transient Reactor Test Facility

TRISO Tristructural Isotropic

TSA Transportation Security Administration

TWR Traveling Wave Reactor

UAF University of Alaska Fairbanks

URS URS Corporation

U.S. United States

U.S. WIN United States Women in Nuclear

USQ Unresolved Safety Question

VEM Visual Examination Machine

VHTR Very High Temperature Reactor

VIPRE Versatile Internals and Component Program for Reactors; EPRI

WANO World Association of Nuclear Operators

WBS Work Break Down Structure

WFO Work for Others

WNUF Wireless National User Facility

ZPPR Zero Power Physics Reactor 


\section{Battelle Energy Alliance, LLC (BEA) 2014 Annual Report for Idaho National Laboratory (INL)}

\section{EXECUTIVE SUMMARY}

This Fiscal Year (FY) 2014 annual report provides the Department of Energy (DOE) with Battelle Energy Alliance, LLC's (BEA) self-assessment of performance managing and operating Idaho National Laboratory (INL) for the period ending September 30, 2014. After considering all of the information related to INL performance during the rating period against the Goals, Objectives, and Notable Outcomes in the FY 2014 Performance Evaluation and Measurement Plan (PEMP), BEA believes it earned an overall grade of an A.

The paragraphs below highlight how INL excelled in delivering innovative and impactful research across the three mission areas; how INL has successfully positioned itself for future growth and sustainment; and how, through strong leadership, INL has set and implemented a strategic direction to ensure we meet and exceed the expectations of DOE and other customers. Attachments 1 through 5 provide additional detail on FY 2014 mission accomplishments, outline corporate contributions for success, highlight national and international awards and recognitions at the organization and individual levels, and describe the performance issues and challenges faced in FY 2014.

- Attachment 1, "Self-Assessed PEMP Ratings"

- Attachment 2, "INL Mission Accomplishments"

- Attachment 3, "Battelle Energy Alliance, LLC, Contributions to INL Success"

- Attachment 4, "FY 2014 Awards, Recognition, Professional Roles and Certifications"

- Attachment 5, "Performance Issues and Challenges."

\section{LEADING INL's STRATEGIC DIRECTION}

FY 2014 was one of BEA's strongest in terms of, excelling in delivery of innovative and impactful research to mission areas; successfully positioning for future growth and sustainment despite the challenges of federal budget uncertainties; and setting and implementing a strongly led strategic direction to meet and exceed expectations of DOE and other customers. This progress was on display during the Secretary of Energy's visit to INL. When addressing both INL and DOE staff, Dr. Ernest Moniz stated INL is a "dramatically changed place in terms of the buildup of core research infrastructure...very impressed with the vision... a well-integrated, coherent strategic view of the kind of capabilities that we need to address near and mid-term nuclear issues."

During the course of the year, INL leadership engaged an unprecedented number of stakeholders to position INL for future success.

- The Laboratory hosted Pat Dehmer, Acting Director for the Office of Science (DOE-SC) to discuss efforts at INL to make our capabilities and talent more available to DOE-SC missions while strengthening INL's fundamental science resources and foundations by better utilization of SC assets. Additionally, a technical exchange meeting was held on the topic of radiation effects, material properties, and fuel properties with Laboratory and university staff who work in the Office of Nuclear 
Energy (DOE-NE) programs, Basic Energy Sciences (DOE-BES) programs, or both. Federal staff from both DOE-NE and DOE-SC (BES and Scientific Study through Advanced Computing [SCiDAC]) also participated. Pat Dehmer from DOE-SC and Pete Lyons, Assistant Secretary for DOE-NE, kicked off the meeting, which was intended to help better align the technical efforts between the two offices, both in scientific programs and in use of major user facilities.

- Engaged Admiral Richardson on efforts to expand INL-Naval Reactors (NR) collaboration in post-irradiation examination (PIE) and High Performance Computing (HPC).

- Continued leadership in the Leadership in Nuclear Energy (LINE) Commission enabling the development of a consent-based process in Idaho, as well as engaging the state in issues of used fuel shipment essential to INL's future mission work.

- $\quad$ Made significant progress to expand membership in the Center for Advanced Energy Studies (CAES) to include Wyoming.

- Facilitated discussions between the State, DOE-NE and the Department of Energy Office of Environmental Management (DOE-EM) on the future of environmental management work scope and responsibilities at the INL Site.

INL senior management led a significant culture change throughout the Laboratory, maximizing INL's impact and turning an important corner during the maturation of the institution. The progress is visible and the excitement is evident as you walk around the Laboratory. These changes include:

- Mission organizations have taken full ownership for research and operations performance as indicated by the work of the research Chief Operating Officers (COOs) and their leadership of the Research Excellence Board; development and implementation of Conduct of Research (CoR); researcher participation to improve institutional processes (Research Integration Team); and the work of the Chief Scientist and Laboratory Fellows building a stronger intellectual infrastructure and growing the next generation of scientists and engineers through engagement of early career researchers in mentoring sessions, strategic thinking, peer reviews, and knowledge transfer sessions.

- The research community, led by the research COOs, initiated a process to look at the Laboratory programs for conducting research from definition and acceptance to communication of results. The process has engaged the research community in an increased ownership of Laboratory results. The $\mathrm{CoR}$ program has also become the organizing construct through which the rest of the Laboratory is examining its procedures and processes, as evidenced by the enthusiastic response of the Laboratory managers in the All-Managers Meetings that defined three key areas for improvement: communicating strategy, valuing human resources, and simplifying processes.

- INL leadership has launched Laboratory initiatives to enhance integration of related research programs, advance scientific understanding, and evaluate and inform policy on nuclear security, hybrid energy systems and grid integration, resilience, and security. Multidisciplinary staff within INL's diverse research programs will work with the Laboratory's HPC capability, measurement and analysis tools, and scientific expertise to create the science, experiments, data, and capacity needed to improve predictive capabilities of systems and models; identify and understand phenomenology and functionality of these systems including how events impact resiliency; develop useful tools and information in collaboration with key stakeholders; and participate in national and international workshops. 
- INL leadership is demonstrating an improved ability to identify, prioritize, and correct problems. The use of LabWay has paved the way for more effective issue identification and resolution with implementation of formal management review meetings to discuss performance becoming routine. The Office of Nuclear Assurance has provided us with an independent regulatory perspective, driving improvements in nuclear safety and conduct of operations and maintenance. Similar impact can be seen in the work of Independent Oversight, which has leveraged leadership and expertise across INL and other DOE laboratories/sites to provide insights into enterprise-wide issues and their resolution.

INL took proactive steps to position the Laboratory for growth and continued success. Major areas of focus were growing our human capital base, strengthening nuclear and radiological safety, streamlining research processes, upgrading plant and equipment, and improving cost affordability and predictability.

- INL has responded the need to grow the human capital base after an extended period of workforce reductions. INL has filled over 550 requisitions with more than $60 \%$ of those requisitions filled by new hires. This high level of hiring activity was accomplished while simultaneously reestablishing a recruiting capability that had been lost during the previous three years of workforce restructuring. INL leadership developed a "toolkit" for hiring managers to recruit and retain critical and strategic staff, and has taken an enterprise approach to filling needs for nuclear facility talent by recruiting common positions across the Advanced Test Reactor (ATR), Materials and Fuels Complex (MFC), and Transient Reactor Test Facility (TREAT), and targeting strategic/critical expertise common to all nuclear operation facilities.

- The restart of TREAT and resumption of the transient testing initiative made substantial progress, including achieving a 10 CFR 830 compliant Safety Analysis Report (SAR), supporting development of materials for completion of the National Environmental Policy Act (NEPA) process and issuance of the Finding of No Significant Impact, and completion of screening activities that provide technical confidence that reactor major systems will support restart without major modification. Field work was initiated on the Automatic Reactor Control System, culminating with a successful startup of one of the system's computers and recovery of software from backups, providing confidence the system will ultimately be successfully returned to service. The reactor roof was replaced, and the plasma hearth enclosure and support equipment were successfully removed. The organization staffing is nearly complete, and key processes have been established for confirmation of system configuration and system operability.

- Building on the progress of FY 2013, INL continued to make improvements to nuclear and radiological safety by addressing schedule integration and adherence in support of DOE reviews and programmatic needs; ensuring Laboratory-level strategic direction is consistently applied across all facilities and projects; coordinating and supporting communications with DOE to ensure a consistent Laboratory message; improving facility/project support and execution through effective training, processes, and performance monitoring; and providing focused Laboratory leadership through participation with industry stakeholders and DOE to guide strategy and policy associated with nuclear safety programs. 
- ATR completed and made significant progress on several initiatives in the area of nuclear safety management. ATR closed the Potentially Inadequate Safety Analysis (PISA) Unresolved Safety Questions (USQ) associated with Water Power Calculator uncertainty, firewater supply, M 6 emergency diesel generator, and the Radiological Monitoring and Seal System (RMSS). By the end of the fiscal year, ATR will take possession of the new core modeling software Helios to model core loading and determine $\mathrm{K}$ effective via a solution to the full transport equation. Helios eliminates a number of empirical post processing codes currently in use, improving fidelity of data and reducing the likelihood of human performance error.

- Improvements were made to MFC Conduct of Operations to reduce error likely situations and human error by standardizing elements of Conduct of Operations (Control of System and Equipment Status, Temporary Modifications, and Log keeping) and strengthening of training. Collectively, these efforts have resulted in improved performance across many areas (labeling, posted operator aids, administrative tags, procedure use). The number and significance of Occurrence Reporting and Processing System (ORPS) events has been reduced by over 30\% from FY 2013. Under the special nuclear material (SNM) disposition program, more than 6,000 pounds of suspect contaminated metal and oxide beryllium plates and blocks were removed from the Zero Power Physics Reactor (ZPPR), thereby eliminating a significant potential respiratory hazard and obstacle to safe, efficient research at MFC.

- Major changes were made to INL's radiological control program with revisions to the Radiological Work Permit (RWP) and as low as reasonably achievable (ALARA) programs, improving work scoping, hazard identification, and mitigation. Improvements were also made to strengthen radiological control training and qualification programs for health physics technicians, supervisors, and radiological engineers. INL's air monitoring program has been changed to place emphasis on frequent small area smoke testing to provide real-time information for proper placement of portable air monitors and lapel sampling. Threshold changes in the air monitoring program have also been made to support bioassay program assumptions with automated notification and reporting systems that have improved monitoring efficiency. INL completed two DOE Laboratory Accreditation Program (DOELAP) accreditation assessments for external dosimetry and the indirect radio bioassay. INL leadership established an Instrument Evaluation Committee to standardize and replace radiological fixed instrumentation across the Laboratory to increase efficiency in training, operations, repairs, calibrations, and replacement. In FY 2014, over \$1M in mid-year funds were allocated to support this effort.

- INL leadership made progress to improve nuclear research facilities and capabilities. INL received delivery of a battery-backed uninterruptable power supply for ATR, replacing the continuously running diesel generators. Once the system is fully operational (expected in April 2015) it will provide improved reliability for electrical power and emergency power while reducing INL stationary diesel air emissions by more than $50 \%$. INL recapitalized major equipment at ATR to improve reliability, replacing the demineralizer tank, cooling tower variable frequency drives, primary coolant pump starter, and canal crane gearbox. INL also completed upgrades to MFC facility safety analyses documents, bringing to completion a 7-year effort to bring safety bases into compliance with DOE expectations. INL made extensive repairs and upgrades to Hot Fuel Examination Facility (HFEF) capabilities, including: Element Contact Profilometer (ECP) and Bow and Length machine and the associated data acquisition system to provide increased accuracy, reliability, and capabilities for future DOE-NE and commercial fuel exams; Gas Assay, Sample, and Recharge (GASR) system to support TerraPower, Fuel Cycle Research and Development (FCRD) and Commercial fuel exams; 
installed the first three of four feedthroughs for the new Visual Examination Machine (VEM) and eddy current equipment in support of commercial fuel exams; digital replacement cell pressure/temperature control consoles were upgraded to commercially available components; construction of a fiber-optic back-bone and development of the Private Facility Control Network (PFCN) (supports new material tracking database, upgraded cell control consoles, and new programmatic equipment); and fabrication of a smear presentation and radiation monitoring station for the HFEF Hot Repair Area, which will improve transfer efficiency and reduce personnel exposure.

- In support of new/expanded mission capabilities, approximately 800 cubic feet of legacy materials and waste have been removed from the HFEF, Fuel Conditioning Facility (FCF), and Analytical Laboratory (AL) hot cells. These efforts have increased the available window space at HFEF for new R\&D equipment by over $25 \%$.

- Two major HPC systems were acquired: Falcon, which is six times faster than INL's existing system, and Xerxes, which will reduce the cost of range testing of heavy armored vehicles though numerical simulation.

- The Laboratory's efforts to improve cost affordability and predictability faced an immediate hurdle at the start of the FY with the lapse in appropriations through the first three weeks of October. The Laboratory managed the impact by ensuring good and timely communication among the Laboratory, DOE-NE senior leadership, Field Office Management, and other Headquarters (HQ) staff; allowing DOE to effectively address impacts and external constituents. From a financial perspective, the Laboratory performed extensive analysis in collaboration with the DOE Idaho Operations Office (DOE-ID) and DOE-HQ to understand the impacts, provide timely and insightful decision support, and proactively position INL for the potential of an extended lapse in appropriations.

- The government shutdown, due to the lapse in appropriations, created significant funding uncertainty and had a major chilling effect on developing and growing programs. The Laboratory received notice late in the FY 2014 planning cycle that the Specific Manufacturing Capability (SMC) would incur a substantial cutback in production, resulting in a reduction of approximately $\$ 26 \mathrm{M}$ in business volume and 40 direct full-time equivalents (FTEs). INL leadership aggressively worked through this challenge by limiting indirect hiring, controlling non-labor expenditures, sweeping indirect budgets, and planning a reserve for events such as this. The Laboratory kept its stretch direct FTE target of 2,183 in place to incentivize growth and avoid the cost of lost opportunities, knowing it had levers in place to absorb a potential shortfall. This strategy was very successful as evidenced by a strongly favorable indirect recovery position and accelerating direct FTE growth later in the fiscal year. The Laboratory was able to release most of the indirect dollars swept earlier in the fiscal year for critical mission and infrastructure investments. Direct FTEs, which were languishing below 2,090 for the first six months of FY 2014, are projected to exceed 2,170 by the end of the FY. This has built positive momentum heading into FY 2015, with direct FTEs continuing to grow to an estimated 2,220-2,250. 
- Revamping the Laboratory's cost model was a major initiative in FY 2014. Several changes were designed, modeled, and vetted with INL management and DOE. The changes were designed to enable more effective and efficient cost management, planning and estimating, resource decisions, accountability, cost conscious behaviors, and transparency; improve customer optics; and address compliance/accounting practice concerns. By removing cost from Laboratory overheads and transferring it into service centers, coupled with applying more indirect cost to materials and subcontracts (more consistent with other DOE laboratories), these changes significantly reduced INL's labor multiplier and general and administrative (G\&A) rate - our most customer-sensitive cost metrics.

- In FY 2014, INL leadership drew upon resources and expertise at Battelle, Babcock and Wilcox (B\&W), URS, Electric Power Research Institute (EPRI), and partner universities and subcontractors to bring value to INL and DOE (see Attachment 3, "Battelle Energy Alliance, LLC, Contributions to INL Success").

INL took action to address FY 2014 challenges and performance weaknesses. INL took action to communicate the basic principle that all uptakes are preventable. A goal was set to minimize operational disruptions by reducing risk and moving toward containment of high activity alpha. Laboratory leadership communicated goals and expectations, took an INL-wide response (not just at MFC), and ensured containment is in place.

Another example of INL leadership overcoming a significant challenge involves the termination of the national insurance program. INL leadership was able to get BEA self-insured under Idaho Law (saving significant insurance premiums); obtain changes to the Idaho Law that greatly benefitted DOE; and successfully negotiate the annual workers' compensation tax down from an original amount of $\$ 500,000$ to $\$ 110,000$. Additional performance issues and challenges INL leadership faced or faces going forward are found in Attachment 5, "Performance Issues and Challenges."

The Laboratory made notable progress in sustaining and improving the facility and infrastructure portfolio to meet Laboratory needs and achieved tangible results as evidenced by beneficial occupancy of the Energy Innovation Laboratory (EIL). The 148,000 square foot EIL provides state-of-the art, re-configurable laboratory space and includes a meeting center for educational events. The beneficial impact was also recognized by DOE Assistant Secretary for Nuclear Energy Pete Lyons and DOE Assistant Secretary for Energy Efficiency and Renewable Energy David Danielson during the EIL dedication ceremony. Additionally, INL exceeded expectations for reducing non-value added space by demolishing more than 13,300 square feet of laboratory and office space. INL's active leadership and participation in the Laboratory Operations Board-sponsored Infrastructure Assessment Team activities resulted in submitting $\$ 40 \mathrm{M}$ worth of INL infrastructure project requests. These requests focused on revitalizing the critically important site-wide power distribution system and provided a potential to maintain momentum towards significant reduction of the deferred maintenance backlog.

\section{DELIVERING R\&D EXCELLENCE}

In FY 2014, INL's nuclear energy research programs made excellent progress, which was demonstrated through strong technical leadership, impactful and relevant research outcomes, a strong and unprecedented publication record, staff recognition, and number and nature of strategic collaborations. This was accomplished while also adding to capabilities developed in prior years. 
- INL continued to provide strong technical leadership for national nuclear energy research programs. INL worked closely with NE-4 to lead the development of a revised Nuclear Energy Roadmap. The Roadmap provided DOE-NE senior management with an improved program strategy consistent with administration priorities and vision for nuclear energy research in the U.S. INL led a multi-laboratory effort to propose a nuclear energy "big idea" that was presented to the Secretary of Energy at the National Laboratories Ideas Summit. The proposed "big idea" offered an innovative approach to accelerate deployment of advanced nuclear energy technologies. DOE-NE leadership fully endorsed the proposal and has begun to integrate elements thereof with program plans and budgets. INL also led a very successful national workshop to develop a programmatic roadmap for Nuclear Hybrid Energy applications under Integrated Energy Systems.

- INL continued to increase its reputation and influence as a leading nuclear energy research institution in the international arena. INL's leadership in nuclear energy was on display through convening of high-level meetings in support of DOE-NE that have led to bi-lateral and multi-lateral action plans and commitments from participating domestic and international organizations (e.g., 6th U.S.-India Civil Nuclear Energy Working Group, and Commissariat à l'énergie atomique et aux énergies Civil Nuclear Energy Bilateral Agreement). Noteworthy accomplishments include the establishment and subsequent chairmanship by INL staff of two new Organization for Economic Co-operation and Development-Nuclear Energy Agency (OECD-NEA) experts groups on Accident Tolerant Fuels, and Validation and Data Centers.

- INL staff continued to be recognized for their outstanding nuclear energy research by external entities through awards and special recognitions. Noteworthy, was the recognition of junior staff for their early career achievements including the Multiphysics Object Oriented Simulation Environment (MOOSE) team of five early career researchers led by Derek Gaston winning a Research and Development (R\&D) 100 Award; Piyush Sabharwall with the American Nuclear Society (ANS) Young Member's Achievement Award; Mike Tonks with The Minerals, Metals, and Materials Society (TMS) Young Leader Professional Development Award; Maria Okuniewski with ANS Material Science and Technology Division 2012 Student Literary Award; Troy Unruh with the Idaho Academy of Sciences Outstanding New Investigator Award; and Troy Unruh and Cathy Riddle, both prize winners in DOE's 2014 Innovations in Fuel Cycle Research Awards Program.

- Research results were published in a diverse set of prestigious journals enhancing INL's reputation as a world-class energy laboratory. INL staff published 237 peer reviewed articles in prestigious journals in FY 2014. This number does not include many other publications that are accepted but not yet published, or publications in conference or workshop proceedings. This increase in the number of journal articles compared to previous years is a testimony to the increasing quality of research being conducted at INL, enabled by the growing technical credentials of staff equipped with improved research capabilities.

- INL's MOOSE has made modeling and simulation more accessible to a broad array of scientists. MOOSE has revolutionized predictive modeling, especially in the field of nuclear engineering, by allowing scientists to develop numerous applications that predict behavior of fuels and materials under operating and accident conditions. INL's initiative to open source MOOSE has also had a profound impact, and the number of contributors and the quality of their contributions has grown by orders of magnitude. Over 40 new applications have been started since March 2014 with more than 2,700 unique visitors to mooseframework.org since launch. 
- INL's relevance to industry continued to grow as evidenced by work performed directly for the industry in diverse areas of nuclear technologies. INL and Arizona Public Service were recognized by the Nuclear Energy Institute (NEI) with a Top Industry Practice award for their development and deployment of an outage management technology that increased efficiency in Palo Verde's Fall 2013 refueling outage, saving an estimated $\$ 48 \mathrm{M}$. INL continues to expand its research partnership with TerraPower with a research portfolio that has grown beyond fuel development to include deployment of control room technologies, seismic risk analysis, safety analyses support, biofuels processing, and assessment of hybrid energy systems. The verification and validation of newly installed irradiation-assisted stress corrosion cracking (IASCC) test rigs enabled the first ATR Center Flux Trap irradiated specimens to produce industry accepted data. The test rigs are a unique global capability with a means to characterize the crack growth and fracture toughness characteristics of very highly irradiated structural materials at size scales relevant to realistic reactor internal structures.

- The Risk-Informed Safety Margin Characterization (RISMC) methodology developed at INL is receiving increasing national and international attention. INL successfully expanded the RISMC methodology to include a broader spectrum of accident scenarios and new stakeholders/participants. While the original focus of the RISMC was on the development of the RELAP-7 thermal hydraulics code, the Grizzly component-aging model, and the combination of these physics models with probabilistic methods, the focus has now expanded to include development of physics models for external events such as seismic and flooding. Consequently, INL has engaged new stakeholders to support development of these tools, including South Texas Plant and the Nuclear Regulatory Commission. International interest on RISMC is also increasing with Japanese and European institutions requesting invited talks and proposing collaborative work.

- INL made notable progress in its development of a process to provide the nation with a domestic supply of highly enriched uranium (HEU). INL completed initial testing using irradiated fuel, representing a major step forward in the testing of the ZIRCEX process to recover HEU from highly enriched spent nuclear fuel.

- INL took significant steps towards establishing one-of-a kind capabilities for characterizing irradiated fuels and materials at the microscopic level. INL completed the Operational Readiness Reviews (ORR) for the Irradiated Materials Characterization Laboratory (IMCL). With the facility operational, INL has proceeded with installation of an electron probe micro-analyzer (EPMA), focused ion beam (FIB), and a modular hot cell for sample preparation (SSPA). Within the next 18 months, the EPMA and FIB will be combined with biological shielding and confinement and a new transmission electron microscope to provide world-class capability for fuel and material analysis at the microscopic level. The type of research IMCL will enable at a larger scale is exemplified by the pioneering work of Melissa Teague and Michael Tonks, who have earned international attention for their groundbreaking work in studying the 3-D microstructure of irradiated nuclear fuel, and feeding that data into cutting-edge fuel behavior models. The expansion of these studies, enabled by IMCL, will form the foundation for an "engineering-driven, science-based approach" to future development of nuclear fuels and materials. 
- INL started a new IASCC testing capability and completed the first IASCC test while producing industry-accepted data for the Light Water Reactor (LWR) fleet. The test rigs are a unique capability in the world that allows INL to remain on the forefront of materials research by providing a means to characterize the crack growth and fracture toughness characteristics of very highly irradiated structural materials at size scales relevant to realistic reactor internal structures. The first test is part of a Cooperative Research and Development Agreement (CRADA) between INL and EPRI to measure IASCC in a Boiling Water Reactor (BWR) component that had been subjected to a specific neutron fluence.

- Making significant progress on completing the end-to-end fuel development capability through the outfitting of the IMCL and the restart of TREAT. Secretary Moniz commented on the vision of INL in developing the ability to design, fabricate, test, and understand the performance of nuclear fuels through the completion of TREAT, Experimental Fuels Facility (EFF), and IMCL, and paired with the capability inherent in the MOOSE computational platforms. The internationally unique materials testing capability added in the Fuels and Applied Science Building and the CAES MaCS laboratory have positioned INL as a key international resource in advancing nuclear energy systems through the critical development path of fuels and materials performance.

- Initiated detailed discussions about future sharing of experimental and computation facilities with the Naval Reactors program. Discussions are ongoing with Naval Reactors Program, including visits from Admiral Richardson, about the potential to jointly use Idaho-based research facilities - both experimental and computational. Successful completion of a joint vision and plan will establish useful national leverage of federal funding to the benefit of both programs.

In FY 2014, INL made outstanding progress to establish the Laboratory as a major center for national security technology development and demonstration. INL provided impactful leadership to reduce national security threats by enhancing international safeguards and security of nuclear and radiological materials, and by advancing security across the 16 national critical infrastructure sectors, including nuclear facilities, national power grid, and communication networks.

- INL scientific and program achievements have significantly reduced threat from weapons of mass destruction. INL supported the Global Threat Reduction Initiative (GTRI) by removing all HEU from Hungary; hosting the GTRI Mini Plate (MP)-1 working group to advance the performance of low enriched uranium fuels; establishing options for low enriched uranium fuel for TREAT; and deploying several novel nuclear and radiological measurement and training standards to enhance national and international capabilities for ultratrace detection and nuclear forensic analyses. INL's distinctive and integrated capabilities enabled the U.S. to negotiate a 123 Agreement and develop an innovative data exchange protocol to enable the implementation of proliferation resistant technologies, safeguards, and cybersecurity for the U.S. and South Korea Joint Fuel Cycle Study.

- INL innovations and thought leadership in industrial control systems cybersecurity has enhanced the security of the nation's critical infrastructure. INL expertise in the integration of cybersecurity, industrial control systems, wireless communications and electric power grid technologies enabled research, development, testing, and deployment of unique technologies and methodologies that significantly contributed to DOE's progress in advancing the reliability, resilience and security of the national power grid and critical infrastructure. INL's successful threat analysis research, methodologies, reports, and advisories disseminated to DOE, Department of Homeland Security (DHS) Industrial Control Systems Cyber Emergency Response Team (ICS-CERT), Department of Defense (DOD), the U.S. Intelligence Community, and collaborative industry partners 
have influenced a change in federal legislation that requires DOE national laboratories to be part of the national cyber threat information sharing process. INL's innovations in vulnerability assessment methodologies and information technologies have resulted in the deployment of solution products such as Sophia, Root Cause Failure Analysis, Cyber Security Evaluation Tool (CSET) Version 6.0/6.1, and an improved Digital Library system for DHS to expand the breadth and impacts of vulnerability assessments of the national critical infrastructure.

- INL enhanced the cybersecurity status of national and global nuclear energy infrastructure by influencing changes in cybersecurity policies and cybersecurity $R \& D$ programs. INL focused on providing cybersecurity support to nuclear energy infrastructure owners, operators, regulators and supervisory groups to advance the state of nuclear-cybersecurity. The results of a unique INL cyber-physical vulnerability assessment on a nuclear facility resulted in DOE/National Nuclear Security Administration (NNSA) altering its programmatic emphasis on cybersecurity of laboratory nuclear facilities. After INL leadership served on consultancy assignments with International Atomic Energy Agency (IAEA) working groups, the IAEA declared INL a leading service provider for physical security and nuclear-cybersecurity. INL also delivered novel assessment methodologies, significant analytical threat reports, and technical position papers for DOE and other federal government organizations to influence changes in their future cybersecurity research programs.

- INL innovations in spectrum sharing technologies are solving national security challenges and influencing wireless R\&D initiatives for defense, public safety, and commercial users. INL is achieving recognition as a leader in spectrum sharing innovations through dissemination of technical research publications, including patents "Wireless Device Monitoring Systems and Monitoring Devices;" "Method and Apparatuses Using Filter Banks for Multicarrier Spread Spectrum Signals;" and "Processing Module Operating Methods, Processing Modules, and Communications Systems." This patented filter banks technology (WSComm) has been recognized as a potential solution to future spectrum sharing challenges for federal organizations such as U.S. SOCOM and the Drug Enforcement Agency. INL completed network connectivity with DOD test ranges at China Lake and Point Mugu to establish INL's Wireless Test Bed as the first DOE-DOD center for command and control to assure continuity of operations during national emergencies and reduce costs of operations and tests. INL delivered several electronic warfare planning software products that enabled DOD organizations to perform more effective air combat mission planning.

- INL programs and investment initiatives have resulted in new capabilities to perform national security research development, demonstration, and deployment (RDD\&D). INL established new national capabilities for offsite use of nuclear and radiological standards, including dispersed short-live radionuclides, for source detection and decontamination training that prepares national, regional, and state emergency responders for nuclear and radiological events. INL obtained DOE-NNSA R\&D funding to house, support, and operate pilot plant-scale uranium reprocessing equipment that will test and validate nuclear nonproliferation detection systems and signature measurements. The nation's capability to manufacture heavy armor has been enhanced with the installation and use of a new research super computer, Xerxes, for modeling and simulation. INL captured funding to invest in new 4th Generation wireless communications testing systems to support defense, public safety, academic, and industry testing on the Wireless Test Bed/Wireless National User Facility (WNUF). Over 40 new staff members were hired to support strategic initiatives and new programs in critical national security technology areas of control systems cybersecurity, wireless communications, electric power-grid resilience, and intelligence. 
- Led national efforts in understanding the system level effects on geomagnetic disturbances on the national electrical grid. Combined the results of system-level testing using the INL grid, with a series of national workshops, to lead a national-level discussion on the state of knowledge of geomagnetic disturbances on grid operation and the efficacy of mitigation methods toward protecting the grid. This context was also briefed to many high-level visitors including the Secretary of Energy, Deputy Secretary of Energy, and Senators Murkowski, Barraso, Crapo, and Risch.

INL science and technology addressing broad DOE missions has significantly exceeded expectations resulting in clear, positive impact to INL and DOE.

- INL is a nationally recognized leader in Electric Vehicle (EV) system diagnostics and testing to speed the deployment of advanced transportation systems. INL won an R\&D 100 Award for the Advanced Electrolyte Model (AEM). AEM is a molecular-based simulation tool that revolutionizes electrolyte materials selection, optimizing combinations and key design elements to make battery design and experimentation quick, accurate, and responsive to specific needs. INL was informed by Sage Publications that Jon Christophersen's 2009 article "Comparison of Prognostic Algorithms for Estimating Remaining Useful Life of Batteries," published in Transactions of the Institute of Measurement and Control was one of the top five most-cited articles over the past 5 years. The paper summarized development of battery health prognostic tools based on standard electrical impedance spectroscopy measurements under no-load conditions. INL completed the first independent testing of a "plugless" wireless charging system for EV and completed the first cyber security testing of General Electric's (GE) Smart electric vehicle charging system. With the data from these tests, INL is helping set Society of Automotive Engineers (SAE) J2954 EV wireless charging standards. INL completed data collection for the EV Everywhere Project, the largest deployment of EV's and charging infrastructure in history. With this data, INL presented a first-of-its-kind paper comparing large EV data sets of real world results at the 2014 SAE World Congress Conference, helping validate SAE standards for EV performance.

- INL Biomass and bioenergy research and Biomass Feedstock National User Facility (BFNUF) capability is advancing technical and economic feasibility of bioenergy by directly supporting U.S. industry. INL conducted numerous proof-of-concept and demonstration tests for U.S. industry and DOE. Key industry customers included Universal Oil Products (Honeywell), DuPont, Forest Products, Michigan Biotechnology, and TerraPower. INL staff members have also received recognition for their presentations and publications, which includes articles in Innovation Magazine and Pellet Mill Magazine. INL collaborated with Pacific Northwest National Laboratory (PNNL), EPRI, Washington State University, and a commercial pellet manufacturer to publish "Logistics, Costs, and GHG Impacts of Utility Scale Cofiring with 20\% Biomass." This report summarized an evaluation of utility scale biomass co-firing in large pulverized coal power plants, and assessed the cost and greenhouse gas reduction benefits of substituting relatively high volumes of biomass for coal.

- INL successfully implemented the Critical Materials Institute (CMI). INL completed all projects and tasks as scheduled and established a pilot demonstration for a new state-of-the-art centrifugal contactor to develop innovative methods for rare earth element separation/purification. 
- INL provided strong technical leadership in the region. INL performed technical, economic, and environmental assessments and developed process models to help optimize nuclear energy hybrid applications. INL completed nuclear hybrid energy system feasibility studies for Wyoming and Utah; a system integration evaluation for a sodium-cooled Advanced Fast Reactor coupled with wind-generated electricity; and a Nuclear Renewable Energy Systems Integration Assessment and Deployment Roadmap. INL was a leading sponsor of the Intermountain Energy Summit, playing a key role framing and developing a strategy for regional energy development, distribution, and consumption. INL's leadership in developing the Western Energy Corridor concept and other regional initiatives was instrumental in bringing the best speakers and audience members together. This event is a launching pad for future regional initiatives that will directly impact INL's future, including playing a leadership role for DOE in realizing energy impact nationally.

- Expanded the regional significance of the Laboratory through the efforts to bring the University of Wyoming into the CAES collaboration. CAES staff members are bringing to conclusion a multi-year effort to expand the reach and impact of the CAES collaboration through the addition of the University of Wyoming to the team. This not only shows the growing impact of INL on supporting the regional energy interests, but also the value of the CAES structure and the importance of partnerships with universities in meeting national energy goals.

- INL supported the Transportation Security Administration (TSA) in improving national airport security. INL issued the TSA Aviation Security System Evaluation Tool (ASSET) Suite 3.0 and accompanying comprehensive User Guide. This third-generation computer-based tool provides a major upgrade to TSA's abilities to evaluate and prepare for threats at airports, thus increasing the security of millions of passengers who fly every day in the U.S. Multiple organizations (airports) within TSA now use ASSET to evaluate changes to airport screening operations.

- INL was selected as a solution provider of choice by the Office of Management and Budget's (OMB) MAX.gov Internet-enabled government online collaboration, data collection, and data analysis team. Utilizing the proprietary INL Generalized Environment for Modeling Systems ( (GEMS), OMB and INL are supporting the Department of Navy's Bureau of Medicine and Surgery (BUMED) to design, implement, and host an optimized interface for the Defense Occupational \& Environmental Health Readiness System (DOEHRS). This is the first of numerous projects of this type expected for INL

INL continued to be recognized at the state and national level through awards and special recognitions for leadership in delivering creative approaches in workforce advocacy, university outreach, and Science, Technology, Engineering and Math (STEM). A recent National Academies report focusing on the status and future of national STEM education highlighted INL's Idaho-STEM (i-STEM) as an example of an innovative, state-of-the-art approach to STEM education. In 2014, the i-STEM program received praise for providing best practices in K-12 teacher professional development, overcoming STEM education barriers in rural states, achieving and sustaining STEM literacy, and building and advancing plans for workforce development.

The INL Internship Program was recognized as a 2014 national Vault Top Internship Program and influenced Vault to establish top internship categories in the STEM fields. As a result of this recognition, Vault invited INL to participate in their review/selection process for 2015. 
In FY 2014, the INL Internship Program sponsored 31 Non-Employee Practicum students. These students are funded directly by U.S. Government grants, fellowships, or another funding source other than the U.S. Government. These students represented 19 academic institutions including students on Nuclear Energy University Program (NEUP) fellowships from Massachusetts Institute of Technology, Oregon State University, Rensselaer Polytechnic Institute, and University of South Carolina. INL also hosted two students with scholarships from Iowa State University's Sustainable Production and Distribution of Bioenergy for the Central USA (CenUSA Bioenergy) Program.

INL increased postdoctoral staff from eight in FY 2013 to 17 in FY 2014 and transitioned six of our postdoctoral researchers to full-time positions. Overall, the postdoc research staff represented 14 academic institutions including two from National University Consortium (NUC) partner schools and one from an Idaho University Consortium (IUC) partner school. INL also hosted a Postdoc and Intern Forum with Dr. Peter Lyons, DOE Assistant Secretary of Nuclear Energy.

INL demonstrated efficient and effective stewardship of its research facilities in six impactful ways:

- Performed research important to the future of nuclear energy at unique nuclear facilities. The newly constructed IASCC test rigs are a unique capability in the world that allows INL to remain on the forefront of materials research by providing a means to characterize the crack growth and fracture toughness characteristics of very highly irradiated structural materials at size scales relevant to realistic reactor internal structures. While two or three other facilities in the world can provide related capability, none can match the shielding characteristics or force application capacity provided by the INL IASCC test rigs. Additionally, the proximity to the ATR, the availability of microanalytical capability at the MaCS laboratory, and the mission to support the ATR-National Scientific User Facility (NSUF) combine to provide an unprecedented domestic research capability. INL's unique irradiation (i.e., ATR) and PIE capabilities, such as the HFEF and its associated Neutron Radiography Reactor (NRAD), are again proving to be important for nuclear energy research. TerraPower and INL are using these capabilities for several significant research efforts that will help TerraPower develop the nuclear fuel for their Traveling Wave Reactor (TWR) nuclear energy system. INL's support of TerraPower doubled in FY 2014 and included establishing new and unique metal fuels fabrication capabilities in the EFF. These capabilities will support current TerraPower as well as future INL research efforts. TerraPower continues to recognize INL's unique capabilities and expertise, and plans to continue its research at INL for several years.

- Engaged with industry and university through national user facilities. ATR NSUF has served as a successful and important tool for collaboration between DOE, the nuclear industry, and university researchers for nuclear energy research for several years. In FY 2014, 38 proposals were awarded to universities including North Carolina State, The Ohio State University, University of Wisconsin, Texas A\&M, University of Idaho, Boise State University, University of Michigan, and University of California at Santa Barbara. These diverse research projects advance the science of radiation-induced microstructural changes for reactor fuels structural materials. Not only does the ATR NSUF enable partnerships and collaborations, the ATR NSUF continues to provide a successful framework for the development of early career faculty and students while advancing R\&D solutions. 
INL had similar success through its newest user facilities: WNUF and BFNUF. Under a grant from the National Science Foundation (NSF), the WNUF co-hosted with Idaho State University (ISU) the National Wireless Research Collaboration Symposium (NWRCS 2014). This symposium assembled academic, industry, and government researchers for technology deployment, policy, and implementation discussions with public safety officials. Testing results on the WNUF with the Stevens Institute of Technology are being used by university researchers in conjunction with Dynamic Spectrum, LLC, in the potential deployment of wireless communications technologies in South Africa.

The BFNUF introduced potential collaborators to its capabilities. BFNUF established a Work for Others (WFO) agreement with DuPont Corporation to evaluate processing conditions for a high-value proprietary feed stream. BFNUF staff completed preparation of materials for a study involving 20 international participants evaluating fast pyrolysis technology to convert the materials to bio-oils and ultimately bio-fuels. The materials were prepared as a fine meal and homogenized so the materials sent to all participants (as much as $100 \mathrm{~kg}$ ) are similar in physical and chemical characteristics.

- Secured the country through nonproliferation research facilities and programs. INL's unique nuclear and radiological materials capabilities were used to prepare purified radioisotope xenon, barium, and other standards used by global measurement programs that respond to potential terrorist use of nuclear weapons and/or radiological dispersal devices. The capability to produce, transport, and disperse short-lived radionuclides is preparing many of national first responders to conduct realistic training and exercises with their detection, safety, and decontamination equipment. INL's $\mathrm{x}$-ray and neutron radiographic characterization systems were used to analyze americium-beryllium sources for inclusion in a national signature/forensics database. The results of these unique characterizations have established a new national need to complete further research to prepare better national emergency response plans for a radiological event involving these sources. INL researchers purified neptunium from irradiated fuels to advance national capability to produce a high-purity Np-236 standard needed for radioisotopic forensic measurements.

- Provided a test bed and research center for clean energy technologies such as electric vehicle batteries. Based on testing conducted at the Battery Test Center, INL posted battery performance test results on the publically available Advanced Vehicle Test Activity (AVTA) website for 46 vehicles. The battery test results and lessons learned are used to verify return on investment of DOE-funded technology development, influence a broad range of stakeholders, and reduce the risk of development, deployment, and ownership decisions.

- Reactivated the Remote Analytical Laboratory (RAL) to demonstrate highly-enriched uranium recovery for national security uses. The RAL at Idaho Nuclear Technology and Engineering Center (INTEC) was in stand-by mode with no future mission, facing possible deactivation in the near future. INL reactivated the facility, under CH2M-WG Idaho, LLC, (CWI) ownership, to perform tests on new technology to recover domestic-origin, highly-enriched uranium from spent naval nuclear fuel. Testing is currently in progress on samples of irradiate naval fuel to demonstrate a recovery process that generates about 300-400 times less waste than the process used at INTEC in the 1950s through the 1980s. This work, along with a number of other potential projects, will provide a solid base of work to be performed in the RAL in the future. 
- Established the EIL as a premier foundational R\&D facility at INL. As evidenced by the enthusiastic response of key visitors to the Laboratory, this state-of-the-art facility that hosts critical research facilities in human performance, in-reactor experimental monitoring, water cleanup solutions, battery performance, and separation science, is a powerful compliment to the large user facilities hosting visitors across the Laboratory. 


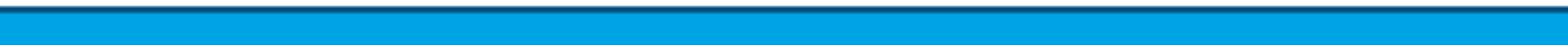




\section{seffassessed PEMP Ratings}

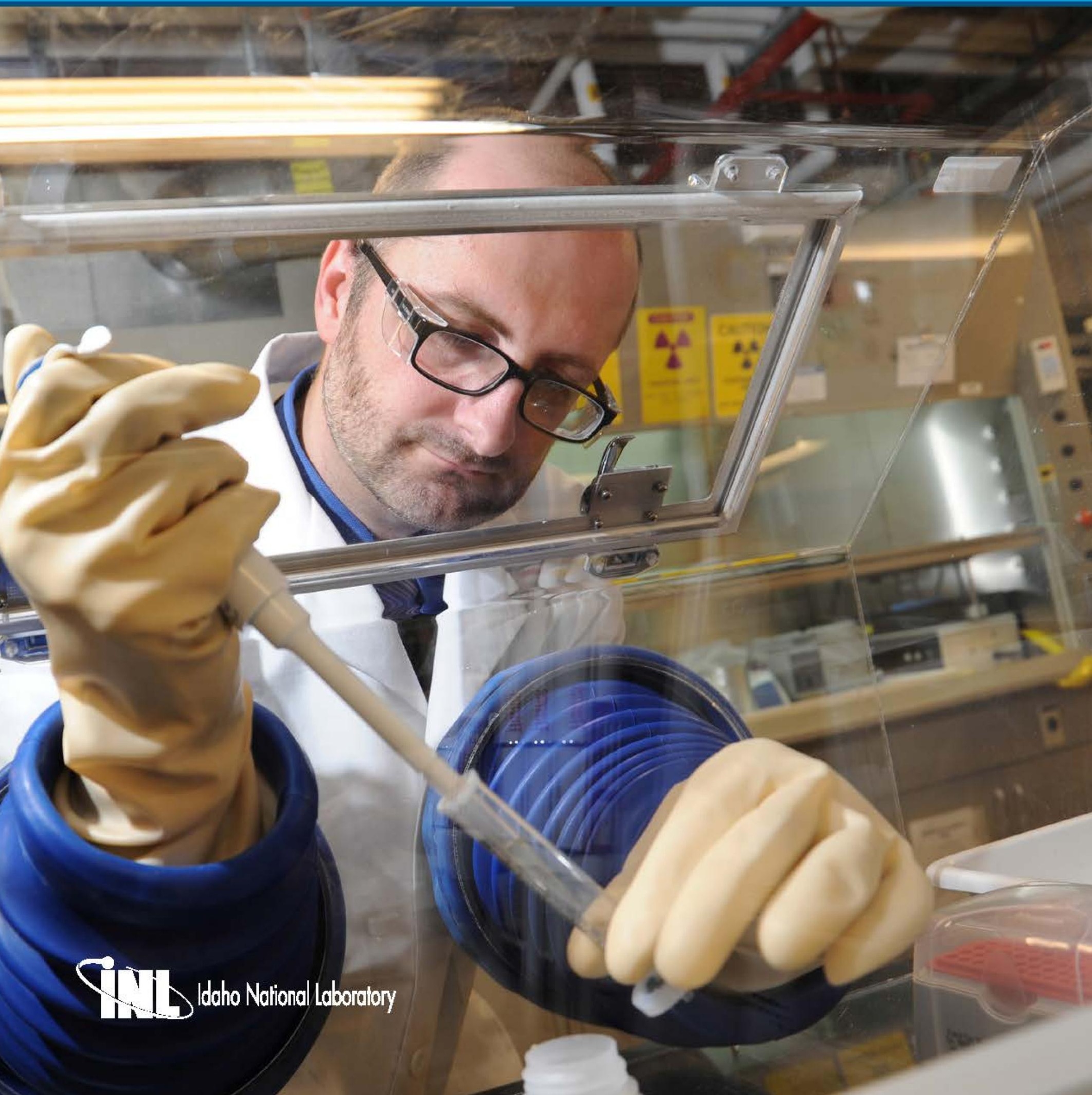




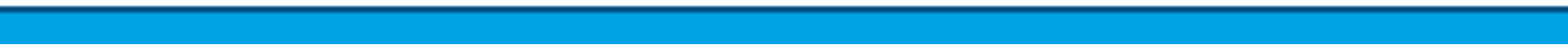




\section{Attachment 1 Self-Assessed PEMP Ratings}

\section{FY 2014 Performance Evaluation and Measurement Plan (PEMP) Stoplight Report by Notable Outcomes}

\begin{tabular}{|c|c|c|}
\hline $\begin{array}{l}\text { Notable } \\
\text { Outcome }\end{array}$ & Description & Status \\
\hline 1.1.A & $\begin{array}{l}\text { Complete all INL activities in support of the Advanced Test Reactor (ATR) irradiation } \\
\text { testing of the accident tolerant fuels: (a) Complete the design, fabrication and analyses } \\
\text { of the test capsule for feasibility testing; and (b) start ATR irradiations provided all fuel } \\
\text { rodlets fabricated by the program participants are delivered to INL according to the } \\
\text { approved schedule. }\end{array}$ & \\
\hline 1.1.B & $\begin{array}{l}\text { Complete all FY } 2014 \text { activities associated with the materials recovery task consistent } \\
\text { with the approved plan towards a Go/No-Go decision in FY } 2015 .\end{array}$ & \\
\hline 1.1.C & $\begin{array}{l}\text { Using the Risk-Informed Safety Management Characterization (RISMC) Toolkit, } \\
\text { complete an integrated framework to perform probabilistic risk analysis including } \\
\text { adaptive sampling techniques to investigate nuclear power plant behavior in proximity } \\
\text { of system failure, post-processing capabilities to identify system failure patterns, and } \\
\text { mechanistic for complex phenomena. Demonstrate feasibility by a case study to } \\
\text { illustrate the RISMC process from beginning to end. }\end{array}$ & \\
\hline 1.1.D & $\begin{array}{l}\text { Complete an implementation plan to support the High Burn-up Dry Storage Cask } \\
\text { Research and Development project to include a schedule of the INL activities required } \\
\text { to support the project requirements. Complete the activities consistent with the DOE } \\
\text { approved plan. }\end{array}$ & \\
\hline 1.1.E & $\begin{array}{l}\text { In order to continue advancing high temperature gas-cooled reactor technology, INL } \\
\text { shall complete first-of-a-kind UCO TRISO source term analyses using AGR } \\
\text { experimental fission product release data and relevant historical UO } \text { UR }_{2} \text { TRISO data, and } \\
\text { maintain the schedule for planned graphite irradiations in ATR by completing the final } \\
\text { design of the AGC- } 4 \text { test train capsule. }\end{array}$ & \\
\hline 1.1.F & $\begin{array}{l}\text { Complete the procurement and initiate installation of the neptunium } 237 \text { repackaging } \\
\text { glovebox in support of the project to reestablish a domestic supply of } \mathrm{Pu}-238 \text {. }\end{array}$ & \\
\hline 1.2.A & $\begin{array}{l}\text { The NHS Mission Support Center (MSC) will provide strategic technical analysis and } \\
\text { specifically requested deliverables to support critical planning and alignment of } \\
\text { investments for the nation's defense as measured by customer formal recognition of } \\
\text { excellent performance. }\end{array}$ & \\
\hline 1.2.B & $\begin{array}{l}\text { Provide outstanding service to the International Atomic Energy Agency, acknowledged } \\
\text { through formal recognition, in leading nuclear cyber security instrumentation \& control } \\
\text { training and education and developing international guidance. }\end{array}$ & \\
\hline
\end{tabular}




\begin{tabular}{|c|c|c|}
\hline $\begin{array}{l}\text { Notable } \\
\text { Outcome }\end{array}$ & Description & Status \\
\hline 1.3.A & $\begin{array}{l}\text { Ensure the successful implementation of INL Critical Materials Institute/Energy } \\
\text { Innovation (CMI) Hub program responsibilities while broadening INL's overall } \\
\text { strategic and critical materials program impact. Implementation of key INL activities } \\
\text { specific to the CMI Hub will include: } \\
\text { - Projects will be initiated and identified milestones will be met; } \\
\text { - Equipment will be procured and received; and } \\
\text { - Project test plans will be defined and documented. }\end{array}$ & \\
\hline 2.1.A & $\begin{array}{l}\text { Complete development of the necessary information/documentation to support a DOE } \\
\text { National Environmental Policy Act (NEPA) decision regarding the resumption of } \\
\text { transient testing. }\end{array}$ & \\
\hline 2.1.B & $\begin{array}{l}\text { Complete development of the necessary information and documentation to support } \\
\text { Critical Decision-1 (CD-1), Approval of Alternative Cost Range for the Advanced } \\
\text { Post-Irradiation Examination Capabilities (APIEC) Project. The plan for obtaining } \\
\text { CD-1 approval (required by DOE in the February 24, } 2014 \text { Contracting Officer letter, } \\
\text { AS-CMD-INL-14-037) will be used to define the specific deliverables in FY } 2014 \text { to } \\
\text { meet this Notable Outcome. }\end{array}$ & \\
\hline 2.2.A & Take beneficial occupancy of EIL and commence conducting research in the facility. & \\
\hline 2.4.A & $\begin{array}{l}\text { Complete the FY } 14 \text { activities consistent with the most recent revision of the Irradiated } \\
\text { Materials Characterization Laboratory (IMCL) equipment installation plan. }\end{array}$ & \\
\hline 2.4.B & $\begin{array}{l}\text { Develop and commence analysis of a set of metrics of success for each of the three } \\
\text { National User Facilities at the INL. }\end{array}$ & \\
\hline 4.2.A & $\begin{array}{l}\text { Assess and submit to DOE an evaluation to inform out-year planning of the current cost } \\
\text { models for the ATR Complex and the MFC activities. Provide recommendations and } \\
\text { options for DOE review and approval that: (1) best support mission objectives; } \\
\text { (2) comply with applicable cost accounting standards; (3) include an implementation } \\
\text { plan/schedule for the recommended changes (if any) that takes into account program } \\
\text { impacts and sufficient time for advance planning; and (4) are coordinated and assessed } \\
\text { with other planned cost model changes as a result of the "INL Business Systems and } \\
\text { Process Evaluation" conducted in FY } 13 \text {. }\end{array}$ & \\
\hline
\end{tabular}




\section{BEA Assessment of PEMP Performance}

\begin{tabular}{|c|c|c|}
\hline Objective & Description & Final* \\
\hline 1.1 & Nuclear Energy & $\mathbf{A}^{1}$ \\
\hline 1.2 & National and Homeland Security & $\mathbf{A}+$ \\
\hline 1.3 & Science and Technology Addressing Broad DOE Missions & $\mathbf{A}+$ \\
\hline 1.4 & Collaborations & $\mathbf{A}$ \\
\hline 2.1 & $\begin{array}{l}\text { Provide Effective Facility Design(s) as Required to Support } \\
\text { Laboratory Programs }\end{array}$ & $\mathbf{A}$ \\
\hline 2.2 & $\begin{array}{l}\text { Provide for the Effective and Efficient Construction of Facilities and/or } \\
\text { Fabrication of Components }\end{array}$ & A- \\
\hline 2.3 & Operation and Maintenance of Facilities & A- \\
\hline 2.4 & $\begin{array}{l}\text { Utilization of Facility(ies) to Provide Impactful S\&T Results and Benefits to } \\
\text { Internal and External User Communities }\end{array}$ & A- \\
\hline 3.1 & Leadership and Stewardship of the Laboratory & $\mathbf{A}+$ \\
\hline 3.2 & Management and Operation of the Laboratory & $A-{ }^{2}$ \\
\hline 3.3 & Contractor Value-Added & $\mathbf{A}+$ \\
\hline 4.1 & $\begin{array}{l}\text { Sustain Excellence and Enhance Effectiveness of Integrated Safety, Health } \\
\text { and Environmental Protection }\end{array}$ & $\mathbf{B}+{ }^{3}$ \\
\hline 4.2 & $\begin{array}{l}\text { Deliver Efficient, Effective, and Responsive Business Systems } \\
\text { and Resources that Enable the Successful Achievement of the Laboratory } \\
\text { Mission(s) }\end{array}$ & $\mathbf{A}$ \\
\hline 4.3 & $\begin{array}{l}\text { Sustain Excellence in Operating, Maintaining, and Renewing the Facility and } \\
\text { Infrastructure Portfolio to Meet Laboratory Needs }\end{array}$ & $\mathbf{A}$ \\
\hline 4.4 & $\begin{array}{l}\text { Sustain and Enhance the Effectiveness of Integrated Safeguards and Security } \\
\text { Management (ISSM) and Emergency Management Systems }\end{array}$ & $\mathbf{A}+$ \\
\hline
\end{tabular}


Attachment 2

INL Mission Accomplishments 


\section{Idaho National Laboratobry Mission Accomplishments}

- Nuclear Energy

- National \&

Homeland Security

- Science \& Technology Addressing Broad DOE Missions

- Collaborations

- Stewardship \& Operation of Research Facilities
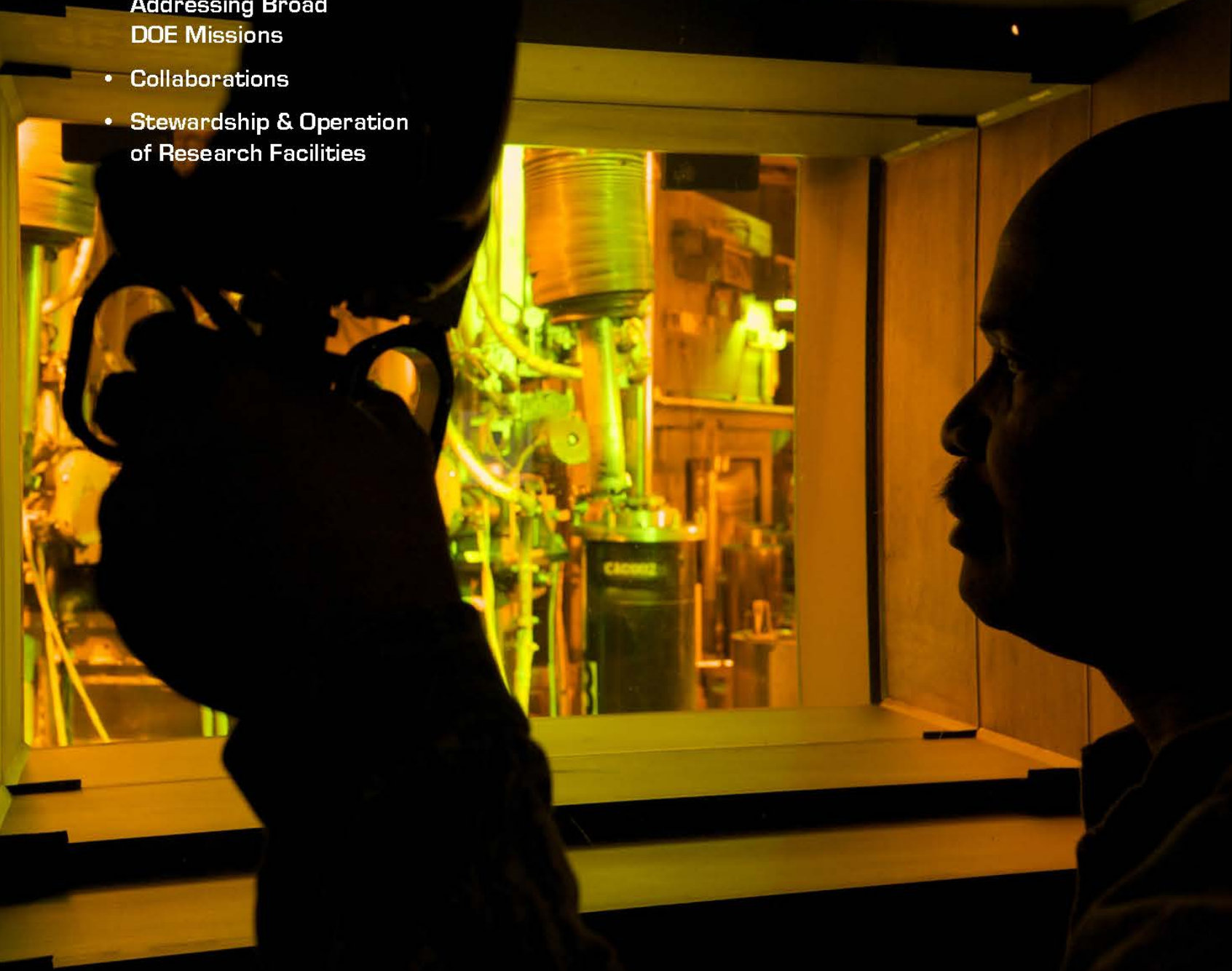

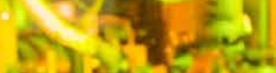

1.

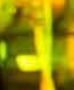

(1) 


\section{DISCLAIMER}

This information was prepared as an account of work sponsored by an agency of the U.S. Government. Neither the U.S. Government nor any agency thereof, nor any of their employees, makes any warranty, expressed or implied, or assumes any legal liability or responsibility for the accuracy, completeness, or usefulness, of any information, apparatus, product, or process disclosed, or represents that its use would not infringe privately owned rights. References herein to any specific commercial product, process, or service by trade name, trade mark, manufacturer, or otherwise, does not necessarily constitute or imply its endorsement, recommendation, or favoring by the U.S. Government or any agency thereof. The views and opinions of authors expressed herein do not necessarily state or reflect those of the U.S. Government or any agency thereof. 


\section{CONTENTS}

ACRONYMS

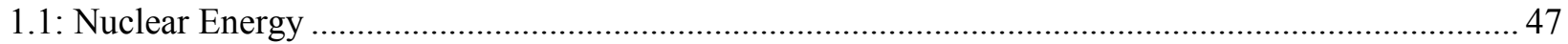

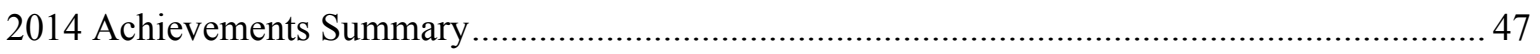

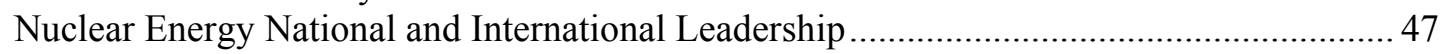

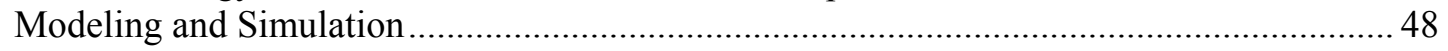

Nuclear Fuels and Materials - Engineering-Driven Science-Based Approach ..................... 49

Nuclear Fuels and Materials - TRISO Fuels, High-Temperature Materials, and

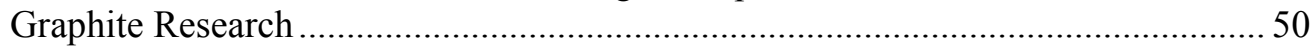

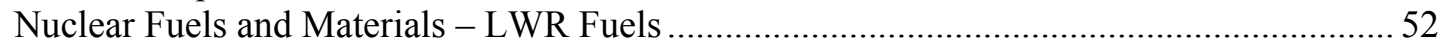

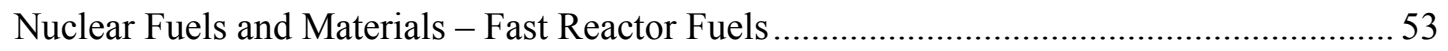

Separations Chemistry and Fuel Cycle Technologies....................................................... 53

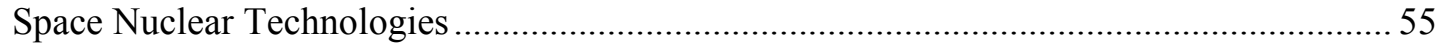

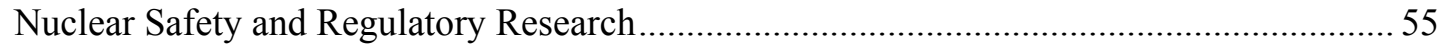

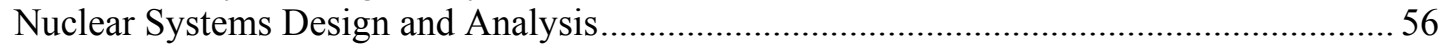

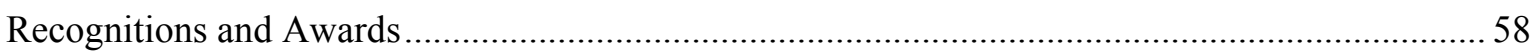

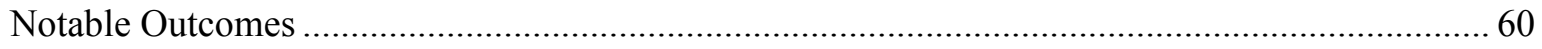

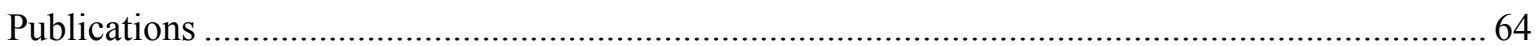

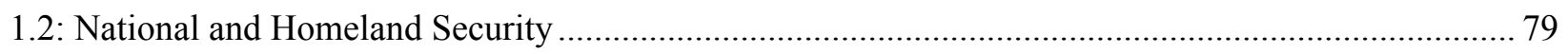

2014 Achievements Summary - Critical Infrastructure Protection............................................... 80

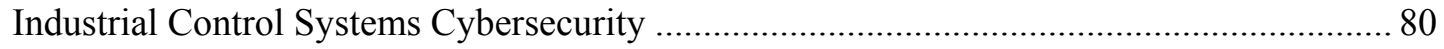

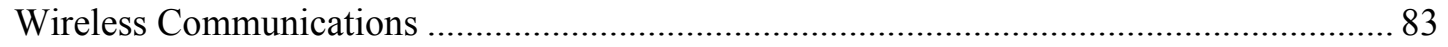

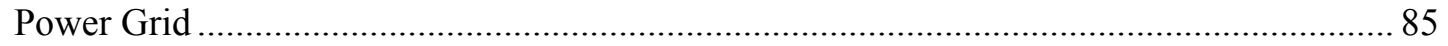

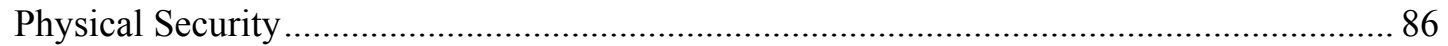

2014 Achievements Summary - Armor Production and Ballistic/Blast Protection ......................... 86

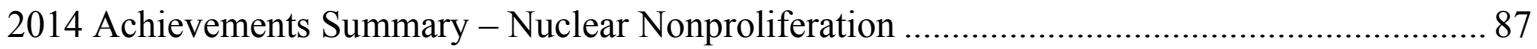

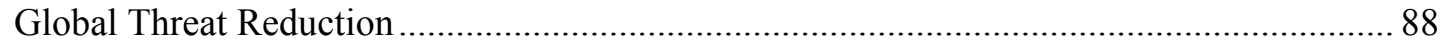

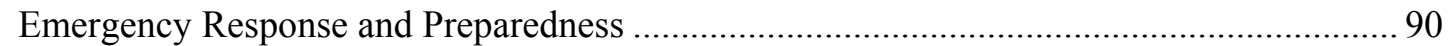

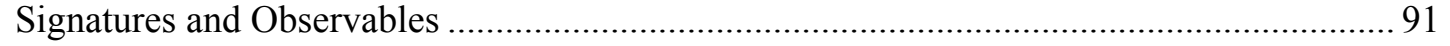

2014 Achievements Summary - Defense and Intelligence ....................................................... 92

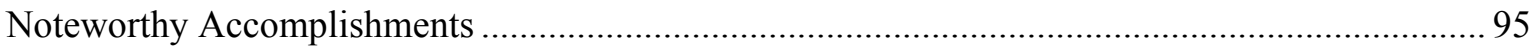

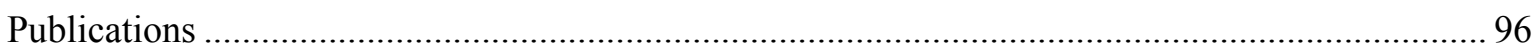

1.3: Science and Technology Addressing Broad DOE Missions........................................................... 99

2014 Achievements Summary — Science Based Performance Assessment for Energy

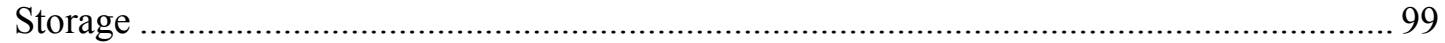

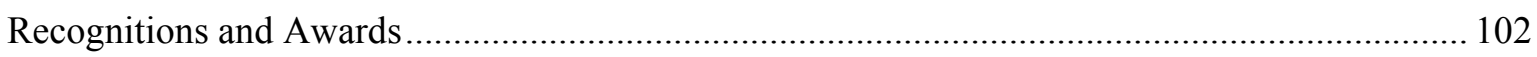

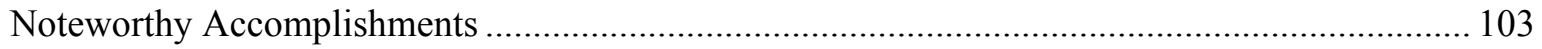

2014 Achievements Summary — Science Based Performance Assessment for Bioenergy Systems 


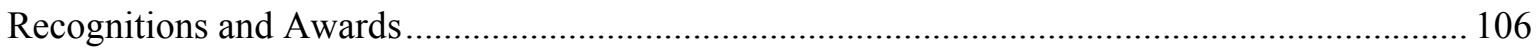

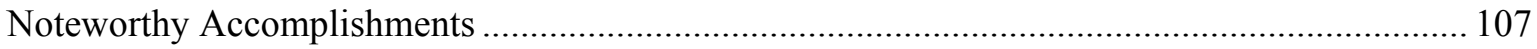

2014 Achievements Summary — Clean Energy Integration Design, Test, Control, and

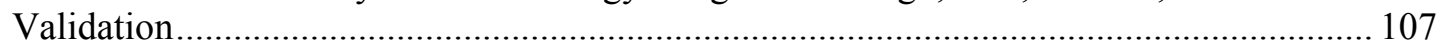

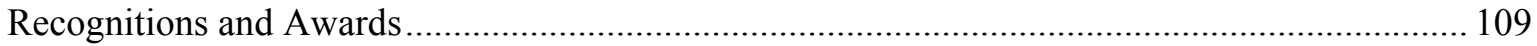

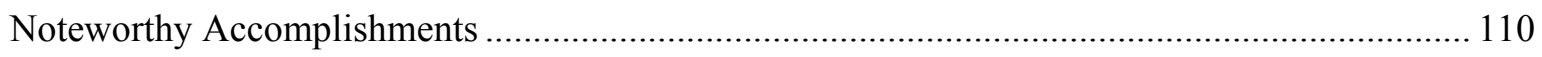

2014 Achievements Summary — Energy Critical Materials .................................................... 110

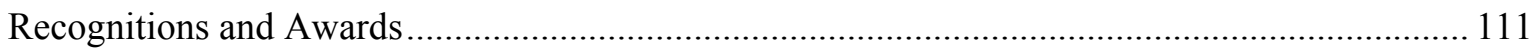

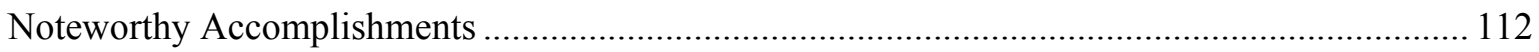

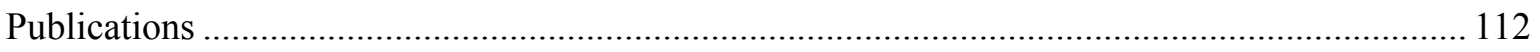

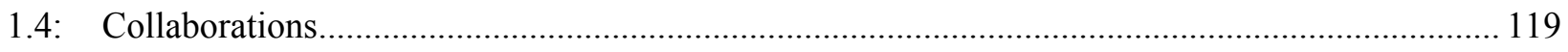

2014 Achievements Summary — Demonstrating Innovation in Regional Workforce

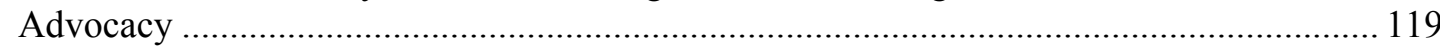

2014 Achievements Summary — Developing Human Resource Pipelines ................................ 121

2014 Achievements Summary — Demonstrating Progress, Impact, and Leadership

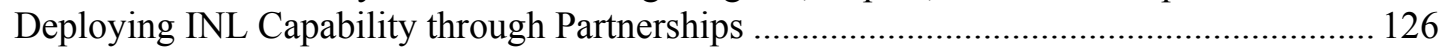

2014 Achievements Summary — Enrich National Research, Development and

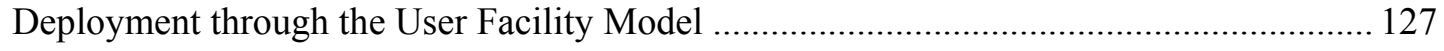

2014 Achievements Summary - Establish and Maintain Partnerships and Relationships with Scientific Communities

2014 Achievements Summary — Broadly Deploy Laboratory Capabilities through Intellectual Property, and Technologies.

2.4: Utilization of Facility(ies) to Provide Impactful S\&T Results and Benefits to Internal and External User Communities

2014 Achievements Summary - Utilization of Facilities ........................................................... 137

ATR Irradiations Delivered Outcomes for INL Programs ....................................................... 138

Materials and Fuels Complex Delivered Impactful Results ...................................................... 140

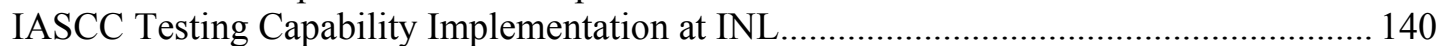

Measurement of Swelling in Irradiated Zircaloy ...................................................... 140

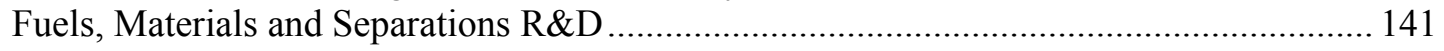

Critical Infrastructure Protection and Nuclear Nonproliferation Missions Deployed

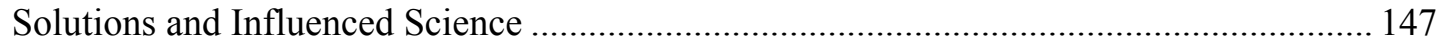

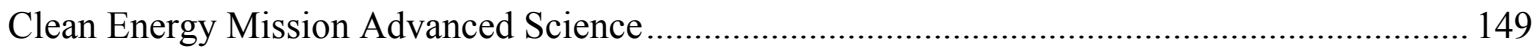

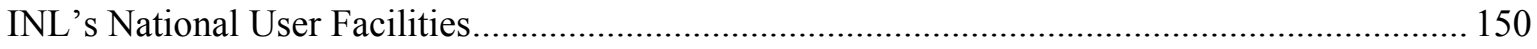

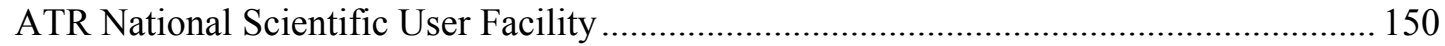

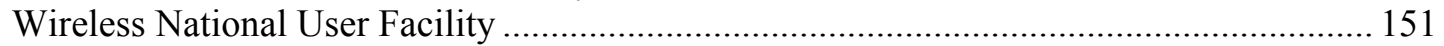

Biomass Feedstock National User Facility ..................................................................... 152 


\section{ACRONYMS}

ACCN Advanced Communications Cellular Network

ACRS Advisory Committee on Reactor Safeguards

ACT Agreements for Commercializing Technology

AEHB Anti-Electrostatic Hydrogen Bond

AEM Advanced Electrolyte Model

AFC Advanced Fuel Cycle

AFCI Advanced Fuel Cycle Initiative

AGC Advanced Graphite Creep

AGR Advanced Gas Reactors

$\mathrm{AL}$

Analytical Laboratory

AMEDD Army Medical Department

ANL Argonne National Laboratory

ANS American Nuclear Society

APS Arizona Public Service

ARC Advanced Reactor Concepts

ARPAe Advanced Research Projects Agency-Energy

ART Advanced Reactor Technologies

ASSET Aviation Security System Evaluation Tool

ASTRID Advanced Sodium Technological Reactor for Industrial Demonstration

ATAC Attack Technology, Analysis, and Characterization

ATF Accident Tolerant Fuels

ATR Advanced Test Reactor

AVTA Advanced Vehicle Test Activity

B\&W Babcock and Wilcox

BEA Battelle Energy Alliance, LLC

BETO BioEnergy Technologies Office

BFNUF Biomass Feedstock National User Facility

BMI Bottom-Mounted Instrumentation

BSU Boise State University

BUMED Bureau of Medicine and Surgery 
BWR Boiling Water Reactor

CAES Center for Advanced Energy Studies

CARB California Air Resources Board

CASL Consortium of Advanced Simulations for LWRs

CATU Classified Advanced Technology Update

CAVE Computer Assisted Virtual Environment

CCIM Cold Crucible Induction Melter

CDS Change Detection System

CEA Commissariat à l'énergie atomique et aux énergies

CERT Cyber Emergency Response Team

CFA Central Facilities Area

CIC Core Internal Change-Out

CITRC Critical Infrastructure Test Range Complex

CLAW Counter Listener Acoustic Warfare

CMI Critical Materials Institute

COA Certificate of Authorization

CRADA Cooperative Research and Development Agreement

CRISP Cybersecurity Risk Information Sharing

CRP Coordinated Research Projects

CSOC Control System Operations Center

CSU Colorado State University

CTBTO Comprehensive Nuclear-Test-Ban Organization

CTD Crosscutting Technology Development

CWI CH2M-WG Idaho, LLC

DAS Deputy Assistant Secretary

DC Direct Current

DEA Drug Enforcement Administration

DEN Direction de l'énergie nucléaire

DHS Department of Homeland Security

DL Digital Library

DoD Department of Defense

DOE Department of Energy 
DOE-CH Department of Energy-Chicago

DOE-EERE Department of Energy-Energy Efficiency and Renewable Energy

DOEHRS Defense Occupational \& Environmental Health Readiness System

DOE-ID Department of Energy Idaho Operations Office

DOE-IN Department of Energy Office of Intelligence and Counterintelligence

DOE-NE Department of Energy Office of Nuclear Energy

DOE-OE Department of Energy Office of Electricity Delivery and Energy Reliability

DOE-SC Department of Energy Office of Science

DTC Dry Transfer Cubicle

EDTA Electric Drive Transportation Association

EES\&T Energy and Environment Science and Technology

EFF Experimental Fuels Facility

EFPD Effective Full-Power Days

EFRC Energy Frontier Research Center

EIA U.S. Energy Information Administration

EPMA Electron Probe Micro-Analyzer

EPRI Electric Power Research Institute

ES\&H Environment, Safety, and Health

ESL Energy Systems Laboratory

EV Electric Vehicle

EVSE Electric Vehicle Supply Equipment

EWM\&S Electronic Warfare Modeling and Simulation

EWS Electronic Warfare Squadron

F\&SS Facility and Site Services

FAA Federal Aviation Administration

FCM Fully Ceramic Matrix

FCRD Fuel Cycle Research and Development

FEMA Federal Emergency Management Agency

FFTF Fast Flux Test Facility

FIB Focused Ion Beam

FirstNet First Responder Network Authority

FLC Federal Laboratory Consortium 


$\begin{array}{ll}\text { FMF } & \text { Fuel Manufacturing Facility } \\ \text { FOA } & \text { Funding Opportunity Announcement } \\ \text { FW } & \text { Far West Division } \\ \text { FY } & \text { Fiscal Year } \\ \text { GEMS } & \text { Generalized Environment for Modeling Systems } \odot \\ \text { GIS } & \text { Geographic Information System } \\ \text { GMD } & \text { Geomagnetic Disturbance } \\ \text { GSM } & \text { Global System for Mobile Communications } \\ \text { GTRI } & \text { Global Threat Reduction Initiative } \\ \text { HazMat } & \text { Hazardous Material } \\ \text { HEM } & \text { Homogeneous Equilibrium Model } \\ \text { HEU } & \text { High-Enriched Uranium } \\ \text { HFEF } & \text { Hot Fuels Examination Facility } \\ \text { HPPC } & \text { Hybrid Pulse Power Characterization } \\ \text { HRA } & \text { Human Reliability Analysis } \\ \text { HSIS } & \text { Hydraulic Shuttle Irradiation System } \\ \text { HTGR } & \text { High-Temperature Gas-Cooled Reactors } \\ \text { IAEA } & \text { International Atomic Energy Agency } \\ \text { IASCC } & \text { Irradiation Assisted Stress Corrosion Cracking } \\ \text { IC } & \text { Intelligence Community } \\ \text { ICIS } & \text { Instrumentation, Control, and Intelligent Systems } \\ \text { ICP-MS } & \text { Inductively Coupled Plasma Mass Spectrometry } \\ \text { ICS } & \text { Industrial Control Systems } \\ \text { ICyS } & \text { Intelligent Cyber Sensor } \\ \text { IDHEAS } & \text { Integrated Decision-tree Human Event Analysis System } \\ \text { IEA } & \text { International Energy Agency } \\ \text { IEEE } & \text { Institute of Electrical and Electronics Engineers } \\ \text { IMCL } & \text { Irradiated Materials and Characterization Laboratory } \\ \text { INL } & \text { Idaho National Laboratory } \\ \text { IP } & \text { Intellectual Property } \\ \text { IRON } & \text { Idaho Regional Optical Networks } \\ \text { IRUG } & \text { International RELAP Users Group } \\ & \end{array}$


ISAS Idaho Science and Aerospace Scholars

ISMS Integrated Safety Management System

i-STEM Idaho-STEM

ISU Idaho State University

IUC Idaho University Consortium

JEWEL Joint Electronic Warfare Evaluation Laboratory

JFCS Joint Fuel Cycle Studies

KAERI Korean Atomic Energy Research Institute

KJRR Ki-Jang Research Reactor

LANL Los Alamos National Laboratory

LDRD Laboratory Directed Research and Development

LEU Low Enriched Uranium

LEUCO Low-Enriched Uranium Oxycarbide

LLNL Lawrence Livermore National Laboratory

LOCA Loss-of-Coolant Accident

LOFT Loss-of-Fluid Test

LWR Light Water Reactor

LWRS Light Water Reactor Sustainability

MaCS Materials and Characterization Suite

MANTRA Measurement of Actinides Neutron Transmutation Rates

MCI Motor Coach Industries

$\mathrm{MeV} \quad$ Modeling, Experimentation, and Validation

MFC Materials and Fuels Complex

MHTGR Modular High-Temperature Gas-Cooled Reactor

MIT Massachusetts Institute of Technology

MITR Massachusetts Institute of Technology Research Reactor

MOOSE Multiphysics Object Oriented Simulation Environment

MSC Mission Support Center

N\&HS National and Homeland Security

NASA National Aeronautics and Space Administration

NCCIC National Cybersecurity and Communications Integration Center

NDA Nondisclosure Agreement 


$\begin{array}{ll}\text { NE } & \text { Nuclear Energy } \\ \text { NEA } & \text { Nuclear Energy Agency } \\ \text { NEAC } & \text { Nuclear Energy Advisory Committee } \\ \text { NEET } & \text { Nuclear Energy Enabling Technology } \\ \text { NEI } & \text { Nuclear Energy Institute } \\ \text { NERC } & \text { North American Electric Reliability Corporation } \\ \text { NEUP } & \text { Nuclear Energy University Program } \\ \text { NFPA } & \text { National Fire Protection Association } \\ \text { NGNP } & \text { Next Generation Nuclear Plant } \\ \text { NNSA } & \text { National Nuclear Security Administration } \\ \text { NPAS } & \text { Nuclear Power Assessment Study } \\ \text { NPS } & \text { Naval Postgraduate School } \\ \text { NR } & \text { Naval Reactors } \\ \text { NRAC } & \text { Nuclear and Radiological Activity Center } \\ \text { NRC } & \text { Nuclear Regulatory Commission } \\ \text { NREL } & \text { National Renewable Energy Laboratory } \\ \text { NRIS } & \text { Near Infrared Spectroscopic } \\ \text { NS\&T } & \text { Nuclear Science and Technology } \\ \text { NSF } & \text { National Science Foundation } \\ \text { NSN } & \text { Nokia Solutions and Network } \\ \text { NSUF } & \text { National Scientific User Facility } \\ \text { NTD } & \text { National Technical Director } \\ \text { NUC } & \text { National University Consortium } \\ \text { NUCO } & \text { Natural Uranium Carbide/Oxide } \\ \text { NWRCS } & \text { National Wireless Research Collaboration Symposium } \\ \text { OECD } & \text { Organization for Economic Co-operation and Development } \\ \text { OEM } & \text { Original Equipment Manufacturer } \\ \text { OMB } & \text { Office of Management and Budget } \\ \text { ORNL } & \text { Oak Ridge National Laboratory } \\ \text { ORR } & \text { Operational Readiness Review } \\ \text { PALM } & \text { Powered Axial Locator Mechanism } \\ \text { PARFUME } & \text { Particle Fuel Model } \\ & \end{array}$


PEMP Performance Evaluation and Measurement Plan

PEV Plug-in Electric Vehicle

PHEV Plug-In Hybrid Electric Vehicle

PIE Post-irradiation examination

PINS Portable Isotopic Neutron Spectroscopy

PNNL Pacific Northwest National Laboratory

POLIMI Politecnico di Milano

PRA Probabilistic Risk Assessment

PWR Pressurized Water Reactor

QA Quality Assurance

R\&D Research and Development

R/B Birth Rate Ratio

RAL Remote Analytical Laboratory

RAP Radiological Assistance Program

RAVEN Reactor Analysis Environment

RCS Resilient Control Systems

RD\&D Research, Development, and Demonstration

RDD Radiological Dispersal Device

RDD\&D Research, Development, Demonstration, and Deployment

RE Renewable Energy

ReACT Response Analysis Characterization Tool

REE Rare Earth Elements

RELAP Next Generation Nuclear System Safety Code

RENDER Risk Evaluation Nexus for Digital Age Energy Reliability

RERTR Reduced Enrichment for Research and Test Reactors

RF Radiofrequency

RISMC Risk-Informed Safety Management Characterization

RMNP Rocky Mountain National Park

S\&T Science and Technology

SAPHIRE Systems Analysis Programs for Hands-on Integrated Reliability Evaluations

SCADA Supervisory Control and Data Acquisition

SCKCEN Studiecentrum Voor Kernenergie Centre D'Etude De L'Energie Nucleaire 
SDPS Space and Defense Power Systems

SMC Specific Manufacturing Capability

SMR Small Modular Reactor

SNL Sandia National Laboratory

SOCOM Special Operations Command

SPS-FO Switchable Polarity Solvent Forward Osmosis

SRS Savannah River Site

STEM Science, Technology, Engineering, and Math

STPI Science and Technology Policy Institute

SWAN Smart Water Networks

TAC Technical Advisory Committee

TAP Technical Assistance Program

TD Technology Deployment

TEAD Tooele Army Depot

TEG Thermoelectric Generator

TEM Transmission Electron Microscope

TIO Technical Integration Office

TIP Top Industry Practice

TMS The Minerals, Metals and Materials Society

TREAT Transient Reactor Test Facility

TRISO Tristructural Isotropic

TSA Transportation Security Administration

TTP Transition to Practice Program

TTWG Technology Transfer Working Group

TWR Traveling Wave Reactor

UAM Uncertainty Analysis in Best Estimate Modelling

UAS Unmanned Aircraft Systems

UCF University of Central Florida

UCO Uranium Oxycarbide

UCSB University of California Santa Barbara

UFD Used Fuel Disposition

UI University of Idaho 


\begin{tabular}{ll}
\hline UMTS & Universal Mobile Telecommunications Systems \\
UNLV & University of Nevada, Las Vegas \\
UOP & Universal Oil Products \\
USABC & U.S. Advanced Battery Consortium \\
USCAR & United States Council for Automotive Research, LLC \\
USDA & United States Department of Agriculture \\
VHTR & Very High Temperature Reactor \\
VSATT & Vehicle Systems Analysis Tech Team \\
VTO & Vehicle Technologies Office \\
WFO & Work for Others \\
WIPP & Waste Isolation Pilot Plant \\
WNUF & Wireless National User Facility \\
WSU & Washington State University \\
WTB & Wireless Test Bed \\
ZPPR & Zero Power Physics Reactor
\end{tabular}


PEMP FY 2014 


\section{Efficient and Effective Mission Accomplishment}

\section{1: Nuclear Energy}

OBJECTIVE 1.1: NUCLEAR ENERGY

Lead and implement relevant, high impact RDD\&D programs. Establish the INL as the preeminent, internationally-recognized laboratory in nuclear energy technologies (including advanced fuel cycles). The primary focus areas include, but are not limited to the following:

- Engineering driven science-based approach to the development and performance of Nuclear Fuels and Materials applicable to current and future generations of reactors;

- Fuel cycle technologies including advancements in pyro and aqueous processing technologies, nuclear materials management and non-proliferation standards;

- Reactor Safety, Material Science, and Human Performance for Life Extension of Light Water Reactors;

- Advanced reactor design and optimization.

\section{Achievements Summary}

The performance in Notable Outcomes under Section 1.1, reported in a later subsection, only covers a small fraction of nuclear energy research, development, and demonstration (RD\&D)-related accomplishments. Without repeating the activities specific to meeting the expectations under the Notable Outcomes, INL provided a highlight of accomplishments in this section for the different nuclear energy RD\&D core competency areas.

\section{Nuclear Energy National and International Leadership}

Idaho National Laboratory (INL) continues its strong technical leadership at various levels for national nuclear energy RDD\&D programs. Supporting Department of Energy Office of Nuclear Energy (DOE-NE), INL led the development of the revised Nuclear Energy Roadmap. As stated by Dr. Peter Lyons on various occasions, the revised Roadmap provides a considerably improved strategy document, consistent with the new programmatic priorities and the longer-term vision of DOE. Also, INL led the multi-laboratory effort to define the nuclear energy "big idea" discussed in the National Laboratories Ideas Summit. The nuclear energy big idea focused on enabling accelerated commercialization of innovative technologies. DOE-NE leadership fully endorsed and is incorporating the elements of the innovation initiative in multiple parts of their program planning.

Kathryn McCarthy, Curtis Smith, and Bruce Hallbert are continuing their leadership roles in the Light Water Reactor Sustainability (LWRS) program. DOE-NE recently restructured NE-74 to combine three programs (Next Generation Nuclear Plant [NGNP], Advanced Reactor Concepts [ARC], and Small Modular Reactor [SMR]) into a single Advanced Reactor Technologies [ART]) Program. David Petti was requested by DOE-NE to serve as a National Technical Director jointly with Bob Hill (Argonne National Laboratory [ANL]). Diane Croson and Jim Kinsey were appointed leadership roles as Technology Area Leads for High Temperature Reactor research and development (R\&D) and Licensing, respectively. Jon Carmack, Terry Todd, Michael Goff, and Roald Wigeland continue to serve as National Technical Directors for Advanced Fuels, Materials Recovery and Waste Forms, Joint Fuel Cycle Studies, and Fuel Cycle Options campaigns under the Fuel Cycle Research and Development (FCRD) program. Steve Hayes and Bruce Hallbert continue their technical leadership positions under the Nuclear Energy Enabling Technology (NEET) program. Rory Kennedy was appointed as the new scientific director of ATR National Scientific User Facility (NSUF). Finally, Douglas Burns continues his role as the deputy director for the Consortium of Advanced Simulations for LWRs (CASL). 
Also noteworthy in FY 2014 the joint initiation of the Nuclear Hybrid Energy program by the Nuclear Science and Technology (NS\&T) and Energy and Environment Science and Technology (EES\&T) directorates. Under the leadership of Shannon Bragg-Sitton and Richard Boardman, INL conducted a very successful national workshop towards the development of a programmatic roadmap for Nuclear Hybrid Energy under Integrated Energy Systems.

Lastly, under the leadership of Daniel Wachs, a transient testing needs workshop was held. The workshop discussed transient testing needs including associated time-frames across multiple national and international programs. The results of the workshop were compiled in a report that will serve as a program planning document for DOE-NE as we approach the restart of the Transient Reactor Test Facility (TREAT).

As reported during the year, INL staff participated in multiple prestigious national and international workshops as key-note/invited speakers and panelists.

- INL continues to increase its reputation and influence as a leading nuclear energy research institution in the international arena. Our leadership in nuclear energy was also on display through convening of high-level meetings in support of DOE-NE that have led to collaborative bi-lateral and multi-lateral action plans and commitments from participating domestic and international organizations (e.g., U.S.-side organization of the 37th Generation IV International Forum Policy Group Meeting in Paris,/France, 6th U.S.-India Civil Nuclear Energy Working Group, and DOE-Commissariat à l'énergie atomique et aux énergies [CEA] Civil Nuclear Energy Bilateral Agreement). Noteworthy accomplishments include the establishment and subsequent chairmanship by INL of the Organization for Economic Co-operation and Development Nuclear Energy Agency (OECD-NEA) expert groups on Accident Tolerant Fuels (chaired by Kemal Pasamehmetoglu), and Validation and Data Centers (chaired by Phillip Finck). The validation and data center expert group will be directly tied to the knowledge and validation center initiative proposed by INL and will be included in the NE program plans.

\section{Modeling and Simulation}

- INL's Multiphysics Object Oriented Simulation Environment (MOOSE) made modeling and simulation more accessible to a broad array of scientists. MOOSE revolutionized predictive modeling, especially in the field of nuclear engineering — allowing nuclear fuels and materials scientists to develop numerous applications that predict the behavior of fuels and materials under operating and accident conditions. Our initiative to convert MOOSE to open source code had a profound impact - the number of contributors and the quality of those contributions has grown by orders of magnitude. Over 48 new applications have started since March 2014 with more than 3,600 unique visitors to mooseframework.org since its launch. Multiple upgrades to enhance the capabilities were completed during FY 2014. In addition, the number of applications being developed under the MOOSE framework continues to grow. The maturity of the application software in providing predictive simulations for nuclear energy applications (ranging from fuels and materials, to reactor cores and reactor systems) continues to improve. Some of those tools have achieved the level of maturity to become essential elements of the research conducted at INL and elsewhere. Specific accomplishments related to MOOSE-based applications are reported below in various core competency areas. 
- The Reactor Analysis Environment (RAVEN), a probabilistic framework primarily developed for use with RELAP-7, is being extended to other MOOSE-based applications enabling risk-based simulations. The associated noteworthy improvements include the extension of the data base infrastructure for RAVEN to handle probability information, thereby allowing the implementation of probability based post processing (e.g., variable correlation analysis, mean values, variance). Also, Hybrid Monte Carlo and Dynamic Event Three were developed.

\section{Nuclear Fuels and Materials - Engineering-Driven Science-Based Approach}

- In collaboration with Los Alamos National Laboratory, atomistic modeling based on density functional theory was used to compute the diffusion constants of fission gas $(\mathrm{Xe})$ in $\mathrm{UO}_{2}-\mathrm{a}$ first-ever multiscale coupling from atomistic to engineering scale for science-based simulation. Predicted gas diffusion rates were implemented in the BISON fuel performance code and used to accurately simulate gas release from a fuel rod irradiation experiment.

- INL took significant steps towards establishing one-of-a-kind capabilities for characterizing irradiated fuels and materials at the microscopic level. The Operational Readiness Review for the Irradiated Materials Characterization Laboratory (IMCL) was completed. With the facility operational, INL has proceeded with installation of an electron probe micro-analyzer (EPMA), focused ion beam (FIB), and a modular hot cell for sample preparation (SSPA). Within the next 18 months, the EPMA and FIB will be combined with radiological shielding and confinement as well as a new transmission electron microscope to provide world-class capability for fuel and material analysis at the microscopic level. The type of research that IMCL will enable at a larger-scale is exemplified by the pioneering work of Melissa Teague and Michael Tonks, who are earning international attention for their groundbreaking work. Their research utilizes a 3-D reconstruction of the irradiated nuclear fuel for fuel microstructure and unique Electron Backscattered Diffraction data. This information has been incorporated into cutting-edge fuel behavior computer models. Work was highlighted in the American Ceramic Society's newsletter. The expansion of these studies that would be enabled by IMCL forms the foundation of the "engineering-driven science-based approach" for the development of nuclear fuels and materials.

- The capabilities of the INL-developed state-of-the-art fuel performance code, BISON, have been greatly enhanced, making it usable in a wider range of conditions. The BISON Verification and Validation Plan was developed and documented both in an external report and verification journal article. Eighteen new LWR cases were added to the BISON validation base including documentation. The second BISON code release occurred on September 30, 2014, and includes source code, multiple example problems, updated theory and user manuals, an expanded validation manual, and extensive training materials. INL successfully coupled the RattleSnake Sn solver with the BISON fuel performance code under the MAMMOTH reactor physics application. A high-resolution macroscopic depletion calculation of a fuel rod in 20 radial rings and up to 350 effective full-power days (EFPD) was conducted for a pressurized water reactor (PWR) fuel pin with MAMMOTH. New features of the BISON code include:

- Mechanistic, transient fission gas release model (burst release)

- Creep behavior of cladding at high temperature; microstructural phase change of cladding at high temperature

- Homogeneous 1-D coolant behavior including multiple convective heat transfer models that encompass the entire boiling curve; and loss-of-coolant accident (LOCA) 
- Demonstration problem including cladding ballooning

- Hydrogen diffusion and precipitation capability enabling analysis of hydride behavior in Zircaloy cladding during irradiation and all phases of interim storage

- The smeared crack modeling capability, including its extension from 2-D to 3-D.

- The capabilities of the INL-developed state-of-the-art microstructure evolution code, MARMOT, have been greatly enhanced getting us closer to truly predictive fuels and materials simulations. We completed the first version of a MARMOT Verification and Validation report. We also developed microstructure-based models for grain growth and fracture in $\mathrm{UO}_{2}$ for BISON. MARMOT's grain growth model for $\mathrm{UO}_{2}$ is being validated by comparing results to experimental data being collected by Don Brown at Los Alamos National Laboratory (LANL).

In addition, to investigate the hydride behavior, we developed a phase field model for a pure Zr system forming delta hydrides, including both elastic and surface energy anisotropy. An advanced model is incorporated in MARMOT that allows for simple development of binary alloy models (e.g., $\mathrm{Zr}-\mathrm{H})$.

- The capabilities of the INL developed state-of-the-art meso-scale to engineering-scale reactor pressure vessel embrittlement code, GRIZZLY, have been greatly enhanced, getting us closer to truly predictive reactor vessel lifetime simulations. We developed a mechanistic ductile to brittle transition model for reactor pressure vessel steels. We used molecular dynamics simulations to investigate defect behavior in irradiated reactor pressure vessel steels. At the engineering scale, we developed the capability to evaluate mixed mode stress intensity factors on fractures in 3-D.

\section{Nuclear Fuels and Materials - TRISO Fuels, High-Temperature Materials, and Graphite Research}

- Corrective measures were developed for defective fuel kernels fabricated for the Advanced Gas Reactors (AGR)-5/6/7 experiments that provide timely execution of important experiments. In-depth analysis and extensive materialography of the tristructural isotropic (TRISO)-coated Natural Uranium Carbide/Oxide (NUCO) particles created during the coating process qualification runs showed the kernels used for these particles had a significant percentage of the population with fissures and other defects. Further investigation into past kernel fabrication runs and kernel quality determined that AGR-2 kernels were the highest quality and exhibited few, if any, of these same defects. The VHTR program was faced with a difficult decision whether to proceed at risk to maintain schedule or scrap the existing AGR-5/6/7 low enriched uranium oxycarbide (LEUCO) kernels and start again. Because of the importance of this fuel to the overall AGR program, the technical judgment of the program was to fabricate a new lot of AGR-5/6/7 LEUCO kernels for the upcoming irradiation, and a new contract was placed with Babcock and Wilcox $(\mathrm{B} \& \mathrm{~W})$. Although the decision resulted in additional cost to the program of approximately $\$ 3.8 \mathrm{M}$, and an overall fabrication schedule extension of about 6 months, it was technically the right decision. Even though the ATR core internal change-out (CIC) schedule is delayed, it is expected the AGR-5/6/7 experiment will complete its irradiation prior to CIC in February 2019.

- AGR-2 and AGR 3/4 experiments were completed in the ATR providing valuable data for our understanding of the TRISO fuel behavior. The AGR-2 experiment included U.S.-fabricated UCO and $\mathrm{UO}_{2}$ fuel, as well as $\mathrm{UO}_{2}$ fuel from France and South Africa. The experiment was designed to provide performance comparisons between $\mathrm{UCO}$ and $\mathrm{UO}_{2}$ TRISO fuel, as well as test TRISO fuel particles fabricated at engineering scale. There were no apparent fuel particle failures during 
irradiation. The AGR-2 Final Irradiation report was prepared and issued based on the final as-run report and data analysis. These reports document the successful performance of the fuel tested during irradiation. The AGR-2 test train was sized at ATR and shipped to Materials and Fuels Complex (MFC) for post-irradiation examination (PIE) in July 2014. Initial AGR-2 PIE activities have begun in the Hot Fuels Examination Facility (HFEF). Gamma scanning of the test train as received was performed using the Precision Gamma Scanner in HFEF. Disassembly and metrology of the first two capsules has been completed.

The AGR-3/4 experiment, which included uranium oxycarbide UCO driver fuel from AGR-1 plus 20 "designed-to-fail" fuel particles in each of the 48 compacts, provided fission product transport data in carbonaceous material from failed fuel. Analysis of the data provided information on fission gas release from failed fuel as a function of temperature and isotopic half-life consistent with the limited historical data available. The AGR-3/4 experiment is stored in the ATR canal for cool down with projected shipping timeframes (two shipments) of December 2014 and January 2015 to MFC for start of PIE.

- INL completed the advanced conceptual design of the AGR-5/6/7 experiment to qualify AGR fuel under irradiation. The design includes options for five or six capsules that will have 172 or 192 total compacts. One capsule will be tested at a higher temperature than the previous AGR experiments to serve as a "margin" test for the fuel type.

- Qualification of Alloy 617 was continued for nuclear design using the ASME Boiler and Pressure Vessel Code. This material is not currently qualified for any use in nuclear systems. The most significant accomplishment this fiscal year was verbal approval of a code case for Alloy 617 for nuclear components in high temperature reactors for design up to $427^{\circ} \mathrm{C}$. This draft code case required successful completion of experimental work and analysis of the fatigue behavior and physical properties; both of these activities were completed at INL.

The high temperature code case is scheduled for submission in September 2015 and will cover the temperature range from 428 to $950^{\circ} \mathrm{C}$. In FY 2014, limits were placed on the allowable amount of cold work in reactor components; it was determined that $<5 \%$ cold work incidental to fabrication and installation of components is acceptable. Based on experimental work carried out by the VHTR R\&D program, and analysis of literature and historical data, it was also determined that there will be no requirement for a reduction factor on creep-rupture stresses associated with welds in Alloy 617. It was also demonstrated that the creep rate at the lower temperature range of application for Alloy 617 in VHTR heat exchangers $\left(750^{\circ} \mathrm{C}\right.$ and below) is controlled by precipitation of the $\mathrm{Ni}_{3} \mathrm{Al}$ intermetallic phase. This finding, which was published in Metallurgical and Materials Transactions, is not only significant for VHTR design, but may play an important role in ultra-supercritical boilers in fossil and solar thermal systems. Each of these issues had the potential to be points of contention for the code case, and the key VHTR findings have provided the basis the basis of the supporting background file for the 2015 high temperature code case filing.

- Analysis of irradiation-induced creep data from Advanced Graphite Creep (AGC)-1 experiment was completed and the design validated. The data demonstrated the specimen irradiation creep levels were similar to previous irradiation creep experiments. 
- The AGC-2 capsule disassembly was completed ahead of schedule. The disassembly team worked diligently to complete the process safely and efficiently. The actual disassembly time at HFEF took roughly half the time and cost 50\% less than similar disassembly of the AGC-1 capsule completed approximately 3 years ago.

- Irradiation of AGC-3 was completed to an approximate dose range of 0.5-3.5 dpa (the desired dose levels). AGC-3 design improvements created extremely uniform axial and radial temperature profiles throughout the capsule. This resolved an issue experienced in AGC-1 and AGC-2 test trains.

\section{Nuclear Fuels and Materials - LWR Fuels}

In addition to the activities noted in Notable Outcome 1.1.A, the following are the highlights in this area:

- New Irradiation Assisted Stress Corrosion Cracking (IASCC) testing capability was established with the first IASCC test producing industry-accepted data for the LWR fleet. IASCC test rigs are a unique capability in the world that allow INL to remain on the forefront of materials research by providing a means to characterize crack growth and fracture toughness characteristics of very highly irradiated structural materials at size scales relevant to realistic reactor internal structures. The very first specimens irradiated using the Loop 2A facility were received in the IASCC test rigs in early April 2014 after being processed in HFEF. This test was part of a Cooperative Research and Development Agreement (CRADA) between INL and the Electric Power Research Institute (EPRI) to measure IASCC in a Boiling Water Reactor (BWR) repair component subjected to a specific neutron fluence. This first IASCC test was successfully completed in September 2014.

- INL made significant progress on measurement of swelling in irradiated zircaloy, providing valuable data to industry. Strain calculations were completed on the first of four irradiation capsules that are the subject of a CRADA between INL and EPRI to measure the combined effect of neutron damage and hydrogen content in several Zircaloy variants, including traditional alloys such as Zry-2 and Zry-4 as well as four experimental, proprietary alloys. Irradiation of a second test capsule to a target neutron damage of 12.3 dpa was completed in early FY 2014 and represented an approximately $20 \%$ higher than the original target damage level (10 dpa) requested by the customer (EPRI). Flexibility within the ATR schedule and re-prioritization by ATR NSUF staff allowed this stretch goal to be achieved. Ensuing measurements of the second capsule in August 2014 allowed a comparison of swelling at two levels of neutron damage; approximately 7 dpa and approximately $12 \mathrm{dpa}$. This data represents expected near end-of-life for BWR fuel channels and allows EPRI and its partners to make critical decisions regarding replacement and alloy selection for BWR fuel channel materials going forward. The project continues with an additional two capsules to be irradiated to damage levels of 20 and $30 \mathrm{dpa}$ in upcoming years. In addition to strain measurements completed for the two irradiation levels, tight temperature control for the irradiation capsules was demonstrated using melt wires and $\mathrm{SiC}$ monitors. Developed at Oak Ridge National Laboratory (ORNL) and implemented at INL, the $\mathrm{SiC}$ monitors represent a relatively new methodology for measuring temperature in irradiation capsules. The $\mathrm{SiC}$ monitors provide a measure of temperature that is more reflective of general irradiation conditions and are less susceptible to temporary temperature excursions than simple melt wires. The $\mathrm{SiC}$ monitor measurements for capsule B ( 12.3 dpa) represent the first data point for an irradiation damage level beyond $8 \mathrm{dpa}$. 
- The Advanced Fuels Campaign issued a Communications Plan on Accident Tolerant Fuels (ATF) R\&D to coordinate the variety of ongoing research, ensure regular communication with key stakeholders, provide program transparency, and develop support for the adoption of ATF technology. As a result, two articles were published in Nuclear News and Nuclear Plant Journal. Finally, Jon Carmack, Advanced Fuel Cycle (AFC) National Technical Director (NTD), gave an overview of ATF to the Foundation for Nuclear Studies in Washington D.C. The Foundation for Nuclear Studies, a 501(c) (3) nonprofit, provides information and educational opportunities for policymakers and the general public about nuclear science and technology, with the objective of promoting sound national policy.

\section{Nuclear Fuels and Materials - Fast Reactor Fuels}

- Futurix-FTA arrived at INL, giving us valuable comparison between thermal and fast spectrum irradiations. On July 24, 2014, nearly 10 years after the implementing arrangement was signed in August 2004, INL's irradiated fuels from the French Phenix reactor arrived at MFC HFEF. PIE will commence in FY 2015. INL can now compare test results from the ATR sister experiments to understand the implications of thermal reactor irradiation of fast reactor fuels.

- Strong commitment toward resolution of the feedstock issue was demonstrated through a Neptunium Oxide Reduction process at INL. Currently, there are no Np metal supplies available within the DOE complex. Current quantities of $\mathrm{Np}$ exist but must be converted to metal. INL reduced $\mathrm{NpO}_{2}$ to produce $15 \mathrm{~g}$ of $\mathrm{Np}$ metal in a laboratory scale with reasonably high purity. Further work is necessary to improve purity of the material. Also, INL purified several grams of metallic Am. In addition, INL acquired a large quantity of material highly loaded with Americium from SRS. The Am will be separated in the FMF TRU Breakout Glovebox, which will provide adequate research quantities of Am.

- Metallic fuel development activities in support of the TerraPower traveling wave reactor is progressing as planned, enabling TerraPower to pursue its aggressive deployment schedule. INL performed neutron radiography of 29 Fast Flux Test Facility (FFTF) fuel rods and gamma scans of another 17 FFTF fuel rods (additional post-irradiation examinations are continuing). We also inserted joint AFC and TerraPower irradiation experiment (AFC-4B) in ATR and the experiment is undergoing irradiation. To enable fuel fabrication development work, INL upgraded the west side of the Experimental Fuels Facility (EFF) including the facility's ventilation system to enable establishment of metal fuels fabrication capabilities. A 150-ton extrusion press, run-out tables, furnaces, and other fuel fabrication support equipment were installed in EFF.

\section{Separations Chemistry and Fuel Cycle Technologies}

In addition to Notable Outcome 1.1.B, the following are other highlights in this area:

- A sodium bismuthate process test for the oxidation and extraction of Am(VI) from the lanthanides was successfully performed at CFA-625 using a recently installed engineering-scale hot test setup, the first such demonstration of $\mathrm{Am}(\mathrm{VI})$ extraction in-process equipment. This test setup provided a new capability for the DOE-NE FCRD Program for the engineering-scale testing of Am oxidants developed at multiple national laboratories. The test was performed using simulated feed solution 
spiked with Am-243 and Ce-139 and three stages of 5-cm diameter centrifugal contactors. Results indicate comparable extraction of Am as obtained in laboratory-scale testing under ideal conditions (62\% extraction).

- Sample Testing was completed for the Waste Isolation Pilot Project (WIPP) to help with decontamination issues. WIPP sent clean, non-contaminated salt samples to INL for testing to determine the most effective decontamination methods. INL scientists brushed the salt surfaces with a non-toxic fluorescent powder. The consistency of the powder is similar to radioactive particles and is easily observed under a microscope. Several methods were tested to remove the powder particles from the salt's surface. The two methods that proved most effective were a water wash and a strippable gel coating. The tests showed salt can be decontaminated.

- A U.S. patent was awarded to INL scientists for $\mathrm{Kr}$ and Xe separation from used fuel. A U.S. Patent (\#8,686,083), “Composite Media For Fluid Stream Processing, A Method Of Forming The Composite Media, And A Related Method Of Processing A Fluid Stream," inventors Troy Garn, Jack Law, Mitchell Greenhalgh and Troy Tranter, was awarded on April 1, 2014. This patent relates to the formation of various adsorption media, including silver mordenite and hydrogen mordenite on a polyacrilonitrile binder, being developed for the separation of $\mathrm{Kr}$ and Xe from used fuel processing offgas

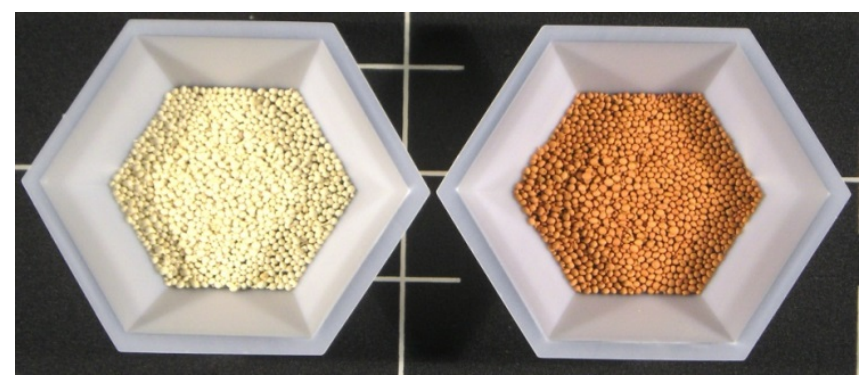
streams as an alternative to cryogenic distillation.

- In addition, the iodine capture experimental equipment in CFA-625 and the $\mathrm{Kr} / \mathrm{Xe}$ capture cryostat experimental equipment in IRC B-1 have been co-located to the new EIL Lab B-214, allowing for the unique capability to perform integrated deep bed testing supporting DOE-NE Fuel Cycle offgas separation R\&D.

- Joint Fuel Cycle Studies (JFCS)-integrated recycling testing design and fabrication of these systems were completed and proof testing was initiated with nonradioactive materials. The Integrated Recycling Test of the JFCS will utilize remote kilogram-scale equipment in the HFEF to develop an understanding of system performance and mass balance of an integrated electrochemical recycling process. Several furnace systems to separate salt and metal process streams will be utilized as a part of the testing.

- Research efforts identified iridium-coated materials as a much less-expensive and more chemically resistant option for oxygen-evolving electrodes in electrochemical recycling systems. In the electrolytic reduction process, oxide ceramics are converted to metals with oxygen gas liberated at an anode. Platinum is the traditional material of construction for this anode, but it suffers from a finite lifetime due to deleterious reactions with certain fission products. 


\section{Space Nuclear Technologies}

In addition to Notable Outcome 1.1.F, the following are other highlights in this area:

- The Space Reactor Technology Program issued the final criteria to DOE for lead follower fuel evaluation to occur in the first quarter of FY 2015. Five factors were identified: (1) evaluation of mission performance, (2) evaluation of fuel performance and process development, (3) evaluation of fuel testing and demonstration needs for performance expectations, (4) evaluation of program cost, schedule, and risk, and (4) reactor launch safety and safeguards. The criteria were developed and coordinated among three DOE laboratories and NASA's Marshall Space Flight Center. Selection of one fuel design is the goal to enable a 2030 launch of a nuclear-thermal propulsion system.

- The Space and Defense Power Systems (SDPS) Technical Integration Office (TIO) Director (INL's Stephen Johnson) is serving as a co-chair on a sub-team of a NASA-chartered technical review panel for the Nuclear Power Assessment Study (NPAS). The study is looking at various options and their respective operational considerations ranging from radioisotope power systems to small reactors for space missions. INL Fellow, Steve Herring, was also chosen by DOE to serve on one of the teams. The various teams and sub-teams have been meeting routinely since May, with a report from the panel to be issued in fall 2014.

\section{Nuclear Safety and Regulatory Research}

- INL released Version 8.1.0 of the SAPHIRE PRA Code providing users with new capabilities. The latest version of Systems Analysis Programs for Hands-on Integrated Reliability Evaluations (SAPHIRE 8) was released in May. SAPHIRE is the Nuclear Regulatory Commission's (NRC) and NASA's primary Probabilistic Risk Assessment (PRA) tool. This new version allows risk modelers to do very sophisticated post-processing of risk results for the purpose of intricate sensitivity analyses, to perform "what-if" studies, add special recovery actions, and support regulatory evaluations of operational events.

- INL's support to the NRC on a new Human Reliability Analysis (HRA) method was completed, providing a better comprehensive tie to basic human psychology. The NRC recognized there were many different methods being used to perform HRA in support of PRA, but they all had strengths and weaknesses that were not well-known. This project evaluated these methods, identified gaps in applicability, and developed a new hybrid method to address these gaps. The Integrated Decision-tree Human Event Analysis System (IDHEAS) method was a collaborative effort of the NRC, Sandia National Laboratory (SNL), ERPI, the University of Maryland, and INL. While the most recent Advisory Committee on Reactor Safeguards (ACRS) PRA subcommittee meetings on this effort have generated numerous suggestions for improvement, the subcommittee chair noted that one of the most praise-worthy aspects of IDHEAS is the research conducted by INL that provided a comprehensive tie to basic human psychology.

- INL-developed instrumentation, control technologies, and human systems simulation work are continuing to grow in scope and impact. INL is working with a dozen nuclear facilities to upgrade technology and provide training. In the future, laboratory researchers plan to move beyond training and perform operator evaluations, which will be used for research and possibly even facilitate operator licensing. The team also developed preliminary concepts for shared human and automated systems designs in TerraPower's preliminary control room designs. This included performing preliminary analyses and developing work domain models, defining functions and function allocation 
for the operation of the plant and major plant systems, and developing preliminary requirements for a prototype control room. Negotiations continue for additional work in FY 2015.

\section{Nuclear Systems Design and Analysis}

- INL accelerated deployment of the new HELIOS-MCNP5 methodology for ATR core physics and fuel management physics support. An 8-week training course was successfully conducted for the ATR engineering staff. The new system is now being used on a trial basis in parallel with the legacy methodology to prepare the physics information for Core Safety Analysis Packages associated with each ATR cycle, beginning with Cycle 157B. The new HELIOS-MCNP5 methodology is also currently being used by NS\&T staff to demonstrate that Ki-Jang Research Reactor (KJRR) fuel can be irradiated in a standard ATR cycle. Hundreds of ATR fuel element loading configurations are being tested to strategize new fuel management practices.

- TerraPower support work was successfully expanded to areas outside the fuel development, leveraging INL's diverse capabilities. Nonlinear seismic soil structure interaction analysis and design seismic isolators for TerraPower's Traveling Wave Reactor are progressing on schedule. We also provided safety analysis of the Traveling Wave Reactor (TWR) systems and a review of gas removal system designs and technologies for TerraPower's reactor system.

- INL played a leading role in International gas cooled reactor modeling activities. The VHTR Methods Simulation group has been involved in two international code-to-code benchmarks in 2014: OECD-NEA Modular High-Temperature Gas-Cooled Reactor (MHTGR) 350 and International Atomic Energy Agency (IAEA) Coordinated Research Projects (CRP) on High-Temperature Gas-Cooled Reactors (HTGR) Uncertainty Analysis in Best Estimate Modelling (UAM). Both of these benchmarks share the objectives of providing state-of-the-art assessments of HTGR reactor modeling, as well as creating peer-reviewed standard test problems that can be used by DOE, NRC, and core designers to validate their simulation tools.

- The collaboration with CEA on Advanced Sodium Technological Reactor for Industrial Demonstration (ASTRID) reactor design is very effective, leveraging U.S. fast reactor expertise. In support of CEA's 600 MWe ASTRID Sodium fast reactor conceptual design, INL has performed assessments on (a) remaining discrepancies of Phase 1 neutronics calculations, (b) uncertainty on the leakage component of the sodium void coefficient, (c) decoupling effects, and (d) applicability of the ZPPR-17 experiment to ASTRID.

- Two main subjects of investigation have been identified for future work on ASTRID: characterization of decoupling effects, and nuclear data issues including utilization of existing or new integral experiments aimed at reducing uncertainties on neutronic design parameters.

- INL continues to lead the highly visible International Handbook of Evaluated Reactor Physics Benchmark Experiments and the International Handbook of Evaluated Criticality Safety Benchmark Experiments. INL staff, participating in the benchmark projects, contributed five reports containing new benchmark evaluation data to the two handbooks and published three journal articles. A two-volume special edition of Nuclear Science and Engineering was organized and coordinated through INL staff participating in the international benchmark projects and will be published in November and December of 2014; seven of the 22 journal articles have INL employees as the sole or primary authors. 
- The collaborative INL-ANL-ISU integral reactor physics experiment Minor Actinide Neutron Transmutation Rates with Accelerator Mass Spectrometry (MANTRA) was presented to the newly established OECD-NEA Expert Group on Improvement of Integral Experiment Data for Minor Actinides Management with very positive feedback. The experiment objective is to infer the effective neutron capture cross-sections for most of the actinides of importance for reactor physics and fuel cycle studies in both fast and epithermal spectra. It has made important progress this fiscal year. The PIE is now almost completed and the as-run analyses have started. In June, the experiment was presented at the ATR NSUF Users Meeting with very positive feedback. ATR NSUF strongly supported this experiment for irradiation, disassembly, chemistry, and shipping.

- The RELAP5 group initiated an international effort to publish developments, applications, and new uses of RELAP5-3D in a dedicated issue of an American Nuclear Society (ANS) journal. In response to the call for papers, 31 abstracts were received at INL and both Nuclear Technology and Nuclear Science and Engineering each plan to publish one dedicated issue on the subject. The target for publication is the summer of 2015. In addition, RELAP5-3D was successfully used to model the VHTR High Temperature Test Facility at Oregon State University. Calculations provided much needed guidance on facility startup and operational procedures. A proprietary project for Bettis Naval Reactors to develop an Appendix K version of RELAP5-3D was completed. RELAP5-3D licenses are at an all-time high of 78. The 2014 International RELAP5 Users Group Meeting and Seminar was held in September 2014 with over 50 attendees from several foreign countries. Royalty income exceeds $\$ 600 \mathrm{~K}$ per year.

- INL supported mPower in qualifying RELAP5-3D for licensing purposes with work scope completed ahead of schedule. Code assessment reports were prepared using Loss-of-Fluid Test (LOFT) and Semiscale experimental data. A summary report describing the RELAP5-3D quality assurance status compared to the requirements of NUREG-1737 was also prepared. An Integral Systems Test Scaling Analysis report was completed for mPower as well. Two Work for Others (WFOs) for NuScale were completed, and a new WFO for code development and a technical support agreement was signed for a total of approximately $\$ 700 \mathrm{~K}$.

- The RELAP-7 development team is making considerable progress in developing the next generation systems analysis code, RELAP-7 that is already attracting attention from outside INL. The team has completed two strategic documents during August.

- A white paper was finished describing the "Summary of Capabilities" anticipated for the December 2014 release of the initial RELAP-7 Beta version. This document provides a RELAP-7 capability list describing analysis features, range of applicability, and reactor components available for the December release of the software.

- A RELAP-7 Technology Transfer Plan was completed. This document provides background information on RELAP-7, technology transfer information related to near-term development, quality assurance, the status of intellectual property, and a summary of key characteristics of the software.

- Also, the capabilities in RELAP-7 are being augmented towards a Beta release in December 2014. We developed an all-speed, all-fluid (vapor-liquid, gas, liquid metal) flow algorithm agnostic of reactor concept (coolant types). Specific hydrodynamic models include single-phase flow (liquid water, liquid metal, and single component gas flow), homogeneous equilibrium two-phase flow model (HEM), and 7-equation two-phase flow with simple closures. We also completed a point kinetics model for simple neutronics analysis, which has been implemented. 
One- and two-dimensional core heat structures strongly coupled with coolant, or conjugate heat transfer are included in the code. Additional equations of state/fluid properties are incorporated into the code.

\section{Recognitions and Awards}

First, a summary of the recognitions and awards from the first half of the year is provided for completeness. Details of these may be found in the mid-year report.

- The American Nuclear Society recognized Dr. Chang Oh posthumously as the recipient of the 2013 Technical Achievement Award at an awards ceremony on November 11, 2013 at the ANS Annual Meeting in Washington, D.C.

- ANS honored Nuclear Science and Technology (NS\&T) employee Piyush Sabharwall with the organization's Young Members Excellence Award at the ANS Annual Meeting in Washington, D.C.

- The Secretary of Energy, Ernie Moniz, has appointed Joy Rempe to the Nuclear Energy Advisory Committee (NEAC).

- Michael Tonks of the Nuclear Fuels and Materials Division staff was announced as one of the 28 winners of The Minerals, Metals and Materials Society (TMS) 2014 TMS Young Leader Professional Development Award.

- Shannon Bragg-Sitton has been selected as the Nuclear Energy Education Advocate Award winner at the annual Partnership for Science and Technology Awards banquet on February 19, 2014.

- Two INL researchers have been selected as recipients of the Idaho Academy of Science achievement awards for 2014. The two award recipients and the award designation include Bruce J. Mincher, Distinguished Scientist/Engineer, and Troy Unruh, Outstanding New Investigator Award, both of INL.

- Terry Todd, Jack Law, and Dean Peterman were honored with Secretary of Energy's Honor Awards for their role in the Salt Waste Disposal Technologies Team.

The recognitions and awards in the second half of the year also were substantial and those are described in detail below:

- The Nuclear Energy Institute (NEI) awarded a Top Industry Practice (TIP) award to Arizona Public Service and INL for the LWRS program-developed outage control center technology. This is the first time INL has been honored with NEI's top distinction. The award was for an innovative process improvement employed by Arizona Public Service (APS) in collaboration with researchers from INL to manage and provide enhanced collaboration of information and activities associated with Palo Verde's fall 2013 refueling outage. APS noted

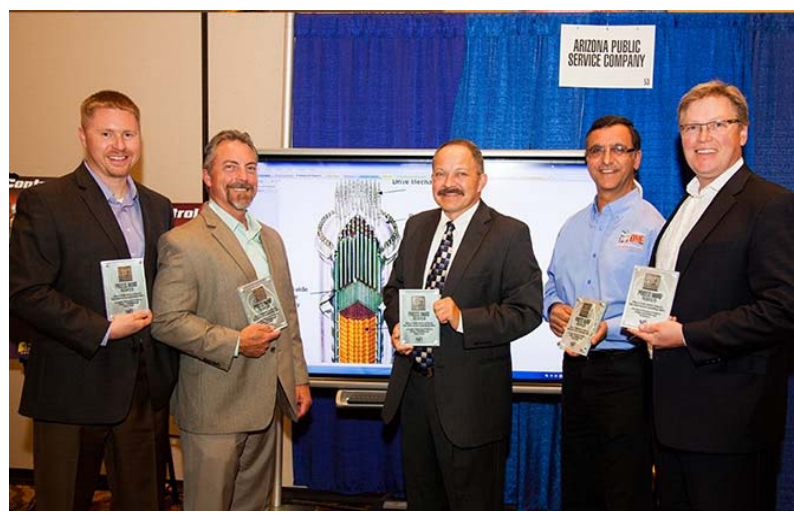
effective management of refueling outages is essential to the long-term commercial viability of nuclear energy facilities. Outage delays incur significant expenses due to the costs of replacement power and additional labor. The Advanced 
Instrumentation, Information, and Control Systems Technologies Pathway of the LWRS program, led by INL's Bruce Hallbert, has included outage safety and efficiency pilot projects in its research portfolio. These pilot projects demonstrate how the advanced instrumentation, information, and control technologies can improve refueling outage performance. APS estimates a savings of $\$ 48 \mathrm{M}$ of value added using the LWRS program-developed technology. A similar bottom-mounted instrumentation (BMI) issue had been experienced at South Texas Project. The time from issue identification to repair at South Texas Project was about 72 days. Use of operating experience, vendor support, and technology improvements allowed Palo Verde Nuclear Generating Station to complete similar repairs in about 32 days. Several Palo Verde Nuclear Generating Station managers involved in resolution of the BMI issue said the improved collaboration tools helped them achieve success in issue resolution. The TIP awards recognize achievements in 13 categories - four reactor vendor awards and nine process awards for innovation to improve safety, efficiency, and nuclear plant performance - as well as an award for vision, leadership, and ingenuity.

- INL's MOOSE simulation tool was awarded the 2014 R\&D 100 Award: Derek Gaston, Cody Permann, David Andrs, Jason Miller, John W. (JW) Peterson, Andrew Slaughter, and Richard Martineau developed this tool to make modeling and simulation more accessible to a broad array of scientists. It has revolutionized predictive modeling, especially in the field of nuclear engineering, allowing nuclear fuels and materials scientists to develop numerous applications that predict the behavior of fuels and materials under operating and accident conditions. The Commonwealth Scientific and Industrial Research Organization, Australia's premier research agency, noted one of their researchers said, "The MOOSE team has managed to find that elusive balance between flexibility and usability, and their method of coupling different physics is incredibly exciting for me; suddenly collaboration with a wide variety of other researchers is possible, and we are looking forward to tackling some very complicated cross-discipline problems." Barry Smith, senior computational mathematician at ANL led a technical review of MOOSE and said, "I can state, without a doubt, that the MOOSE simulation tool is one of the best, if not the best, to come out of the DOE laboratories in recent years."

- The Federal Laboratory Consortium (FLC) Far West Division (FW) awarded INL two awards during the 2014 competition. INL's Gary Smith and Derek Gaston received FLC FW's 2014 award for Outstanding Commercialization Success. Smith in Technology Deployment, and Gaston, along with his team members, worked diligently to offer MOOSE via an open source software mechanism. As of February, their efforts have produced 50 license agreements (17 domestic laboratories and commercial users, 25 domestic universities, three international commercial users, and five international universities). In February, MOOSE became the first BEA-developed software code to be offered to the public using open source software licensing.

- The ANS Materials Science and Technology Division honored INL leaders with achievement awards at the ANS meeting in Reno, Nevada. The awards are given every 2 years. Kemal Pasamehmetoglu was honored as the 2013 recipient of its Special Achievement Award. The division's most prestigious award recognizes international leadership in establishing a science-based approach to nuclear fuel development and seminal contributions to the nuclear materials area. Todd Allen was honored as the 2012 recipient of the Outstanding Achievement Award for his leadership and many contributions to nuclear materials area. Heather Chichester was presented the 2012 Past Chair Award for her dedication to the leadership and advancement of the Materials Science and Technology Division of ANS. Maria Okuniewski was awarded the 2012 Student Literary Award for "Atomic Properties of 
Body-Centered Cubic Uranium," published in the Journal of Physics: Condensed Matter, Number 24, February 2012. She teamed with Benjamin Beeler and Chaitanua Deo of Georgia Institute of Technology and Michael Baskes of University of California, San Diego, and LANL on the paper. The awards were presented at the ANS Embedded Topical Meeting on Nuclear Fuels and Structural Materials on June 17, 2014.

- $\quad$ U. S. Congressman Mike Simpson recognized the work of Deputy Laboratory Director Todd Allen and Associate Laboratory Director for Nuclear Science and Technology Kemal Pasamehmetoglu on June 23, 2014. "Our nation needs to continue investing in research and development to enhance economic prosperity, energy security and U.S. leadership," Simpson said. "It is appropriate that the American Nuclear Society has recognized Drs. Allen and Pasamehmetoglu for their technical contributions, and I would like to offer my own thanks to Todd and Kemal for their great work."

- Two NS\&T researchers (Troy Unruh and Catherine Riddle) were honored for their work related to nuclear fuel cycles in the DOE 2014 Innovations in Fuel Cycle Research Awards Program. These awards are given annually to graduate and undergraduate students who have completed significant research in nuclear science or engineering.

- Troy Unruh, who is currently pursuing his Ph.D. in nuclear engineering from ISU, won second place in the Advanced Fuels Category. His winning paper, entitled "In-core Flux Sensor Evaluations at the ATR Critical Facility," is part of a joint INL-ISU-French Atomic Energy Commission project. The paper documents results from tests of a new capability that Unruh helped to establish that measures neutron flux in a nuclear reactor.

- Catherine Riddle, who received her Ph.D. in radiochemistry from the University of Nevada, Las Vegas, (UNLV) in May, won first place in the "Competition for Students Who Attend Universities with less than $\$ 600$ Million in 2012 R\&D Expenditures." Her winning paper was entitled "Characterization of Bismuthate Oxidized Americium (V, VI) in Acidic Solution using X-ray Absorption Fine Structure Spectroscopy," and formed one of three research chapters in her dissertation.

- The DOE Pulse featured the research successes of two INL researchers: Melissa Teague and Michael Tonks. The two early-career researchers are earning international attention for their groundbreaking work. They're getting a long-sought look into the 3-D microstructure of irradiated nuclear fuel, and feeding that data into cutting-edge fuel behavior models. Pulse is a newsletter about accomplishments at the DOE's national laboratories.

- The appointment of Joy Rempe to ACRS has been extended to a second term.

\section{Notable Outcomes}

All the requirements for the Performance Evaluation and Measurement Plan (PEMP) 1.1 notable outcomes have been achieved except the start of irradiation testing of accident tolerant fuel capsules in ATR. The leak detected in Loop 2E in August resulted in ATR shutdown. The reactor will not restart before the end of the fiscal year due to extensive cleanup and repair required for safe restart of the reactor. This incident, while unfortunate, is out of INL's control. The remaining achievements in the notable outcomes and related activities demonstrate the diversity of the nuclear energy related research conducted at INL.

Notable Outcome 1.1.A. Complete all INL activities in support of the Advanced Test Reactor (ATR) irradiation testing of the accident tolerant fuels: (a) Complete the design, fabrication, and analyses of the 
test capsule for feasibility testing; and (b) start ATR irradiations provided all fuel rodlets fabricated by the program participants are delivered to INL according to the approved schedule.

Due to the shutdown of ATR, as a result of an unanticipated leak in one of the test loops, Part (b) of this notable outcome was not completed in FY 2014. While INL had a focused effort on the integrated schedule between ATR, MFC, and NS\&T personnel to ensure the completion of this notable outcome, the timing of the unexpected leak was unfortunate. As the leak occurred in the final month of the fiscal year, it did not allow sufficient time for the necessary repairs and safe restart of the reactor prior to the end of the fiscal year.

Part (a) was successfully completed through a diligent coordination effort between INL, the industry fuel suppliers, and DOE program managers. The team was able to accommodate the scope change in terms of welding the rodlets at INL instead of welding at the industry fabrication sites due to Quality Assurance (QA) considerations and welding equipment failure issues, the first test for insertion into ATR was fabricated in September. The first test that contains at least one fuel from each of the industry teams is ready for insertion into ATR as soon as the reactor is safely restarted after completion of the loop repairs.

Notable Outcome 1.1.B. Complete all FY 2014 activities associated with the materials recovery task consistent with the approved plan towards a Go/No-Go decision in FY 2015.

Activities associated with this notable outcome were met. The approved project execution plan for this project is PLN-4508, Rev. 1, "Material (HEU) Recovery Studies." The FY 2014 milestone stated in Table 2 of this plan is completion of Testing with Zircaloy at Central Facilities Area (CFA) by June 2014, which included a deliverable of completion of functional and leak testing with equipment ready to move into the Remote Analytical Laboratory (RAL) hot cells. This was accomplished in May 2014. The schedule in the plan showed hot testing in RAL (Line 13) starting in July 2014 (completing in January 2015) with a September 30, 2014, Go/No-Go decision point by DOE on proceeding with the experiments. The hot testing was started in July 2014, and a recommendation to DOE on continuing the research, based on all positive results from the Zircaloy and irradiated fuel tests, was made in September. In recent months, multiple briefings were provided at various levels of DOE including the Secretary of Energy Ernest Moniz, senior advisor to the Secretary of Energy John MacWilliams, Pete Lyons (NE-1), Monica Regalbuto (EM-1 pending confirmation), and Andy Griffith (from NE-5).

Notable Outcome 1.1.C. Using the Risk-Informed Safety Management Characterization (RISMC) Toolkit, complete an integrated framework to perform probabilistic risk analysis including adaptive sampling techniques to investigate nuclear power plant behavior in proximity of system failure, post-processing capabilities to identify system failure patterns, and mechanistic for complex phenomena. Demonstrate feasibility by a case study to illustrate the RISMC process from beginning to end.

The expectations for this notable outcome in FY 2014 have been exceeded. The report titled "Analysis of Pressurized Water Reactor Station Blackout Caused by External Flooding Using the RISMC Toolkit" by C. Smith, D. Mandelli, S. Prescott, A. Alfonsi, C. Rabiti, J. Cogliati, and R. Kinoshita, documents the completion of this notable outcome. This task demonstrates using the RISMC toolkit to illustrate the RISMC process from beginning to end, focusing on both internal (e.g., failures of diesel generators) and external events (e.g., external flooding).

In addition, the RISMC methodology developed at INL is receiving increasing national and international attention. In FY 2014, working with EPRI, we have completed a demonstration and a prioritized list of needs that can be addressed by RISMC methodology. INL successfully expanded the 
RISMC methodology to include a broader spectrum of accident scenarios and new stakeholders/participants. While the original focus of the RISMC was on the development of the RELAP-7 thermal hydraulics code, the GRIZZLY component-aging model, and the combination of these physics models with probabilistic methods, the focus has now expanded to include development of physics models for external events such as seismic and flooding. We have succeeded in bringing in new stakeholders to support the development of these tools, including, for example, South Texas Plant (who is interested in application of the RISMC methodology to a particular problem of interest to them), and the NRC (which has a potential interest in funding flooding modeling that leverages the RISMC pathway flooding modeling that began this fiscal year). International interest on RISMC is also increasing as evidenced by the number of invited talks requested by Japanese and European institutions as well as subsequent requests on collaborative work.

Notable Outcome 1.1.D. Complete an implementation plan to support the High Burn-up Dry Storage Cask Research and Development project to include a schedule of the INL activities required to support the project requirements. Complete the activities consistent with the DOE-approved plan.

The expectations for this notable outcome have been exceeded. Working with Department of Energy Idaho Operations Office (DOE-ID), INL prepared an implementation a plan for supporting the High Burnup Dry Storage Demonstration R\&D project. Specifically, a plan was provided that summarized all activities needed to receive and safely store up to 25 high burnup fuel rods at INL (if INL were to be selected for that mission). It detailed the work to be accomplished to plan and prepare for receiving a fuel rod shipment, the work needed to handle and unload the cask, how to safely store and protect the fuel rods in a hot cell, and return of the cask to its owner. The plan also included a cost estimate range for the work and a proposed schedule for work accomplishment. The plan was finalized and distributed on August 27, 2014. Additional activities completed included:

- A condition assessment was performed of PIE equipment that would be needed for follow-on work with the fuel. This assessment provided recommendations for improved configuration management for the equipment and complete spares lists for all critical equipment needed for potential sister rod characterization and testing.

- A document was prepared that details the PIE proposed for the fuel rods. This report documents the PIE exams that can be used to document the condition of the sister rods, and testing that can be performed in support of used fuel disposition UFD Storage and Transportation data needs.

- A hot cell waste clean out program was implemented at the HFEF that will enable improved PIE operations inside the hot cell. A significant amount of waste was removed from the hot cell.

- Investments were made in a new gas mass spectrometer and a new hydrogen-nitrogen-oxygen analyzer that will benefit both the UFD sister rod characterization and other projects. This equipment will allow INL to perform highly accurate fission gas analyses on the sister rods and determine total hydrogen in the fuel cladding.

Notable Outcome 1.1.E To continue advancing high temperature gas-cooled reactor technology, INL shall complete first-of-a-kind UCO TRISO source term analyses using AGR experimental fission product release data and relevant historical $\mathrm{UO}_{2}$ TRISO data, and maintain the schedule for planned graphite irradiations in ATR by completing the final design of the AGC-4 test train capsule.

All expectations associated with this notable outcome have been met or exceeded. Notable Outcome 1.1.E was achieved by completing first-of-its-kind UCO TRISO source term analyses using AGR experimental fission product release data and relevant historical $\mathrm{UO}_{2}$ TRISO data, and by issuing 
the final design of the AGC-4 test train capsule to maintain the schedule for planned graphite irradiations in ATR, as detailed below. Completion of this outcome supports defining the source term for modular HTGRs using UCO fuel.

Results of the source term analyses were documented in four reports. Two of the reports compare predicted fission product releases during irradiation and under accident conditions from the INL PARticle FUel ModEl (PARFUME) code to actual quantities released, as measured during post-irradiation examination and safety testing of AGR-1 experiment fuel particles, compacts, capsules, and other components. Prior to the AGR experiments, very little source term data existed relative to UCO fuel. Because of that lack of UCO source term data, PARFUME is based on correlations using German uranium dioxide $\left(\mathrm{UO}_{2}\right)$ TRISO data from IAEA Technical Document-978 (TECDOC-978). Fission product releases predicted using the $\mathrm{UO}_{2}$ TRISO fuel data from TECDOC-978 (in terms of correlations embedded in the PARFUME code for effective diffusion coefficients of the kernel and coating layers) were compared to measured releases from the AGR-1 experiment. This comparison allows a demonstration of the superior performance of UCO TRISO fuel. Now there can be "fine-tuning" of PARFUME to make more accurate predictions on future experiments.

A third report analyzes release rate to birth rate ratios $(\mathrm{R} / \mathrm{B})$ of fission gases from exposed kernels in the AGR-2 irradiation and designed-to-fail fuel in the AGR-3/4 irradiation. The R/B data were correlated as a function of temperature and isotopic half-life. With thousands of data collected during the irradiation, the $\mathrm{R} / \mathrm{B}$ trends have a strong statistical basis; the uncertainty in the correlation is within a factor of 2.5 at $95 \%$ confidence. Conclusions reached as a result of this analysis include: (a) there is not a significant effect of fuel burnup on fission gas release; (b) AGR-2 and AGR-3/4 R/B data are consistent with each other and are complementary; (c) AGR-2 and AGR-3/4 R/B data are consistent with the limited R/B data from historical irradiations considered to be benchmarks (HRB-17/18, COMEDIE-BD1, HFR-B1, and HRB-21); and (d) AGR-2 and AGR-3/4 R/B data are consistent with two conservative benchmark models developed by General Atomics and German researchers.

The fourth report addresses the measured behavior of I-135 during the irradiation of the AGR-1, AGR-2, and AGR-3/4 experiments. In addition, the report discusses the unexpected ability to measure the very low quantity of I-131 released from one capsule of the AGR-3/4 experiment during the impurity injection phase of the irradiation. Historic iodine data are sparse because of the short half-lives of most of the isotopes. This report demonstrates the measurement of xenon- $135 \mathrm{~m}$ can be used to quantify the short-lived iodine releases.

One of the objectives of the AGR Fuel program is to establish the UCO source term to support NRC licensing of a prismatic HTGR using UCO TRISO fuel. Results from the AGR-1 irradiation and PIE, and the AGR-3/4 fission product monitoring data obtained during irradiation have provided the first look at actual source term data. PIE of the AGR-2 and AGR-3/4 experiments will provide a more complete picture of the source term for the UCO TRISO fuel form.

Design of AGC-4 was completed in FY 2014. Because of the similarity between the AGC-3 and AGC-4 experiments, the design team was able to utilize the approved AGC-3 design package, combined with lessons learned from the AGC-3 experiment, and complete the AGC-4 final design 3 months ahead of schedule and $20 \%$ under budget.

Notable Outcome 1.1.F Complete the procurement and initiate installation of the neptunium-237 repackaging glovebox in support of the project to reestablish a domestic supply of Pu-238. 
All the requirements for this notable outcome have been successfully achieved. The Pu-238 Supply Program continues to establish a new capability in the Fuel Manufacturing Facility (FMF) at MFC for repackaging Np-237 for use as targets. ORNL's High-Flux Isotope Reactor and INL's ATR will be used to irradiate these targets to transmute the $\mathrm{Np}$ to heat-source material. Fabrication of a new Np repackaging glovebox was completed in March, and inspected at the vendor location in April. It was shipped to MFC in May. An installation subcontract was awarded in March, followed by initiation of installation of the Np repackaging glovebox in FMF on June 2, 2014, and finishing on July 12, 2014. Accomplishment of this installation completes an important milestone toward establishing this new capability necessary for re-establishing a domestic supply of $\mathrm{Pu}-238$. After completion of a maintenance outage in FMF, MFC personnel will perform as much acceptance testing on the Np repackaging glovebox and support facility systems as possible to allow turnover of systems to operations. Complete turnover and readiness activities will be completed after the new transuranic glovebox (which shares a hood with the Np repackaging glovebox) and facility monitoring system (funded by other programs) are installed and tested. $\mathrm{Np}$ repackaging operations are currently scheduled to begin by end of FY 2015.

\section{Publications}

Research results were published in a diverse set of prestigious journals enhancing INL's reputation as a world-class energy laboratory. Overall, INL staff published approximately 238 peer reviewed articles in prestigious journals in FY 2014. This number does not include publications that are accepted but not yet published, or publications in conference or workshop proceedings. Where appropriate published article citations are provided at the end of each report section in this document

Allahar, K. N., Burns, J., Jaques, B., Wu, Y.Q., Charit, I., Cole, J., Butt, D. P., "Ferritic oxide dispersion strengthened alloys by spark plasma sintering," Journal of Nuclear Materials, Vol. 443, No. 1-3, November 2013, pp. 256-265.

Anderson, N., and Sabharwall, P., "RELAP5-3D Modelling of Heat Transfer Components (Intermediate Heat Exchanger and Helical-Coil Steam Generator) for NGNP Application," International Journal of Nuclear Energy Science and Technology, Vol. 8, No. 1, January-March 2014, pp. 72-88.

Anderson, N. A., Sabharwall, P., "RELAP5-3D transient modelling for NGNP integrated plant," International Journal of Nuclear Energy Science and Technology, Vol. 8, No. 3, 2014, 2014, pp. 213-237.

Anderson, D. A., Garcia, P.; Liu, X. -Y., Pastore, G., Tonks, M., Millett, P., Dorado, B., Gaston, D. R., Andrs, D., Williamson, R. L., Martineau, R. C., Uberuaga, B. P., Stanek, C. R., "Atomistic modeling of intrinsic and radiation-enhanced fission gas $(\mathrm{Xe})$ diffusion in $\mathrm{UO} 2+/-\mathrm{x}$ : Implications for nuclear fuel performance modeling," Journal of Nuclear Materials, Vol. 451, No. 1-3, August 2014, pp. $225-242$.

Arnold, R., Augier, C., Baker, J. D., Barabash, A. S., Basharina-Freshville, A., Blondel, S., Blot, S., Bongrand, M., Brudanin, V., Busto, J., Caffrey, A. J., Cerna, C., Chapon, A., Chauveau, E., Duchesneau, D., Durand, D., Egorov, V., Eurin, G., Evans, J. J., Flack, R., Garrido, X., Gomez, H., Guillon, B., Guzowski, P., Hodak, R., Hubert, P., Hugon, C., Jullian, S., Klimenko, A., Kochetov, O., Konovalov, S. I., Kovalenko, V., Lalanne, D., Lang, K., Lemiere, Y., Liptak, Z., Loaiza, P., Lutter, G., Mamedov, F., Marquet, C., Mauger, F., Morgan, B., Mott, J., Nemchenok, I., Nomachi, M., Nova, F., Nowacki, F., Ohsumi, H., Pahlka, R. B., Perrot, F., Piquemal, F., Povinec, P., Ramachers, Y. A., Remoto, A., Reyss, J. L., Richards, B., Riddle, C. L., Rukhadze, E., Saakyan, R., 
Sarazin, X., Shitov, Yu., Simard, L., Rimkovic, F., Smetana, A., Smolek, K., Smolnikov, A., Soldner-Rembold, S., Soule, B., Rtekl, I., Suhonen, J., Sutton, C. S., Szklarz, G., Thomas, J., Timkin, V., Torre, S., Tretyak, V .I., Tretyak, V. I., Umatov, V .I., Vanushin, I., Vilela, C., Vorobel, V., Waters, D., and Zukauskas, A., "Search for neutrinoless double-beta decay of 100Mo with the NEMO-3 detector," Physical Review D:Particles, Fields, Gravitation, and Cosmology, Vol. 89, No. 11 Article 111101, June 1, 2014.

Bai, X-M., Zhang,Y., and Tonks, M. R., "Strain Effects on Oxygen Transport in Tetragonal Zirconium Dioxide," Physical Chemistry Chemical Physics, Vol. 15, No. 44, November 28, 2013, pp. 19438-19449.

Balden, M., Endstrasser, N., Humrickhouse, P. W., Rohde, V., Rasinski, M., von Toussaint, U., Elgeti, S., Neu, R., "Collection strategy, inner morphology, and size distribution of dust particles in ASDEX Upgrade," Nuclear Fusion, Vol. 54, No. 7, Article 073010, July 2014.

Baldwin, C. A., Hunn, J. D., Morris, R. N., Montgomery, F. C., Silva, C. M., and Demkowicz, P. A., "First Elevated-Temperature Performance Testing of Coated Particle Fuel Compacts from the AGR-1 Irradiation Experiment," Nuclear Engineering and Design, Vol. 271, May 2014, pp. 131-141.

Barr, C. M., Vetterick, G. A., Unocic, K., Hattar, K., Xian-Ming Bai, X-M., and Taheri, M., "Anisotropic Radiation-induced Segregation in 316L Austenitic Stainless Steel with Grain Boundary Character," Acta Materialia, Vol. 67, April 2014, pp. 145-155.

Besmann, T. M., Ferber, M. K., Lin, H-T., and Collin, B. P., "Fission Product Release and Survivability of UN-kernel LWR TRISO Fuel," Journal of Nuclear Materials, Vol. 448 No. 1-3, May 2014, pp. 412-419.

Bess, J. D., Briggs, J. B., Marshall, M. A., "Identification of Possible Discrepancies in HEU Metal Benchmarks," Nuclear Data Sheets, Vol. 118, April 2014, pp. 466-468.

Briggs, J. B., Bess, J D., and Guilliford, J., "Integral Benchmark Data for Nuclear Data Testing Through the ICSBEP \& IRPhEP," Nuclear Data Sheets, Vol. 118, April 2014, pp. 396-400.

Brown, D.W., Alexander, D. J., Clarke, K. D., Clausen, B., Okuniewski, M. A., and Sisneros, T.A., "Elastic Properties of Rolled Uranium-10 wt.\% Molybdenum Nuclear Fuel Foils," Scripta Materialia, Vol. 69, No. 9, November 2013, pp. 666-669.

Brown, D. W., Okuniewski, M. A., Almer, J. D., Balogh, L., Clausen, B., Okasinski, J. S., and Rabin, B. H., "High Energy X-ray Diffraction Measurement of Residual Stresses in a Monolithic Aluminum Clad Uranium-10 wt\% Molybdenum Fuel Plate Assembly," Journal of Nuclear Materials, Vol. 441, No. 1-3, October 2013, pp. 252-261.

Carmack, J., and Goldner, F., "Forward for special JNM issue on accident tolerant fuels for LWRs," Journal of Nuclear Materials, Vol. 448, No. 1-3, May 2014, pp 373.

Chadwick, M. B., Dupont, E., Bauge, E., Blokhin, A., Bouland,O., Brown, D. A., Capote, R., Carlson, A., Danon, Y., De Saint Jean, C., Dunn, M., Fischer, U., Forrest, R. A., Frankle, S. C., Fukahori, T., Ge, Z., Grimes, S. M., Hale, G. M., Herman, M., Ignatyuk, A., Ishikawa, M., Iwamoto, N., Iwamoto, O., Jandel, M., Jacqmin, R., Kawano, T., Kunieda, S., Kahler, A., Kiedrowski, B., Kodeli, I., Koning, A. J., Leal, L., Lee, Y.O., Lestone, J. P., Lubitz, C., MacInnes, M., McNabb, D., McKnight, R., Moxon, M., Mughabghab, S., Noguere, G., Palmiotti, G., Plompen, A., Pritychenko, B., Pronyaev, V., Rochman, D., Romain, P., Roubtsov, D., Schillebeeckx, P., 
Salvatores, M., Simakov, S., Soukhovitskin1, E. Sh., Sublet, J. C., Talou, P., Thompson, I., Trkov, A. Vogt, R., and van der Marck, S., "The CIELO Collaboration: Neutron Reactions on 1H, 16O, 56Fe, 235, 238U, and 239Pu," Nuclear Data Sheets, Vol. 118, April 2014, pp. 1-25.

Chakraborty, P., Tonks, M., and Pastore, G., "Modeling the Influence of Bubble Pressure on Grain Boundary Separation and Fission Gas Release," Journal of Nuclear Materials, Vol. 452, May 6, 2014, pp. 95-101.

Chang, Y. J. Bley, D., Criscione, L., Kirwan, B., Mosleh, A., Madary, T., Nowell, R., Richards, R., Roth, E., Scott Sieben, Zoulis, A., The SACADA database for human reliability and human performance," Reliability Engineering \& System Safety, Vol. 125, May 2014, pp. 117-133.

Chen, T., Chen, D., Sencer, B. H., Shao, L., "Molecular dynamics simulations of grain boundary thermal resistance in $\mathrm{UO}_{2}$," Journal of Nuclear Materials, Vol. 452, No. 1-3, September 2014, pp. 364-369.

Clark, R. A., Robertson, D. J., and Schwantes, J. M., "Intrinsic Dosimetry: Elemental Composition Effects on the Thermoluminescence of Commercial Borosilicate Glass," Radiation Measurements, Vol. 59, December 2013, pp. 270-276.

Collin, B. P., "Modeling and analysis of UN TRISO fuel for LWR application using the PARFUME code," Journal of Nuclear Materials, Vol. 451, No. 1-3, August 2014, pp. 65-77.

Courty, O., Motta, A. T., and Hales, J. D., "Modeling and simulation of hydrogen behavior in Zircaloy-4 fuel cladding," Journal of Nuclear Materials, Vol. 452, No. 1-3, September, 2014, pp. 311-320.

Crapps, J., Decroix, D. S., Galloway, J. D., Korzekwa, D. A., Aikin, R., Fielding, R, Kennedy, R., and Unal, C., "Separate Effects Identification via Casting Process Modeling for Experimental Measurement of U-Pu-Zr alloys," Journal of Nuclear Materials, Vol. 443, No. 1-3, November 2013, pp. 176-184.

Daw, J., Tittmann, B., Reinhardt, B., Kohse, G., Ramuhalli, P., Montgomery, R., Chien, H.-T., Villard, J.-F., Palmer, J., and Rempe, J., "Irradiation Testing of Ultrasonic Transducers," IEEE Transactions on Nuclear Science, Vol. 61, No. 4, August 2014, pp. 2279-2284.

De Frías, G. J., Aquino, W., Pierson, K. H., Heinstein, M. W., and Spencer, B. W., "A Multiscale Mass Scaling Approach for Explicit Time Integration Using Proper Orthogonal Decomposition," International Journal for Numerical Methods in Engineering, Vol. 97, No. 11, March 2014, pp. 99-818.

Delage, F., Carmack, J., Lee, C. B., Mizuno, T., Pelletier, M., and Somers, J., "Status of advanced fuel candidates for Sodium Fast Reactor within the Generation IV International Forum," Journal of Nuclear Materials, Vol. 441, No. 1-3, October 2013, pp. 515-519.

Dickson, J., Zhou, L., Paz y Puente, A., Fu, M., Keiser Jr., D. D., and Sohn, Y. H., "Interdiffusion and Reaction Between Zr and Al Alloys from 425 to $625^{\circ}$ C," Science Direct, Vol. 49, June 2014, pp. 154-162.

Dupont, E., Chadwick, M. B., Danon, Y., De Saint Jean, C., Dunn, M., Fischer, U., Forrest, R. A., Fukahori, T., Ge, Z., Harada, H., Herman, M., Igashira, M., Ignatyuk, A., Ishikawa, M., Iwamoto, O., Jacqmin, R., Kahler, A. C., Kawano, T., Koning, A. J., Leal, L., Lee, Y. O., McKnight, R., McNabb, D., Mills, R. W., Palmiotti, G., Plompen, A., Salvatores, M., and Schillebeeckx, P., "Working Party on International Nuclear Data Evaluation Cooperation (WPEC)," Nuclear Data Sheets, Vol. 120 SI, June 2014, pp. 264-267. 
Engelbrecht, J. A. A., Janz, E., Henry, A., and van Rooyen, I. J., "Impact of Dielectric Parameters on the Reflectivity of 3C-SiC Wafers with a Rough Surface Morphology in the Reststrahlen Region Physica B," Condensed Matter, Vol. 439, April 2014, pp. 115-118.

Engelbrecht, J. A. A., Deyzel, G., Minnaar, E. G., Goosen, W. E., and van Rooyen, I. J., "The Influence of Neutron-Irradiation at Low Temperatures on the Dielectric Parameters of 3C-SiC Physica B," Condensed Matter, Vol. 439, April 2014, pp. 169-172.

Field, K. G., Miller, B. D., Chichester, H. J. M., Sridharan, K., and Allen, T. R., "Relationship Between Lath Boundary Structure and Radiation Induced Segregation in a Neutron Irradiated 9 wt.\% Cr Model Ferritic/Martensitic Steel," Journal of Nuclear Materials, Vol. 445, No. 1-3, February 2014, pp. 143-148.

Fielding, R. S., and Porter, D. L., "Volatile species retention during metallic fuel casting," Journal of Nuclear Materials, Vol. 441, No. 1-3, October 2013, pp. 530-534.

Fiorina, C., Stauff, N. E., Franceschini, F., Wenner, M. T., Stanculescu, A., Kim, T. K., Cammi, A., Ricotti, M. E., Hill, R. N., Taiwo, T. A., and Salvatores, M., "Comparative Analysis of Thorium and Uranium Fuel for Transuranic Recycle in a Sodium Cooled Fast Reactor," Annals of Nuclear Energy, Vol. 62, December 2013, pp. 26-39.

Freiderich, M. E., Peterman, D. R., Klaehn, J. R., Marc, P., Delmau, L. H., "Chemical Degradation Studies on a Series of Dithiophosphinic Acids," Industrial \& Engineering Chemistry Research, Vol. 53, No. 9, March 5, 2014, pp. 3606-3611.

Garabalino, M. A., Heber, E. M., Hughes, M., Monti, A., Pozzi, E. C. C., Molinari, A. J., Nigg, D. W., Bauer, W., Trivillin, V. A., and Schwint, A. E., "Boron biodistribution for BNCT in the hamster cheek pouch oral cancer model: Combined administration of BSH and BPA," Applied Radiation and Isotopes,_Vol. 88, June 2014, pp. 64-68.

Ghrayeb, S. Z., Ougouag, A. M., Ouisloumen, M., and Ivanov, K. N., "Multi-Group Formulation of the Temperature-Dependent Resonance Scattering Model and its Impact on Reactor Core Parameters," Annals of Nuclear Energy, Vol. 63, January 2014, pp. 751-762.

Gofryk, K., Saparov, B., Durakiewicz, T., Chikina, A., Danzenbaecher, S., Vyalikh, D. V., Graf, M. J., Sefat, A. S., "Fermi-Surface Reconstruction and Complex Phase Equilibria in CaFe2As2," Physical Review Letters, Vol. 112, No. 18, Article 186401, May 7, 2014.

Gofryk, K.,Du, S., Stanek, C. R., Lashley, J. C., Liu, X-Y., “Anisotropic Thermal Conductivity in Uranium Dioxide," Nature Communications, Vol. 5, No. 4551, August 1, 2014.

Greenhalgh, M., Garn, T. G., and Law, J. D., "Development of a Hydrogen Mordenite Sorbent for the Capture of Krypton from Used Nuclear Fuel Reprocessing Off-Gas Streams," Journal of Nuclear Science and Technology, Vol. 51, No. 4, April 2014, pp. 476-481.

Grimes, T., and Nash, K., "Acid Dissociation Constants and Rare Earth Stability Constants for DTPA," Journal of Solution Chemistry, Vol. 43, No. 2, February 2014, pp. 298-313.

Grimes, T., Tilltoson, R., and Martin, L., "Trivalent Lanthanide/Actinide Separation using Aqueous-Modified TALSPEAK Chemistry," Solvent Extraction and Ion Exchange, Vol. 32, No. 3, June 2014, pp 378-390. 
Groth, K. M., Smith, C. L., and Swiler, L. P., "A Bayesian method for using simulator data to enhance human error probabilities assigned by existing HRA methods," Reliability Engineering and System Safety, Vol. 128, August 2014, pp. 32-40.

Grover, S. B., "Status of the NGNP Graphite Creep Experiments AGC-1 and AGC-2 Irradiated in the Advanced Test Reactor," Nuclear Engineering and Design, Vol. 271, May 2014, pp. 275-282.

Grover, S. B., and Petti, D. A., "Status of the NGNP Fuel Experiment AGR-2 Irradiated in the Advanced Test Reactor," Nuclear Engineering and Design, Vol. 271, May 2014, pp. 238-243.

Grover, S. B., and Petti, D. A., "Design and Status of the NGNP Fuel Experiment AGR-3/4 Irradiated in the Advanced Test Reactor," Nuclear Engineering and Design, Vol. 271, May 2014, pp. 142-148.

Hales, J. D., Novascone, S. R., Spencer, B. W., Williamson, R. L., Pastore, G., and Perez, D. M., "Verification of the BISON fuel performance code," Annals of Nuclear Energy, Vol. 71, September 2014, pp. 81-90.

Hales, J. D., Williamson, R. L., Novascone, S. R., Perez, D. M., Spencer, B. W., and Pastore, G., "Multidimensional Multiphysics Simulation of TRISO Particle Fuel," Journal of Nuclear Materials, Vol. 443, No. 1-3, November 13, 2013, pp. 531-543.

Hanson, C., Phongikaroon, S., and Scott, J. R., "Temperature effect on laser-induced breakdown spectroscopy spectra of molten and solid salts," Spectrochimica Acta-Part B Atomic Spectroscopy, Vol. 97, July 1, 2014, pp. 79-85.

He, J., Wan, F., Sridharan, K., Allen, T. R., Certain, A., Wu, Y.Q., "Response of 9Cr-ODS steel to proton irradiation at $400^{\circ}$ C," Journal of Nuclear Materials, Vol. 452, No. 1-3, September 2014, pp. 87-94.

He, L. F., Pakarinen, J., Kirk, M. A., Gan, J., Nelson, A. T., Bai, X.-M., El-Azab, A., Allen, T. R., "Microstructure evolution in Xe-irradiated $\mathrm{UO}_{2}$ at room temperature," Nuclear Instruments and Methods in Physics Research, Section B: Beam Interactions with Materials and Atoms, Vol. 330, July 1, 2014, pp. 55-60.

He, L.-F., Gupta, M., Yablinsky, C. A., Gan, J., Kirk, M. A., Bai, X-M., Pakarinen, J., and Allen, T. R., "In situ TEM Observation of Dislocation Evolution in Kr-irradiated $\mathrm{UO}_{2}$ Single Crystal," Journal of Nuclear Materials, Vol. 443, No. 1-3, November 13, 2013, pp. 71-77.

Heffner, M., Asner, D. M., Baker, R. G., Baker, J., Barrett, S., Brune, C., Bundgaard, J., Burgett, E. Carter, D., Cunningham, M., Deaven, J., Duke, D. L., Greife, U., Grimes, S., Hager, U., Hertel, N., Hill, T., Isenhower, D., Jewell, K., King, J., Klay, J.L., Kleinrath, V., Kornilov, N., Kudo, R., Laptev, A. B., Leonard, M., Loveland, W., Massey, T. N., McGrath, C., Meharchand, R., Montoya, L., Pickle, N., Qu, H., Riot, V., Ruz, J., Sangiorgio, S., Seilhan, B., Sharma, S., Snyder, L., Stave, S., Tatishvili, G., Thornton, R. T., Tovesson, F., Towell, D., Towell, R.S., Watson, S., Wendt, B., Wood, L., and Yao, L., "A time projection chamber for high accuracy and precision fission cross-section measurements," Nuclear Instruments and Methods in Physics Research, Section A: Accelerators, Spectrometers, Detectors and Associated Equipment, Vol. 759, September 21, 2014, pp. 50-64.

Hiruta, M., Johnson, G., Rostamian, M., Potirniche, G. P, Ougouag, A. M., Bertino, M., Franzel, L., and Tokuhiro, A., "Computational and Experimental Prediction of Dust Production in Pebble Bed Reactors," Part II, Nuclear Engineering and Design, Vol. 263, October 2013, pp. 509-514. 
Hosemann, P., Martos, J. N., Frazer, D., Vasudevamurthy, G., Byun, T. S., Hunn, J. D., Jolly, B. C., Terrani, K., and Okuniewski, M., "Mechanical Characteristics of SiC Coating Layer in TRISO Fuel Particles," Journal of Nuclear Materials, Vol. 442, No. 1-3, November 2013, pp. 133-142.

Huang, K., Kammerer, C.C., Keiser Jr., D.D., and Sohn, Y.H., "Diffusion Barrier Selection from Refractory Metals (Zr, Mo and $\mathrm{Nb}$ ) Via Interdiffusion Investigation for U-Mo RERTR Fuel Alloy," Journal of Phase Equilibria and Diffusion, Vol. 35, No. 2, April 2013, pp. 146-156.

Huang, K., Park, Y., Zhou, L., Coffey, K. R., Sohn, Y. H., Sencer, B. H., Kennedy, J. R., "Effects of $\mathrm{Cr}$ and $\mathrm{Ni}$ on interdiffusion and reaction between $\mathrm{U}$ and Fe-Cr-Ni alloys," Journal of Nuclear Materials, Vol. 451, No. 1-3, August 2014, pp. 372-378.

Hughes, A. M., Pozzi, E.C.C., Thorp, S., Garabalino, M. A., Farias, R. O., Gonzalez, S. J., Heber, E. M., Itoiz, M. E., Aromando, R. F., Molinari, A. J., Miller, M., Nigg, D.W., Curotto, P., Trivillin, V. A., and Schwint, A. E., "Boron Neutron Capture Therapy for Oral Precancer Proof of Principle in an Experimental Animal Model," Oral Diseases, Vol. 19, No. 8, November 2013, pp. 789-795.

Janney, D. E., Kennedy, J. R., Madden, J. W., and O'Holleran, T. P., “Crystal structure of high-Zr inclusions in an alloy containing $\mathrm{U}, \mathrm{Pu}, \mathrm{Np}, \mathrm{Am}, \mathrm{Zr}$ and rare-earth elements," Journal of Nuclear Materials, Vol. 448, No. 1-3, May 2014, pp. 109-112.

Jue, J.-F., Keiser Jr., D. D., Breckenridge, C. R., Moore, G. A., and Meyer, M. K., "Microstructural characteristics of HIP-bonded monolithic nuclear fuels with a diffusion barrier," Journal of Nuclear Materials Vol. 448, No. 1-3, May 2014, pp. 250-258.

Katsui, H., Katoh, Y., Hasegawa, A., Shimada, M., Hatano, Y., Hinoki, T., Nogami, S., Tanaka, T., Nagata, S., and Shikama, T., "Tritium trapping in silicon carbide in contact with solid breeder under high flux isotope reactor irradiation," Journal of Nuclear Materials, Vol. 442, No. 1-3, November 2013, pp. S497-S500.

Kaur, M., Zhang, H., Martin, L., Todd, T., and Qiang, Y., "Conjugates of Magnetic Nanoparticle - Actinide Specific Chelator for Radioactive Waste Separation," Environmental Science and Technology, Vol. 47, No. 21, November 5, 2013, pp. 11942-11959.

Keiser, D. D., Jr., Jue, J.-F., Miller, B. D., Gan, J., Robinson, A. B., Medvedev, P., Madden, J., Wachs, D., and Meyer, M., "Scanning Electron Microscopy Analysis of Fuel/Matrix Interaction Layers in Highly-Irradiated U-Mo Dispersion Fuel Plates with Al and Al-Si Alloy Matrices," Nuclear Engineering and Technology, Vol. 46, No. 2, April 2014, pp. 147-158,

Khatkhatay, F., Jiao, L., Jian, J., Zhang, W., Jiao, Z., Gan, J., Zhang, H., Zhang, X., and Wang, H., "Superior corrosion resistance properties of TiN-based coatings on Zircaloy tubes in supercritical water," Journal of Nuclear Materials, No. 1-3, August 2014, pp. 346-351.

Khatkhatay, F., Jian, J., Jiao, L., Su, Q., Gan, J., Cole, J. I., and Wang, H., "Diffusion Barrier Properties of Nitride-Based Coatings on Fuel Cladding," Journal of Alloys and Compounds, Vol. 580, December 15, 2013, pp. 442-448.

Kim, Y. S., Hofman, G. L., Robinson, A. B., and Wachs, D. M., "Improved Irradiation Performance of Uranium-Molybdenum/Aluminum Dispersion Fuel by Silicon Addition in Aluminum," Nuclear Technology, Vol. 184, No. 1, October 2013, pp. 42-53. 
Kim, I., Jiao, L., Khatkhatay, F., Martin, M. S., Lee, J., Shao, L., Zhang, X., Swadener, J. G., Wang, Y. Q., Gan, J., Cole, J. I., and Wang, H., "Size-Dependent Radiation Tolerance in Ion Irradiated TiN/AIN Nanolayer Films," Journal of Nuclear Materials, Vol. 441, No. 1-3, October 2013, pp. 47-53.

Kim, J. H., Kim, H. T., Woo, Y. M., Kim, K. H., Lee, C. B., and Fielding, R. S., "Interaction Studies of Ceramic Vacuum Plasma Spraying for the Melting Crucible Materials," Nuclear Engineering and Technology, Vol. 45, No. 5, October 2013, pp. 683-688.

Kim, J. H., Song, H., Kim, H. T., Ki Kim, H., Lee, C. B., and Fielding, R. S., "Development of a New Casting Method to Fabricate U-Zr Alloy Containing Minor Actinides," Journal of Radioanalytical and Nuclear Chemistry, Vol. 299, No. 1, January 2014, pp. 103-109.

Kim, K. H., Lee, C. T., Lee, C. B., Fielding, R. S., Kennedy, J. R., "Ceramic plasma-sprayed coating of melting crucibles for casting metal fuel slugs," Journal of Nuclear Materials, Vol. 441, No. 1-3, October 2013, pp. 535-538.

Kim, Y. S., Hofman, G. L., Ryu, H. J., Park, J. M., Robinson, A. B., and Wachs, D. M., "Modeling of Interaction Layer Growth between U-Mo Particles and an AL Matrix," Nuclear Engineering and Technology, Vol. 45, No. 7, December 2013, pp. 827-838.

Kobayashi, M., Shimada, M., Hatano, Y., Oda, T., Merrill, B., Oya, Y., Okuno, K., "Deuterium trapping by irradiation damage in tungsten induced by different displacement processes," Fusion Engineering and Design, Vol. 88, No. 9-10, October 2013, pp. 1749-1752.

Law, J. D., Tripp, J. L., Smith, T. E., Svoboda, J. M., Rutledge, V. J., Garn, T. G., and Macaluso, L., "Microfluidic-Based Robotic Sampling System for Radioactive Solutions," Nuclear Technology, Vol. 185, No. 2, February 2014, pp. 216-225.

Leenaers, A., Van den Berghe, S., Van Eyken, J., Koonen, E., Charollais, F., Lemoine, P., Calzavara, Y., Guyon, H., Jarousse, C., Geslin, D., Wachs, D., Keiser, D., Robinson, A., Hofman, G., and Kim, Y. S., "Microstructural Evolution of U(Mo)-Al(Si) Dispersion Fuel Under Irradiation - Destructive Analyses of the LEONIDAS E-FUTURE Plates," Journal of Nuclear Materials, Vol. 441, No. 1-3, October 2013, pp. 439-448.

Levitskaia, T. G., Peterson, J. M., Campbell, E. L., Casella, A. J., Peterman, D. R., and Bryan, S. B., "Fourier Transform Infrared Spectroscopy and Multivariate Analysis for Online Monitoring of Dibutyl Phosphate Degradation Product in Tributyl Phosphate/n -dodecane/nitric acid Solvent," Industrial and Engineering Chemistry Research, Vol. 52, No. 49, December 11, 2013, pp. 17607-17617.

Loveland, W., Yao, L., Asner, D. M., Baker, R. G., Bundgaard, J., Burgett, E., Cunningham, M., Deaven, J., Duke, D. L., Greife, U., Grimes, S., Heffner, M., Hill, T., Isenhower, D., Klay, J. L., Kleinrath, V., Kornilov, N., Laptev, A. B., Massey, T. N., Meharchand, R., Qu, H., Ruz, J., Sangiorgio, S., Selhan, B., Snyder, L., Stave, S., Tatishvili, G., Thornton, R. T., Tovesson, F., Towell, D., Towell, R. S., Watson, S., Wendt, B., and Wood, L., "Targets for Precision Measurements," Nuclear Data Sheets, Vol. 119, May 2014, pp. 383-385. 
Luo, Y. X., Rasmussen, J. O., Hamilton, J. H., Ramayya, A. V., Frauendorf, S., Hwang, J. K., Stone, N. J., Zhu, S. J., Brewer, N. T., Wang, E., Lee, I. Y., Liu, S. H., TerAkopian, G. M., Daniel, A. V., Oganessian, Y. T., Stoyer, M. A., Donangelo, R., Ma, W. C., Cole, J. D., Shi, Y., $\mathrm{Xu}, \mathrm{F}$. R., "New insights into the nuclear structure in neutron-rich 112,114,115,116,117,118Pd," Nuclear Physics A, Vol. 919, December 2, 2013, pp. 67-98.

Marshall, M. A., and Bess, J. D., "Evaluation of Delayed Critical ORNL Unreflected HEU Metal Sphere," Nuclear Data Sheets, Vol. 118, April 2014, pp. 469-471.

Meharchand, R., Asner, D. M., Baker, R. G., Bundgaard, J., Burgett, E., Cunningham, M., Deaven, J., Duke, D. L., Greife, U., Grimes, S., Heffner, M., Hill, T., Isenhower, D., Klay, J. L., Kleinrath, V., Kornilov, N., Laptev, A. B., Loveland, W., Massey, T. N., Qu, H., Ruz, J., Sangiorgio, S., Seilhan, B., Snyder, L, Stave, S., Tatishvili, G., Thornton, R. T., Tovesson, F., Towell, D., Towell, R. S., Watson, S., Wendt, B., and Wood, L., "Commissioning the NIFFTE Time Projection Chamber: Towards the 238U / 235U (n, f) Cross-section Ratio," Nuclear Data Sheets, Vol. 119, May 2014, pp. 373-376.

Meyer, M. K., Gan, J., Jue, J. F., Keiser, D. D., Perez, E.; Robinson, A., Wachs, D. M., Woolstenhulme, N., Hofman, G. L., Kim, Y. S., Irradiation Performance of U-Mo Monolithing Fuel, Nuclear Engineering and Technology 1738-5733, Vol. 46, No. 2, April 2014, pp. 169-182.

Mincher, B., and Wishart, J., "The Radiation Chemistry of Ionic Liquids: A Review," Solvent Extraction and Ion Exchange, Vol. 32, No. 6, May 2014, pp. 563-583.

Mincher, B. J, Mezyk, S. P., Elias, G., Groenewold, G. S., LaVerne, J. A., Nilsson, M., Pearson, J., Schmitt, N. C., Tillotson, R. D., and Olson, L. G., "The Radiation Chemistry of CMPO," PART 2. Alpha Radiolysis Solvent Extraction and Ion Exchange, Vol. 32, No. 2, February 23, 2014, pp. 167-178.

Mincher, B. J., Schmitt, N. C., Tillotson, R. D., Elias, G., White, B. M., and Law, J. D., "Characterizing Diamylamylphosphonate (DAAP) as an Americium Ligand for Nuclear Fuel-Cycle Applications," Solvent Extraction and Ion Exchange, Vol. 32, No. 2, February 23, 2014, pp. 153-166.

Mincher, B. J., Mezyk, S. P., Elias, G., Groenewold, G. S., Riddle, C. L., and Olson, L. G., "The Radiation Chemistry of CMPO: Part 1. Gamma Radiolysis," Solvent Extraction and Ion Exchange, Vol. 31, No. 7, November 2013, pp. 715-730.

Morgan, S. W., King, J. C., Pope, C. L., "Beam characterization at the Neutron Radiography Reactor," Nuclear Engineering and Design, Vol. 265, December 2013, pp. 639-653.

Navarro, J., Ring, T.A., and Nigg, D.W., "A Feasibility and Optimization Study to Design a Nondestructive ATR Fuel Permanent Scanning System to Determine Fuel Burnup," Nuclear Data Sheets, Vol. 118, April 2014, pp. 571-574.

Nilsson, M., Zalupski, P. R., Antonio, M. R., "Supramolecular Aspects of Stable Water-In-Oil Microemulsions in Chemical Separations," Ion Exchange and Solvent Extraction, Vol. 21, Chapter 6, December 2013, p. 197.

Oya, Y., Shimada, M., Tokunaga, T., Watanabe, H., Yoshida, N., Hatano, Y., Kasada, R., Nagasaka, T., Kimura, A., Okuno, K., "Behavior of deuterium retention and surface morphology for VPS-W/F82H," Journal of Nuclear Materials, Vol. 442, No. 1-3, November 2013, pp. S242-S245, Supp. 1. 
Pakarinen, J., He, L., Gupta, M., Gan, J., Nelson, A., El-Azab, A., and Allen, T. R., "2.6 MeV Proton Irradiation Effects on the Surface Integrity of Depleted $\mathrm{UO}_{2}$," Nuclear Instruments and Methods in Physics Research, Section B: Beam Interactions with Materials and Atoms, Vol. 319, January 15, 2014, pp. 100-106.

Palmiotti, G., Salvatores, M., Aliberti, G., Herman, M., Hoblit, S. D., McKnight, R. D., Oblo`zinsk'y, P., Talou, P., Hale, G. M., Hiruta, H., Kawano, T., Mattoon, C. M., Nobre, G. P. A., Palumbo, A., Pigni, M., Rising, M. E., Yang, W.-S., and Kahler, A. C., "Combined Use of Integral Experiments and Covariance Data," Nuclear Data Sheets, Vol. 118, April 2014, pp. 596-636.

Park, Y., Yoo, J., Huang, K., Keiser Jr., D. D., Jue, J. F., Rabin, B., Moore, G., and Sohn, Y. H., "Growth kinetics and microstructural evolution during hot isostatic pressing of U-10 wt.\% Mo monolithic fuel plate in AA6061 cladding with Zr diffusion barrier," Journal of Nuclear Materials, Vol. 447, No. 1-3, April 2014, pp. 215-224.

Paz Y Puente, A, Dickson, J., Keiser Jr., D. D., and Sohn, Y. H., "Investigation of Interdiffusion Behavior in the Mo-Zr binary System via Diffusion Couple Studies," International Journal of Refractory Metals and Hard Materials, Vol. 43, March 2014, pp. 317-321.

Perez, E., Keiser Jr., D. D., and Sohn, Y. H., "Phase Development in a U-7 wt.\% Mo vs. Al-7 wt.\% Ge Diffusion Couple," Journal of Nuclear Materials, Vol. 441, No. 1-3, October 2013, pp. 159-167.

Petti, D.A., Hobbins, R. R., Lowry, P., and Gougar, H., "Representative Source Terms and the Influence of Reactor Attributes on Functional Containment in Modular High-Temperature Gas-Cooled Reactors," Nuclear Technology, Vol. 184, No. 2, November 2013, pp. 181-197.

Pham, B. T. and Einerson, J. J., "The Statistical Analysis Techniques to Support the NGNP Fuel Performance Experiments," Journal of Nuclear Materials, Vol. 441, No. 1-3, October 2013, pp. 563-573.

Pham, B. T., Hawkes, G. L., and Einerson, J. J., "Improving Thermal Model Prediction Through Statistical Analysis of Irradiation and Post-Irradiation Data from AGR Experiments," Nuclear Engineering and Design, Vol. 271, May 2014, pp. 209-216.

Ploger, S., Demkowicz, P. A., Hunn, J. D., and Kehn, J. S., "Microscopic analysis of Irradiated AGR-1 Coated Particle Fuel Compacts," Nuclear Engineering and Design, Vol. 271, May 2014, pp. 221-230.

Pozzi, E. C., Trivillin, V. A., Colombo, L. L., Hughes, A. M., Thorp, S. I., Cardoso, J. E., Garabalino, M. A., Molinari, A. J., Heber, E. M., Curotto, P., Miller, M., Itoiz, M. E., Aromando, R. F., Nigg, D. W., and Schwint, A. E., "Boron Neutron Capture Therapy (BNCT) for Liver Metastasis in an Experimental Model, dose-response at five-week follow-up based on retrospective dose assessment in individual rats," Radiation and Environmental Biophysics, Vol. 52, No. 4, November 2013, pp. 481-491.

Quach, D. L., Mincher, B. J., and Wai, C. M., "Supercritical fluid extraction and separation of uranium from other actinides," Journal of Hazardous Materials, Vol. 274, June 15, 2014, pp. 360-366.

Rabenberg, E. M., Jaques, B. J., Sencer, B. H., Garner, F. A., Freyer, P. D., Okita, T., and Butt, D. P., "Mechanical behavior of AISI 304SS determined by miniature test methods after neutron irradiation to 28 dpa," Journal of Nuclear Materials, Vol. 448, No. 1-3, May 2014, pp. 315-324. 
Rashkeev, S. N., Glazoff, M. V., and Tokuhiro, A., "Ultra-High Temperature Steam Corrosion of Complex Silicates for Nuclear Applications," A Computational Study, Journal of Nuclear Materials, Vol. 444, No. 1-3, January 2014, pp. 56-64.

Rempe, J. L., and Knudson, D. L., "Instrumentation Performance during the TMI-2 Accident," IEEE Transactions on Nuclear Science, Vol. 61, No. 4, pp. 1963-1970, August 2014.

Rempe, J. L., Knudson, D. L., Daw, J. E., Unruh, T. C., Chase, B. M., Davis, K. L., Palmer, A. J., Schley, R. S., "Advanced In-Pile Instrumentation for Materials Testing Reactors," IEEE Transactions on Nuclear Science, Vol. 61, No. 4, August 2014, pp. 1984-1994.

Riley, B. J., Pierce, D. A., Chun, J., Matyá, J., Lepry, W. C., Garn, T. G., Law, J. D., and Kanatzidis, M. G., "Polyacrylonitrile-chalcogel hybrid sorbents for radioiodine capture," Environmental Science and Technology, Vol. 48, No. 10, May 20, 2014, pp. 5832-5839.

Rostamian, M., Johnson, G., Hiruta, M., Potirniche, G. P., Ougouag, A. M., Cogliati, J. J., and Tokuhiro, A., "Computational and Experimental Prediction of Dust Production in Pebble Bed Reactors-Part I," Nuclear Engineering and Design, Vol. 263, October 2013, pp. 500-508.

Ruz, J., Asner, D. M., Baker, R. G., Bundgaard, J., Burgett, E., Cunningham, M., Deaven, J., Duke, D. L., Greife, U., Grimes, S., Heffner, M., Hill, T., Isenhower, D., Klay, J. L., Kleinrath, V., Kornilov, N., Laptev, A. B., Loveland, W., Massey, T. N., Meharchand, R., Qu, H., Sangiorgio, S., Seilhan, B., Snyder, L., Stave, S., Tatishvili, G., Thornton, R. T., Tovesson, F.,Towell, D.,Towell, R. S., Watson, S., Wendt, B., Wood, L., "The NIFFTE project," Journal of Instrumentation, Vol. 8, No. 12, Article C12018, December 2013.

Sabharwall, P., Bragg-Sitton, S. M., and Stoots, C., "Challenges in the Development of High Temperature Reactors," Energy Conversion and Management, Vol. 74, October 2013, pp. 574-581.

Salvatores, M., Palmiotti, G., Aliberti, G., Archier, P., De Saint Jean, C., Dupont, E., Herman, M., Ishikawa, M., Ivanova, T., Ivanov, E., Kim, S.-J., Kodeli, I., Manturov, G., McKnight, R., Pelloni, S., Perfetti, C., Plompen, A. J. M., Rearden, B. T., Rochman, D., Sugino, K., Trkov, A., Wang, W., $\mathrm{Wu}, \mathrm{H}$., and Yang, W. S., "Methods and Issues for the Combined Use of Integral Experiments and Covariance Data: Results of a NEA International Collaborative Study," Nuclear Data Sheets, Vol. 118, April 2014, pp. 38-71.

Sanchez, R., Rabiti, C., and Wang, Y. "Nonlinear Acceleration of a Continuous Finite Element Discretization of the Self-Adjoint Angular Flux Form of the Transport Equation," Nuclear Science and Engineering, Vol. 175, No. 3, November 2013, pp. 213-226.

Scates, D. M., Walter, J. B., Maki, J. T., Sterbentz, J. W., and Parry, J. R., "The Effect of Birthrate Granularity on the Release-To-Birth Ratio for the AGR-1 In-Core Experiment," Nuclear Engineering and Design, Vol. 271, May 2014, pp. 231-237.

Shaltry, M., Phongikaroon, S., "Experimental study of salt bead dissolutions in aqueous solvents," Industrial and Engineering Chemistry Research, Vol. 53, No. 34, August 27, 2014, pp. 13550-13556.

Short, M. P., Gaston, D., Stanek, C. R. and Yip, S., "A Perspective on Coupled Multiscale Simulation and Validation in Nuclear Materials," MRS Bulletin, Vol. 39, No. 1, January 2014, pp. 71-77.

Shrivastava, A., Williams, B., Siahpush, A. S., Savage, B., Crepeau, J., "Numerical and experimental investigation of melting with internal heat generation within cylindrical enclosures," Applied Thermal Engineering, Vol. 67 No. 1-2, June 2014, pp 587-596. 
Snead, L., Allen, T., and Wiffen, B., "Special Section on Proceedings of the Third Symposium on Nuclear Fuels and Structural Materials for Next Generation Nuclear Reactors (NFSM-3) Preface," Journal of Nuclear Materials, Vol. 441, No. 1-3, October 2013, pp. 514-514.

Snyder, E., Drake, J., Cardarelli, J., Hall, K., Szabo, J., Demmer, R., Lindberg, M., Riggs, K., James, R., "Assessment Of Self-Help Methods to Reduce Potential Exposure to Radiological Contamination after a Large-Scale Radiological Release," Health Physics, Vol. 107 No. 3. September 2014, pp. 231-241.

Snyder, L., Asner, D. M., Baker, R. J., Bundgaard, J., Burgett, E., Cunningham, M., Deaven, J., Duke, D. L., Greife, U., Grimes, S., Heffner, M., Hill, T., Isenhower, D., Klay, J. L., Kleinrath, V., Kornilov, N., Laptev, A. B., Loveland, W., Massey, T. N., Meharchand, R., Qu, H., Ruz, J., Sangiorgio, S., Seilhan, B., Stave, S., Tatishvili, G., Thornton, R. T., Tovesson, F., Towell, D., Towell, R. S., Watson, S., Wendt, B., and Wood, L., "Measuring the $\alpha /$ SF Branching Ratio of $252 \mathrm{Cf}$ with the NIFFTE TPC," Nuclear Data Sheets, Vol. 119, May 2014, pp. 386-388.

Sohn, Y., Keiser, D. D. Jr., "How Fundamentals of Phase Equilibria and Diffusion Contribute to the RERTR program," Journal of Phase Equilibria and Diffusion, Vol. 35, No. 1, February 2014, p. 1.

Solbrig, C. W., Pope, C. L., Andrus, J. P., "Stress and diffusion in stored Pu ZPPR fuel from alpha generation," International Journal of Heat and Mass Transfer, Vol. 74, July 2014, pp. 251-262.

Solbrig, C. W., Pope, C., Andrus, J., "Transient response and radiation dose estimates for breaches to a spent fuel processing facility," Nuclear Engineering and Design, Vol. 275, August 2014, pp. 352-367.

Stanculescu, A. O., “Accelerator Driven Systems for Nuclear Transmutation,” Annals of Nuclear Energy, Vol. 62, December 2013, pp. 607-612.

Stave, S., Asner, D. M., Baker, R. G., Bundgaard, J., Burgett, E., Cunningham, M., Deaven, J., Duke, D. L., Greife, U., Grimes, S., Heffner, M., Hill, T., Isenhower, D., Klay, J. L., Kleinrath, V., Kornilov, N., Laptev, A. B., Loveland, W., Massey, T. N., Meharchand, R., Qu, H., Ruz, J., Sangiorgio, S., Seilhan, B., Snyder, L., Tatishvili, G., Thornton, R T., Tovesson, F., Towell, D., Towell, R. S., Watson, S., Wendt, B., and Wood,, L., "The Data Analysis Framework for the NIFFTE Fission Time Projection Chamber, "Nuclear Data Sheets, Vol. 119, May 2014, pp. 380-382.

Taller, S. A., and Bai, X-M., "Assessment of Structures and Stabilities of Defect Clusters and Surface Energies Predicted by Nine Interatomic Potentials for $\mathrm{UO}_{2}$," Journal of Nuclear Materials, Vol. 443, No. 1-3, November 2013, pp. 84-98.

Taylor, C. N., Allain, J. P., Luitjohn, K., E., Kristic, P. S., Dadras, J., and Skinner, C. H., "Differentiating the Role of Lithium and Oxygen in Retaining Deuterium on Lithiated Graphite Plasma-Facing Components," Physics of Plasmas, Vol. 21, No. 5, Article 057101, May 2014.

Taylor, C. N., Luitjohan, K. E., Heim, B., Kollar, L., Allain, J. P., Skinner, C. H., Kugel, H. W., Kaita, R., Roquemore, A. L., and Maingi, R., "Surface Chemistry Analysis of Lithium Conditioned NSTX Graphite Tiles Correlated to Plasma Performance," Fusion Engineering and Design, October 2013.

Taylor, C. N., Shimada, M., Merrill, B. J., Drigert, M. W., Akers, D. W., and Hatano, Y., "Development of Positron Annihilation Spectroscopy for Characterizing Neutron Irradiated Tungsten," Physica Scripta, Vol. 2014, No. T159, April 2014. 
Taylor, C. N., Dadras, J., Luitjohan, K. E., Allain, J. P., Krstic, P. S., and Skinner, C. H., "The Role of Oxygen in the Uptake of Deuterium in Lithiated Graphite," Journal of Applied Physics, Vol. 114, No. 22, December 14, 2013.

Teague, M., Gorman, B., Miller, B., and King, J., "EBSD and TEM Characterization of High Burn-Up Mixed Oxide Fuel," Journal of Nuclear Materials, Vol. 444, No. 1-3, January 2014, pp. 475-480.

Teague, M.; Gorman, B., "Utilization of dual-column focused ion beam and scanning electron microscope for three dimensional characterization of high burn-up mixed oxide fuel," Progress in Nuclear Energy, Vol. 72, April 2014, pp. 67-71.

Teague, M., Gorman, B. King, J., Porter, D., and Hayes, S., "Microstructural Characterization of High Burn-Up Mixed Oxide Fast Reactor Fuel," Journal of Nuclear Materials, Vol. 441, No. 1-3, October 2013, pp. 267-273.

Teague, M., Tonks, M., Novascone, S., and Hayes, S., "Microstructural Modeling of Thermal Conductivity of High Burn-Up Mixed Oxide Fuel," Journal of Nuclear Materials, Vol. 444, No. 1-3, January 2014, pp. 161-169.

Tonks, M., Zhang, Y, Bai, X., and Millett, P., "Demonstrating the Temperature Gradient Impact on Grain Growth in $\mathrm{UO}_{2}$ Using the Phase Field Method," Materials Research Letters, Vol. 2, No. 1, 2014, pp. 23-28, 2014.

Trivillin, V. A., Garabalino, M. A., Colombo, L. L., Gonzalez, S. J., Farias, R. O., Monti Hughes, A., Pozzi, E. C. C., Bortolussi, S., Altieri, S., Itoiz, M. E., Aromando, R. F., Nigg, D. W., and Schwint, A. E., "Biodistribution of the boron carriers boronophenylalanine (BPA) and/or decahydrodecaborate (GB-10) for Boron Neutron Capture Therapy (BNCT) in an experimental model of lung metastases," Applied Radiation and Isotopes, Vol. 88, June 2014, pp. 94-98.

Tung, Y.-H., Ferng, Y.-M., Johnson, R. W., and Chieng, C.-C., "Study of natural circulation in a VHTR after a LOFA using different turbulence models," Nuclear Engineering and Design, Vol. 263, October 2013, pp. 206-217.

Tung, Y.-H., Johnson, R. W., Ferng, Y.-M. (1); Chieng, C.-C., "Bypass flow computations on the LOFA transient in a VHTR," Applied Thermal Engineering, Vol. 62, No. 2, January 2014, pp. 415-423.

Unruh,T., Chase, B., Rempe, J., Nigg, D., Imel, G., Harris, J., Sherman, T., Villard, J-F., "In-Core Flux Sensor Evaluations at the ATR Critical Facility," Nuclear Technology, Vol. 187, No. 3, September 2014, pp. 308-315.

Van Rooyen, I. J., Janney, D. E., Miller, B. D., Demkowicz, P. A., and Riesterer, J., "Electron Microscopic Evaluation and Fission Product Identification of Irradiated TRISO Coated Particles from the AGR-1 Experiment," A preliminary review, Nuclear Engineering and Design, Vol. 271, May 2014, pp. 114-122,

Van Rooyen, I. J., Dunzik-Gougar, M. L., and van Rooyen, P. M., "Silver (Ag) Transport Mechanisms in TRISO Coated Particles," A critical review, Nuclear Engineering and Design, Vol. 271, May 2014, pp. $180-188$.

Van Rooyen, I. J., Lillo, T. M., and Wu, Y. Q., "Identification of Silver and Palladium in Irradiated TRISO Coated Particles of the AGR-1 Experiment," Journal of Nuclear Materials, Vol. 446, No. 1-3, March 2014, pp. 178-186. 
Verhoeven, J. D., Spitzig, W. A., Jones, L. L., Downing, H. L., Trybus, C. L., Gibson, E. D., Chumbley, L. S., Fritzemeier, L. G., Schnittgrund, G. D., "Development of deformation processed copper-refractory metal composite alloys," Journal of Materials Engineering and Performance, Vol. 22, No. 10, October 2013, pp. 2847-2859.

Wang, Y., Zhang, H., and Martineau, R. C., "Diffusion Acceleration Schemes for Self-Adjoint Angular Flux Formulation with a Void Treatment," Nuclear Science and Engineering, Vol. 176, No. 2, February 2014, pp. 201-225.

Wood, L., Asner, D. M., Baker, R. G., Bundgaard, J., Burgett, E., Cunningham, M., Deaven, J., Duke, D. L., Greife, U., Grimes, S., Heffner, M., Hill, T., Isenhower, D., Klay, J. L., Kleinrath, V., Kornilov, N., Laptev, A. B., Loveland, W., Massey, T. N., Meharchand, R., Qu, H., Ruz, J., Sangiorgio, S., Seilhan, B., Snyder, L., Stave, S., Tatishvili, G.,Thornton, R. T., Tovesson, F., Towell, D., Towell, R. S., Watson, S., and Wendt, B., "An Ethernet-based Data Acquisition System for the NIFFTE Time Projection Chamber," Nuclear Data Sheets, Vol. 119, May 2014, pp. 377-379.

Xing, C., Folsom, C., Jensen, C., Ban, H., and Marshall, D. W., "A correction scheme for thermal conductivity measurement using the comparative cut-bar technique based on 3D numerical simulation,"_Measurement Science \& Technology, Vol. 25, No. 5 Article 055602, May 2014.

Xing, C., Jensen, C., Folsom, C., Ban, H., and Marshall, D. W., "An Optimal Guarding Scheme For Thermal Conductivity Measurement Using A Guarded Cut-Bar Technique, Part 1 Experimental Study," Applied Thermal Engineering, Vol. 62, No. 2, January 25, 2014, pp, 850-857.

$\mathrm{Xu}, \mathrm{Z}$., "A Stochastic Analysis of Steady and Transient Heat Conduction in Random Media Using a Homogenization Approach," Applied Mathematical Modelling, Vol. 38, No. 13, July 1, 2014, pp. 3233-3243.

Yang, Y.; Lo, W-Y., Dickerson, C., Allen, T. R., "Stoichiometry effect on the irradiation response in the microstructure of zirconium carbides," Journal of Nuclear Materials, Vol. 454, No. 1-3, August 19, 2014, pp. 130-135.

Youinou, G., Vondrasek, R., Veselka, H., Salvatores, M., Paul, M., Pardo, R, Palmiotti, G., Palchan, T., Nusair, O., Nimmagadda, J., Nair, C., Murray, P., Maddock, T., Kondrashev, S., Kondev, F. G., Jones, W., Imel, G., Glass, C., Fonnesbeck, J., Berg, J., and Bauder W., "MANTRA: An Integral Reactor Physics Experiment to Infer the Neutron Capture Cross Sections of Actinides and Fission Products in Fast and Epithermal Spectra," Nuclear Data Sheets, Vol. 119, May 2014, pp. 169-172.

Yoon, S.-J., and Sabharwall, P., "Parametric study on maximum transportable distance and cost for thermal energy transportation using various coolants," Progress in Nuclear Energy, Vol. 74, July 2014, pp. 110-119.

Yoon, S-J., Sabharwall, P., and Kim, E-S., "Numerical Study on Crossflow Printed Circuit Heat Exchanger for Advanced Small Modular Reactors," International Journal of Heat and Mass Transfer, Vol. 70, March 2014, pp. 250-263.

Zalupski, P. R.; McDowell, R.; and Clegg, S. L., "Isopiestic Determination of the Osmotic Coefficients of $\mathrm{NaNO} 3+\mathrm{Eu}(\mathrm{NO} 3)(3)+\mathrm{H} 2 \mathrm{O}$ at $298.15 \mathrm{~K}$ and Representation with an Extended Ion-Interaction (Pitzer) Model," Journal of Chemical Engineering Data, Vol. 59, No. 5, May 2014, pp. 1574-1582.

Zhang, X., O’Brien, J. E., O’Brien, R. C., and Housley, G. K., "Durability Evaluation of Reversible Solid Oxide Cells," Journal of Power Sources, Vol. 242, November 15, 2013, pp. 566-574. 
Zhang, Y., Millett, P., Tonks, M., Bai, X-M., and Biner, S. B., "Molecular Dynamics Simulations of Intergranular Fracture in $\mathrm{UO}_{2}$ with Nine Empirical Interatomic Potentials," Journal of Nuclear Materials, Vol. 452, No. 1-3, May 27, 2014, pp. 296-303.

Zhao, H., Zou, L., and Zhang, H., "Simulation of Thermal Stratification in BWR Suppression Pools with one Dimensional Modeling Method," Annals of Nuclear Energy, Vol. 63, January 2014, pp. 533-540.

Zheng, G., Xu, P., Sridharan, K., and Allen, T., "Characterization of structural defects in nuclear graphite IG-110 and NBG-18," Journal of Nuclear Materials, Vol. 446, No. 1-3, March 2014, pp. 193-199. 
PEMP FY 2014 


\section{Efficient and Effective Mission Accomplishment}

\section{2: National and Homeland Security}

OBJECTIVE 1.2: NATIONAL AND HOMELAND SECURITY

Lead and implement relevant, high impact RDD\&D programs. Establish the INL as a major center for national security technology development and demonstration. The primary focus areas include, but are not limited to the following:

- Critical infrastructure protection to include industrial cyber security, wireless communications, and grid reliability and security;

- Armor production which meets Department of the Army cost, production schedules, and quality requirements for Specific Manufacturing Capability (SMC) and explosives/ blast protection:

- Nuclear nonproliferation and emergency response technology RDD\&D and training including work with special nuclear materials; and

- Applied solutions to satisfy requirements for Defense and Intelligence Community customers.
INL National and Homeland Security (N\&HS) is exceeding almost all strategic goals, award-fee goals and objectives, and is significantly contributing to the achievement of DOE's mission and strategic goals for science, energy, and nuclear security. Our science and engineering accomplishments have notably enhanced the overall mission of the laboratory through discovery, delivery, and deployment of innovative technical products, strategic leadership, and technical expertise. N\&HS program performance has enabled the nation to solve complex national security challenges.

During FY 2014, the impacts of our technical solutions were recognized by the DOE, National Nuclear Security Administration (NNSA), Department of Defense (DoD), Department of Homeland Security (DHS), U.S. Intelligence Community (IC), and multiple peer technical leadership organizations. INL successfully completed FY 2014 PEMP Notable Outcomes 1.2.A and 1.2.B in addition to the completion of multiple noteworthy programmatic research, development, demonstration, testing, and deployment milestones and deliverables. N\&HS science achievements included discovery of new materials for chemical detection, ballistic protection, and energetic safety; cyber, physical, and infrastructure independency vulnerabilities that threaten the security of our critical infrastructure; and electromagnetic-physical-mechanical phenomena that will enable the protection of the national power grid and ensure wireless communications. N\&HS developed, disseminated, and delivered innovative technical prototypes, fieldable technology products, publications, reports, and thought leadership positions that have protected the U.S. warfighter, prepared emergency responders, secured nuclear materials, prevented/detected/mitigated threats to critical infrastructure, and influenced national and international policy. INL's thought leadership has changed the field of cybersecurity through the development and initiation of new federal $R \& D$ programs; influenced the national strategy for the production of heavy armor, protection of the national grid from the effects of geomagnetic disturbance, and assurance of wireless communications within a shared spectrum environment; established new methodologies for the national and international protection of nuclear facilities and the exchange of nuclear energy technology information; and re-invented methodologies for threat analysis and public-private information sharing for the U.S. Intelligence Community.
1.2.A

The NHS Mission Support Center (MSC) will provide strategic technical analysis and specifically requested deliverables to support critical planning and alignment of investments for the nation's defense as measured by customer formal recognition of excellent performance.

Notable Outcome 1.2.A was achieved as a result of dissemination of analytical threat assessment, delivery of unique technology prototypes, and completion of complex infrastructure testing. The MSC was formally recognized for excellent performance in service to the nation by a federal sponsor of the MSC. 
The culmination of our achievements significantly enabled progress in achieving the DOE 2014 Strategic Plan objectives to protect and secure a resilient U.S. energy infrastructure; to strengthen DOE's science, technology, and engineering capabilities and DOE's national security infrastructure; and to safeguard nuclear and radiological materials from proliferation and terrorism threats. N\&HS scientific and engineering leadership has resulted in changes to the requirements and objectives of national RD\&D programs within DOE and other organizations responsible for addressing significant national security technical challenges. Substantial advancements were made in realizing INL's strategic end state objectives for achieving recognition of leadership in N\&HS technical focus areas, capturing RD\&D programs aligned with and expanding INL's missions, and building unique and differentiating research, development, demonstration, and deployment (RDD\&D) capabilities for the security of nuclear energy facilities, critical infrastructure's industrial control systems, the national power grid, next generation wireless communications, and emergency response. Significant accomplishments during FY 2014 are summarized in the following descriptions.

\section{Achievements Summary - Critical Infrastructure Protection}

N\&HS RDD\&D achievements aligned with our Critical Infrastructure Protection mission demonstrate INL is significantly exceeding expectations through innovative application of N\&HS capabilities to solve relevant, high-priority, highly complex technical national security challenges. N\&HS leadership has influenced the fields of industrial control systems cybersecurity; wireless communications spectrum sharing; power grid reliability and security; and national infrastructure physical protection. INL technical expertise and RDD\&D capabilities have resulted in the dissemination and deployment of $R \& D$ experimental results and technical solutions that are enabling public and private sector organizations to prepare, detect, and respond to cyber and physical threats to national and international critical infrastructure. INL's impact is recognized in enhanced public policy and federal $\mathrm{R} \& \mathrm{D}$ program strategy, deployment of technologies for government and commercial applications, and peer acknowledgement of innovations in science and engineering.

\section{Industrial Control Systems Cybersecurity}

- INL RDD\&D resulted in the dissemination of more than 250 original peer-reviewed cybersecurity advisories, over 90 onsite cybersecurity assessments to government and industry, and three emergency flyaway responses supporting the DHS Industrial Control Systems Cyber Emergency Response Team (ICS-CERT). The impacts in protecting the national infrastructure due to the dissemination of these scientific and engineering products has assisted DHS in obtaining new legislation that establishes the DHS National Cybersecurity and

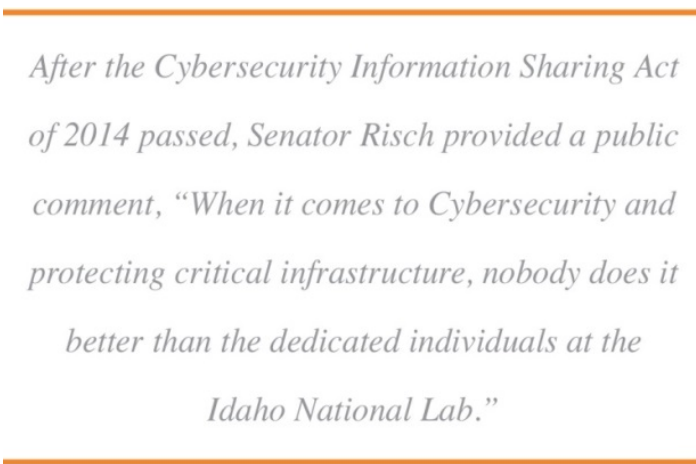
Communications Integration Center (NCCIC) as the federal civilian information sharing interface, providing cybersecurity incident response and technical assistance to the private sector, legislation, which was approved by the Senate, Homeland Security, and Governmental Affairs Committee.

- Also, based on this successful ICS-CERT partnership among DHS, DOE Office of Intelligence and Counterintelligence (DOE-IN), and INL along with the influence of INL's Mission Support Center (MSC) threat analysis products delivered to DOE and the IC, U.S. Senator James Risch (Idaho) 
authored an approved amendment to the "Cyber Information Sharing Act of 2014" requiring DOE national laboratories be part of the coordination process for timely sharing of cyber threat indicators.

- INL's research, development, testing, and implementation of novel vulnerability assessment methodologies has improved the security of electric power utilities' industrial controls systems. In support of DOE's strategic goal to secure the nation's power grid, INL, with CRADA partners, successfully piloted several innovative vulnerability assessment methodologies through the Risk Evaluation Nexus for Digital Age Energy Reliability (RENDER) Program for DOE Office of Electricity Delivery and Energy

Reliability (DOE-OE). Products from this

“ATAC/ReACT provides asset owners with a process that enables them to efficiently analyze and document critical system primary threat vectors in a consistent and repeatable manner.” RENDER CRADA partner program include: "Attack Technology, Analysis, and Characterization (ATAC)," "Root Cause Failure Analysis," and "Response Analysis Characterization Tool (ReACT)."

- Also, in contributing to DOE progress in achieving objectives to improve cybersecurity within the energy sector of critical infrastructure, INL leadership influenced the creation of new cybersecurity and wireless R\&D initiatives within the R\&D programs of DOE-NE, DOE-OE, DOE-IN, and DOE/NNSA. Examples of these initiatives are demonstrated in the development of DOE research programs such as the Nuclear Energy-Cybersecurity RD\&D Program Plan, the Intelligence Innovation Program, and the Cyber Sciences Laboratory.

- INL furthered DOE's progress in infrastructure protection and economic development through deployment of Sophia, a novel control systems network security tool. Sophia, comprised of an INL patent application and 11 asserted copyrights, has been licensed to NexDefense, Inc. To enable NexDefense to prepare for an October 2014 commercial release of Sophia, INL successfully defended a legal challenge to the intellectual property and provided Technical Assistance Program (TAP) funding to support a turnover of the

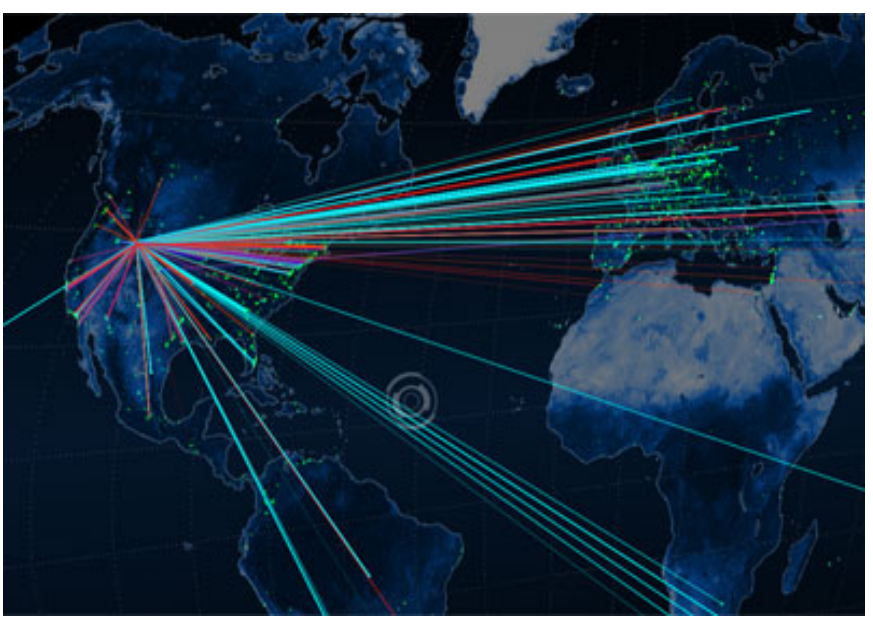

INL's Oglnet, copyright asserted, displays a map of control system network communications within the Sophia cybersecurity tool (patent pending). software program from INL developers to technical personnel of NexDefense. In addition to this commercial deployment, INL is spearheading the further deployment of Sophia for government use by providing a government-use version for DHS ICS-CERT's onsite cybersecurity assessments and 12 other U.S. Government users. 
- INL delivered unique methodologies and risk analysis tools that enable the enhancement of DHS, state, local, and territorial infrastructure protection capabilities for conducting risk and vulnerability assessments and to define infrastructure interdependencies across all 16 critical infrastructure sectors: Internet Protection Gateway, Cybersecurity Evaluation Tool (CSET) Version 6.0 and 6.1, IP Digital Library, and Rapid Survey Tool (RST). As a demonstration of the utility of RST, more than 90 infrastructure surveys utilizing the tool were scheduled within 2 weeks of DHS releasing it to state, local, and territorial jurisdictions.

- INL's Instrumentation Controls and Intelligence Systems (ICIS) Distinctive Signature continued to lead the national discussion on resilient control systems R\&D for infrastructure protection by successfully hosting "Resilience Week." This seventh annual international forum for engaging industry, academia, and government involved over 160 attendees and 50 papers focused on sharing research progress in resilient systems that protect cyber-physical infrastructures from unexpected and malicious threats.

- The Intelligent Cyber Sensor (ICyS), developed by INL's Todd Vollmer as part of an ICIS Laboratory Directed Research and Development (LDRD) project and technically matured within a DOE-OE cybersecurity R\&D project, was selected for further research product maturation by the DHS Science and Technology (S\&T) Transition to Practice Program (TTP). Consistent with DOE's strategic emphasis on the deployment of laboratory science products, the resulting TTP ICyS tool is intended for deployment with federal and private organizations for use in detecting and mitigating cyber intrusion on control system networks.

- Examples of FY 2014 technical peer recognition of INL's leadership in critical infrastructure protection RDD\&D are:

- INL's ICIS Distinctive Signature receipt of the Institute of Electrical and Electronics Engineers (IEEE) Region 6 Northeast Area Directors Special Award for 2014 for leadership in the development and advancement of research in the new field of resilient, cyber-physical systems

- INL's Digital Library research product was announced as a recipient of a Computerworld Editors' Choice Awards

- Ms. Cherrie Black, an N\&HS program manager, was inducted into the International Women in Homeland Security and Emergency Management Hall of Fame

- INL researcher served as guest editor for the IEEE Special Issue on Resilient Control Systems and Architectures in the Transactions on Cybernetics. 


\section{Wireless Communications}

- INL was awarded the U.S. Patent 8,731,027, "Methods and Apparatuses Using Filter Banks for Multi-carrier Spread Spectrum Signals," and received notification of allowance of an additional patent for this transformational communications technology (referred to as "WSComm") that will enable the U.S. to achieve the National Broadband Plan objectives for spectrum sharing.

- INL researchers successfully demonstrated the functionality of WSComm as a transformational video surveillance capability for the Drug Enforcement Administration (DEA). The success of the prototype has allowed DEA to develop a national strategy, including a more than $\$ 40 \mathrm{M}$ proposed $\mathrm{R} \& \mathrm{D}$ program, to resolve the capability gaps that have evolved from federal policy changes to radiofrequency spectrum (RF) access and sharing.

- Based upon WSComm's technical capabilities to function in highly congested RF environments and

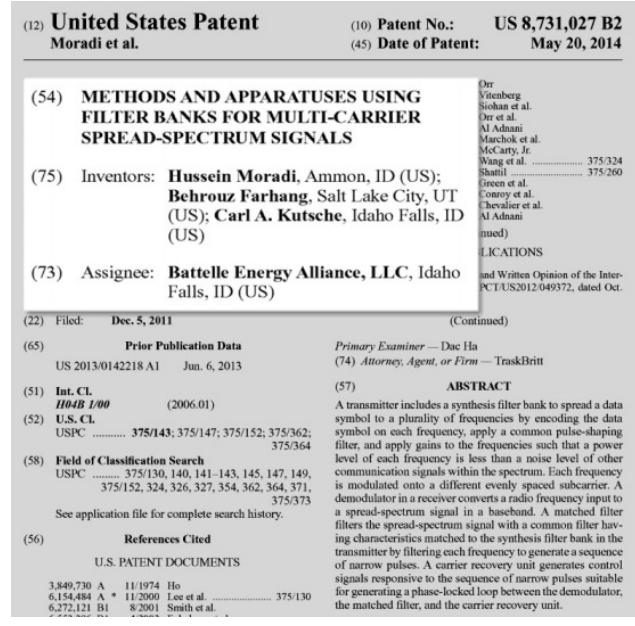

INL LDRD researchers were awarded a patent for a transformational wireless communications technology that will solve national requirements for spectrum sharing. ensure low probability of interception, U.S. Special Operations Command has initiated a research program to mature this technology to address future operational requirements for military operations.

- INL completed network connectivity with China Lake and Point Mugu to establish INL's Wireless Test Bed (WTB) as a preferred center for command and control of DoD Joint Improvised Explosives Device Defeat Organization's (JIEDDO) national test ranges. Completion of this new national capability achieves DOE's mission objectives to provide access to DOE's world-class scientific user facilities and enables the implementation of DoD's goals to enhance their technical testing capabilities, ensure continuity of operations during national emergencies, and address costs of operating test ranges.

- Testing results on the INL Wireless National User Facility (WNUF) with the Stevens Institute of Technology will be used by Dynamic Spectrum, LLC, to deploy wireless communications technologies in South African rural and urban environments. Citing completion of S2 Corporation's testing on the WNUF as a contributing factor, Dr. Kris Merkel, President and CEO of S2 Corporation,

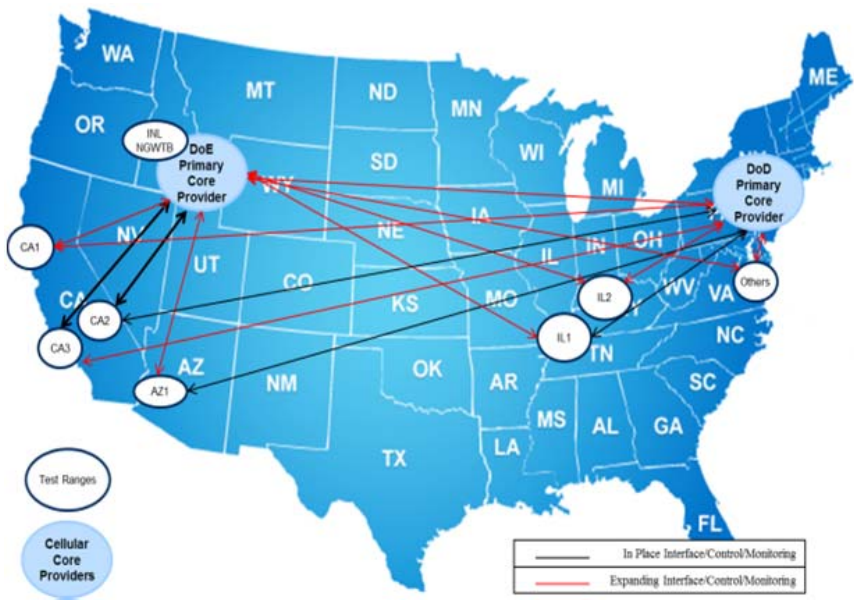

During FY 2014, INL's Wireless Test Bed became the first DOE test facility to be listed in DoD's Joint Test Board's catalog, recognizing INL's differentiating capabilities for testing to defeat threats from improvised explosive devices. 
received the 2014 Association of Old Crows' Jerry Sowell Radio Frequency Award. The results of the S2 Corporation WNUF testing is also the basis for an S2 Corporation and INL collaboration to participate in the development of a joint proposal for wideband spread spectrum R\&D.

- ISU in collaboration with INL's WNUF, via a National Science Foundation grant, successfully hosted the National Wireless Research Collaboration Symposium (NWRCS 2014). This Symposium resulted in the nation's first public discussion forum for academic, industry, and government spectrum sharing technology researchers with Public Safety implementation officials.

- INL leadership influence and R\&D testing successes resulted in DOE-IN supporting wireless testing infrastructure enhancements on INL's WTB. The potential impact of these WTB enhancements to meet IC RDD\&D requirements also caused DOE-IN to include a wireless communication R\&D component into the DOE-IN Intelligence Innovation Program.

- INL WNUF research author publications such as the National Public Safety Telecommunications Council's report, "Defining Public Safety Grade Systems and Facilities"; Association of Public Safety Communications Officials' Public Safety Mission Communications, "The Reality of Broadband"; Mission Critical Magazine, "Critical Infrastructure Opportunities and Challenges in Wireless"; and an INL cybersecurity position paper have resulted in the development and implementation of a cybersecurity strategy into the First Responder Network Authority (FirstNet) implementation plan for the nationwide Public Safety broadband network.

- Recognition of INL's thought leadership in best approaches for the implementation of national policy spectrum sharing $R \& D$ for Public Safety implementation is demonstrated by multiple

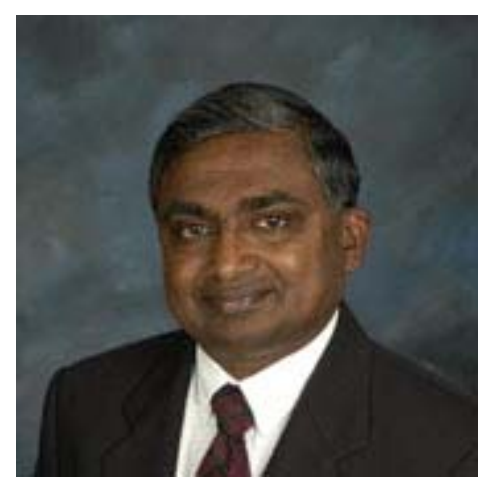

Dr. Daniel Devasirvatham's publications promote INL's Wireless National User Facility. invitations to participate in national advisory positions.

Committee and working group participation include: the DOE-Office of Science (SC) Policy Wireless Spectrum R\&D Senior Steering Group; Wireless Innovation Forum Steering Group on Spectrum Sharing; Association of Public Safety Communications Broadband and Standards Development committees; National Public Safety Telecommunications Council Site Hardening document development group; Federal Communications Commission Public Safety and Homeland Security working group; and Oregon's FirstNet working group.

- In achieving DOE objectives for securing nuclear and radiological materials and deployment of innovative technologies that enhance our national economic competitiveness, INL established a CRADA with Image Insight, LLC, to integrate INL's CellRad patent-pending intellectual property innovations with Image Insight's patented GammaPix ${ }^{\mathrm{TM}}$, Gamma-Phone, Gamma-Video, and Gamma-Net product lines. 


\section{Power Grid}

- INL was recognized as a Grid Center of Excellence for Geomagnetic Disturbance (GMD) Effects by Michael Kuliasha, Defense Threat Reduction Agency's (DTRA) Director of Nuclear Technologies. This recognition is a result of INL's research and testing of the potential effects of GMD on the reliability and security of the nation's power grid. Kuliasha acknowledged the impact INL has made in influencing the GMD community by hosting an international workshop and producing science-based empirical data for model development, equipment design, mitigation techniques, and government grid protection policies.

- During an INL-hosted FY 2014 GMD Workshop as part of the DuPont Summit, Washington, D.C., U.S. Congressman Trent Franks (Arizona) (leader of EMP/GMD Congressional Caucus) and James Woolsey (former CIA Director) publically acknowledged INL's groundbreaking leadership in addressing the threat of GMD to the national grid.

- INL research paper, “INL's Geomagnetic Disturbance (GMD) Test Results," presented to the North American Electric Reliability Corporation (NERC) GMD Task Force, influenced NERC's proposed GMD policy and mitigation strategies in

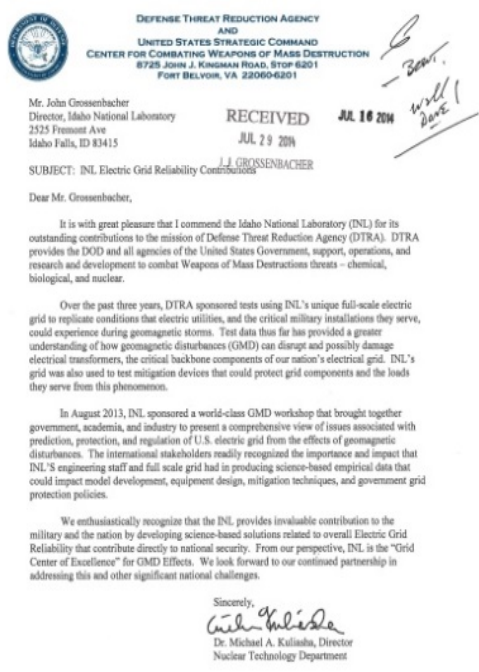

Defense Threat Reduction Agency recognizes INL as the "Grid Center of Excellence for Geomagnetic Disturbance Effects." response to the Federal Energy Regulatory Commission reliability standards that will be issued to mitigate GMD impacts on the national bulk-power system.

- In assisting DOE with achieving strategic goals for implementation of a reliable and secured Smart Grid, INL's MSC researchers are providing quarterly strategic threat briefs for DOE-OE Assistant Secretary. These MSC briefings, delivered at the request of DOE-IN, are in support of DOE-OE as the Critical Infrastructure Sector Specific Agency Lead.

- INL technical leadership in cybersecurity, power grid testing, and wireless communications R\&D influenced the program direction of DOE-OE to include wireless communications reliability and wireless cybersecurity into future DOE-OE research for power grid protection.

- Through the completion of three significant national security tests on the INL power grid, N\&HS provided unique capabilities and participated in the collection of experimental results that support national requirements to understand the reliability and resilience of the electrical power systems servicing U.S. Government installations. All tests continue to demonstrate INL's capabilities to advance DOE's strategic objective to build and make available for use DOE's science and engineering infrastructure in support of the nation's security. For these tests, INL's range was selected for its unique capabilities, technical expertise, and security after reviews of national power grid testing locations. In addition, for one of these tests, INL was selected due to its progress in an LDRD that obtained unique experimental results in power line analytics.

- Additional LDRD power grid research accomplishments were peer-reviewed and disseminated via an invited paper, "A Multi-Agent Approach to Smart Grid Control Architecture," in the IEEE Smart Grid Newsletter; a technical publication "Revealing Occupancy Patterns in an Office building 
through the Use of Occupancy Sensor Data" in Energy and Buildings; and U.S. Patent 8,573,571 "Dissipative Structures and Related Method" (an invention featured in discussions with electrical utilities and DHS as a solution to address national concerns regarding the threat of ballistic attack against electrical substations).

\section{Physical Security}

- To achieve DOE strategic objectives to secure nuclear materials, INL vulnerability analysis experts completed security assessments at NNSA's Sandia National Laboratory, LANL, Lawrence Livermore National Laboratory (LLNL), Savannah River Plant, Pantex Plant, and Y-12 Plant. INL's participation, at the invitation of DOE/NNSA, supported DOE objectives to determine the health of physical security and systems with regards to implementation of NA-71's Physical Security Supplement.

- N\&HS's Nonproliferation Director served on an NNSA Red Team Review of the proposed Uranium Processing Facility at Y-12 to evaluate options for establishing NNSA program capabilities at Y-12.

- INL Physical Analysis group subject matter experts, in cooperation with INL's Lab Protection, developed INL's Laboratory Protection's Vulnerability Assessment documentation for DOE Headquarters Office of Independent Oversight comprehensive security assessment. This documentation enabled INL's compliance status in meeting all DOE requirements for protecting special nuclear materials and critical assets.

- INL Physical Security analysts delivered innovative Classified Matter Protection and Control program solutions that will improve DOE/NNSA's capabilities to protect nuclear weapon information.

\section{Achievements Summary - Armor Production and Ballistic/Blast Protection}

N\&HS RDD\&D achievements within the Defense Systems' mission demonstrate INL is exceeding expectations in operations and production of armor at the Specific Manufacturing Capability (SMC), and through the innovative application of INL capabilities to solve challenging technical requirements for ballistic and threat defeat applications.

- In a Memorandum for Record, U.S. Army

Lieutenant Colonel Harold B. Hodge,

Product Manager Abrams Tank Systems, declared INL as the Abrams Armor Center of Excellence. This announcement also includes a description of the influence "...INL is the only facility that has the unique manufacturing capabilities and the security INL's R\&D, manufacturing capabilities, requirements necessary to manufacture Turret Front Armor for U.S. Army tanks...” Abrams Armor Production Memorandum for Record 
and high-quality performance has had in altering the U.S. Army's future strategy for development and procurement of heavy armor systems.

- SMC has met all of the Army's production requirements, development milestones, and product delivery expectations while effectively planning and executing a Workforce Restructuring plan that maintains the viability of the nation's capability and capacity for the Army's long-term strategy for tank armor design, engineering, testing, and production.

- SMC has successfully installed, and is conducting research with, a new super computer, Xerxes, for modeling and simulation for prediction of ballistic events in support of Army requests for research on armor designs. Demonstrations of INL modeling and simulation breakthroughs significantly contributed to the U.S. Army's decision to transition future engineering design and production projects to INL.

- SMC expanded its role in support of the U.S. Army Main Battle Tank Systems through five additional projects, totaling more than $\$ 1 \mathrm{M}$, for engineering design enhancements at U.S. Army facilities for vehicle propulsion testing, surrogate soil study for vehicle roll-over testing, building design and modifications for depleted uranium handling, and building design modifications for reductions in cadmium exposure.

\section{Achievements Summary - Nuclear Nonproliferation}

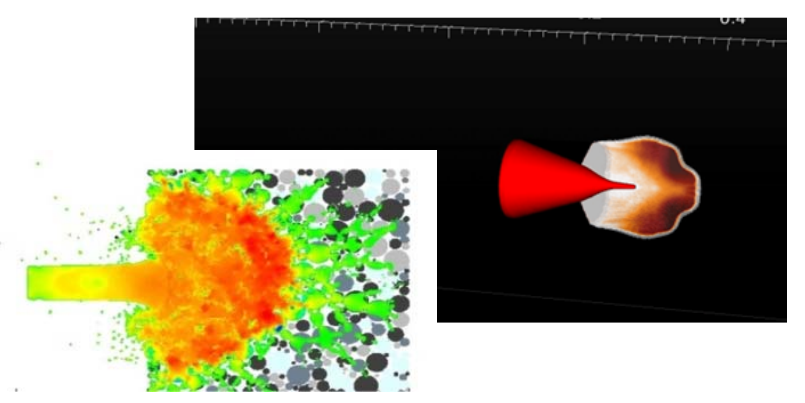

INL researchers use high performance modeling and simulation capabilities to develop new armor materials and designs that protect the U.S. warfighter.

INL's Nonproliferation program achievements have substantially exceeded expectations through significant reductions in global threats to the nation's security from special nuclear materials, radiological materials, and weapons of mass destruction. Scientific and engineering innovations have spearheaded progress in developing and implementing policies for international security and the safeguarding of nuclear and radiological materials, and advanced national technical capabilities to determine and enhance the nonproliferation status of nuclear facilities and processes, and in expanding the nation's readiness to detect and respond to threats from nuclear and radiological proliferation and terrorist actions. INL has integrated capabilities across multiple fields of science and engineering to deploy solutions relevant to high-priority, highly complex national security challenges. These capabilities include, but are not limited to, nuclear fuel design; nuclear materials experimentation and testing; nuclear reactor and fuel reprocessing system design and operations; radioisotopic production, separation, detection and analyses; facility safeguards and physical security; control system cybersecurity; wireless communications; and explosives detection and testing. INL's impact on global security was demonstrated by the progress achieved in international nonproliferation agreements; improved preparedness of the nation to prevent, detect, and respond to nuclear or radiological events; and disseminated science and engineering discoveries with peers and collaborators. 


\section{Global Threat Reduction}

- INL's capabilities, as a center for nonproliferation research, development, demonstration, and deployment (RDD\&D), were publically recognized during comments by U.S. Senator James Risch (Idaho) during a Senate Foreign Relations Committee meeting, and by follow-on testimony from DOE Deputy Secretary Daniel Poneman.

- INL successfully completed an NNSA Level 1 milestone "RERTR-12 Complete" (a miniplate experiment incorporating a matrix of specimens that includes low, intermediate, and high fission rates; low, intermediate, and high burnup; and thin and thick metal fuel plates) with results that will contribute to the eventual submittal of the U-Mo monolithic Base Fuel Qualification Report to the NRC.

- INL, working with the DOE-NE and NNSA, enabled the implementation of a process for the exchange of nuclear energy $R \& D$ data between the United States and Republic of Korea in support of the JFCS. This study will allow both sides to evaluate the technical and economic feasibility as well as the non-proliferation acceptability of electrochemical recycling and other options for the management of used nuclear fuel. INL developed the methodology to allow for transfer of information via nuclear datasheets. They also provided training for other national laboratories involved in the study.

- During the INL-hosted Electrochemical Recycling and Safeguards and Security Working Groups meeting for the JFCS with the Republic of Korea, INL researchers provided more than 30 presentations addressing the design for kilogram-scale equipment.

1.2.B

Provide

outstanding service to the International Atomic Energy Agency, acknowledged through formal recognition, in leading nuclear cyber security instrumentation $\&$ control training and education and developing international guidance.

Notable Outcome 1.2.B was achieved as a result of multiple accomplishments demonstrating outstanding service to the International Atomic Energy Agency (IAEA) for the advancement of nuclear cyber security policies, guidance, and training. Khammar Mrabit, IAEA Director of the Division of Nuclear Security, issued a letter of appreciation to INL acknowledging INL's leadership as a key contributor in cybersecurity in building a global nuclear security framework.

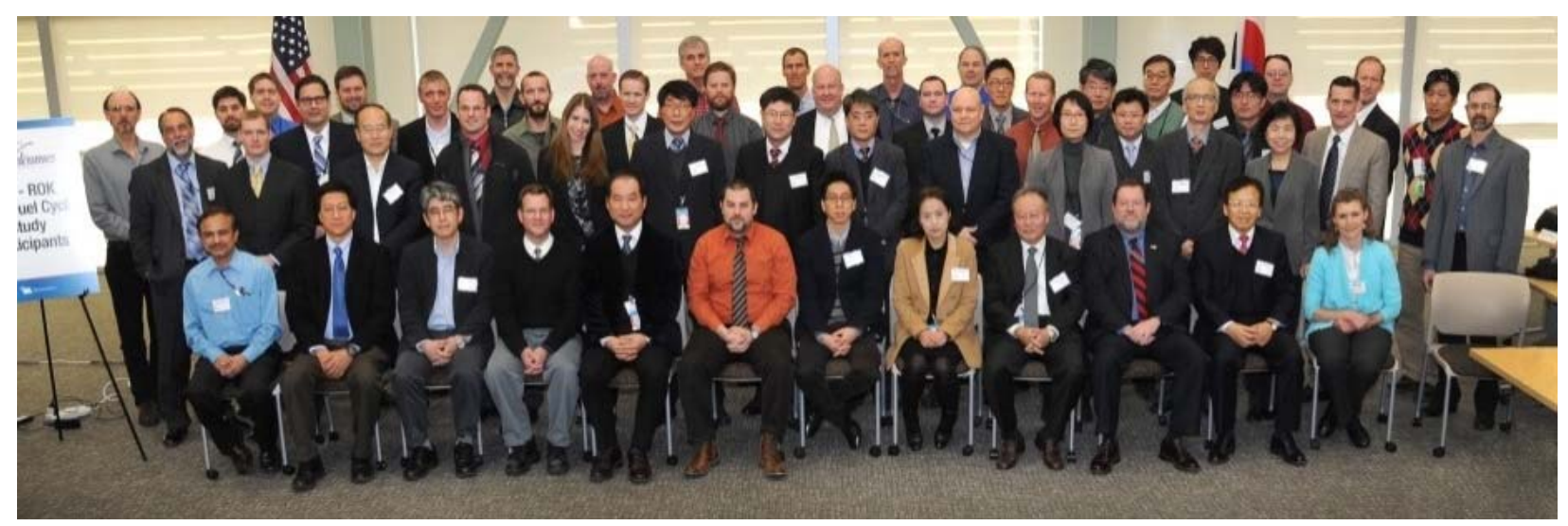

INL hosted the Joint Electrochemical Recycling and Safeguards and Security Working Group Meetings for the U.S.-Republic of Korea Joint Fuel Cycle Study. 
- At the Institute of Nuclear Materials Management's 55th annual meeting July 20-24, 2014, in Atlanta, Georgia, N\&HS experts from INL were recognized as thought leaders in the field of nuclear materials safeguards by co-chairing sessions on "International Safeguards: Advances in Safeguards Technology and Instrumentation for Pyroprocessing"; "International Safeguards: Interface among Safety, Security and Safeguards"; and "Materials Control and Accountability: Neutron Measurements III."

- In completing a multi-year, international effort coordinated between Hungary, United States, Russian Federation, IAEA, and NNSA, INL's program leadership capabilities contributed to the successful removal of all remaining highly enriched uranium from Hungary as part of NNSA's Russian-Origin Nuclear Material Removal Program.

- N\&HS influenced the implementation of cybersecurity for international nuclear energy through delivery of expert consulting support to IAEA. INL's leadership resulted in cybersecurity education and training in Japan, South Korea and Ghana; a set of cybersecurity recommendations for an addendum to nuclear security series guidance documents; and the agenda and speakers for IAEA's first International Conference on Nuclear Security in a Computer World: Prevention, Detection and Response."

- INL researchers published "A Citizen Approach to Nonproliferation" in the Public Interest Report issued by the Federation of American Scientists. This paper describes a novel approach of involving international citizen volunteers as the core of a global proliferation reporting system, a concept now included in a NA-24 Safeguards Policy Team proposal call for using social media to identify undeclared nuclear activity.

- As part of meeting national objectives to accelerate the pace of reactor conversions from highenriched uranium (HEU) to low-enriched uranium (LEU), INL has achieved significant progress in the potential conversion of reactor fuels by selecting a pre-conceptual design phase fuel system that can be used for successful conversion of TREAT to LEU fuel.

- INL's Igor Bolshinsky and Savannah River National Laboratory's John Dewes were selected for Hungary's Golden Cross of Merit, the country's highest national civilian award, for their participation in the removal of high-enriched uranium (HEU) from Hungary.

- Proof-of-principle experiments and threat analyses of protective

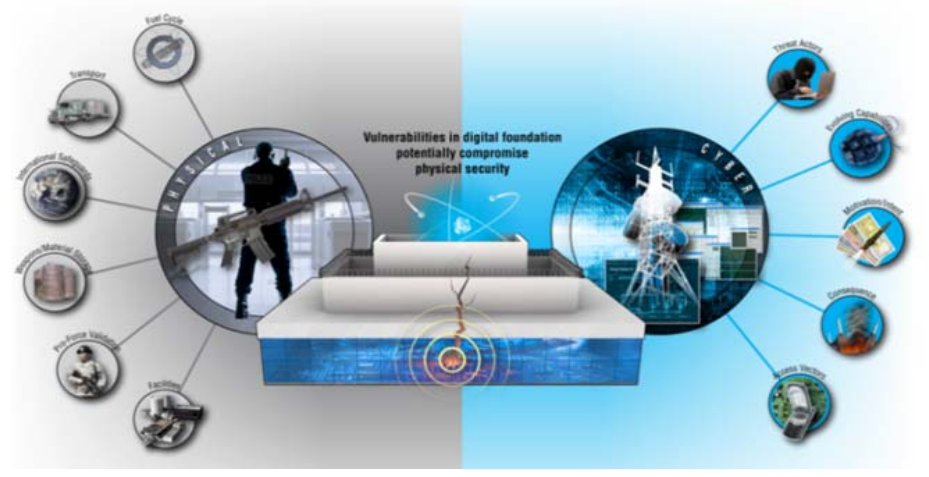

INL's integration of nuclear energy fuel cycle with industrial control systems cybersecurity and physical security is influencing the direction of federal cybersecurity $R \& D$ programs. security systems within INL facilities have resulted in an INL leadership role as co-lead for laboratories on the NA-20 Cyber Task Force chartered to develop a DOE/National Nuclear Security Administration (NNSA) cybersecurity R\&D plan. 
- INL is collaborating with the University of Michigan in the university-led consortium sponsored by NNSA to improve nuclear arms control verification technology and safeguards effectiveness.

- INL received a note of thanks from the first selected U.S. safeguards inspector who attended INL's Pre-Inspector Course. Savannah River National Laboratory's Adrian Mendez-Torres was appointed by the IAEA as a Nuclear Safeguards Inspector with the Department of Safeguards. With the completion of another course during May 2014, INL has trained over 30 engineers and scientists from across the U.S. on IAEA policy, inspection methods, and technology.

\section{Emergency Response and Preparedness}

- To prepare the nation to respond to a terrorist radiological dispersal device event, INL has successfully delivered 26 Radiological Dispersal Device (RDD) Emergency Response Training sessions, including deploying equipment/personnel/radiological sources, to approximately 350 emergency responders for personnel in FBI, Navy Explosives Ordnance, State Hazardous Material (HazMat), and city emergency response teams, as well as public safety organizations within Idaho.

- In support of NA-40's mission to provide national capability to respond to threats from nuclear and radiological materials, INL participated in 13 Radiological Assistant Program (RAP) national preparation exercises and team activation events.

- INL conducted nuclear fuel cycle training for the DTRA to approximately 100 military personnel. These training sessions, conducted by INL and other national laboratory collaborators, included education classes, training, and facility tours in preparing the DoD to respond to global actions that involve nuclear energy facilities and

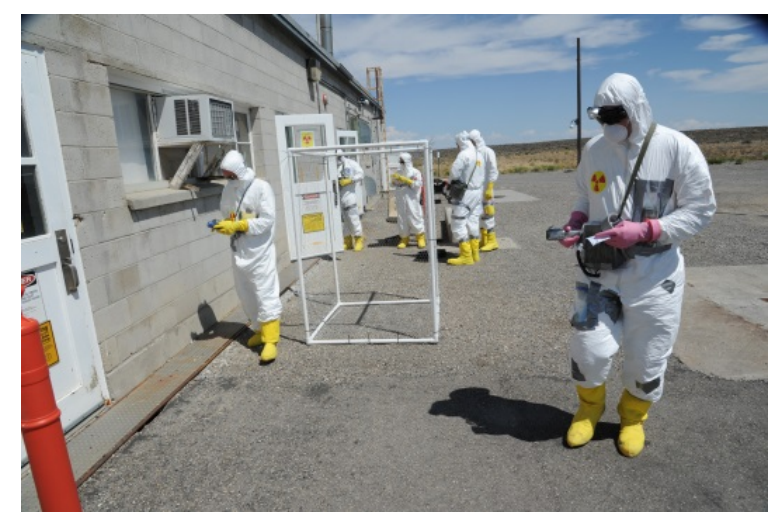

U.S. Army Medical Department personnel conduct emergency response training and exercises on INL's test range. materials.

- INL continued to demonstrate the strategic success of the Nuclear and Radiological Activity Center (NRAC) through completion of several DOE/NNSA-sponsored experimentation and demonstration tests of several prototype nuclear and gamma detection technologies that support arms control treaty verification and nuclear/radiological search and response. Collaborative NRAC tests utilized Zero Power Physics Reactor (ZPPR), ATR, and other INL nuclear and nonnuclear facilities, and were completed with national laboratory researchers from LLNL, ORNL, and Pacific Northwest National Laboratory (PNNL), as well as federal emergency responders from U.S. Army Medical Department (AMEDD) and U.S. Army 20th Support Command Nuclear Disablement Teams.

- INL researchers presented three papers at SORMA XV, an international series of technical symposia dealing with ionizing radiation and its applications. These papers, to be printed in a special edition of Nuclear Instruments and Methods in Physics Research Section A: Accelerators, Spectrometers, Detectors and Associated Equipment, were titled, "Predictions of the Performance of Fast Neutron Multiplicity System for Nuclear Material Accountancy," "Time-correlated Neutron Analysis of a Multiplying HEU Source," and "OSIRIS - Gamma Ray Spectroscopy Software for On-Site Inspections under the Comprehensive Nuclear Test-Ban Treaty." 


\section{Signatures and Observables}

- INL delivered technology products, including radioisotopic reference standards and short-lived radionuclide dispersal methods, in support of DOE/NNSA NA-40-Israel Bi-lateral Collaboration on Combating Nuclear and Radiological Terrorism.

- INL obtained a multi-year agreement with, and began to deliver xenon standards to, the Preparatory Commission for the Comprehensive Nuclear-Test-Ban Organization (CTBTO). These standards are used for CTBTO's quality control program to ensure the nonproliferation status of internationally declared nuclear activities.

- INL researchers have discovered a new approach for

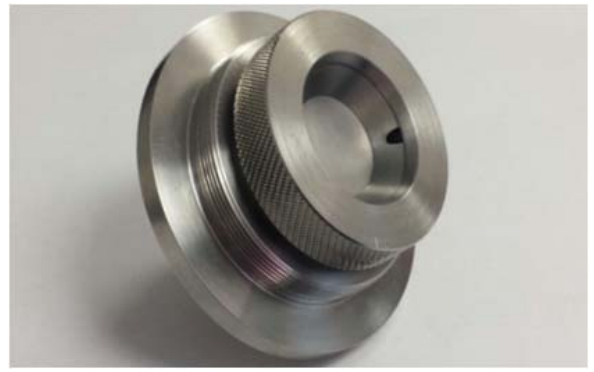

A fission product collection system, developed within LDRD, enables INL to address national requirements for short-lived radionuclide forensic standards. dissolving uranium dioxide using an ionic liquid containing fluorohydrogenate anions. The methodology generates stable uranium fluoroanions without using potentially hazardous fluorination reactions or oxidizing acids. Initial experiments with zirconium species that demonstrated the principle of the stability of fluorohydrogenate clusters have been published (Journal of Physical Chemistry A, Volume 117, 2013, pp. 14191-14199 and Rapid

Communications in Mass Spectrometry, Volume 26, 2014, pp. 1233-1242). The recent experiments with uranium indicate improved detection is achievable for nonproliferation nuclear material accountability and environmental measurements. This new approach may also lead to further experiments on novel pathways for fuel<smiles>CC[n+]1ccn(C)c1</smiles>
[EMIm] $^{+}$<smiles>FCPF</smiles>

$\left[\mathrm{F}(\mathrm{HF})_{2}\right]^{-}$<smiles>FCP=C(F)F</smiles>

$\left[\mathrm{F}(\mathrm{HF})_{3}\right]^{-}$

INL LDRD research discovers new actinide-ionic liquid compounds that will enable ultratrace analysis of treaty verification and environmental samples. dissolution.

- At the American Nuclear Society's 8th International Conference on Isotopes in Chicago, Illinois, the Laboratory's expertise in ultratrace and nuclear forensics was highlighted with presented papers: "Preparation of High Purity Isotopic Reference Standards for Isotope Dilution Mass Spectrometry," and "Environmental Cesium Isotope Ratio Measurements: Nuclear Forensic Applications," and "High Pressure Marinelli for Counting Low Activity Compressed Gas Samples," and "International Sealed Source Database: A Radiological Forensics Signature Library." 


\section{Achievements Summary - Defense and Intelligence}

INL's innovative RDD\&D solutions have substantially exceeded expectations for the DoD and the IC. Products requiring unique expertise, equipment, laboratories, and test ranges have significantly strengthened our warfighters' capabilities to perform mission planning, execute mission operations, and respond to national threats. Achievements required science and engineering discoveries in technical disciplines that include, but are not limited to, control systems, radiofrequency propagation, metallurgy, energetic materials, and sensors.

- INL and DOE/NNSA laboratory capabilities in cyber threat analysis and industrial control system research and development were recognized during Senate Select Committee on Intelligence testimony from U.S. Senator James Risch (Idaho) and the Director of National Intelligence James Clapper.

- INL MSC researchers served as strategic advisors in cybersecurity, wireless communications, and energetic materials in assisting DOE-IN during development of DOE-IN's Intelligence Innovation Program. The resulting 5-year technology development plan for DOE-IN is intended to implement new DOE R\&D investments in the unique DOE science and technology capabilities.

- INL assisted DOE-IN-40 with the development of an approach to achieve additional security benefits from the Cybersecurity Risk Information Sharing Program (CRISP). INL's proposed concepts will create and implement new cyber threat analysis capabilities and products among multiple agencies to better enable success for DOE-OE while serving in their role as the Sector Lead for protection of the nation's critical infrastructure energy sector.

- MSC delivered a detailed threat report that described INL's methodologies for re-inventing how the IC determines technical indicators for future threats. Based on this approach, the IC has funded new MSC projects that will enable U.S. Government senior leaders to use a new forward-looking defensive strategy for protection of critical infrastructure.

- The successful testing of MSC's threat analysis doctrine by a DoD organization has resulted in this organization redefining their methodology for cyber threat analysis.

- INL's Portable Isotopic Neutron Spectroscopy (PINS) has enabled the U.S. Army and other first responders to safely identify, package, and remove chemical weapons and other hazardous materials from public areas and military environments in Alabama, Arkansas, California, Delaware, Florida, Hawaii, Maryland, Utah, and Washington, D.C. 
- INL expanded the international deployment of patents and copyrights for PINS technology through delivery of training to South Korean first responders after they purchased 12 third-generation PINS systems from the INL licensee, AMETEK, Inc. PINS researchers also published two papers on PINS at the IEEE Nuclear Science Symposium in Seoul, South Korea. Additional PINS systems were sold by AMETEK to the Italian government, with INL personnel providing training.

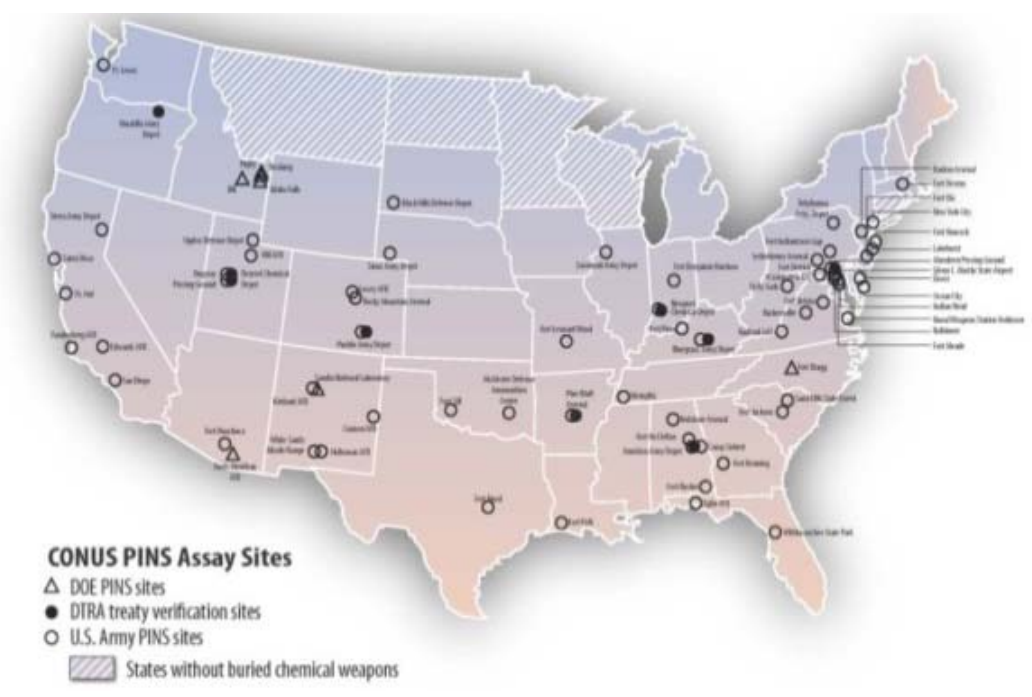

PINS systems have been used by the U.S. Army to resolve chemical weapon threats in nearly every state of the U.S. and during military operations across the globe.

- Electronic and energetic materials researchers delivered prototypes and limited quantity production systems using complex multi-physics solutions that incorporate integrated chemical, mechanical, electronic, and energetic components. These novel energetic systems meet unique requirements for national security technologies that support military operations.

- INL's LDRD research collaboration with Texas Tech University has discovered and developed more efficient and safer energetic materials. Since 2012, this collaboration has resulted in eight technical journal publications and two patent applications emphasizing advancements in the field of energetic materials and systems that provide for precise control of the release of energy and avoid unplanned discharges due to electrostatic initiation.

- INL's Change Detection System (CDS) prototype, Ruby Sun, has been deployed by a U.S. Government organization to significantly alter their decades-old methods for ensuring command and control processes the nation uses to deploy strategic assets. CDS, which has been

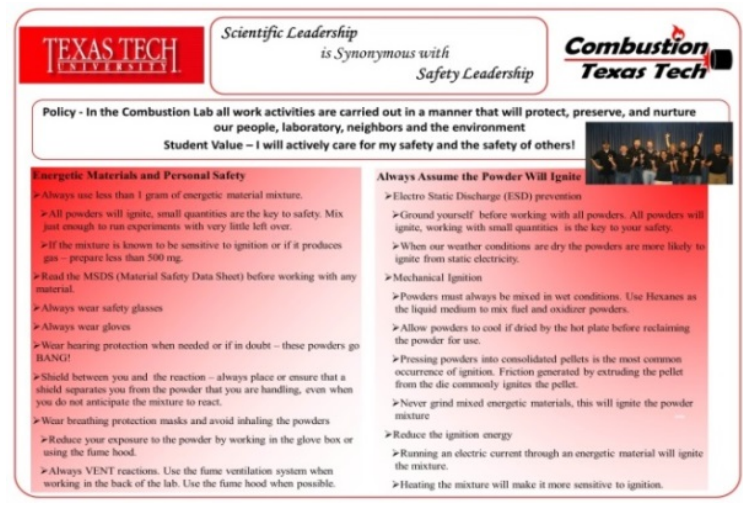

INL and Texas Tech University materials science research has enabled the exchange of good laboratory practices for safe handling of energetic materials. awarded two patents and an R\&D 100 Award, is deployed for use by multiple government organizations for applications including law enforcement surveillance and forensics, information assurance, physical security, and warfighter protection. 
- Innovations in Operational Security practices implemented by INL's Counterintelligence Office have resulted in policy changes within the DOE-IN to formalize processes for providing DOE expertise for the IC while ensuring adequate management of risks for DOE-IN and the Secretary of Energy.

These practices have established new standards for ensuring sufficient risk management for DOE-IN and the Secretary of Energy across all of the DOE/NNSA Field Intelligence Elements.

- Sprint 8, an INL software engineering development product, released a new version of the software package to the U.S. Army. The software enables the Army to extend the service life of legacy logistics systems deployed throughout the world.

- N\&HS's Electronic Warfare Modeling and Simulation $(E W M \& S)$ research team developed and delivered the final version of the Counter Listener Acoustic Warfare (CLAW) 1.0 software to the Air Force Research Laboratory as the first fully integrated FalconView ${ }^{\mathrm{TM}}$ acoustic solution that enables the success of battle planning, air support operations, and intelligence missions.

- INL delivered EWM\&S products for enhanced situational awareness and mission planning capabilities to the Air Force Special Operations Command; Global Command and Control System, Joint Mission Planning System, and U.S. Air Force 453rd Electronic Warfare Squadron (453rd EWS).

- In recognition of the impact of INL's software products, the U.S. Air Force changed its approach to funding the INL EWM\&S program, which conducts research and development of combat and surveillance mission planning software. During FY 2014, the 453rd EWS altered its annual R\&D procurement strategy from incremental funding to a single allocation for a full year's program scope to ensure the continued development of the INL software products: Improved Many-on-Many and Distributed Information Operations Constructive Environment.

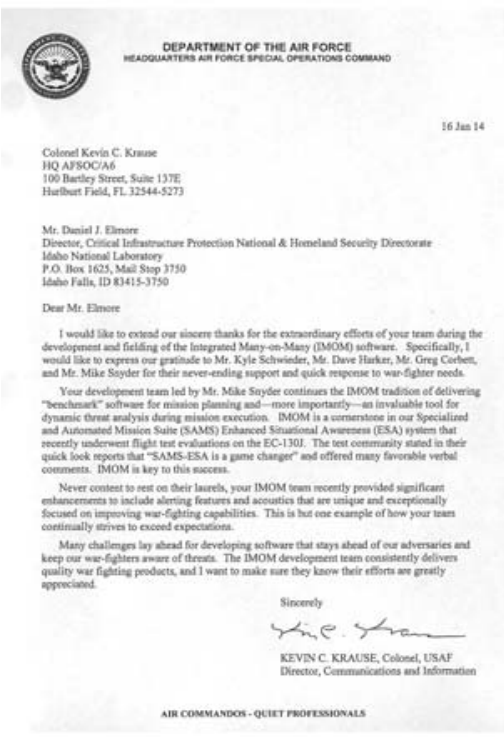

U.S. Air Force commends INL for the innovation and quality of our electronic warfare mission planning products.

- INL's WTB research team completed a test with the U.S. Special Operations Research, Development and Acquisition Center to advance implementation and eventual acquisition of the Special Operations Command (SOCOM) Fly Away Broadcast System. 


\section{Noteworthy Accomplishments}

- INL is listed as one of NNSA's critical technical partners in a National Journal article, "NNSA Marks 10th Anniversary of Global Threat Reduction Initiative," (http://www.nationaljournal.com/library/1 $\underline{60907)}$ in reducing threats of terrorist access to nuclear and radiological materials.

- INL's control systems security leadership is featured in The Economist

"These men and women distinguished themselves

and exceeded all expectations to ensure that the

warfighter receives their equipment in a cost

effective and timely manner." Scott Brown, SOAC

Tactical Communications Systems

(July 12, 2014), which describes INL's

"elite engineers" as protecting the national infrastructure against cyber attacks.

- In cooperation with the DHS Domestic Nuclear Detection Office, INL's RAP team members provided subject matter expertise and radiological sources in support of Radiological Nuclear Detection Seminars and Mobile Detection Deployment Just-in-Time training at Eastern Idaho Technical College (Idaho Falls, Idaho) and Gowen Field (Boise, Idaho). These events were featured in news stories in the Idaho State Journal, Post Register, and the Domestic Nuclear Detection Office's The Source.

- INL cybersecurity researcher Richard Wyman presented a keynote address focused on the significance of network data security for water utilities at the Smart Water Networks (SWAN) Forum 2014 Conference in Madrid, Spain.

- INL successfully defended a patent reexamination for an INL invention, U.S. Patent 7,786,894, "Methods, Apparatus, and Systems for Monitoring Transmission Systems," to protect the economic development and technology deployment objectives of DOE, INL, and the technology licensee Lindsey Manufacturing, Inc.

- INL's Henry Chu and Ben Langhorst's LDRD-based U.S. Patent 8,573,571, "Dissipative Structures and Related Method," has been featured in DHS and public utility discussions regarding R\&D solutions to address recent national concerns and pending regulatory standards to prevent significant consequences from ballistic attack against critical electrical substations.

- Other INL patents awarded during 2014 from research performed under N\&HS LDRDs include: U.S. Patent 8,551,607 “Armor Systems Including Coated Core Materials"; U.S. Patent 8,701,560 "Apparatus, System, and

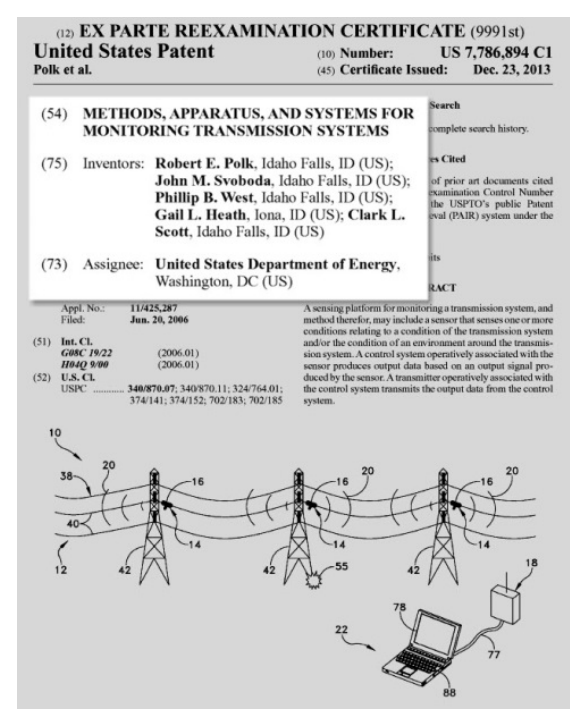

INL successfully defended reexamination of the INL Transmission Line Monitor patent in support of the technology's private sector licensee.

Method for Synchronizing a Timer Key"; U.S. Patent 8,731,027 "Methods and Apparatuses Using Filter Banks for Multi-Carrier Spread-Spectrum Signals"; U.S. Patent 8,741,119 “Actinide Ion Sensor 
for Pyroprocess Monitoring"; U.S. Patent 8,737,965 "Wireless Device Monitoring Systems and Monitoring Devices, and Associated Methods"; and U.S. Patent 8,831,220 "Processing Module Operating Methods, Processing Modules, and Communications Systems."

- In furthering researcher community recognition of INL as thought leaders for the integration of autonomous control systems for power grid resiliency and energy efficiency, INL's Craig Rieger published LDRD-based papers, "A Multi-Agent Approach to Smart Grid Control Architecture," in the IEEE Smart Grid Newsletter and "Revealing Occupancy Patterns in an Office building through the Use of Occupancy Sensor Data," in Energy and Buildings.

\section{Publications}

Arnold, R. et al., "Investigation of double beta decay of 100Mo to excited states of 100Ru," Nuclear Physics A: Nuclear and Hadronic Physics, Vol. 925, May 2014, pp.25-36.

Carney, K. P., Finck, M. R., McGrath, C. A., Martin, L. R., and Lewis, R. R., "The Development of Radioactive Glass Surrogates for Fallout Debris," Journal of Radioanalytical and Nuclear Chemistry, Vol. 299, No. 1, January 2014, pp. 363-372.

Chichester, D. L. and Kinlaw, M. T., "The Marvel Assembly for Neutron Multiplication," Applied Radiation and Isotopes, Vol. 80, October 2013, pp. 42-48.

Chichester, D. L., Watson, S. M., Johnson, J. T., "Comparison of BCF-10, BCF-12, and BCF-20 Scintillating Fibers for Use in a 1-Dimensional Linear Sensor," IEEE Transactions on Nuclear Science, No. 5, October 2013, pp. 4015-4021.

Collins, E. S., Gesner, J. P., Pantoya, M. L., and. Daniels, M. A., "Synthesizing Aluminum Particles Towards Controlling Electrostatic Discharge Ignition Sensitivity," Journal of Electrostatics, Vol. 72, No. 1, February 2014, pp. 28-32.

Collins, E., Pantoya, M. Neuber, A., and Daniels, M., "Piezoelectric Ignition of Nanocomposite Energetic Materials," Journal of Propulsion and Power, Vol. 30, No. 1, January-February 2014, pp. 15-18.

Derr, K., and Manic, M., "Adaptive Control Parameters for Dispersal of Multi-Agent Mobile Ad Hoc Network (MANET) Swarms," IEEE Transactions on Industrial Informatics, Vol. 9, No. 4, November 2013, pp. 1900-1911.

Devasirvatham, D., "The Reality of Broadband: Standards for First Responders," Public Safety Communications, April 14, 2014, pp. 45.

Devasirvatham D., and Austad, W., "How Wireless Networks Impact Security," Mission Critical Communications, May 14, 2014.

Dolan, J. L., Marcath, M. J., Flaska, M., Pozzi, S. A., Chichester, D. L., Tomanin, A., and Peerani, P., "Active-Interrogation Measurements of Fast Neutrons from Induced Fission in Low-Enriched Uranium," Nuclear Instruments and Methods in Physics Research, Section A: Accelerators, Spectrometers, Detectors and Associated Equipment, Vol. 738, February 21, 2014, pp. 99-105.

Duarte, C., Van Den Wymelenberg, K., and Rieger, C., "Revealing Occupancy Patterns in an Office Building Through the Use of Occupancy Sensor Data," Energy and Buildings, Vol. 67, December 2013, pp. 587-595. 
Hanson, C., Phongikaroon, S., and Scott, J. R., “Temperature effect on laser-induced breakdown spectroscopy spectra of molten and solid salts," Spectrochimica Acta-Part B Atomic Spectroscopy, Vol. 97, July 1, 2014, pp. 79-85.

Johnson, B. B., Schwoebel, P. R., Resnick, P. J., Holland, C. E., Hertz, K.L., and Chichester, D. L., "Field Ionization Characteristics of an Ion Source Array for Neutron Generators," Journal of Applied Physics, Vol. 114, No. 17, November 7, 2013.

Langhorst B., Lillo T., and Chu H., "A Residual Mass Ballistic Testing Method to Compare Armor Materials or Components (Residual Mass Ballistic Testing Method)," Journal of Testing and Evaluation, Vol. 42, No. 3 Paper ID: JTE20130092, May 2014.

Matthias, C. M., Troffaes, G.W., and Kelly, D., "A robust Bayesian approach to modeling epistemic uncertainty in common-cause failure models," Reliability Engineering \& System Safety Vol. 125, May 2014, pp. 13-21, ESREL 2012-PSAM 11.

Neel, J., Cook, P., Mellen, N., Akbar, I., Devasirvatham, D., Sheehe, C., Schutz, B., "The Role of Context in Cognitive Systems," Journal of Signal Processing Systems, April 2014.

Stanley, F. E., Spencer, K. J., Schwartz, D. S., Watrous, M. G., and Delmore, J. E., "Investigating enhanced thorium ionization in TIMS using Re/Pt porous ion emitters," Journal of Radioanalytical and Nuclear Chemistry, Vol. 299, No. 3, March 2014, pp. 1447-1452.

Vollmer, T., Manic, M., Linda, O., "Autonomic intelligent cyber-sensor to support industrial control network awareness," IEEE Transactions on Industrial Informatics, Vol. 10, No. 2, May 2014, pp. 1647-1658.

Vollmer, T., Manic, M., and Linda, O., "Cyber-Physical System Security With Deceptive Virtual Hosts for Industrial Control Networks," IEEE Transactions on Industrial Informatics, Vol. 10, No. 2, May 2014, pp. 1337-1347.

Weir, C., Pantoya, M. L., and Daniels, M. A., "The Role of Aluminum Particle Size in Electrostatic Ignition Sensitivity of Composite Energetic Materials," Combustion and Flame, Vol. 160, No. 10, October 2013, pp. 2279-2281.

Wijayasekara, D., Linda, O., Manic, M., and Rieger, C., "Mining Building Energy Management System Data Using Fuzzy Anomaly Detection and Linguistic Descriptions," IEEE Transactions on Industrial Informatics, Vol. 10, No. 3, August 2014, pp. 1829-1840. 
PEMP FY 2014 


\section{Efficient and Effective Mission Accomplishment 1.3: Science and Technology Addressing Broad DOE Missions \\ OBJECTIVE 1.3: SCIENCE AND TECHNOLOGY ADDRESSING BROAD DOE MISSIONS \\ Lead and implement relevant, high impact RDD\&D \\ 2014 Achievements Summary - Science Based Performance Assessment for Energy Storage} programs. Establish the INL as a multi-program National Laboratory with world-class nuclear capabilities. The primary focus areas include, but are not limited to the following:

- Science based performance assessment for energy storage and bioenergy systems;

- Clean energy integration design, test, control, and validation; and

- Energy critical materials.
INL advanced U.S. energy security and industrial competitiveness through leadership and technical accomplishment, significantly accelerating mission objectives in the areas of advanced process, materials and decision science and technology, systems integration and engineering, and science-based performance assessment. As a result, INL is leading the development of energy systems integration (hybrid) concepts while fostering strong regional relationships and DOE Laboratory collaborations. INL is the nationally recognized leader in

Electric Vehicle (EV) system diagnostics and testing, providing data/results used by industry to speed the deployment of advanced transportation systems. INL biomass and bioenergy research and Biomass Feedstock National User Facility (BFNUF) capability is advancing technical and economic feasibility of bioenergy by directly supporting U.S. industry. Critical Materials Institute was successfully implemented with all projects and tasks completed as scheduled. A new state-of-the-art centrifugal contactor pilot demonstration capability was established and all seven technology projects are underway. Overall, science and technology addressing broad DOE missions has significantly exceeded expectations resulting in clear, positive impact for both INL and DOE. The information provided below highlight noteworthy areas of performance demonstrating significant improvement to the overall mission of the Laboratory.

Energy Storage and Transportation Systems recently completed the data collection phase of the EV Everywhere Project. Funded by DOE, the EV Project is the largest deployment of electric vehicles and charge infrastructure in history. INL's role is to collect and analyze data to characterize vehicle use in diverse topographic and climatic conditions and evaluate the effectiveness of charging infrastructure.

The ultimate goal of the project is to utilize the lessons learned from the thousands of EVs now deployed to streamline the development of the next generation of EVs. INL staff collected data from 8,228 Nissan Leafs, Chevrolet Volts, and Smart car Electric Drive vehicles and provided 124.3 million miles of driving profiles. Data was also collected from 12,356 Level 2 and DC Fast Chargers, which documented 4.2 million charge events; 34,200AC MWh were used for electric transportation.

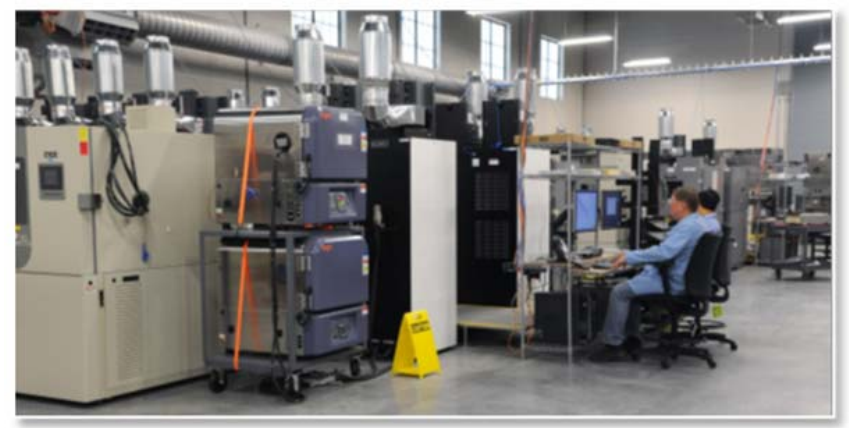

Energy Storage (Battery) Testing Laboratory at ESL. 
Major accomplishments were made in battery testing regimes, advancement of industry standards, cybersecurity for vehicles, and electrolyte research. Battery testing achievements included:

- Completed the first independent testing of a "plugless" wireless charging system (Evatran's Plugless Wireless Charging System), garnering extensive trade and general media attention. INL research engineer Barney Carlson reported the charging system tests proved wireless charging works and is safe, while incorporating a large number of variables such as distances from charging nodes, efficiency, effectiveness, and amount of power delivered.

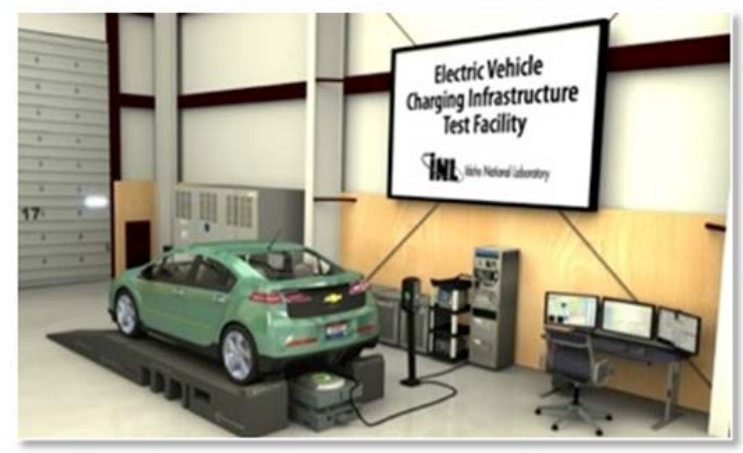

- Published DOE -Energy Efficiency and

Renewable Energy (EERE) Vehicle Technologies Office Vehicle Technologies Program: Battery Test Manual for Plug-In Hybrid Electric Vehicles (INL/EXT-14-32849), a key milestone supporting performance and life characterization of advanced battery devices under development for Plug-In Hybrid Electric Vehicles (PHEVs).

- Successfully tested innovative technique of employing a 3-D printer to fabricate a unique fixture that safely supported a large format cylindrical battery cell $(\sim 8.5$ in. $\mathrm{H} \times \sim 2.25 \mathrm{in}$. diameter), reducing cost and time to test by approximately $50 \%$ ( 1 day versus 2 days for the test).

- Validated testing for PHEV that led to the finalization of the Hybrid Pulse Power Characterization (HPPC) test procedure for the soon-to-be-published United States Council for Automotive Research, LLC, (USCAR) PHEV testing manual revision. Results were presented to USCAR's Test Methods and Definitions team.

- $\quad$ Signed a key Non-Disclosure Agreements (NDA) and initiated a direct WFO project with Ford Motor Company permitting INL to receive proprietary information concerning Ford's electric drive vehicle and charging operational data to benchmark vehicle operations and charging.

- Compiled and presented results from INL's 12-volt accessory load analysis conducted for GM, Ford, and Chrysler to Original Equipment Manufacturers (OEM) and Vehicle Systems Analysis Tech Team (VSATT) members. These results assist USCAR members in evaluating performance and interactions of automotive components and subsystems to focus future research on maximizing fuel efficiency improvements and emissions reduction.

- Co-authored a report “AVTA Federal Fleet PEV Readiness Data Logging and Characterization Study for the National Park Service: Rocky Mountain National Park" (INL/EXT-14-132720). Jim Francfort and Stephen Schey reported on the study, focusing on the RMNP's fleet identifying vehicle operational characteristics, missions and support for the successful introduction of plug-in electric vehicles. The report concludes that by replacing 189 internal combustion engine vehicles with PEVs could result in an annual greenhouse gas savings of over 1,200,000 lb-CO2e (50\% reduction) and an annual fuel cost savings of over $\$ 369,000$ (88\% reduction). Francfort authored or co-authored several similar reports to evaluate use of selected vehicles for daily missions, including:

- A study to validate use of advanced electric drive in the Caribou Targhee National Forest (INL/EXT-14-32202). 
- A report on "AVTA Federal Fleet PEV Readiness Data Logging and Characterization Study for the National Park Service: Golden Gate National Recreation Area" (INL/EXT-14-31368).

- Maintained vigorous flow of information, posting more than 65 technical fact sheets to the Advanced Vehicle web site at http://avt.inl.gov. These fact sheets benchmark the performance and life characteristics of electro-chemical energy storage devices for hybrid, plug-in hybrid, and electric vehicles against goals established in cooperation with industry through the U.S. Advanced Battery Consortium (USABC).

- Continued participation in National Institute of Standards and Technology working group investigating electric vehicle fueling and submetering to aid in decisions on information configurations for electric vehicles.

- INL staff participated in several battery industry forums, expanding the Laboratory's impact and relationships within the battery manufacturing and auto industries. Key forums included:

- DOE Energy Vehicle Technologies Office 2014 Annual Merit Review and Peer Evaluation Meeting in Washington, D.C., collaborating to evaluate the status of DOE-funded projects with DOE and key industry representatives.

- SAE J2954 standard meeting for wireless electric vehicle charging sharing report of first independent testing with automakers, suppliers, industry experts, and government representatives.

- Presented testing results from INL's Battery Testing Laboratory at the quarterly review meetings for Saft and Maxwell battery manufacturer's testing which is part of the company's contract with the USABC. INL is the lead performance test facility for Saft and Maxwell corporations.

- $\quad$ Shared testing results from INL's Battery Test Laboratory with the USABC Technical Advisory Committee (TAC) for the K2 Energy, Farasis Energy, and Hydro Quebec corporations, which will aid in guiding future R\&D needed to advance energy storage technology for use in electric drive vehicles.

- Presented real-world plug-in electric vehicle (PEV) infrastructure usage to the California Air Resources Board, California Energy Commission, and California Public Utilities Commission. This information will be used to guide policy and funding decisions related to PEV infrastructure deployment in California.

- INL electric vehicle expert James Francfort responded to more than a dozen invited speaker opportunities, delivering key presentations to prestigious forums around the world. A selected summary of those includes:

- Plug-In Electric Vehicle Infrastructure Options and Use at the Pacific Coast Collaborative Workshop on Zero Emission Vehicles in Fleets in Portland, Oregon. Jurisdictions in California, Oregon, Washington, and British Columbia have committed to a goal of "expanding the use of zero-emission vehicles, aiming for 10 percent of new vehicle purchases in public and private fleets by 2016."

- National Governors Association Workshop on Advanced Technology Vehicles outlining key achievements of the DOE's Advanced Vehicle Testing Activity with a focus on the Level 2 Electric Vehicle Supply Equipment (EVSE) and DC fast charger use by Plug-In Electric Vehicles.

- Electric Drive Transportation Association conference concerning research in hybrid systems, fuel cell advances, and other technological advances for electrified automation. 
- Standards for the battery and auto industries were advanced with INL delivering a series of manuals and products guiding policy formulation based on research results. These included:

- DOE-EERE Vehicle Technologies Program: Battery Test Manual for Plug-In Hybrid Electric Vehicles (INL/EXT-14-32849) based on technical targets for commercial viability for PHEV to provide battery performance and life characterization.

- Validated testing results of PHEV to the Test Methods and Definitions team for the USCAR, advancing USCAR's PHEV testing manual revision.

- EEST, working with INL National and Homeland Security experts, completed the cyber security testing of GE's Smart EVSE (electric vehicle charging system). The GE EVSE evaluation is the first of four Smart EVSEs, funded by a DOE-OE Funding Opportunity Announcement (FOA) award to be tested by INL, and the second EVSE system cyber tested at INL.

- Electrolyte research for the battery, automotive, and other industries were advanced significantly by INL's copyrighted Advanced Electrolyte Model (AEM), which provides a molecular-based, scientifically proven simulation tool. AEM revolutionizes electrolyte selection, optimizing material combinations and key design elements to make battery design and experimentation quick, accurate, and responsive to specific needs. AEM predicts and catalogs electrolyte metrics, evaluating and comparing more than 35 parameters to recommend optimal solutions. A "disruptive, virtual scientific simulation tool," AEM delivers to industry a DNA-like investigation of electrolytes.

\section{Recognitions and Awards}

- INL researcher Kevin Gering spent more than 12 years working to invent AEM, which won the prestigious international 2014 R\&D 100 Award. AEM is a molecular-based, scientifically proven simulation tool that delivers to industry a DNA-like investigation to all industries using electrolytes. AEM earned more significant recognition including:

- Selected by the Federal Laboratory Consortium Far West Division as an Early Stage Development Technology award winner for 2014.

- Earned superb recognition from Dow Chemical's Doug Brune who said, "The AEM narrowed down our choices and identified solvents we hadn't considered" and "the model saved us a lot of time" (e.g., conducted 300 experiments instead of 1,000).

- Battery Design Studio President Robert Spotnitz said AEM, "has simplified the design process for lithium-ion batteries which are used in many markets, including consumer, aerospace, military and automotive."

- INL electrical engineering researcher Jon Christophersen's 2009 article, "Comparison of Prognostic Algorithms for Estimating Remaining Useful Life of Batteries," was one of the top five most cited articles over the past 5 years (Sage Publications for their journal Transactions of the Institute of Measurement and Control, 2009 Volume 31 (3-4), 293-308).

- INL's John Smart's presentation to the Society of Automotive Engineers 2014 Hybrid and Electric Vehicle Technologies Symposium in La Jolla, California earned praise from a GM vehicle electrification manager who said, "Great presentation. These results are really useful." Smart's presentation, "PEV Infrastructure Deployment Costs and Driver's Charging Preferences," provided impressive results from the largest-ever electric vehicle charging infrastructure demonstration, which addressed infrastructure installation costs, popularity of charging by EV drivers at different venues, and the potential for plug-in electric vehicles in the real world to offset petroleum consumption with electricity. 
- In response to INL hosting DOE-EERE's Vehicle Technologies Office (VTO) independent merit review, USCAR representative Natalie Olds wrote, "Having the time to do a deep dive of the INL work regarding the EV project and reviewing the ChargePoint data in detail is extremely important to understanding what works and doesn't work." She added, "We all appreciated your staff staying long to answer the many questions the team had regarding the project" and "the important work that INL is doing for our country was observed all day. I am still in awe."

- During the August 2014 visit by DOE Secretary Ernie Moniz and Congressional Appropriations Chair U.S. Congressman Mike Simpson (Idaho), John Smart provided both an overview of INL's electric vehicle and charging infrastructure data collection, but also detailed how INL works with automakers to analyze the potential of two different vehicle technologies (plug-in hybrid electric vehicles versus battery electric vehicles). Smart noted one paper has been published for the Chevrolet Volt and Nissan Leaf and additional papers will be published for Ford, Toyota, and Honda vehicles. DOE-EERE's David Anderson said "I'm continually impressed with John's (Smart) insight and mastery of the complexities involved with analysis of enormous vehicle data-sets."

- Matt Shirk's work on INL's DC fast, wireless, and conductive charging project was cited in a recent issue of HybridCars.com.

- ABC News interviewed INL's Barney Carlson about the Evatran's Plugless Wireless Charging System testing project, the first independent study of this technology. Carlson described Evatran's charging system equipment, its operation, and how INL's tests were conducted.

\section{Noteworthy Accomplishments}

- INL established its research reputation in battery storage and electric vehicles as a national leader in EV system diagnostics and testing, providing data/results used by industry to speed the deployment of advanced transportation systems. Testing and development of standards and manuals that guide testing, plus a noteworthy series of presentations to key government and industry forums, added to the achievement of this goal during 2014.

- INL sought to advance Energy Storage technologies. During 2014, INL researcher Kevin Gering has delivered an award-winning, molecular-based model to examine and optimize electrolyte materials for all industries using electrolyte materials. It is an award-winning achievement. AEM delivers a "disruptive, virtual scientific simulation tool," for industry that offers a DNA-like investigation of electrolytes.

- Testing results conducted by INL for DOE's Advanced Vehicle Testing Activity, and subcontracted testing facilities at Intertek in Phoenix, Arizona, recently appeared in several online news sources. The articles covered the DC fast charging for electric vehicles and other testing conducted by DOE's Advanced Vehicle Test Activity (AVTA) program. News sources include: The Auto Channel, Autoblog Green, HazMat Management, Bodyshop Magazine, Machinery and Equipment, 4-Traders Website, Herald Online, and Fort Mills Times. This level of public reporting illustrates the impact and interest industry has in INL's test capabilities.

- Energy Storage and Transportation Systems staff members Barney Carlson and John Smart presented two papers at the 2014 SAE World Congress Conference in Detroit, Michigan. The SAE World Congress is the premier automotive engineering conference. Carlson presented "Test Results of the Plugless Inductive Charging System from Evatran Group, Inc." The results presented included system efficiency, electromagnetic-field strength, and power quality results from the first electric vehicle 
wireless charging system independently tested. Smart presented "Actual Versus Estimated Utility Factor of a Large Set of Privately Owned Chevrolet Volts." This paper (co-authored with transportation researchers at Colorado State University) compared a widely-used estimate of the amount of miles that will be driven by plug-in hybrid vehicle demonstration. This is the first known paper to make this comparison of large data sets of real world results since the estimation method was published as an SAE standard (SAE 2014 World Congress \& Exhibition).

\section{Achievements Summary - Science Based Performance Assessment for Bioenergy Systems}

In July 2013, INL's years of expertise in researching biomass feedstock was recognized and elevated with DOE's designation as the BFNUF. This was the culmination of extensive research, engineering redesigns, chemical investigation, and publication of articles sharing results. FY 2014 became the year to launch BFNUF, conduct industry testing, collaborate with a wide variety of biomass public and private enterprises, and share research with academia, government, and the bioenergy industry.

The key accomplishments during the past year include:

- Advanced the international collaborations with China's National Energy Administration (NEA), which reflects a 5-year developing relationship sponsored by the DOE's BioEnergy Technologies Office and DOE-EERE's International Office. A joint Memorandum of Understanding by DOE, United States Department of Agriculture (USDA) and NEA outline a broad agreement intended to produce stronger collaborations. INL is in the initial stages of developing a Work for Others with Petrochina for work that will focus on modeling biomass feedstock supply systems in China with a goal to improve its ability in implement bioenergy technologies. These efforts are intended to help the largest growing energy user in the world reduce future pressure on energy commodities. Another goal is to specifically identify technology options that can readily be deployed to China's large market to improve U.S. trade and market penetration. Petrochina is the fifth-largest oil and gas company in the world.

- Conducted research that addressed various approaches to blending, binding materials, energy content, thermal properties, and standardization.

- Successfully developed and tested a new BFNUF Chemical Preconversion System that was brought online to expand capability.

- Added capabilities, over six new industry users have used the capabilities of BFNUF to test selected specialized proprietary technologies. Among those are DuPont, Forest Products, Michigan Bioenergy, and TerraPower. For example:

- Initiated a specialty pellet characterization project for TerraPower in late July to support a bioenergy technology feasibility study being conducted by the company. The pellets are produced by Washington State University (WSU) and are being analyzed for density, durability, and energy content.

- Used a non-exclusive rights agreement to license Cogent Energy Systems a thermal plasma gasification technology developed at INL, which can make use of a variety of feedstock, including municipal waste to generate synthesis gas. Funding further development of this technology, Cogent and INL are executing WFOs to deploy the technology in micro-grid applications and make use of low-value waste streams. 
- BFNUF completed several key DOE BioEnergy Technologies Office (BETO) milestones. For example:

- Completed batch acid-precipitation experiments to assess for BETO the potential technical feasibility of selectively precipitating lignin or silica from the liquid phase of alkali-extracted corn stover. This research may help determine the economic feasibility of this approach.

- Reported on different sludge drying systems for their applicability to drying algae paste. Advanced a design for a bench-scale drum drying system proposed for future construction and testing.

- Analyzed several different processes to reduce ash in southern pine biomass using mechanical and chemical approaches for comparisons in effectiveness and cost. Ash removal technologies included sieving separation and washing/mild leaching experiments, which provided the basis for developing a kinetic model and a process resource/demand model.

- Completed a joint INL-PNNL report ("Logistics, Costs, and GHG Impacts of Utility-Scale Cofiring with $20 \%$ Biomass"), which summarizes an evaluation of utility-scale biomass co-firing in large pulverized coal power plants. This evaluation assessed the cost and greenhouse gas reduction benefits of substituting relatively high volumes of biomass for coal, and will assist in helping determine how states and regions can best meet the new Clean Air Act (Section 111[b] and Section $111[\mathrm{~d}])$ that curtails and reduces $\mathrm{CO}_{2}$ emissions for new and existing power generation. Collaboration included EPRI, WSU, and a commercial pellet manufacturer.

- Biomass experts continued building BFNUF and INL reputations by addressing a number of key forums, including:

- Lucia Petkovic presented "Aging study of algae bio-oils produced by different methods" at the 248th ACS (American Chemical Society) National Meeting held in San Francisco, California.

- William Smith contributed on behalf of the DOE Bioenergy Technologies Office to the National Fire Protection Association (NFPA) Technical Committee on Sprinkler System Discharge Criteria to detail ongoing efforts by the Biomass Feedstock Industry Committee on Codes and Standards.

- Richard Hess and Kevin Kenney represented BFNUF with presentations at the Biomass 2014 conference in Washington, D.C. Hess addressed opportunities for farmers in biomass at a plenary session, and Kenney outlined BFNUF capabilities and services.

- Kara Cafferty presented at the NEWBio Annual Meeting, addressing "A Life Cycle Assessment of Hybrid Willow Harvest and Logistics in the Northeastern, U.S." NEWBio is a USDA-supported consortium focused on developing perennial energy crops, especially willow and warm-season grass in the northeastern U.S. for bioenergy (http://www.newbio.psu.edu/).

- Jeffrey Lacey presented at the Symposium on Biotechnology for Fuels and Chemicals, sharing results from corn stover ash reduction mechanical fractionation work (http://sim.confex.com/sim/36th/cfp.cgi). 
- Advanced Unmanned Aircraft Systems (UAS) for application to agriculture and national security. UAS is a rapidly expanding industry with significant potential application in both agriculture and forestry. Specific accomplishments include:

- Selected to coordinate development of new UAS communication protocol technology for the U.S. Navy's Space and Naval Warfare Command.

- Continued support of INL Idaho Governor's UAS Idaho Working Group to further develop UAS support capabilities for testing and training within the state. The goal of this group is to leverage capabilities and technologies from INL, local universities, and Idaho companies to attract business from the expanding UAS industry. Efforts have received regional and agricultural trade media coverage.

- Established a WFO agreement with regional ag-business leader, Simplot Corporation, to conduct a comprehensive review of sensors that could be flown using UAS to collect information for identifying early stress indicators in crops.

- Proposed an additional Certificate of Authorization (COA) from the Federal Aviation Administration (FAA) by INL and Idaho State University to operate and conduct aerial surveys of potato fields in the northwest boundaries of the INL site.

- Derek Wadsworth was also approached by the University of Idaho (UI) to provide UAS operations over a test site in the Lemhi Valley to support a habitat study sponsored by the USDA that requires aerial imagery.

\section{Recognitions and Awards}

- Richard Hess was an invited participant at the Science and Technology Policy Institute (STPI) forum, "Alternative Jet Fuel Research, Development, Demonstration, and Deployment: Challenges, Opportunities, and a Strategic Way Forward Workshop" in Arlington, Virginia. The federally funded workshop was to gain insight into the challenges and related technological barriers to wide-scale commercial production and use of alternative jet fuel. Results from the workshop will be used to inform a National Alternative Jet Fuels Strategy, which will be

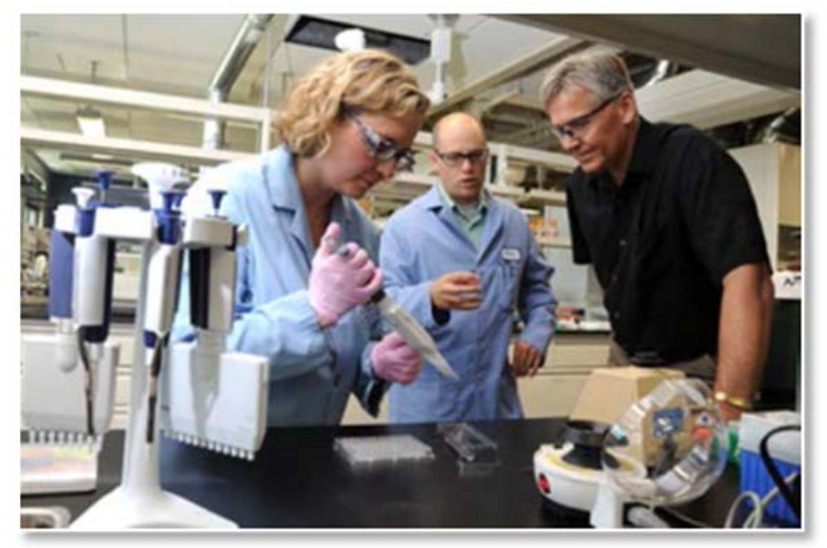
released under the auspices of the National Science and Technology Council.

- BFNUF staff, including Kevin Kenney, Gary Gresham, and Dan Stevens recently attended the International Biomass Conference and Expo in Orlando, Florida, with an exhibit on BFNUF capabilities and presentations on various feedstock issues. This March "trade-show" venue helped introduce BFNUF to a wider audience in the bioenergy industry. The conference followed an Innovation Magazine article introducing BFNUF and its considerable capabilities and quoting Michigan Biotechnology's Bernie Steele, who noted that BFNUF's work in analyzing AFEX pretreatment systems has reduced development time significantly, "maybe up to a year." 
- BFNUF director Kevin Kenney and pellet expert Jaya Shankar Tumuluru conducted an extensive interview with Pellet Mill Magazine for the January-March 2014 quarterly edition. Kenney outlined BFNUF's mission and capabilities, including the type of engineering and scientific analysis offered. Tumuluru addressed questions on challenges to pellet production, including use of binding material, standardization, energy content evaluation, and other details.

- Derek Wadsworth conducted an interview with the Capital Press (The West's Ag Website, http://www.capitalpress.com/idaho) concerning the Idaho UAS Working Group and Idaho's efforts to develop a center of excellence for UAS.

\section{Noteworthy Accomplishments}

INL successfully introduced the recently designated BFNUF to the bioenergy industry, trade media, and academic researchers. BFNUF director Kevin Kenney and staff successfully introduced the new user facility leveraging appearances at the major biomass conferences, obtained general and industry media coverage, and contacted more than three dozen potential customers, based on a business sector survey conducted in 2013.

INL's Bioenergy researchers and BFNUF increased their biomass feedstock reputation with outreach to those in the bioenergy industry and other potential customers. This was achieved and is supported by a growing business clientele that includes TerraPower, DuPont, Honeywell's Universal Oil Products, and other well-known enterprises in the biomass industry.

The BFNUF team forged a strong relationship with DOE BETO. In support of BETO, BFNUF contributed significantly to achieving multiple milestones established by BETO.

\section{Achievements Summary - Clean Energy Integration Design, Test, Control, and Validation}

INL demonstrated significant and sustained strategic leadership and produced influential results in advancing and laying future foundations for clean energy integration research. Performance during this period supported conceptual and technical development of hybrid energy systems that connect nuclear energy as an integral part of those systems. This leadership led to noteworthy collaboration between DOE-NE and DOE-EERE, creating strong partnerships between the Assistant Secretaries for both organizations, as well as new hybrid energy system program funding $(\$ 2 \mathrm{M}+)$ from these offices.

In direct support of nuclear technology industry and several regional states, INL developed technical, economic, and environmental assessments and process models to advance the optimization of nuclear energy hybrid applications. Key achievements and performances include:

- Sponsored the NE-Renewable Energy (RE) Integration Workshop, which gathered key state leaders, utilities and industry, and universities to discuss game-changing regional hybrid energy systems.

- Prepared NE-RE hybrid energy systems white paper for the Secretary of Energy, providing a contextual overview of NE-RE hybrid energy systems and representing the collaboration between DOE-NE and DOE-EERE senior leadership.

- Designed a nuclear-synfuels process and economic integration model for TerraPower, supporting their in-house proprietary design optimization studies and training TerraPower engineers to use the models. Using the ASPEN PLUS process modeling software, the model leverages heat and power from TerraPower's TWR to supplement the process to reduce greenhouse gas emissions. 
- $\quad$ Signed a new CRADA with TerraPower, initiating analysis of nuclear hybrid energy systems to convert biomass, coal, natural gas, and solid municipal waste to refined products.

- Completed a report for NuScale Power (“An Analysis of Hydrogen Production via High-Temperature Electrolysis Using a NuScale Power Nuclear Reactor") that changes the paradigm for light-water reactors by demonstrating the technical feasibility of LWRs with high-temperature reactors and other chemical processes. The approach proposes recovering heat and using it to augment the heat delivered by lower-temperature reactors. Also, in leveraging the expanding relationships within the Center for Advanced Energy Studies (CAES), INL is helping guide the coal-to-liquid hybrid research University of Wyoming will perform for NuScale.

- INL's Richard Boardman co-authored with CRADA partner NuScale Power a peer reviewed paper ("Extending Nuclear Energy to Non-Electrical Application") to share the technical and economic practicality of using a NuScale Power plant for desalination, oil refining, and hydrogen production. Results will be presented at the upcoming Pacific Basin Nuclear Conference.

- Presented at the Organization for Economic Co-operation and Development in Paris, France, INL's dynamic modeling and simulation research concerning hybrid energy systems advanced Modelica-based computational techniques. Also at this forum, INL delivered an invited lecture on "Nuclear Hybrid Energy Systems: Challenges \& Opportunities."

- Completed three nuclear hybrid energy system feasibility studies for the western states of Wyoming and Utah.

- Completed a system integration evaluation for a sodium-cooled Advanced Fast Reactor coupled with wind-generated electricity. This report adds additional justification for using nuclear energy to manage variable electric grid demand, including variability exerted by renewable energy build-up. The study evaluated applications that included hydrogen production via high-temperature steam electrolysis, methanol production via steam methane reforming to produce carbon monoxide, and hydrogen, which are used to feed a methanol synthesis reactor.

- Developed and delivered the INL/National Renewable Energy Laboratory (NREL) Nuclear-Renewable Energy Systems Integration Assessment and Deployment Roadmap.

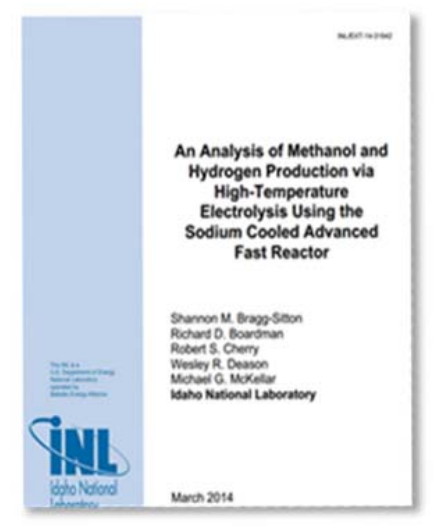

- Sponsored and aided in organizing the first Intermountain Energy Summit in August 2014, held in Idaho Falls, Idaho. INL helped frame and plan this forum that attracted senior administration officials, members of strategic House and Senate committees, and key energy industry leaders. The forum produced a dialogue centered on regional energy opportunities and challenges, and is a result of INL's leadership in developing of the Western Energy Corridor concept and other regional initiatives. More significant national exchanges will be launched from this event. 
- Completed a wide variety of renewable energy studies and provided expert technical support to DoD as part of DoD's "Net Zero Installations" initiative in response to directed "Renewable and Energy Conservation." INL initiated, continued, and/or completed projects valued at over $\$ 3.75 \mathrm{M}$ at 13 different DoD facilities. INL provided significant technical support to Pantex, which dedicated a renewable energy facility in Amarillo, Texas, during the summer of 2014 and is the largest U.S. federal wind project (11.5 megawatts nameplate capacity).

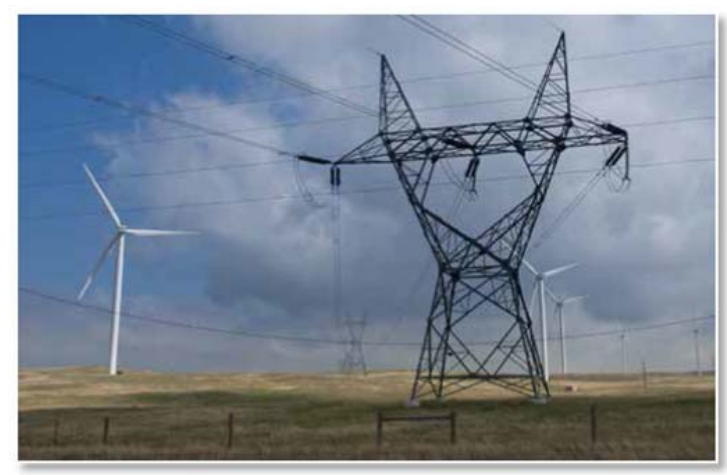

- Co-authored a report ("Hydrogen Fueling Station in Honolulu, Hawaii Feasibility Analysis") to aid in deciding the viability of deploying a hydrogen fueling station at the Fort Armstrong site in Honolulu, Hawaii.

INL researchers were invited speakers and presenters to a significant number of conferences and forums, including:

- Invited speakers (RichardBoardman and Kurt Myers) presented to IEEE-Energy Policy Committee and National Governors Association on energy systems integration and industrial heat applications.

- Invited speaker, INL renewable energy expert Kurt Myers, presented at GreenGov Dialogue on Energy Management in Washington, D.C. (http://ofee.gov/greengov-dialogue-agenda.asp). The invitation was from the White House Council on Environmental Quality to facilitate interagency discussion on renewable energy technology applications. Kurt discussed INL's wind and solar energy projects at locations such as Pantex, FE Warren AFB, Tooele Army Depot (TEAD) and others.

- Invited speaker, Richard Boardman, addressed the prestigious IEEE-Energy Policy Committee concerning hybridization of nuclear energy with power generation and industrial heat applications as a viable approach to balancing high levels of renewable power generation. This approach shows promise to significantly reduce greenhouse gas emissions in both the power generation and industrial manufacturing energy sectors.

\section{Recognitions and Awards}

- INL authors Jake P. Gentle, Michael R. West, Shane A. Carnohan, Kurt S. Myers, and Jason W. Bush were recognized for their paper, "Dynamic Line Rating Systems: Research and Policy Evaluation," with the Best Paper award at IEEE's international 2014 Power \& Energy Society General Meeting.

- Researcher and mentor Greg Mines, along with interns Rachel Wood and Hillary Hanson, received a special recognition award at the National Geothermal Summit held in August 2014 for "their outstanding achievement in the geothermal industry." The INL researchers analyzed data on geothermal operations at California and Nevada power plants for the U.S. Energy Information Administration

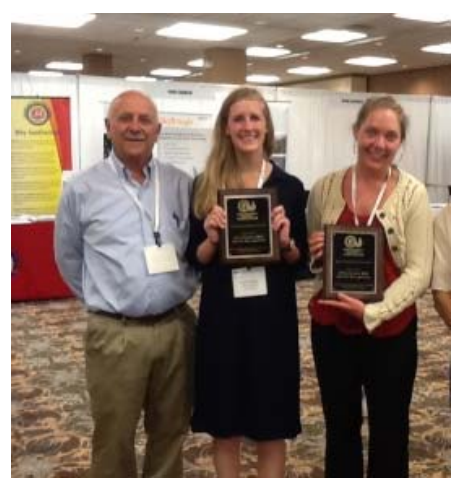
(EIA). The interns are scheduled to present their results at a DOE geothermal forum in Washington, D.C. during the fall of 2014. 
- Mitch Plummer received the Geothermal Resource Council Best Presentation Award at the 2013 Geothermal Resource Council Annual Meeting. His presentation was titled "Insights into cold water injection stimulation effects through analytical solutions to flow and heat transport." In addition, the British Society for Geomorphology Executive awarded Plummer and his collaborators the Dick Chorley Medal and Prize (£500) for Postgraduate Research for their contribution to the 2013 Geology paper on "Drainage capture and discharge variations driven by glaciation in the Southern Alps, New Zealand."

\section{Noteworthy Accomplishments}

Clean energy integration design, test, control, and validation are growing in importance to America. INL has advanced nuclear hybrid energy systems concepts during the past several years and 2014 produced visibility, commitments, and many peripheral elements. INL produced studies, papers, and presentations providing detailed approaches to various challenges and concerns. From closing on a TerraPower CRADA to completing seminal studies for energy industry enterprises, INL is leading the development of energy systems integration (hybrid) concepts while fostering strong regional relationships and DOE laboratory collaborations.

\section{Achievements Summary - Energy Critical Materials}

INL earned a berth on the Critical Materials Institute team led by Ames National Laboratory. Efforts in 2014 are beginning to show an early harvest in progress. Significant foundations are now in place to begin advancing in INL's designated areas of Rare Earth Elements (REE) and critical material recovery, recycle, and reuse goals. Key foundational accomplishments include:

- Delivered testimony in front of the House Natural Resources Committee's Subcommittee on Energy and Mineral Resources on July 23, 2014. Eric Peterson addressed the hearing, "American Metals \& Mineral Security: An examination of the domestic critical minerals supply and demand chain." Providing Congress a perspective on the area of critical materials and the crucial roles they play in our technologic society, Peterson focused on INL's Efficient Use and Recycling component of DOE's Critical Materials Institute and the importance of research and development relating to the recycle and reuse of critical materials.

1.3.A

Ensure the successful implementation of INL Critical Materials Institute/Energy Innovation (CMI) Hub program responsibilities while broadening INL's overall strategic and critical materials program impact. Implementation of key INL activities specific to the CMI Hub will include:

- Projects will be initiated and identified milestones will be met;

- Equipment will be procured and received;

- Project test plans will be defined and documented.

All tasks associated with Notable Outcome 1.3.A were met and exceeded expectations. The Critical Materials Institute established a state-of-the-art centrifugal contactor pilot demonstration capability.

- Installed and tested state-of-the-art centrifugal contactor pilot demonstration system that will aid in developing new methods for rare earth element separation and purification.

- Granted rights to INL's R\&D 100 Award winning technology, Switchable Polarity Solvent Forward Osmosis (SPS-FO) under a license option agreement with Porifera, Inc. The company also signed a CRADA for further development of the innovative, patent-pending water cleansing process, which was also selected for the Early Stage Technology Award from the Federal Laboratory Consortium, Far West Division. 
- Aided WIPP by testing decontamination methods on salt samples, which may offer alternatives for cleanup at WIPP.

- Successful test of INL's Cold Crucible Induction Melter (CCIM) Pilot Plant validated the ability to produce durable glass-ceramic high-level radioactive waste form surrogates. In support of the NE fuel cycle program, these waste forms have higher waste loadings compared to the current standard of borosilicate glass.

- In direct support to NNSA's Global Threat Reduction Initiative (GTRI) in the Office of Defense Nuclear Nonproliferation, INL worked in partnership with LANL's Off-site Source Recovery Project and LLNL to identify, recover, and dispose of disused and unwanted sources throughout the U.S. that do not have a disposal pathway. During FY 2014, the INL team successfully completed seven Cs-137 recoveries and four Co-60 recoveries from the $10-160 \mathrm{~B}$ cask. The team also completed six disposals using the 10-160B cask. These disposals included two

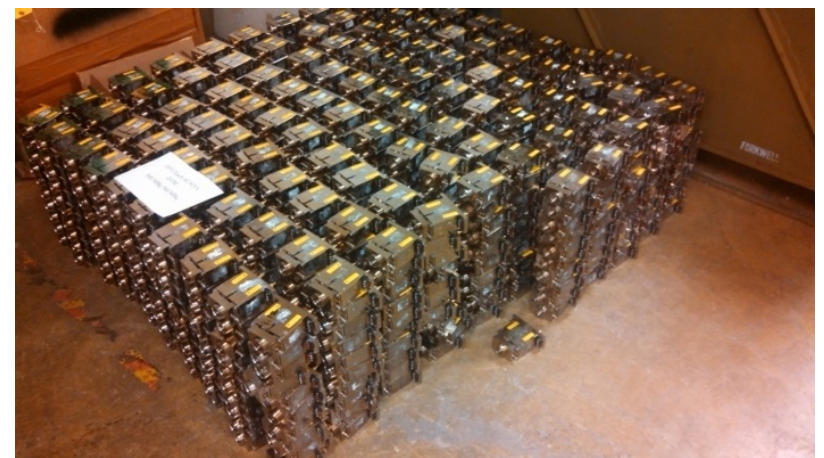

Nickel-63 sources from US Army chemical weapons detectors.

Cs-137 disposals and four Co-60 disposals. Working with the Army Joint Munitions Command under a work-for-others agreement, the team disposed of one shipment of Ni-63 sources and two shipments of Sr-90 sources. These complex transfers require exact planning and attention to detail and enable NNSA's broad strategy to keep dangerous nuclear and material safe and secure by enhancing our nation's security.

\section{Recognitions and Awards}

- $\quad$ Serving as technical program chair for the 2014 International Topical Meeting on Advances in Thermal Hydraulics, Donna Guillen also presented the paper, "Thermal Evaluation of Alternate Shipping Cask for Global Threat Reduction Initiative (GTRI) Experiments." This paper assesses the Battelle Research Reactor cask as an alternate to the GE-2000 cask.

- What started as LDRD research using a switchable polarity solvent (SPS) for water purification has led INL scientists to make a discovery that could upend one of the most basic assumptions in chemistry and physics. In follow-on to

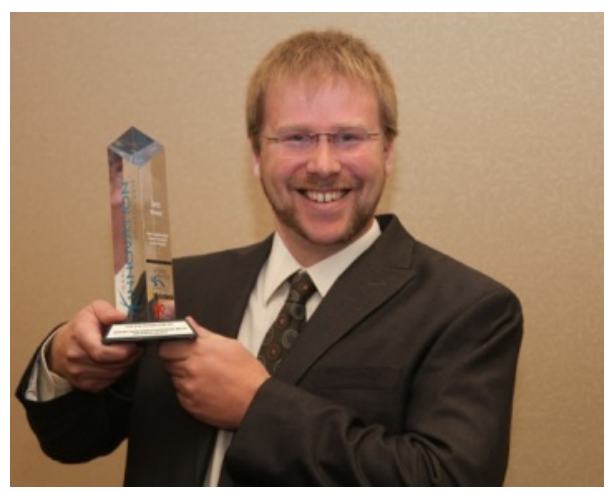
SPS-FO research, INL researchers are engaged in scientific collaboration to investigate the fundamental nature of the hydrogen bond called a theorized the anti-electrostatic hydrogen bond (AEHB). The hypothesis is that covalent bonding does occur, enabling hydrogen to bond with other atoms using more than just electrostatic forces. However, empirical data to confirm the theory until INL X-ray crystal structures discovered while studying Switchable Polarity Solvents, as well as Nuclear Magnetic Resonance Spectroscopy data and freezing point data from the SPS research, all provided evidence of the existence of an AEHB in solutions. 


\section{Noteworthy Accomplishments}

The first annual Critical Materials Institute (CMI) INL Summary Meeting was held on August 5, 2014. The meeting was attended by DOE Idaho Field Office representatives, INL Fellows, and INL CMI researchers. Presentations on the CMI Hub and INL focus areas were provided along with technical presentations on each INL project. All milestones were met by year end and a new state-of-the-art centrifugal contactor pilot demonstration system was brought online to develop new methods for rare earth element separation and purification.

\section{Publications}

Benz, J. K., Carroll, L. J., Wright, J. K., Wright, R. N., and Lillo, T. M., “Threshold Stress Creep Behavior of Alloy 617 at Intermediate Temperatures," Metallurgical and Materials Transactions A, Vol. 45, No. 7, June 2014, pp. 3010-3022.

Bonner, I. J., Muth Jr., D. J., Koch, J. B. Karlen, and Douglas, L., "Modeled Impacts of Cover Crops and Vegetative Barriers on Corn Stover Availability and Soil Quality," Bioenergy Research, Vol. 7, No. 2, June 2014, pp. 576-589.

Bonner, I. J., Smith, W. A., Einerson, J. J., and Kenney, K. L., "Impact of Harvest Equipment on Ash Variability of Baled Corn Stover Biomass for Bioenergy," BioEnergy Research, Vol. 7, No. 3, September 2014, pp. 845-855.

Cabet, C., Carroll, L., and Wright, R., "Low Cycle Fatigue and Creep-Fatigue Behavior of Alloy 617 at High Temperature," Journal of Pressure Vessel Technology-Transactions of the ASME, Vol. 135, No. 6, December 2013.

Carpenter, D., Westover, T. L., Czernik, S., and Jablonski, W., "Biomass feedstocks for renewable fuel production: a review of the impacts of feedstock and pretreatment on the yield and product distribution of fast pyrolysis bio-oils and vapors," Green Chemistry, Vol. 16, No. 2, February 2014, pp. 384-406.

Craft, A. E., O’Brien, R. C., Howe, S. D., and King, J. C., "Submersion criticality safety of tungsten-rhenium urania cermet fuel for space propulsion and power applications," Nuclear Engineering and Design, Vol. 273, July 1, 2014, pp. 143-149.

Crum, J., Maio, V., McCloy, J., et.al., "Cold Crucible Induction Melter Studies for Making Glass Ceramic Waste Forms," Journal of Nuclear Materials, Vol. 444, No. 1-3, January 2014, pp. 481-492.

Deng, B., Chernatynskiy, A., Khafizov, M., Hurley, D. H., and Phillpot, S. R. "Kapitza resistance of $\mathrm{Si} / \mathrm{SiO}_{2}$ interface," Journal of Applied Physics, Vol. 115, No. 8, Article 084910, February 28, 2014.

Deng, S., Li, H., Ma, G., Huang, H., and Li, X., "Simulation of Shale-Proppant interaction in hydraulic fracturing by the discrete element method," International Journal of Rock Mechanics and Mining Sciences, Vol. 70, September 2014, pp. 219-228.

Dufek, E. J., Lister, T. E., and Stone, S. G., "Sampling dynamics for pressurized electrochemical cells," Journal of Applied Electrochemistry, Vol. 44, No. 7, July 2014, pp. 849-855.

Glazoff, M. V., Hiromoto, R., and Tokuhiro, A., "Morphological analysis of zirconium nuclear fuel retaining rods braided with $\mathrm{SiC}$ : Quality assurance and defect identification," Journal of Nuclear Materials, Vol. 451, No. 1-3, August 2014, pp. 216-224. 
Glazoff, M. V., Rashkeev, S. N., and Herring, J. S., "Controlling chromium vaporization from interconnects with nickel coatings in solid oxide devices," International Journal of Hydrogen Energy, Vol. 39, No. 27, September 12, 2014, pp. 15031-15038.

Glazoff, M. V., Tokuhiro, A., Rashkeev, S. N., and Sabharwall, P., "Oxidation and Hydrogen Uptake in Zirconium, Zircaloy-2 and Zircaloy-4: Computational Thermodynamics and Ab Initio Calculations," Journal of Nuclear Materials, Vol. 444, No. 1-3, pp. 65-75, January 2014.

Greenwood, D. M., Gentle, J. P., Myers, K. S., Davison, P. J., West, I. J., Bush, J. W., Ingram, G. L., and Troffaes, M. C. M., "A comparison of real-time thermal rating systems in the U.S. and the U.K.," IEEE Transactions on Power Delivery, Vol. 29, No. 4, August 2014, pp. 1849-1858,

Gresham, G. G., and Johnson, J., Do Yield and Quality of Big Bluestem and Switchgrass Feedstock Decline over Winter?, Bioenergy Research, Vol. 7, No. 1, March 2014-April 8, 2014, pp. 68-77.

Groenewold, G. S., Delmore, J. E., Benson, M. T., et.al.,’Fluorohydrogenate Cluster Ions in the Gas Phase: Electrospray Ionization Mass Spectrometry of the [1-ethyl-3-methylimidazolium +$][\mathrm{F}(\mathrm{HF})$ 2.3-] Ionic Liquid," Journal of Physical Chemistry A, Vol. 117, No. 51, December 27, 2013, pp. 14191-14199.

Groenewold, G. S., Delmore, J. E., Benson, M. T., Tsuda, T., Hagiwara, R., "Generation of gas-phase zirconium fluoroanions by electrospray of an ionic liquid," Rapid Communications in Mass Spectrometry, Vol. 28, No. 11, June 15, 2014, pp. 1233-1242.

Harrison, S., Rowan, A. V., Glasser, N. F., Knight, J., Plummer, M. A., and Mills, S. C., "Little Ice Age Glaciers in Britain: Glacier-climate modelling in the Cairngorm Mountains," The Holocene, Vol. 24, No. 2, February 2014, pp. 135-140.

Harrup, M. K., Rollins, H. W., Jamison, D. K., Dufek, E. J., Gering, K. L., and Luther, T. A., "Unsaturated phosphazenes as co-solvents for lithium-ion battery electrolytes," Journal of Power Sources, July 24, 2014.

Hoover, A. N., Tumuluru, J. Shankar, Teymouri, F., Moore, J., and Gresham, G., "Effect of pelleting process variables on physical properties and sugar yields of ammonia fiber expansion pretreated corn stover," Bioresource Technology, Vol. 164, July 2014, pp. 128-135.

Hurley, M. F., Olson, C. R., Ward, L. J., Jaques, B. J., Johnson, K. A., Gunnerson, J. K., and Butt, D. P., "Transgranular stress corrosion cracking of 304L stainless steel pipe clamps in direct use geothermal water heating applications," Engineering Failure Analysis, Vol. 33, October 2013, pp. 336-346.

Khafizov, M., Park, I.-W., Chernatynskiy, A., He, L., Lin, J., Moore, J. J., Swank, D., Lillo, T., Phillpot, S. R., El-Azab, A., and Hurley, D. H., "Thermal Conductivity in Nanocrystalline Ceria Thin Films," Journal of the American Ceramic Society, Vol. 97, No. 2, February 2014, pp. 562-569.

Khafizov, M., Yablinsky, C., Allen, T. R., and Hurley, D. H., "Measurement of thermal conductivity in proton irradiated silicon," Nuclear Instruments and Methods in Physics Research, Section B: Beam Interactions with Materials and Atoms, Vol. 325, April 15, 2014, pp. 11-14.

Knappenberger, T., Flury, M., Mattson, E. D., and Harsh, J. B., "Does water content or flow rate control colloid transport in unsaturated porous media?," Environmental Science and Technology (0013-936X), Vol. 48, No. 7, April 1, 2014, pp. 3791-3799. 
Li, Z., Haynes, R., Sato, E., Shields, M. S., Fujita, Y., and Sato, C., Microbial Community Analysis of a Single Chamber Microbial Fuel Cell Using Potato Wastewater, Water Environment Research, Vol. 86, No. 4, April 2014, pp. 324-330.

Lin, W.-C., Villez, K. R. E. , and Garcia, H. E., "Experimental validation of a resilient monitoring and control system," Journal of Process Control, Vol. 24, No. 5, May 2014, pp. 621-639.

Martin-Hayden, J. M., Plummer, M., and Britt, S. L., "Controls of Wellbore Flow Regimes on Pump Effluent Composition," Groundwater, Vol. 52, No. 1, January 2014, pp. 96-104.

McJunkin, T. R., Trowbridge, T. L., Wright, K. E., and Scott, J. R., "Integrated fiducial sample mount and software for correlated microscopy," Review of Scientific Instruments, Vol. 85, No. 2 Article 023701, February 2014.

Meakin, P., Huang, H., Malthe-Srenssen, A., and Thgersen, K., "Shale Gas: Opportunities and Challenges Environmental Geosciences," Geoscience World, Vol. 20, No. 4, December 2013, pp. 151-164.

Mozetic, M., Ostrikov, K., Ruzic, D. N., Curreli, D., Cvelbar, U., Vesel, A., Primc, G., Leisch, M., Jousten, K., Malyshev, O. B., Hendricks, J. H., Kövér, L., Tagliaferro, A., Conde, O., Silvestre, A. J., Giapintzakis, J., Buljan, M., Radic, N., Drazic, G., Bernstorff, S., Biederman, H., Kylián, O., Hanuš, J., Miloševic, S., Galtayries, A., Dietrich, P., Unger, W., Lehocky, M., Sedlarik, V., Stana-Kleinschek, K., Drmota-Petric, A., Pireaux, J. J., Rogers, J. W., and Anderle, M., "Recent advances in vacuum sciences and applications," Journal of Physics D: Applied Physics, Vol. 47, No. 15, Article No. 153001, April 16, 2014.

Muth Jr., D. J., Langholtz, M. H., Tan, E. C. D., Jacobson, J. J., Schwab, A., Wu, M. M., Argo, A., Brandt, C. C., Cafferty, K. G., Chiu, Y.-W., Dutta, A., Eaton, L. M., and Searcy, E. M., "Investigation of thermochemical biorefinery sizing and environmental sustainability impacts for conventional supply system and distributed pre-processing supply system designs," Biofuels, Bioproducts and Biorefining, Vol. 8, No. 4, July/August 2014, pp. 545-567.

Mylavarapu, S. K., Sun, X., Glosup, R. E., Christensen, R. N., and Patterson, M. W., "Thermal hydraulic performance testing of printed circuit heat exchangers in a high-temperature helium test facility," Applied Thermal Engineering, Vol. 65, No. 1-2, April 2014, pp. 605-614.

Parks, D., and Tittmann, B., "Radiation tolerance of piezoelectric bulk single-crystal aluminum nitride," IEEE Transactions on Ultrasonics, Ferroelectrics and Frequency Control, Vol. 61, No. 7, July 2014, pp. 1216-1222.

Pepper, S., and Ogden, M., "Perrhenate extraction studies by Cyphos 101-IL; Screening for implementation in technetium removal," Separation and Purification Technology, Vol. 118, October 30, 2013, pp. 847-852.

Philip, B., Wang, Z., Berrill, M. A., Birke, M., and Pernice, M., "Dynamic implicit 3D adaptive mesh refinement for non-equilibrium radiation diffusion," Journal of Computational Physics, Vol. 262, April 1, 2014, pp. 17-37.

Pollyea, R. M., Fairley, J. P., Podgorney, R. K., and McLing, T. L., "A Field Sampling Strategy for Semivariogram Inference of Fractures in Rock Outcrops," Stochastic Environmental Research and Risk Assessment, Vol. 27, No. 7, October 2013, pp. 1735-1740. 
Pollyea, R. M., Fairley, J. P., Podgorney, R. K., and Mcling, T. L., "Physical constraints on geologic $\mathrm{CO} 2$ sequestration in low-volume basalt formations," Bulletin of the Geological Society of America, Vol. 126, No. 3-4, March 2014, pp. 344-351.

Putnam, A. E., Schaefer, J. M., Denton, G. H., et.al., "Warming and Glacier Recession in the Rakaia Valley, Southern Alps of New Zealand, during Heinrich Stadial 1," Earth and Planetary Science Letters, Vol. 382, November 15, 2013, pp. 98-110.

Reardon, C. L., Magnuson, T. S., Boyd, E. S., Leavitt, W. D., Reed, D. W., and Geesey, G. G., "Hydrogenase Activity of Mineral-Associated and Suspended Populations of Desulfovibrio desulfuricans Essex 6," Microbial Ecology, Vol. 67, No. 2, February 2014, February 2014, pp. 318-326.

Redden, G., Fox, D., Zhang, C. Fujita, Y., Guo, L., and Huang, H., "CaCO $\mathrm{CaC}_{3}$ Precipitation, Transport and Sensing in Porous Media with In situ Generation of Reactants," Environmental Science and Technology, Vol. 48, No. 1, January 7, 2014, pp. 542-549.

Richardson, C. D., Hinman, N. W., and Scott, J. R., "Evidence for Biological Activity in Mineralization of Secondary Sulphate Deposits in a Basaltic Environment: Implications for the Search for Life in the Martian Surface," International Journal of Astrobiology, Vol. 12, No. 4, October 2013, pp. 357-368.

Roege, P. E., Collier, Z. A., Mancillas, J., McDonagh, J. A., and Linkov, I., "Metrics for energy resilience," Energy Policy, Vol. 72, September 2014, pp. 249-256.

Roni, Md S., Eksioglu, S. D., Searcy, E., and Jha, K., "A supply chain network design model for biomass co-firing in coal-fired power plants," Transportation Research Part E-Logistics and Transportation Review, Vol. 61, January 2014, pp. 116-134.

Roni, Md. S., Eksioglu, S. D., Searcy, E., and Jacobson, J. J., "Estimating the variable cost for high-volume and long-haul transportation of densified biomass and biofuel," Transportation Research Part D: Transport and Environment, Vol. 29, June 2014, pp. 40-55.

Rowan, A. V., Brocklehurst, S. H., Schultz, D. M., Plummer, M. A., Anderson, L. S., and Glasser, N. F., "Late Quaternary glacier sensitivity to temperature and precipitation distribution in the Southern Alps of New Zealand," Journal of Geophysical Research-Earth Surface, Vol. 119, No. 5, May 2014, pp. 1064-1081.

Ruth, M. F., Zinaman, O. R., Antkowiak, M., Boardman, R. D., Cherry, R. S., and Bazilian, M. D., "Nuclear-renewable hybrid energy systems: Opportunities, interconnections, and needs," Energy Conversion and Management, Vol. 78, February 2014, pp. 684-694,

Sarkar, M., Kumar, A., Tumuluru, J. S., Patil, K. N., and Bellmer, D. D., "Gasification performance of switchgrass pretreated with torrefaction and densification," Applied Energy,, Vol. 127, August 15, 2014, pp. 194-201.

Sarkar, M., Kumar, A., Shankar T. J., Patil, K. N., and Bellmer, D., "Thermal Devolatilization Kenetics of Switchgrass Pretreated with Torrefaction and Densification," Transactions of the ASABE, Vol. 57, No. 4, July-August 2014.

Sazhin, S. V., Gering, K. L., Harrup, M. K., and Rollins, H. W., "Highly quantitative electrochemical characterization of non-aqueous electrolytes and solid electrolyte interphases," Journal of the Electrochemical Society Vol. 161, No. 3, January 7, 2014, pp. A393-A402. 
Schneider, E., Carlsen, B., Tavrides, E., van der Hoeven, C., and Phathanapirom, U., "Measures of the Environmental Footprint of the Front End of the Nuclear Fuel Cycle," Energy Economics, Vol. 40, November 2013, pp. 898-910.

Schneider, E., Carlsen, B., Tavrides, E., van der Hoeven, C., and Phathanapirom, U., "A Top Down Assessment of Energy, Water and Land use in Uranium Mining, Milling, and Refining," Energy Economics, Vol. 40, November 2013, pp. 911-926.

Tidwell, V. C., Moreland, B. D., Zemlick, K. M., Roberts, B. L., Passell, H. D., Jensen, D., Forsgren, C., Sehlke, G., Cook, M. A., King, C. W., and Larsen, S., "Mapping water availability, projected use and cost in the western United States," Environmental Research Letters, Vol. 9, No. 6, Article 064009, May 2014.

Tong, J. X., Hu, B. X., Huang, H., Guo, L. J., and Yang, J. Z., “Application of a data assimilation method via an ensemble Kalman filter to reactive urea hydrolysis transport modeling," Stochastic Environmental Research and Risk Assessment, Vol. 28, No. 3, March 2014, pp 729-741.

Tumuluru, J. S., "Effect of process variables on the density and durability of the pellets made from high moisture corn stover," Biosystems Engineering, Vol. 119, March 2014, pp. 44-57.

Tumuluru, J. S., Sokhansanj, S., Bandyopadhyay, S., and Bawa, A. S., "Storage, Nutritional and Sensory Properties of High-Fat Fish and Rice Flour Coextrudates," Journal of Food Processing and Preservation, Vol. 37, No. 5, October 2013, pp. 684-693.

Tumuluru, J. S., Sokhansanj, S., Lim, C. J., Bi, T., Kuang, X. Y., and Melin, S., "Effect of Low and High Storage Temperatures on Headspace Gas Concentrations and Physical Properties of Wood Pellets," International Wood Products Journal, Vol. 4, No. 4, November 2013, pp. 207-216.

Tumuluru, J. S., Tabil, L. G., Song, Y., Iroba, K. L., and Meda, V., "Grinding Energy and Physical Properties of Chopped and Hammer-Milled Barley, Wheat, Oat, and Canola Straws," Biomass and Bioenergy, Vol. 60, January 2014, pp. 58-67.

Wang, X., Khafizov, M., and Szlufarska, I., "Effect of Surface Strain on Oxygen Adsorption on Zr $\left(\begin{array}{lll}0 & 0 & 1\end{array}\right)$ Surface," Journal of Nuclear Materials, Vol. 445, No. 1-3, February 2014, pp. 1-6.

Wang, N., Rokkam, S., Hochrainer, T., Pernice, M., and El-Azab, A., "Asymptotic and uncertainty analyses of a phase field model for void formation under irradiation," Computational Materials Science, Vol. 89, June 15, 2014, pp. 165-175.

Wendt, L. M., Bonner, I. J., Hoover, A. N., Emerson, R. M., and Smith, W. A., "Influence of Airflow on Laboratory Storage of High Moisture Corn Stover," BioEnergy Research, April 2014.

Wilson, A. D., and Stewart, F. F., "Structure-function study of tertiary amines as switchable polarity solvents," RSC Advances, Vol. 4, No. 22, February 3, 2014, pp. 11039-11049.

$\mathrm{Xu}, \mathrm{Z}$., and Meakin, P., "Upscaling of Solute Transport in Heterogeneous Media with Non-uniform Flow and Dispersion Fields," Applied Mathematical Modeling, Vol. 37, No. 18-19, October 1, 2013, pp. 8533-8542.

Yancey, N. A., Tumuluru, J. S., and Wright, C. T., "Drying, Grinding and Pelletization Studies on Raw and Formulated Biomass Feedstock's for Bioenergy Applications," Journal of Biobased Materials and Bioenergy, Vol. 7, No. 5, October 2013, pp. 549-558. 
Yang, P., Ames, D. P., Fonseca, A., Anderson, D., Shrestha, R., Glenn, N. F., and Cao, Y., "What is the effect of LiDAR-derived DEM resolution on large-scale watershed model results?," Environmental Modelling and Software, Vol. 58, August 2014, pp. 48-57.

Yoon, J. W., Lou, Y., Yoon, J., and Glazoff, M. V., “Asymmetric Yield Function Based on the Stress Invariants for Pressure Sensitive Metals," International Journal of Plasticity, Vol. 56, May 2014, pp. 184-202. 
PEMP FY 2014 


\section{Efficient and Effective Mission Accomplishment}

\section{4: Collaborations}

\section{OBJECTIVE 1.4: COLLABORATIONS}

Foster new academic, industry, government, and international collaborations to produce the investment, programs and expertise that assure the DOE Vision for INL is realized. The primary focus areas include, but are not limited to the following:

- Demonstrating innovation in regional workforce advocacy to attract and retain "best and brightest" in areas of relevance to regional industry, including workforce development, university outreach, and K-12;

- Developing human resource pipelines to ensure the Laboratory is connected with universities whose educational programs align with the critical staffing needs of the INL;

- Demonstrating progress, impact, and leadership deploying INL capability and through regional partnerships identify and solve regional and industry challenges associated with national clean energy, environmental sustainability, and security challenges;

- Enrich the national research, development, and deployment of advanced science-base technologies through the sharing of Laboratory facilities through a user facility model;

- Establish and maintain long-term partnerships/ relationships that maintain appropriate relations with the scientific and local communities; and

- Broadly deploy Laboratory capabilities, intellectual property, and technologies to support and impact industry and other key non-DOE customer needs through Cooperative Research and Development Agreements (CRADA), Work For Others (WFO) Agreements, Agreements for Commercializing Technology (ACT), user facility access, technology based economic development and Intellectual Property (IP) management and licensing.

Professional Development Leadership" Award for leadership in the K-12 program. The leadership of INL's STEM program was also acknowledged by Idaho Science and Aerospace Scholars (ISAS) at the ISAS VIP Luncheon in Boise. Additionally, the INL i-STEM program was recognized with an invited talk at the 2014 STEM Innovations Conference: Idaho STEM Education Challenges and Innovative Solutions: "Overcoming STEM Education Barriers in Rural States. Idaho governor C. L. "Butch" Otter also proclaimed June 2014 as STEM Education Month as a result of the impact INL i-STEM program and i-STEM Institutes have on STEM Education and the future STEM Workforce in Idaho.

\section{Achievements Summary - Demonstrating Innovation in Regional Workforce Advocacy}

Demonstrating innovation in regional workforce advocacy to attract and retain "best and brightest" in areas of relevance to regional industry, including workforce development, university outreach, and $K-12$ : INL exceeded expectations to provide the advancement of regional and national Science, Technology, Engineering, and Math (STEM) efforts to attract and retain the best and brightest. The following accomplishments demonstrate INL delivered creative, new and unconventional methods for our DOE customer, industry, and our academic collaborators.

The Laboratory continued to exhibit excellence in STEM education (and in turn, advocating for the future workforce) from the regional to the national level. INL's Idaho-STEM (i-STEM) program worked with regional and Idaho schools, industry, and Native American communities to provide real-world STEM training and education strategies for educators. Several STEM related post mid-year highlights are provided:

- INL's STEM program received external and peer recognition in several instances. For example, INL's i-STEM was recognized as an outstanding U.S. Department of Education's Mathematics and Science Partnerships Program (MSP) program, the International Association for Science, Technology, Engineering and Mathematics Leaders awarded INL its "STEM 
- INL's STEM program personnel led implemented and served in a variety of positions that advanced the vision and leadership of workforce development. For instance, INL represented DOE and Battelle on the board of the Pacific Northwest Louis Stokes Alliance for Minority Participation. INL participated in a literacy summit in Arlington, Virginia, Committing to Lead: Business Role in Achieving and Sustaining STEM where U.S. Vice President Joe Biden recognized the contributions of Corporate America and stakeholders to improve widespread STEM literacy, and lent support to future planning efforts. Finally, INL represented the Idaho State Department of Education on behalf of the Idaho Building Capacity for State Science Education leadership team.

- The successful implementation of INL's STEM program hinges on our ability to communicate and influence leaders, engage partners, and connect with key collaborators. Since May, INL's program personnel presented several papers including "Place-Based STEM: Leveraging Local Resources to Engage K-12 Teachers in Teaching Integrated STEM and for Addressing the Local STEM Pipeline," at the 121st American Society for Engineering Educators Annual Conference and Exposition, a keynote presentation at Wyoming's Math and Science Partnership Teacher Professional Development, "Power of PLACE Summit," and an invited talk at the 3rd Annual International STEM Conference in Vancouver, British Columbia, "Evidence-Based Practices and Solutions." Finally, INL's K-12 and STEM education activities were presented as part of the DOE-EERE's virtual town hall.

- INL's leadership fostered partnerships with several regional collaborators to advance workforce development, university outreach and K-12 STEM education. The outreach activities bolstered interest, excitement, and knowledge of STEM education, and career awareness to enhance workforce readiness for over 7,000 students in Idaho, Wyoming, Nevada, and Utah, as well as nearly 700 educators who attended the 2014 i-STEM Summer Institutes "Getting to the Core," and 39 Native American students from the Shoshone-Bannock Tribe who attended Native American STEM day. Key partnerships were realized with the Alaskan-based Nenana City School District where the INL i- STEM team provided a 3-day STEM Teacher Professional Development Institute.

INL's approach to university outreach and industrial partnerships is particularly important for the near- and long-term success of the Laboratory. University and industrial engagement is rooted in each of INL's core mission areas and enabled by Laboratory investments and expertise. Our ability to focus strategically on university engagement and other external cooperative association's recent endeavors is a component of our success. These activities are detailed in the following bullets:

- Todd Allen is mentoring six Ph.D. students at the University of Wisconsin, two of which are making key contributions to INL's Energy Frontier Research. Sarah Khalil recently graduated after finishing her Ph.D. on the study of stoichiometry effects in voids in $\mathrm{UO}_{2}$. Laura Jamison defended her Ph.D. and will be joining ANL as a postdoctoral fellow. Mahima Gupta, Guiqiu Zheng, Brian Kelleher, Sam Briggs, and Alex Mairov are continuing on their studies. Sam Briggs and Alex Mairov are active users of the CEAS Materials and Characterization Suite (MaCS) facility. Mahima Gupta was a 
featured presenter for both the Pat Dehmer and Ernest Moniz visits to INL. Kolton Urso and Adam Reinecke defended their M.S. degrees. Both researchers did significant work with INL and CAES as part of their M.S. thesis projects.

- Brent Stacey, N\&HS Associate Laboratory Director, and Dr. Sujeet Shenoi, University of Tulsa Professor, signed a Memorandum of Understanding on June 17,2014, to initiate a strategic partnership intended to mutually enhance INL's and Tulsa's capabilities and reputations as leaders in cybersecurity of critical infrastructure. This partnership resulted in several technical seminars by Tulsa students, the hiring of a new Ph.D. cyber researcher, and several position interviews and pending offers with other graduate students.

- Pete Gasper, INL's Senior Analyst, presented the paper "Practical Cyber Vulnerability Assessment Techniques for Naval Platforms" at Naval Postgraduate School (NPS) Classified Advanced Technology Update (CATU) Symposium. The paper, based on a novel intelligence analysis doctrine originating from LDRD research within INL's MSC. As a result of interest from this paper, INL and NPS have begun discussions of CRADA or a joint appointment agreement to collaborate on research projects and provide access to INL's full-scale testing infrastructure.

- An LDRD collaboration with the University of Utah for conducting spectrum sharing research resulted in a significant series of innovations that will advance the nation's economic competitiveness with wireless communication technologies. These innovations include an awarded patent "Method and Apparatuses Using Filter Banks for Multicarrier Spread Spectrum Signals," notification of allowance of a patent for another filter bank technology, and an INL application for a third patent describing a wireless encryption technology. This INL-owned intellectual property resulted in new RDD\&D programs at INL to develop new communications technologies for the DoD and the Drug Enforcement Agency.

\section{Achievements Summary — Developing Human Resource Pipelines}

Developing human resource pipelines to ensure the Laboratory is connected with universities whose educational programs align with the critical staffing needs of INL: INL is exceeding expectations to cultivate relationships to develop human resource pipelines through education programs, access to experts, strategic and key hires, postdoctoral appointments, and career enhancement through graduate research. Examples of achievements demonstrating success include:

- INL hosted the TREAT Knowledge Transfer Workshop. The workshop included previous employees from the original facility design and start-up to employees who performed major facility upgrades in the early 1980s. Current INL staff participated in the workshop including interns and early career employees. The workshop provided an opportunity to engage in conversations about lessons learned and first-hand knowledge of facility access. The workshop was a timely and invaluable experience supporting the TREAT facility start-up.

- INL Internship Program was recognized as a 2014 national Vault Top Internship Program and influenced Vault to establish top internship categories in the STEM fields. As a result of this recognition, Vault invited INL to participate in its review/selection process for 2015. 
- In FY 2014, INL Internship Program sponsored 31 Non-Employee Practicum students. These students are funded directly by U.S. Government grants, fellowships, or a funding source other than the U.S. Government. These students represented 19 academic institutions including students on Nuclear Energy University Program (NEUP) fellowships from Massachusetts Institute of Technology, Oregon State University, Rensselaer Polytechnic Institute, and University of South Carolina. INL also hosted two students with scholarships from Iowa State University's Sustainable Production and Distribution of Bioenergy for the Central USA (CenUSA Bioenergy) Program.

- In FY 2014, INL increased postdoctoral staff from eight in FY 2013 to 17 in FY 2014 and transitioned six of our postdoctoral researchers to full-time positions. Overall, the postdoctoral research staff represented 14 academic institutions, including two from National University Consortium (NUC) partner schools and one from an Idaho Universities Consortium (IUC) partner school. INL hosted a Postdoctoral and Intern Forum with Dr. Peter Lyons, DOE Assistant Secretary of Nuclear Energy. In addition INL hosted:

- Five International Technical Specialists fostering new academic collaborations with Ecoles Polytechnique, Polytechnic University of Milan, RWTH-Aachen, Germany, Politecnico di Milano (POLIMI), and University of Rome "La Sapienza." Their research contributes to DOE's efforts in risk-weighted optimization processes for nuclear power plants, fuel modeling, and performance of a full comparison of the INL system codes RELAP-7 and RELAP5-3D.

- Seven Ph.D. researchers worked in support of the Korean Atomic Energy Research Institute (KAERI) CRADA to expand the Joint Fuel Cycle Studies between the United States and the Republic of Korea. The Koreans' expertise in fuel cycle processes related to electrochemical recycling provides a valuable contribution to DOE's efforts on the nuclear fuel cycle.

- One internationally acclaimed Research Scholar was provided the opportunity to collaborate on preliminary reactor physics analysis for the conceptual design of CEA's 600 MWe ASTRID sodium-cooled fast reactor concept based on benchmark specifications to be provided by CEA. The objective of the collaboration is to evaluate major neutronic reactor design parameters and their associated uncertainties using U.S. reactor physics methods and cross sections.

- In FY 2014, INL had 238 employees take 1,158 courses from 22 universities (of which five were Idaho Universities). INL had 30 students graduate with advanced degrees including: two Ph.D., 15 master's, 12 bachelor's, and two associate's. We currently have 138 employees enrolled in 232 courses for the fall 2014 semester; 129 of the 138 employees are degree-seeking students.

- Catherine Riddle successfully defended her Ph.D. dissertation in Radiochemistry from UNLV. The LDRD program supported research for her Ph.D., entitled "Speciation Behavior of Americium Higher Oxidation States for the Separation of Americium from Curium," which brought in unique new capabilities to MFC. This LDRD also supported a first-time collaboration between INL and UNLV for a new distance education program for chemists with a master's degree to continue their pursuit of a Ph.D. in radiochemistry while working at a national laboratory. Catherine Riddle is the first graduate of this new collaborative program.

- Todd Vollmer, an INL Counterintelligence Tech Expert, successfully defended his dissertation on cybersecurity research with the UI. His Ph.D. research was conducted under the direction of Dr. Milos Manic and was initially funded by an ICIS LDRD and then continued under DOE-OE. The dissertation, "Autonomic Intelligent Network Sensor Model for Protection of Critical Infrastructure Systems," culminated in the proof-of-principle of a sensor for detecting control system attacks upon critical infrastructure. 
- INL hosted the 5th Annual Modeling, Experimentation, and Validation (MeV) Summer School, which focused on "Advances in Nuclear Reactor Safety."

- INL successfully executed the third Nuclear Nonproliferation and Safeguards university course at ISU and Utah State University. Based on the effectiveness in outreach to students and quality of materials, NA-241 requested that INL assist other laboratories in establishing similar programs to expand the impact of NA-241's Next Generation Safeguard Initiative Human Capital Development

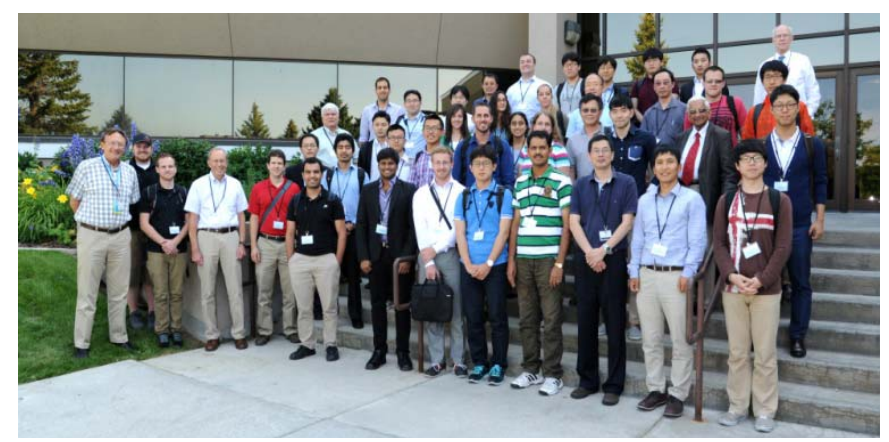
Program. Additionally, INL received a note of thanks from the first selected U.S. safeguards inspector who attended INL's Pre-Inspector course- - a course also sponsored by NA-24 to support the NNSA objective to enhance the level of U.S. representation within the IAEA.

- An ICIS research initiative, which included researchers from CAES, Idaho Regional Optical Networks (IRON), and Colorado State University (CSU) developed an educational course to teach the concepts of automatic control of the electric grid, resilient control systems, human factors, and cyber security. A new simulator called "Grid Game" was developed by the team to support the special topics class "Resilient Control Systems" and gained national interest during the INL-sponsored Resilience Week Symposium. The "Grid Game" also expanded its outreach into the Resilient Control Systems (RCS) Course given remotely to the three Idaho research universities, and improving its capability to engage more students by expanding the game to multiple players/operators.

- Researchers in INL's Energetic Materials Development Group have been collaborating with Texas Tech's Dr. Pantoya and her research students to develop more efficient and safe energetic materials. This LDRD collaboration resulted in multiple technical journal publications and patent applications that emphasize the development of safer materials and systems to conduct energetic material research and prototyping of specialty products. INL and Texas Tech researchers exchange safety processes and practices that both protect the researchers and instill a good safety mindset for staff that may eventually be hired into the INL research group. As a result of this collaboration, Texas Tech released a safety video that incorporates the principles of an Integrated Safety Management System (ISMS) by emphasizing the building of competence and experience before students conduct experiments.

- INL hosted its 1st Postdoctoral and Intern Forum. The inaugural speaker was Dr. Peter Lyons. Dr. Lyons spoke about his own career path and answered questions on a variety of energy related topics with a group of $\sim 20$ postdoctoral students and interns.

- In developing a cadre of researchers to build wireless communications R\&D programs, INL was successful in applying LDRD research to hire two early career researchers. After completing research on components of INL's transformational WSComm technology, Dr. Brandon Lo, a recent Ph.D. graduate from Georgia Institute of Technology, and Dr. Daryl Wasden, a recent Ph.D. graduate from the University of Utah, have been hired. As employees, Dr. Lo and Dr. Wasden are continuing to perform programmatic research on WSComm and on new LDRD research for new concepts in securing wireless communications. 
INL's foundation is its employees who demonstrate leadership in world-class R\&D, safe operations, and management. INL enables this talent to succeed and make sustained national impact by obtaining advanced educations in graduate areas we have chosen as key to INL's success. Advancing nuclear energy RDD\&D solutions, demonstrating leadership in National Homeland Security and exhibiting excellence in clean energy integration to enhance the DOE mission is noted in FY 2014 by several of the technical leadership awards our INL researchers have obtained to date:

- Derek Gaston, Cody Permann, David Andrs, Jason Miller, J. W. Peterson, Andrew Slaughter, and Richard Martineau received an R\&D 100 Award for the Multiphysics Object Oriented Simulation Environment (MOOSE), which makes it easier for scientists to predict phenomena ranging from nuclear fuel and reactor performance to groundwater and chemical movement. Such simulations can help speed the pace of scientific discovery but traditionally required more computing resources than most scientists and engineers could readily access.

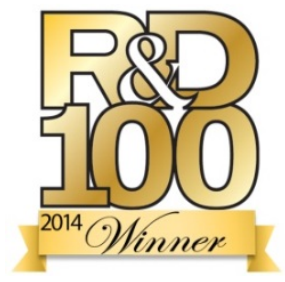

- Gary Smith and Derek Gaston received the FLC FW, Outstanding Commercialization Success Award for Deployment of MOOSE.

- Catherine Riddle won first place in the DOE FCRD Innovations in Fuel Cycle Research for her paper "Characterization of Bismuthate Oxidized Americium (V, VI) in Acidic Solution using X-Ray Absorption Fine Structure Spectroscopy." Troy Unruh et al.'s peer-reviewed journal article, "In-core Flux Sensor Evaluations at the ATR Critical Facility," placed second in the FCRD Innovations in Fuel Cycle Research Open Competition for the Advanced Fuels category. The publication communicates results from flux detector comparisons using the new capability established at the ATRC. The capability can be used in the future for further neutron flux and gamma detector evaluations for programs such as NEET, NGNP, and FCRD.

- Terry Todd, Jack Law, and Dean Peterman were honored by Secretary of Energy for their role in the Salt Waste Disposal Technologies Team. The team represented a collaboration among DOE program offices and laboratories, industry, and academia for its work to combine fundamental and applied research, technology development, and other elements to develop and deploy new technologies for the safe and cost-effective disposition of large volumes of radioactive salt waste.

- Bruce Hallbert, Ron Farris, Shawn St. Germain, and Arizona Public Service were recipients of the NEI, TIP Award for the LWRS program-developed outage control center technology. This is the first time INL has been honored with NEI's top distinction. The award was for an innovative process improvement employed by APS in collaboration with researchers from INL to manage and provide enhanced collaboration of information and activities associated with Palo Verde's fall 2013 refueling outage.

- Maria Okuniewski, teamed with researchers from the Georgia Institute of Technology and University of California, San Diego, and Los Alamos National Laboratory, was awarded the ANS Materials Science and Technology Division 2012 Student Literary Award for "Atomic Properties of Body-Centered Cubic Uranium," published in the Journal of Physics: Condensed Matter, Number 24, February 2012.

- Kelly Lively, INL department manager for Radioisotope Power Systems, received Idaho State University's Professional Achievement Award. Since 2003, Lively has been associated with the radioisotope power systems program at MFC. 
- $\quad$ Leigh Martin, Aqueous Separations \& Radiochemistry Department, was one of 10 individuals honored at the 2014 Idaho Falls Chamber of Commerce Distinguished Under-40 Awards Luncheon. The award honors professionals with a bright career and contribute locally to our community.

- Heather Chichester, Advanced Fuels Campaign Irradiation Testing Technical Lead, was recognized by the ANS Materials Science and Technology Division which presented her the 2012 Past Chair Award for her dedication to the leadership and advancement of the Materials Science and Technology Division of ANS.

- Kemal Pasamehmetoglu was honored by the ANS Materials Science and Technology Division as the 2013 recipient of its Special Achievement Award. The division's most prestigious award recognizes international leadership in establishing a science-based approach to nuclear fuel development and seminal contributions to the nuclear materials area. Todd Allen was honored as the 2012 recipient of the Outstanding Achievement Award for his leadership and many contributions to nuclear materials area.

- Igor Bolshinsky, Ken Allen, and Mike Tyacke were members of a team of DOE and laboratory employees who received the DOE 2013 Secretarial Honor Awards for NNSA's Global Threat Reduction Program. This award recognized the significant progress in securing special nuclear materials from the threat of diversion to proliferation programs. In special recognition of the impact of these achievements:

- Igor Bolshinsky and Savannah River National Laboratory's John Dewes were selected for Hungary's Golden Cross of Merit, the highest national civilian award, for their participation in the removal of HEU from Hungary.

- A collaborative team of DOE-IN security officers and INL employees from N\&HS, Counterintelligence, and Facilities \& Site Services received the Secretary of Energy's Honor Award for support to the Industrial Control Systems Cyber Emergency Response Team, which significantly improves the security of the nation's critical infrastructure by establishing the Cyber Security Operations Center into an INL-operated and DOE-accredited facility.

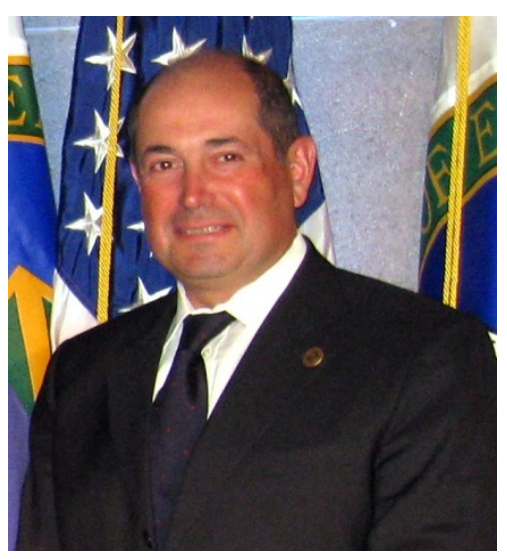

INL's Igor Bolshinsky was awarded Hungary's Golden Cross of Merit for leading the international effort to remove $>200 \mathrm{~kg}$ of high enriched uranium from Hungary.

- Kevin Gering received an R\&D 100 Award for the AEM, which is a powerful tool that analyzes and identifies potential electrolytes for battery systems. It offers significant resource savings by optimizing material combinations for new batteries. AEM predicts and reports key properties underlying electrolyte behavior in the electrochemical cell environment.

- Kevin Gering received the FLC FW Outstanding Technology Development Award for the Advanced Electrolyte Model.

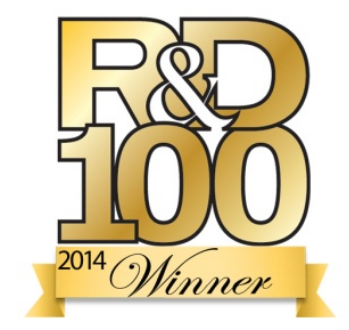

- Aaron Wilson, Fred Stewart, and Mark Stone received the Idaho Technology Council 2013 Early Stage Innovation of the Year Award. They were honored for their patent-pending technology, "Switchable Polarity Solvent - Forward Osmosis (SPS- FO)." 
- Researcher Greg Mines along with interns Hillary Hanson and Rachel Wood received a Special Recognition Award at the National Geothermal Summit held August 5, 2015, in Reno, Nevada, for "their outstanding achievement in the geothermal industry." The INL researchers analyzed data on geothermal operations in California and Nevada for their work on geothermal power plants for the U.S. Energy Information Administration. The Geothermal Energy Association is a trade association comprised of U.S. companies that support expanded use of geothermal energy, developing geothermal resources worldwide for electrical power generation and direct-heat uses.

\section{Achievements Summary - Demonstrating Progress, Impact, and Leadership Deploying INL Capability through Partnerships}

Demonstrating progress, impact, and leadership deploying INL capability and through regional partnerships identify and solve regional and industry challenges associated with national clean energy, environmental sustainability, and security challenges: INL is surpassing expectations by demonstrating leadership in several key partnerships and developing and deploying technologies for energy security.

As a regional and national leader, INL is making a difference in developing strategies to improve U.S. energy security. Consistent with INL's objectives to establish partnerships with private sector energy system stakeholders, INL continues to build collaborations through regional outreach. These efforts demonstrate INL's growth in leadership and influence in the integration of national energy needs with security requirements across the U.S.

- The NE-4 Consolidated Innovative Nuclear Research FOA highlighted the incorporation of the ATR NSUF into the FOA, allowing university, industry, and national laboratory researchers to submit a single proposal for NEUP or NEET financial support coupled with no-cost ATR NSUF access.

- Harold McFarlane and George Griffith produced a report for State of Utah Governor's Office of Energy Development "Nuclear Energy Systems Options for Utah's Energy Future." INL employees additionally briefed Governor Gary Herbert on the report, while Richard Boardman briefed the governor about the potential benefits of hybrid energy systems for Utah's energy resources. The report was released during the Utah Governor's Energy Development Summit 2014 during the nuclear breakout session in which McFarlane was a panelist.

- $\quad$ STARCORE, a small Saskatchewan HTGR gas reactor company and the provincial government invited David Petti and Hans Gougar to act as technical experts in HTGR technology. STARCORE is interested in deploying small HTGRs off-grid to mines and remote villages where the costs of electricity are extremely high ( $>50$ mills/kWhr), whereas NGNP is more interested in conventional modular HTGRs of $600 \mathrm{MWth}$ in size. Additionally, a group of stakeholders associated with the University of Saskatchewan is very interested in technology innovation and would like to develop a nuclear center of excellence with INL.

- INL successfully expanded the risk-informed safety margin characterization methodology to include a broader spectrum of accident scenarios and new stakeholders/participants. Industrial collaborators include South Texas Plant and the Nuclear Regulatory Commission.

- As part of the DOE-OE-funded National Supervisory Control and Data Acquisition (SCADA) Test Bed Program, INL issued a report, "RENDER Concept of Operation." This report describes the progress of this novel approach in preemptively identifying and mitigating vulnerabilities in industrial control systems. This proof-of-concept experimentation project, involving CRADA partners Alstom Grid Inc., Siemens Energy, Inc., and Telvent USA, Inc., demonstrated a new and effective 
methodology for a public-private partnership with enhanced cybersecurity information sharing between operators, vendors, and governments.

- INL's WNUF and Idaho State University successfully co-hosted the National Science Foundation's National Wireless Research Collaboration Symposium (NWRCS 2014). This symposium, originally intended to bring together national leaders in spectrum sharing research, was expanded to include Public Safety officials and researchers from universities, vendors, and governments. The resulting discussions provided a first-of-its-kind public forum for the research and public safety communities to engage in discussions regarding the future implementation needs for technology deployment, implementation policy, and standards development applicable to public safety requirements.

- DHS ICS-CERT, DOE-IN, and INL's collaborative leadership in the development and implementation of processes for sharing threat information with the private sector is contributing to the successful implementation of national policy for protection of critical infrastructure and cybersecurity threat information sharing. These successes within US-CERT and ICS-CERT, implemented through their respective watch floors, have led to legislative change that formalizes implementation of the DHS NCCIC.

- INL leadership delivered national security and energy security briefs for U.S. Senators and Congressman from Idaho, Wyoming, and Alaska to elevate their awareness of the national challenges for the national grid's reliability, resilience, and security. National security briefs described vulnerabilities and INL research in threat analysis and technology solutions related to cybersecurity, industrial control systems, wireless, GMD, and physical threats. Discussions related to energy security described INL's R\&D programs for the successful integration of renewable and hybrid energy systems. Additionally, INL is providing support to the University of Wyoming's School of Energy Resources, the Western Research Institute, and the Wyoming Hybrid Energy Systems Working Group in establishing Wyoming's energy policy and legislative actions that support the growth of future energy business.

- U.S. Department of Energy's SunShot Initiative for \$2.8M enabled CAES researchers (BSU, ISU, INL, UI, and BYU) to develop PVMapper, a geographic information system (GIS) that helps large-scale photovoltaic project developers take social preferences and constraints into account. David Solan, BSU co-associate director for CAES and Director of the Energy Policy Institute at BSU, was interviewed about the project. The article was published in Solar Industry Magazine. PVMapper currently exists as an online software tool based on large-scale maps of the U.S. for identifying potential PV (photovoltaic)-appropriate sites based on factors such as solar insulation, slope, land usage types, and nearby geographical features. A key goal of PVMapper is to make the tool usable across the entire U.S.

\section{Achievements Summary - Enrich National Research, Development and Deployment through the User Facility Model}

Enrich the national research, development, and deployment of advanced science-base technologies through the sharing of Laboratory facilities through a user facility model: INL is surpassing expectations by advancing national research, development, and deployment, and evolving science-based technologies through the sharing of Laboratory facilities as validated in our partnerships and leadership of the NEUP, NEET, ATR NSUF, and NUC programs. Creative, unconventional implementation methods of these programs demonstrate we are reaching the greater scientific communities and are accelerating paradigm shifts, as demonstrated in the accomplishments below: 
- The DOE-NE conducts crosscutting technology development (CTD), nuclear energy R\&D, and associated infrastructure support activities to develop innovative technologies that offer the promise of dramatically improved performance for advanced reactors and fuel cycle concepts, all while maximizing the impact of DOE resources through the Consolidated Innovative Nuclear Research Awards (NEUP/NEET-CTD, NEET-CTD Infrastructure). INL competes in both areas, as a principal or collaborator in NEET-CTD, and only as a collaborator in NEUP. For FY 2014, \$67M was awarded from the Consolidated Innovative Nuclear Research FOA (DE-FOA-0000998) and the General Scientific Infrastructure Support FOA (DE-FOA-0000814).

In total, INL won $\$ 4.45 \mathrm{M}$ in 17 awards.

- Lead Awards:

- NEET-CTD: \$1,000,000 from one award to develop, fabricate, and demonstrate the performance of enhanced Micro-Pocket Fission Detectors suitable for use as real-time reactor core neutron flux and temperature monitors in high-temperature advanced reactors.

- Fifty-four applications were submitted (seven by INL) resulting in 12 awards. Total FY 2014 funds available were $\sim \$ 11.5 \mathrm{M}$. In FY 2013, INL won one award for $\$ 1 \mathrm{M}$ in a field of 39 applications (two from INL). Total FY 2013 funds available were $\sim \$ 9 \mathrm{M}$.

- $\quad$ NEET-CTD Infrastructure: \$1,228,693 from two awards. The first award is to purchase a 3-dimensional computed tomography system to perform high-resolution non-destructive imaging of unique sensors. The second award will upgrade the Materials and Characterization Suite by purchasing a Fischione 1040 NanoMill to improve the quality of sample preparation and a system to provide phase mapping capabilities on an existing Transmission Electron Microscope (TEM).

- Seven applications were submitted (two from INL) with INL winning both possible awards. Competitive infrastructure awards for national laboratories are a new area of support for DOE-NE.

- Collaborations:

- NEUP Collaborations: \$1,497,500 from 12 awards made to U.S. universities. Of significance in these awards is an award to INL of $\$ 599,000$ as a collaborator on the University of Wisconsin Integrated Research Project "Advanced Instrumentation for Transient Reactor Testing."

- NEET-CTD Collaborations: \$725,000 from two awards

- As a composite, INL was awarded $\$ 2.2 \mathrm{M}$ as collaborators with universities and other national laboratories for R\&D. This is an increase from FY 2013 of 1.5 fold.

- INL partnered with Boise State University (BSU) to receive the NEET-CTD award (\$980K) to develop high-efficiency and reliable thermoelectric generators (TEGs) for self-powered sensors utilizing thermal energy from nuclear reactors or fuel cycles. The project will identify suitable hot surfaces for TEG implementation, develop a robust TEG prototype with shielded package, and study the radiation effect on TEG properties and performances.

- The NUC and INL, either individually or collaboratively as lead or partner, were successful in 15 awards totaling just over $\$ 20 \mathrm{M}$ of the $\$ 68 \mathrm{M}$.

- Through the FY 2014 NUC effort, INL has co-supported 33 postdoctoral and master's students, culminating in seven Theses/Dissertations, 28 conference talks, eight proceedings papers, 16 peer-reviewed publications, and one patent application; submitted two grant proposals; provided input into 10 reports; and one invited talk. An additional 22 papers are in process or submission. 
- CAES Computer Assisted Visualization Environment (CAVE) hosted over 100 visitors in FY 2014, including numerous government and congressional leaders, EPRI, Singapore Energy Market Authority, IAEA, and others.

- Meimie Li (ANL) received a Presidential Early Career Award for Scientists and Engineers for her contributions to the understanding of nuclear materials. Her research, enabled through the ATR NSUF, studied Characterization of Irradiation-Induced Defects and Precipitation in Austenitic Stainless Steels and Synchrotron X-ray Diffraction Study of Microstructural Evolution in Irradiated Mod.9Cr-1Mo Steel, and seeks to understand the behavior of materials in reactor environments and develop high-performance materials that can be used in a wide range of nuclear energy systems.

- Multiple power grid, wireless tests, and explosives tests were completed in collaboration with government and industry participants on INL's full-scale testing infrastructure. These tests advanced the deployment of relevant science- and engineering-based phenomena related to GMD interactions with the national power grid, radiofrequency jamming with communications technologies that are protecting warfighters from improvised explosive devices, and materials properties leading to enhanced ballistic protection for physical security systems.

- INL expanded its research partnership with TerraPower with a research portfolio that has grown beyond fuel development to include deployment of control room technologies, seismic risk analysis, safety analyses support, biofuels processing, and assessment of hybrid energy systems.

\section{Achievements Summary - Establish and Maintain Partnerships and Relationships with Scientific Communities}

Establish and maintain long-term partnerships/relationships that maintain appropriate relations with the scientific and local communities: FY 2014, INL exceeded expectations in establishing and maintaining long-term partnerships that maintain appropriate relations with the scientific and local communities. INL has continued to deliver technical expertise to scientific and local communities that heighten industry knowledge in nuclear energy, critical infrastructure, and energy security. The following are examples of achievements that meet this objective:

- INL provided assistance, leadership, and panelists for the Intermountain Energy Summit. Several public acknowledgements of appreciation were offered recognizing INL's role: (1) Idaho Falls Mayor Rebecca Casper, Jerry Brady and Roger Plothow of the Post Register publically stated their great appreciation to INL for their hard work behind the scenes in assisting with logistics, providing panelists and program organization to ensure a successful summit, (2) the Post Register credited INL in numerous stories, (3) Partners of Science and Technology, City Club of Idaho Falls, Grow Idaho Falls, and Bannock County Economic Development provided positive feedback to INL, (4) U.S. Senator Mike Crapo (Idaho) also reiterated the importance of continued discussions at the regional level on our nation's energy needs and significant contributions from INL.

- INL's Technology Deployment Director, acting in the role of Technology Transfer Working Group Chair, assisted DOE Senior Advisor Ellen Williams in reviewing and distributing two separate DOE data collection requests for use by Secretary of Energy Moniz in responding to a Congressional request for an Advisory Report on the status of DOE technology transfer. The first data request focused on technology transfer data and the second focused on user facilities and shared R\&D facilities. From that effort and process, a draft advisory report on technology transfer from 2009 to 2013 was prepared and is currently going through final internal review at DOE. Also emerging 
from this exercise is a template for future technology transfer data reporting that significantly expands the vision of how DOE measures the impact of technology transfer on the U.S. economy. In parallel, the Secretary of Energy's advisory board recently appointed a task force led by former Advanced Research Projects Agency-Energy Director, Arun Majumbar, to evaluate technology transfer and ways the Laboratory can increase its industry impact. The Technology Transfer director and INL's Laboratory Director have participated in an initial interview with the task force.

- Karim Ahmed, a collaborator from Purdue University, received the Best Poster Award for his Energy Frontier Research Center (EFRC)-supported work on phase field modeling of grain growth in porous $\mathrm{UO}_{2}$ at the Third International Symposium on Phase-Field Method 2014-PFM 2014. The symposium, held at Penn State University, is an internationally recognized venue for phase-field modeling of microstructure evolution providing technical peer-reviews, evaluating current status, and identifying future direction of the phase-field method.

- Todd Allen presented to the National Rural Electric Cooperative Association, which is the national service organization for more than 900 not-for-profit rural electric cooperatives and public power districts providing retail electric service to more than 42 million consumers in 47 states, sharing an obligation to serve its members by providing safe, reliable, and affordable electric service.

- Dave Petti and Joy Rempe were invited to participate on a committee to assist Massachusetts Institute of Technology (MIT) to consider the future of the MIT research reactor (MITR). The committee is tasked with providing recommendations on how the Nuclear Reactor Laboratory, either in its present form or in a modified or entirely new configuration, could contribute most effectively with the Department of Nuclear Science and Engineering to develop a vision for future MIT leadership in nuclear technology R\&D and education.

- Joy L. Rempe, Laboratory Fellow and Group Leader for Instrumentation Development Irradiation Testing, has been invited by Dr. Frank Carre, Scientific Director of the CEA/DEN, to serve as an international expert in the annual Scientific Committee review meeting for their division in Saclay, France. The nearly 20 international experts invited to this meeting will review and provide recommendations on current CEA/DEN R\&D programs on Severe Accidents for LWR and fast neutron reactors.

- The Space and Defense Power Systems Technical Integration Office Director (INL's Stephen Johnson) will serve as a co-chair on a sub-team of a NASA-chartered technical review panel for Nuclear Power Assessment Study (NPAS), which is looking at various options and their respective operational considerations from radioisotope power systems to small reactors for space missions.

- INL Fellow, Steve Herring, was chosen by DOE to serve on a team for the NPAS panel to add some realism and technical expertise in reactor fuels development.

- Joy L. Rempe was reappointed to a second 4-year term on the U.S. NRC's ACRS. The ACRS serves many roles, including: (1) reviewing and reporting on safety studies and reactor facility license and license renewal applications, (2) advising the Commission on the hazards of proposed and existing production and utilization facilities and the adequacy of proposed safety standards, (3) initiating reviews of specific generic matters or nuclear facility safety-related items, and (4) providing advice in the areas of health physics and radiation protection. 
- Joy L. Rempe was appointed by Department of Energy Secretary Ernest Moniz to a 3-year term on the NEAC. NEAC reviews and provides advice and recommendations on the long-range plans, priorities, and strategies to effectively address scientific and engineering aspects of DOE's research and development efforts. In addition, the committee provides advice on national policy and scientific aspects of nuclear energy research issues as requested by the Secretary of Energy or the Assistant Secretary for Nuclear Energy.

- Jon Christophersen's 2009 article was among the top five most-cited articles for the Transactions of the Institute of Measurement and Control publication. The paper

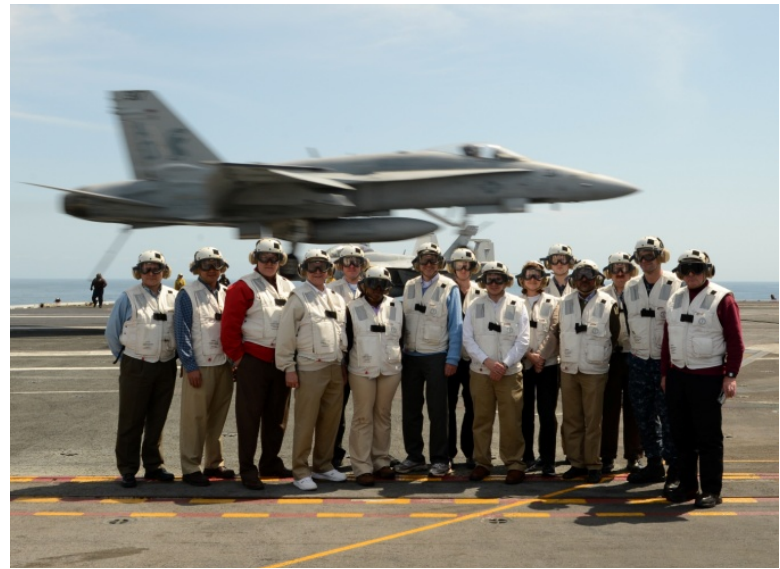

ACRS members during a George H. W. Bush Aircraft Carrier tour. summarized development of some battery health prognostic tools based on standard electrical impedance spectroscopy measurements under no-load conditions.

- John Smart spoke to Secretary Moniz and U. S. Congressman Mike Simpson (Idaho) regarding INL's EV and charging infrastructure data collection. John's remarks focused on how INL is working with several automakers to analyze the potential of two different vehicle technologies (PHEVs versus battery EV) to allow customers to drive on electric power. The automakers want an independent analysis of real-world data to present to the California Air Resources Board (CARB) as part of their request that CARB change how they calculate zero-emission vehicle credits.

- Energy Storage and Transportation Systems staff member John Smart published an analysis of results on workplace electric vehicle charging practices at the Facebook, Inc., corporate office in Menlo Park, California, which examined the usage of EVSE from May 1, 2013, to August 15, 2013, at the Menlo worksite.

- John Smart presented at an invitation-only meeting of the CARB in Sacramento, California. John presented on multi-function public parking/charging facilities along travel corridors, which focused on away-from-home charging, primarily public charging infrastructure, and the role in increasing PEV adoption and electric vehicle miles traveled. This information will directly assist CARB in validating model assumptions used in their Statewide PEV Infrastructure Plan.

- The 9th U.S./China Electric Vehicle and Battery Technology workshop at the University of Washington, Seattle, Washington, invited INL's Jim Francfort to present "Infrastructure Plug-in Electric Vehicle Data Collection in the U.S." The presentation entitled "Light-Duty Plug-in Electric Vehicle \& Charging Infrastructure Data Collection in the U.S.," was prepared by staff members Barney Carlson, Matt Shirk, and John Smart (INL/CON-14-32829) and offered an overview of INL's 
work to support DOE's goal of petroleum reduction and energy security by performing cost-effective testing and demonstrations of advanced technology vehicles and fueling infrastructure.

- Jim Francfort and Mindy Kirkpatrick presented, "Level 2 EVSE and DC Fast Charger Use by Plug-in Electric Vehicles," at the National Governors Association Workshop on Advanced Technology Vehicles. The overview shared results on electric vehicle and charging infrastructure use profiles. Jim Francfort and Mindy Kirkpatrick also presented at the Electric Drive Transportation Association (EDTA) conference. EDTA is an industry forum for technology advances and electric vehicle consumer adoption.

- Jim Francfort recently co-authored, "AVTA Federal Fleet PEV Readiness Data Logging and Characterization Study for the United States Forest Service: Caribou-Targhee National Forest" (INL/EXT-14-32202), which identified daily operational characteristics of select vehicles and reported findings on vehicle and mission characterizations to support the successful introduction of PEVs into the agencies' fleets.

- As part of the National Laboratories Subsurface Big Idea team, Earl Mattson and Hai Huang contributed five white papers to the DOE SubTER tech team, which were presented at the DOE "Big Ideas" Deputy Assistant Secretary (DAS-1) meeting in mid-May. These white papers are helping DOE define the FY 2016 budget scope.

- 248th ACS National Meeting. Special session-Reclaiming Precious and Rare Earth MetalsDavid Reed was an invited speaker. His presentation was entitled, "From Urban Mining to Recycling-Microbial mediated recovery of recycled REE" (http://www.acs.org/content/acs/en/meetings/fall-2014.html).

- Eric Peterson was invited to testify in front of the U.S. House of Representatives Natural Resources Committee's Subcommittee on Energy and Mineral Resources regarding Efficient Use of Critical Materials, which includes recovery, reuse, remanufacturing, and recycling. Eric Peterson spoke on behalf of the Critical Materials Institute, an Energy Innovation Hub.

- Bob Anderson, Rob Hoffman, and Brent Stacey are invited members of IAEA working groups to develop and disseminate recommendations for cybersecurity through nuclear series guidance documents and develop the agenda and speakers for IAEA's first International Conference on Nuclear Security in a Computer World: "Prevention, Detection and Response."

- INL's ICIS continues to demonstrate international leadership in the resiliency of industrial control systems R\&D by successfully hosting "Resilience Week." Held during August 2014, this symposium was sponsored by INL, IEEE, and other partners with academic, industry, and professional organizations. Dedicated to promising research in resilient systems that will protect cyber-physical infrastructure from unexpected and malicious threats, this symposium, chaired by INL's Dr. Craig Rieger, included over 160 attendees from multiple universities, national laboratories, federal organizations and industry. Plenary keynote speakers included Dr. Kevin Moore, dean of the College of Engineering and Computational Sciences at Colorado School of Mines, Samara Moore, senior policy advisor for the Under Secretary for Science and Energy within the DOE, and Rosemary Wenchel, deputy assistant secretary for cybersecurity coordination in the DHS's National Protection and Program Directorate. 


\section{Achievements Summary - Broadly Deploy Laboratory Capabilities through Intellectual Property, and Technologies}

Broadly deploy Laboratory capabilities, intellectual property, and technologies to support and impact industry and other key non-DOE customer needs through Cooperative Research and Development Agreements (CRADA), Work for Others (WFO) Agreements, Agreements for Commercializing Technology (ACT), user facility access, technology-based economic development, and Intellectual Property (IP) management and licensing. As noted by INL's significant accomplishments with RAVEN, MOOSE, RELAP5-3D, and Sophia, as well as other FY 2014 licenses, we are exceeding expectations to deploy technology. Selected significant achievements are highlighted in the following:

- DOE-Chicago (CH) approved INL's decision to assert copyright (CW-14-01) on its RAVEN software for a period of 10 years. The MOOSE application is a complex software tool that will improve RISMC by providing the following functionalities: simulating plant control systems, simulating operator actions, performing Monte Carlo sampling of randomly distributed events, and performing event-based analysis. RAVEN has been licensed to ISU (Lic. No. 14-LA-27) and University of Rome (Lic. No. 14-LA-30).

- The MOOSE software is designed as a framework for the development of complex multi-dimensional engineering analysis applications using the finite element method. In FY 2014, BEA obtained all necessary approvals to release MOOSE with an open-source license. Scientists and engineers all over the globe can now easily access

MOOSE by visiting mooseframework.com. By open-sourcing MOOSE, INL aims to have a broader impact across a diverse set of engineering fields. The MOOSE team also hosted quarterly workshops focusing on new users of the software, detailing how to utilize MOOSE to create multiphysics simulation tools. In addition, MOOSE licenses were signed with LANL, LLNL, ANATECH, Technical Research Centre of Finland,

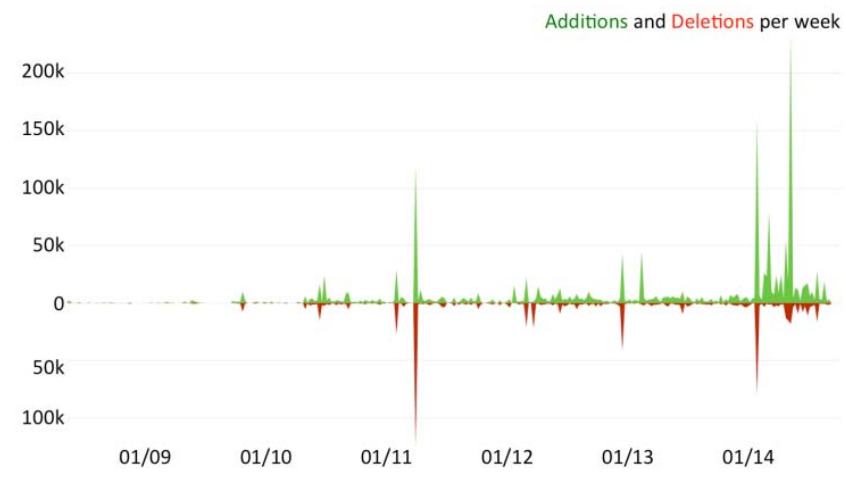
University of California Berkley, and BSU. In FY 2014, the MOOSE application had seven new license agreements. Since March 2014, there have been greater than 3,600 unique, non-INL visitors to the mooseframework.org website. Additionally, over 48 new MOOSE-based applications have been created since March.

- INL received permission from DOE-CH to assert copyright (CW-14-03), for a period of 10 years, on its software PIKA. PIKA is a MOOSE-based application for modeling micro-structure evolution of seasonal snow by implementing three equations: the phase-field equation for tracking the evolution of the ice-air interface within seasonal snow at the grain-scale; the heat equation for computing the temperature of both ice and air within the snow; and the mass transport equation for monitoring diffusion of water vapor in the pore space of snow. 
- $\quad$ RELAP5 3-D was also deployed through a number of licenses in FY 2014. Licenses were signed with the University of Maryland, U.S. Military Academy, Penn State University, Studiecentrum Voor Kernenergie Centre D'Etude De L'Energie Nucleaire (SCKCEN), Belgium, NuScale Power, LLC, the NRC, University of Florida, Nuclear Safety Associates, Inc., Nuclear Regulation

Authority, Japan, Warsaw University of Technology, Poland, Arizona Public Service, and University of New Mexico. BEA continues to support this growing number of licensees through the "International RELAP Users Group" (IRUG), which currently has a total of 78 member institutions with RELAP5-3D licenses. The annual IRUG meeting was held in Idaho Falls, Idaho, and was preceded by 3 days of advanced RELAP53D training. Over 30 members participated in the training which helps to educate the next generation of users.

- RELAP5-3D continues to impact nuclear industry as GSE Systems, Inc., a supplier of simulators to the nuclear industry incorporates RELAP5-3D into their simulators. Current simulators are in use at Bruce Power L.P., Ontario, Canada, Indiana Michigan Power Co., Bridgman, Michigan, Krafgtwerks-Simulator-Geselllschaft, mbH, Germany, South Ukraine Nuclear Power Plant, Ukraine, Japan Atomic Energy Agency, Japan, Harbin Engineering University, China, and China Nuclear Power Design Co. Ltd., China.

- In support of the Transportation Security Administration (TSA), INL has issued the TSA Aviation Security System Evaluation Tool (ASSET) Suite 3.0 and accompanying comprehensive User Guide. This third-generation computer-based tool provides a major upgrade to TSA's abilities to evaluate and prepare for threats at airports, thus increasing the security of millions of passengers who fly every day in the U.S. ASSET is now used in multiple organizations (airports) within TSA and is used to evaluate every potential change to the TSA airport screening operations including aiding airport security operations at the "plan of the day" level. The Checked Baggage application is in testing now.

- Utilizing the proprietary Generalized Environment for Modeling Systems $\mathbb{C}$ (GEMS), INL was selected as a solution provider of choice by the Office of Management and Budget's (OMB) MAX.gov Internet-enabled government online collaboration, data collection, and data analysis team. This resulted in an integrated OMB/INL offering called "MAX-GEMS." The first result of this collaboration is a project for the Department of Navy's Bureau of Medicine and Surgery (BUMED) to design, implement, and host an optimized interface to the Defense Occupational and Environmental Health Readiness System (DOEHRS). This is the first of numerous projects of this type expected for INL.

INL is investing in science and technology innovations, resulting in patents and software copyrights, to deploy national security technologies through licensing of intellectual property into the commercial sector. The following examples of these efforts demonstrate INL's success in achieving DOE mission objectives in enhancing U.S. security and economic growth through transformative technology innovations:

- INL's PINS systems, commercially available from AMETEK, Inc., through an INL license agreement, continue to have national impact in providing the U.S. Government with capabilities to remove hazardous materials from public and private locations. Additionally, this product's market and its resulting impact have now extended internationally to U.S. Allies in South Korea and Italy, whose governments have purchased PINS-3 systems from AMETEK. INL continues to provide assistance to the licensee through delivering R\&D innovations included in this new product version, and by providing PINS training for the product's users. 
- In achieving DOE objectives for both infrastructure protection and economic development through deployment of technical innovations, INL provided Sophia Licensee, NexDefense, Inc., with TAP support to accelerate the commercialization of Sophia. Due to this assistance, Sophia, an industrial control system cybersecurity assessment tool, is scheduled for a Fall 2014, commercial software release. In further expanding the deployment of Sophia to protect the nation's critical infrastructure, INL also has developed a government use license for DHS ICS-CERT to allow the use of INL's Sophia software during onsite cybersecurity assessments of government and private facilities, and has also provided an additional 12 licenses to other U.S. government entities.

- INL is investing royalty funds to accelerate the development for deployment of additional national security technologies. These royalty fund investments include: developing prototype gas standard vessels that can be used for both gamma detection and shipping to improve the quality of xenon gas measurement reference standards; completing initial research trials on a wireless communications encryption technology that will improve security of communications within a spectrum sharing environment; and producing test samples of spark plasma sintered ceramics for ballistic protection. Each of these projects has either an industry or university collaborator.

- INL investments in patent applications have resulted in recent patent awards that secure the intellectual property licensed to a local small business, RFinity, which was formed by two former INL employees (Steve McCown and Aaron Turner). These patents include U.S. 8,737,965, "Wireless Device Monitoring Systems and Monitoring Devices, and Associated Methods," and U.S. 8,831,220, "Processing Module Operating Methods, Processing Modules, and Communications Systems."

- INL, with DOE and BEA Board of Directors' approval, invested in the successful legal defense of INL's intellectual property through a Federal District Court filing. The resulting court approved a litigation settlement agreement that stopped the open source development of a software product that infringed upon the copyright and patent pending claims for INL's Sophia industrial control system cybersecurity assessment tool. Reaching this agreement will enable the licensee, NexDefense, Inc., to move forward with their Sophia commercialization plan.

As a multi-program laboratory with world-class clean energy capabilities, INL is advancing the clean energy integration design and critical materials R\&D, and delivering environmentally friendly technology alternatives. INL continues to deploy technologies that deliver energy solutions, for example:

- A collaboration between INL and the start-up company Porifera won support from NETL's "Novel Crosscutting Research and Development to Support Advanced Energy Systems" Funding Opportunity Announcement. The project will help develop an INL patent-pending wastewater treatment process to utilize waste heat and $\mathrm{CO}_{2}$ for water treatment at power plants (http://go.usa.gov/WExG).

- The SPS-FO technology was also selected for the 2013 Early Stage Technology Award from the FLC FW.

- As a further example of the impact and reach of the SPS-FO technology, Mark Philbrick, DOE Executive Branch Fellow and technology coordinator of the DOE's Water-Energy Technology Team (WETT), is featuring the technology in his talk at the 2014 Water Environment Federation Annual Technical Exhibition and Conference, the largest annual water quality event in the world.

- Motor Coach Industries (MCI) and INL recently installed in the CAES building an enhanced simulator. MCI working under a CRADA with INL Facilities and Site Services, CAES researchers, and human factor R\&D personnel are enabling human factors testing in a controlled laboratory 
environment. The simulator includes a front chassis, a steering wheel, brakes, and gas pedal that respond like a real 50,000-pound vehicle driving at $65 \mathrm{mph}$. Continuing research using the simulator will provide data to develop models for safe and fuel-efficient driving behaviors under various conditions.

- INL established five new NDAs with Cohen Ventures, Inc.: DBA Energy Solutions, Farasis Energy, Inc., Envia Systems, Pennsylvania State University, and University of Maryland, which are focused on generating and/or sharing information needed to improve battery performance to accelerate the development and deployment of electric vehicles and advanced transportation systems.

- Chester LNG, LLC, a subsidiary of Chester Engineers, has executed two license agreements with BEA and has been granted non-exclusive rights to the suites of intellectual property developed at INL related to the natural gas liquefaction process and the L-CNG refueling process. Chester plans to design, engineer, fabricate, deploy, and service natural gas liquefaction plants and L-CNG refueling plants based on the license patents in the U.S. as well as global markets.

- A leading commercial provider of environmental laboratory testing services has been granted exclusive rights to a soil sampling technology developed at INL to detect and quantify environmental asbestos contamination. The technology has been evaluated by the Environmental Protection Agency and is considered to have strong potential for complementing and/or displacing other well-known methods for asbestos detection. The licensee plans to provide sample preparation services for both domestic and foreign customers making use of the INL-developed technology.

- INL's Technology Based Economic Development (TBED) program is designed to build, connect, and inspire economic activity with researchers, industry, academia, and the economic development community.

- $\quad$ In FY 2014 TBED served on eight economic development boards across the state representing INL in the community.

- INL's Technical Assistance Program (TAP) worked to assist job creation and enhance the entrepreneurial climate for emerging companies. During the past 10 years, INL has provided more than 8,556 hours of technical work. This year INL delivered nine technical assistance projects with more than 216 hours of assistance.

- INL's TBED grants program provided unallowable funding to 16 projects to spur economic development, technology-based economic development, entrepreneurship, and innovation throughout the state. 


\section{Efficient and Effective Stewardship and Operation of Research Facilities}

\section{4: Utilization of Facility(ies) to Provide Impactful S\&T Results and Benefits to Internal and External User Communities}

\section{Achievements Summary - Utilization of Facilities}

As noted in the INL's Laboratory Plan, facilities are one of three critical capabilities needed for the laboratory to achieve its goals. INL facilities are home to nationally unique capabilities to conduct relevant and impactful scientific RDD\&D of solutions that enable the success of INL's missions. Our facilities are used for experimentation that delivers transformational results for excellence in program performance, advance the viability of our investments in future capabilities needed to achieve DOE's long-term strategic objectives, and enable collaborative access for external user communities to advance knowledge through science and enhance national economic competiveness through accelerating deployment of technologies.

In FY 2014, INL is showing efficient and effective stewardship of its research facilities in four important ways: (1) performing research that significantly advances the strategic objectives in the NE Roadmap for the future of nuclear energy, (2) engaging with industry and universities through National User Facilities to provide unique capabilities to internal and external user communities, (3) securing the country by achieving our critical infrastructure protection and nonproliferation missions through innovative use of facilities and equipment, (4) providing a test bed and research center for clean energy technologies such as electric vehicle batteries, geothermal, wind, biofuels, and strategic materials. In FY 2014, INL played a major role in National Laboratory Day, joining with directors and representatives from the other $16 \mathrm{DOE}$ national laboratories to showcase demonstration projects across five theme areas: energy innovation and environmental sustainability, manufacturing innovations, high-performance computing, national security, and discovery science. U. S. Senator James Risch (Idaho) provided a comment supporting INL's role in developing new breakthrough technologies and discoveries to address some of the nation's most pressing challenges.

"From coast to coast, the Department of Energy's national laboratories contribute groundbreaking scientific research in a number of disciplines, including energy innovation, national security and basic research," said U.S. Senator James Risch (Idaho). "In order to conduct this research, our national labs are equipped with unique assets - be it their location, one-of-a-kind instruments and, most importantly, the world's leading scientists. My home state is fortunate to have the Idaho National Laboratory located in Idaho Falls, the nation's lead nuclear laboratory and a world leader in securing the ever-growing cyber network." 


\section{ATR Irradiations Delivered Outcomes for INL Programs}

As it has for many years, INL's ATR is anchoring much of the laboratory's FY 2014 nuclear energy research. ATR is a unique, cutting-edge resource that is important to the future of nuclear energy in the United States. In FY 2014, ATR irradiated 26 different experiments sponsored by five separate program areas (Naval Reactors, NEET-NSUF, Reactor Concept RD\&D - Advanced Reactor Technology, Fuel Cycle R\&D - Advanced Fuels, and WFO).

Ten of these experiments support the NR's program of Powered Axial Locator Mechanism (PALM) high-power testing, material corrosion testing, and evaluating fuel designs for fleet reactor retrofit.

Eight of the experiments supported the ATR NSUF program. Of these eight, two demonstrated BEA's collaboration with EPRI and one demonstrated BEA's collaboration with NRC. The EPRI experiments EPRI-3 (first cycle completed) and EPRI-ZG-B involve irradiation of specimens consisting of alloys X-750, XM-19, and Zircaloy for EPRI. As a companion experiment to EPRI-3, 304 Stainless Steel specimens were irradiated for the NRC. The objectives of the EPRI-3 experiment and for the NRC experiment are to obtain quantitative data on crack growth rates and fracture toughness of the irradiated alloys, to provide irradiated material for micro-structure examinations, and to provide irradiated material for subsequent detailed investigation of crack growth mechanisms. The EPRI-ZG-B irradiation experiment is a CRADA between Battelle Energy Alliance (BEA) and EPRI to obtain data on the anomalous growth of zirconium alloys under certain reactor operating conditions. The experiment will provide data on a postulated hydrogen-assisted irradiation growth rate mechanism that may be operative in zirconium alloys and is associated with Boiling Water Reactor (BWR) channel bowing. Pre- and post-irradiation dimensional measurements will be used to provide information on zirconium growth rates. Post-irradiation TEM analysis will provide data on the irradiation growth mechanism.

The other three ATR NSUF experiments included the following collaborations:

- The Measurement of Actinides Neutron Transmutation Rates (MANTRA)-2 experiment, which is a collaboration with ISU and ANL, is designed to measure neutron absorption cross sections for advancing the assessment of advanced fuel cycle design requirements by increasing the accuracy of neutron absorption cross-section data.

- The University of California Santa Barbara (UCSB-2) experiment focuses on determining the effects of small alloy compositional changes on post-irradiation micro-structures and mechanical properties. The irradiation test matrix includes steels that also have been irradiated in other programs that are already in the various databases. The experiment irradiated approximately 1,500 specimens, which will be subjected to a wide range of post-irradiation studies. All of these specimens have very similar compositions. The experiment used a variety of special pre-machined and/or pre-cracked specimen geometries to minimize irradiated sample preparation for characterization techniques, such as atom probe and electron microscopy.

- Powered by Our People Campaign, a NEI's online publication (August 2014), featured Peter Wells (Ph.D. candidate at the UCSB) who is conducting research at INL through the ATR NSUF. His project relates to safely extending nuclear plant operating licenses to 80 years. Wells' profile is the second from INL to be featured, and is highlighted on several of NEI's public and social media platforms. 
- The University of Central Florida (UCF-1) experiment, which was irradiated using the ATR's unique Hydraulic Shuttle Irradiation System (HSIS), is designed to examine the changes in metallic fuels from low fluence including defect formation, fission product formation, fission product nucleation, constituent redistribution, and micro-structural degradation. Little or no data exists for low fluences of metallic fuels. However, it is known that the changes that lead to fuel degradation start at low burnup (e.g., $<0.9 \%$ ). Initial changes in the micro-structure of the fuel and fuel/cladding assemblies will provide critical information that will have a significant effect on long-term behavior of metallic fuels. The objective of this experiment is to provide data on the $\mathrm{U}-\mathrm{Zr}$ and $\mathrm{U}-\mathrm{Mo}$ behavior at two fluences ( 0.01 and 0.1 displacements per atom [dpa]) and seven temperatures (ranging from $150^{\circ} \mathrm{C}$ to $800^{\circ} \mathrm{C}$ ). This will be accomplished by varying exposure times using the unique capabilities of ATR's HSIS system. Detailed scientific findings from this study will provide thermo-kinetic parameters that are critical and required for predictive modeling capability for AFCI and Reduced Enrichment for Research and Test Reactors (RERTR) programs.

Two of the ATR experiments support the NGNP program. One is the AGC-3 experiment and is the third in a series of six experiments to irradiate graphite materials that will be used in the NGNP design. The experiment purpose is to determine irradiation creep when under a compressive load and is in support of qualifying new graphite for design and licensing. The second experiment is the AGR-3/4 experiment, which supports the development of the Very-High-Temperature Gas Cooled Reactor. The goals of this series of experiments are to provide irradiation performance data to support fuel process development, qualify fuel for normal operating conditions, support development and validation of fuel performance and fission product transport models and codes, and provide irradiated fuel and materials for post-irradiation examination (PIE) and safety testing. AGR-3/4 combines the third and fourth in this series of planned experiments to test tristructural-isotropic (TRISO)-coated, low-enriched UCO fuel. This combined experiment is intended to support the refinement of fission product transport models, and to assess the effects of sweep gas impurities on fuel performance and fission product transport.

The six remaining ATR experiments support the AFCI and WFO programs. The AFCI experiment (AFC-3C, AFC-3D, AFC-4A) and WFO experiment (AFC-4B) are part of new innovative fuel and cladding designs. Performance data from the AFC experiments will include irradiation growth and swelling, helium production, helium and fission gas release fractions, fission product and fuel constituent migration, fuel phase equilibria, and fuel-cladding chemical interaction. ATF-1 G/O and ATF-1 A/W experiments are part of DOE's response to the Fukushima events of 2011. DOE's emphasis shifted to accident performance of the fuels under extended loss of active cooling and steam exposure. Enhancing the accident tolerance of the fuel is the focal point of the initiative. Fuels with enhanced accident tolerance are those that, in comparison with the standard zircaloy - $\mathrm{UO}_{2}$ system currently used by the light water reactor (LWR) industry, can tolerate loss of active cooling in the core for a considerably longer time period while maintaining or improving the fuel performance during normal operations, operational transients, and design-basis events.

ATR's successful contribution to these five programs was accomplished through the integrated process of bringing in new experiments, some containing fissile material, facilitating irradiation in the reactor core, resizing the experiments in the ATR Canal or Dry Transfer Cubicle (DTC) when needed, and eventually shipping the experiments using a shielded cask for post-irradiation examination without experiencing a single skin or clothing contamination event. 


\section{Materials and Fuels Complex Delivered Impactful Results}

The employees' technical knowledge and multiple unique capabilities at INL facilities are being used to enhance our reputation as a global leader in nuclear research and development. The following subsections are a few technical highlights.

\section{IASCC Testing Capability Implementation at INL}

With completion of verification and validation exercises, as well as management assessment early in FY 2014, the newly built IASCC test rigs were fully qualified to begin testing irradiated reactor internal materials in support of sustainability of LWR fleet. The test rigs are a unique capability in the world that allow INL to remain on the forefront of materials research by providing a means to characterize the crack growth and fracture toughness characteristics of very highly irradiated structural materials at size scales relevant to realistic reactor internal structures. While two or three other facilities in the world can provide related capability, none can match the shielding characteristics or force application capacity provided by the new INL IASCC test rigs. Additionally, the proximity to the ATR and mission to support the ATR NSUF combine to provide an unprecedented domestic research capability.

Following completion of verification and validation exercises, the very first specimens irradiated using the Loop 2A facility recently installed in the ATR Center Flux Trap, were received in the IASCC test rigs in early April 2014 after being processed in the HFEF. The first IASCC test was successfully initiated during the week of April 21, 2014, on an Inconel alloy X-750 that had been irradiated to a fluence of $1.93 \times 10^{20} \mathrm{n} / \mathrm{cm}^{2}$ (damage level $\sim 0.28 \mathrm{dpa}$ ) in the ATR Center Flux Trap. This test is part of a CRADA between INL and the EPRI to measure IASCC in a BWR repair component that had been subjected to specific neutron fluence. This first IASCC test was successfully completed in late September 2014. Technical highlights for FY 2014 include:

- Completed verification and validation of newly installed IASCC test rigs

- Completed management self-assessment of newly installed IASCC test rigs

- Received the first ATR Center Flux Trap irradiated specimens in the IASCC test rigs

- Initiated the first IASCC test in the IASCC test rigs

- Completed the first IASCC test in the IASCC test rig while producing industry accepted data.

\section{Measurement of Swelling in Irradiated Zircaloy}

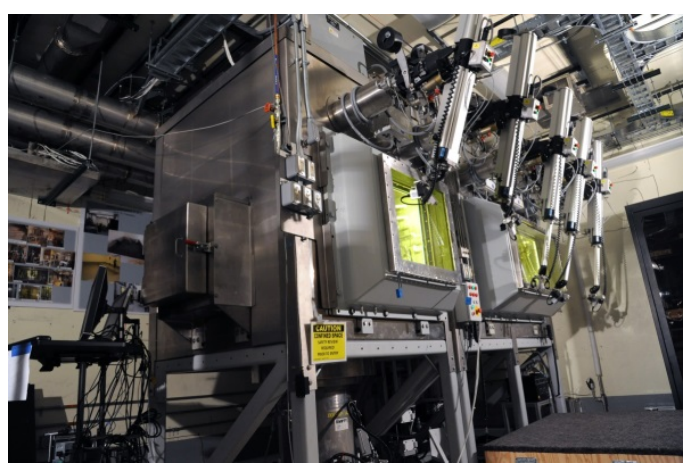

Newly constructed irradiation assisted stress corrosion cracking test rigs.

During FY 2014, strain calculations were completed on the first of four irradiation capsules that are the subject of a CRADA between INL and the EPRI to measure the combined effect of neutron damage and hydrogen content in several zircaloy variants including traditional alloys such as Zry-2 and Zry-4, as well as four experimental, proprietary alloys. Irradiation of a second test capsule to a target neutron damage of 12.3 dpa was completed in early FY 2014 and represented an approximately $20 \%$ higher than original target damage level $(10 \mathrm{dpa})$ that was requested by the customer (EPRI). Flexibility within the ATR schedule and re-prioritization by ATR NSUF staff allowed this stretch goal to be achieved. Ensuing 
measurements of the second capsule in August 2014 allowed a comparison of swelling at two levels of neutron damage: approximately $7 \mathrm{dpa}$ and approximately $12 \mathrm{dpa}$. This data represents expected near end-of-life for BWR fuel channels and allows EPRI and its partners to make critical decisions regarding replacement and alloy selection for BWR fuel channel materials going forward. The project continues with an additional two capsules to be irradiated to damage levels of 20 and 30 dpa in upcoming years.

In addition to strain measurements completed for the two irradiation levels, tight temperature control for the irradiation capsules was demonstrated using melt wires and SiC monitors. Developed at ORNL and implemented at INL, the SiC monitors represent a relatively new methodology for measuring temperature in irradiation capsules. The $\mathrm{SiC}$ monitors provide a measure of temperature more reflective of general irradiation conditions and less susceptible to temporary temperature excursions than simple melt wires. The $\mathrm{SiC}$ monitor measurements for Capsule B ( 12.3 dpa) represent the first data point for an irradiation damage level beyond $8 \mathrm{dpa}$. The following are technical R\&D highlights for FY 2014:

- Finalized strain measurements for the first zircaloy irradiation capsule (Capsule A)

- Completed melt wire and $\mathrm{SiC}$ monitor evaluations to confirm temperature profile for Capsule A

- Completed irradiation of second zircaloy irradiation capsule in ATR (Capsule B) to a neutron damage level of $12.3 \mathrm{dpa}$, meeting customer request to exceed original $10 \mathrm{dpa}$ target

- Completed length measurements of all zircaloy specimens in second irradiation capsule (Capsule B)

- Completed melt wire and $\mathrm{SiC}$ monitor evaluations to confirm temperature profile for Capsule B; this is the first successful use of $\mathrm{SiC}$ monitors in an irradiation exceeding $8 \mathrm{dpa}$

- Finalized strain calculations for the second zircaloy irradiation capsule (Capsule B).

\section{Fuels, Materials and Separations R\&D}

An important component in fuel fabrication R\&D is a need for an available wide range of feedstock materials with a variety of actinide isotopic and material compositions. The Fuel Cycle Research Development and High Performance Researcher Reactor programs are continuing to expand the on-hand library of actinide feedstocks in both the metallic and oxide forms while influencing nuclear material R\&D.

INL demonstrated a strong commitment toward resolution of the feedstock supply issues. Currently, there are no Np metal supplies available within the DOE complex. Np does exist in an oxide form but must be converted to metal. Researchers at MFC developed a Neptunium Oxide Reduction process at INL and demonstrated through reducing $\mathrm{Np}$ oxide to produce $15 \mathrm{~g}$ of $\mathrm{Np}$ metal in a laboratory scale with reasonably high purity. Additional work is necessary to improve purity of the material to publicize the results. MFC staff also purified (removal of $\mathrm{Np}, \mathrm{Pb}, \mathrm{O}$ ) several grams of metallic Am. This demonstration supports programmatic objectives of procuring feedstock material highly loaded with americium from the Savannah River Site, which when separated in the FMF TRU Breakout Glovebox, will position INL as a leader in R\&D with research quantities of Am.

- In the paper entitled "Microstructural Characterization of Irradiated U-7Mo/Al-5Si Dispersion to High Fission Density," J. Gan, B. D. Miller, D. D. Keiser, Jr., A. B. Robinson, J. W. Madden, P. G. Medvedev, and D. M. Wachs, results are reported that describe the microstructure of a highly-irradiated nuclear fuel observed using TEM. Typically, TEM analysis of irradiated fuel is very rare due to the difficulty in preparing samples. At INL, these types of samples can be routinely produced for TEM analysis by using a scanning electron microscope with a focused ion beam. The 
data reported in this paper is first-of-its-kind and is critical for understanding the irradiation performance of low-enriched uranium fuels to high-burnup. Specifically, a detailed description at a low-length-scale could be made of the high-burnup microstructure of U-Mo fuel, as a result of the data reported in the paper. This type of information is critical for understanding things such as fuel swelling and fission gas release. This new information will allow for improved understanding of the fuel's performance to support computer modelling, and could possibly lead to future improvements in the fuel's irradiation performance. These fuels are being qualified for use in research and test reactors that currently use HEU fuels, and such efforts are of interest from a non-proliferation perspective.

- Post-irradiation examination of plate fuel specimens from the RERTR-12 experiment provided insight into the failure mechanism for U-Mo fuel at very high burnup. A combination of neutron radiography, gamma scanning, profilometry, irradiated fuel bend testing, and metallography, together with 3-dimensional microscopic imaging of the pore structure using a FIB on similar fuel specimens, provided the data necessary to establish a concrete failure hypothesis. Radiography, 3-dimensional imaging of irradiated fuel microstructures, and mechanical testing of irradiated U-Mo fuel foils are capabilities unique to MFC and key in developing an understanding of the failure mode. This valuable information on failure modes of fuel will be used in the report submitted to NRC for acceptance of the base monolithic U-Mo fuel. This low-enriched fuel design is proposed as a replacement for high-enriched fuel in several U.S. research reactors. RERTR-12 PIE provides valuable information on failure modes of fuel that will be used in the report submitted to NRC for acceptance of the base U-Mo fuel. This LEU enriched fuel design is proposed as a replacement for high-enriched fuel in several U.S. research reactors.

- Sample analyses were completed for the characterization of sectioned fuel plates. The experiments are the first in a series of tests to determine and identify if model predicted high burn-up "edge effects" are real or model phenomena. Analyses included selective dissolution of the uranium, determination of fission products by Inductively Coupled Plasma Mass Spectrometry (ICP-MS) and gamma spectroscopy, and high-precision isotopic measurements of uranium isotope ratios via Multi-Collector ICP-MS.

- RCL researchers completed noteworthy transuranic complexation kinetics. Studies related to transuranic complexation kinetics have not been evaluated since the late 1990s. The potentiometric studies for acid dissociation constants and europium complexation constants provide valuable insight into actinide binding kinetics with aqueous phase complexants.

- Analyses in support of the Fission Product Retention Experiment for Iodine were completed. A method developed in the Analytical Laboratory during FY 2013 was applied to sectioned fission-capture tubing. The results indicated the successful capture of I-129 from the Global Threat Reduction Initiative fuel experiment. The unique experimental design focused not only on the fuel portion of the tests, but the subsequent important detection of the analyses of interest.

- Specimens prepared in HFEF supported an international partnership with Nelson Mandela Metropolitan University in Port Elizabeth, South Africa. The R\&D collaboration provided a detailed examination of TRISO fuel particles to determine the mechanism for silver migration through the $\mathrm{SiC}$ layer. These specimens were examined at MFC and prepared for detailed characterization using atom probe tomography and advanced transmission electron microcopy at CAES. The results suggest a complex transport mechanism for Ag transport associated with grain boundaries and other fission products, but further work is needed before more definitive conclusions can be drawn. 
- Characterization of AFIP-6 MKII was completed and a report was issued. The experiment evaluated a single plate irradiated at high-power density and high-coolant flow rates to intermediate burnup. The purpose was to evaluate mechanical integrity during normal operating conditions, geometric stability of flat plates, and stable and predictable behavior. Results provided confidence that U-Mo monolithic base fuel performance is suitable for a reactor mission envelope extending to high power at moderate burnup, and reactor design requirements for steady state performance can be met by using this fuel. Characterization of the fuel prior to irradiation provided information at the microstructural level that can be used for comparison after irradiation, and is necessary to evaluate the effects of irradiation on the fuel.

- A report on elevated temperature tensile testing was completed. The mechanical testing of unirradiated fuel was used to provide data on the linkages between material chemistry, process parameters, microstructure, and mechanical properties. Stress-strain properties of DU-10Mo foils were completed at $650^{\circ} \mathrm{C}$ for three different foil fabrication conditions. Results provided information on the effects of the fabrication conditions and temperature.

- A report was issued detailing the iodine release and measurement experiments. The U-Mo monolithic fuel system performs differently than current dispersion fuel plates with respect to fission gas migration and plate failure modality, blister formation, and clad breach mechanics, requiring fission product release measurements to support reactor conversions. Measurement of iodine release as a gas from the fuel during irradiation will be used to support NRC licensed reactor conversions.

The mission of the FCRD AFC is to perform RD\&D activities for advanced fuel forms (including cladding) to enhance the performance and safety of the nation's current and future reactors; enhance proliferation resistance of nuclear fuel; effectively utilize nuclear energy resources; and address the longer-term waste management challenges. This includes development of a state-of-the art R\&D infrastructure to support the development of advanced fuel systems using a "goal-oriented science-based approach." Specific scientific achievements in these three areas of R\&D have been accomplished in FY 2014.

A possible nuclear fuel technology that could provide significant improvement to fission gas retention during LWR accident scenarios is the "Fully Ceramic Matrix" (FCM) concept. Two peer-reviewed journal articles have been published in this area in FY 2014 by Blaise Collin. These papers address key issues in the performance of the FCM fuel system. The PARFUME fuel performance code developed by the NGNP program has been used to analyze the performance of the proposed FCM fuel design focusing primarily on the behavior of the $\mathrm{SiC}$ layer.

- Collin, B. P., "Modeling and Analysis of UN TRISO Fuel for LWR Application Using the PARFUME code," Journal of Nuclear Materials, 2013, Vol. 451.

- Besman, T. M., M. K. Ferber, H-T.L. Lin, B. P. Collin, "Fission Product Release and Survivability of UN-Kernel LWR TRISO Fuel," Journal of Nuclear Materials, 2014, Vol. 448. 
The composition of advanced transmutation fuels can be a complex multi-component mixture of fissile elements, inert stabilizing materials, minor actinides, and rare earth species. Under irradiation, the behavior of these elements greatly affects nuclear fuel system performance. It is critical to understand the phase behavior, material properties, and species diffusion in transmutation fuels during fabrication, during irradiation, and following irradiation during recycling and storage of the fuels. Significant accomplishments include:

- A paper authored by D. Janney et al., was accepted for publication in the Journal of Nuclear Materials. Entitled "Am phases in the matrix of a U-Pu-Zr alloy with $\mathrm{Np}, \mathrm{Am}$, and rare-earth elements," the paper presents results of characterization work conducted at INL on the matrix of AFC2-A7 (nominal composition 52U-20Pu-3Am-2Np-8.0RE-15Zr). To our knowledge, this paper contains the first published TEM data on any Am alloy, as well as the first structural and microchemical characterization of individual matrix phases in any U-Pu-Zr alloy. It has been known for a long time that Am was likely to occur in RE inclusions, but this work shows there are also at least two Am-bearing matrix phases.

- Recent studies on the microstructure of high burnup oxide fuels discovered during post-irradiation examination have been published by Melissa Teague. In addition, Teague with Michael Tonks have made significant progress in developing meso-scale materials models representing the evolution of these microstructures over time during irradiation. Drs. Teague and Tonks have successfully demonstrated the integration of this data in high fidelity computer simulations using the MARMOT computer code.

- Published in 2014, "EBSD and TEM Characterization of High Burn-up Mixed Oxide Fuel” written by Melissa Teague, Brian Gorman, Brandon Miller, and Jeffrey King, reports the results of first-of-its-kind microstructural characterization of irradiated fuel using a scanning electron microscope and a focused ion beam, which includes a 3-D reconstruction of the fuel microstructure and unique Electron Backscattered Diffraction data. This information has been incorporated into cutting-edge fuel behavior computer models. According to a recent press release of this work, the effects (of the work) are far-reaching: "Such atomic-scale data ... can help inform the development of nuclear fuel with enhanced safety and performance. The information can reveal how and why certain materials perform better than others. It can also make testing and validation more efficient by cutting down the number of time-consuming irradiation experiments required to qualify a new material." Key publications in this area are:

- $\quad$ Teague, M., B. Gorman, J. King, D. Porter, S. Hayes, "Microstructural Characterization of High Burn-up Mixed Oxide Fast Reactor Fuel," Journal of Nuclear Materials, Vol. 441, 2013, pp. 267-273.

- Teague, M., B. Gorman, B. Miller, J. King, "EBSD and TEM characterization of high burn-up mixed oxide fuel," Journal of Nuclear Materials, Vol. 444, 2013, pp. 475-480.

- Teague, M., M. Tonks, S. Novascone, S. Hayes, "Microstructural modeling of thermal conductivity of high burn-up mixed oxide fuel," Journal of Nuclear Materials, Vol. 444, 2014, pp. 161-169.

- A paper on the "Microstructure changes and thermal conductivity reduction in $\mathrm{UO}_{2}$ following $3.9 \mathrm{MeV} \mathrm{He}_{2}{ }^{+}$ion irradiation" has been published in the Journal of Nuclear Materials. Authored by researchers at UW-Madison, INL (M. Khafizov), UT-Knoxville, LANL, and Purdue, this work was conducted using the thermal conductivity microscope. The irradiation damage contribution to conductivity degradation is not well examined, and some of the irradiation-induced defects anneal out 
by the time post-irradiation measurements can be performed using traditional techniques. The instrument allows for measurement of thermal conductivity changes immediately following ion irradiation to support development of a greater understanding of how thermal conductivity degrades with irradiation. This work was performed as part of the EFRC.

- Development and demonstration of advanced capabilities, such as separate effects testing for modeling and simulation data generation, advanced in-pile instrumentation, characterization, and PIE techniques, are key tenants in the FCRD AFC. INL has achieved significant results and scientific advances in the areas of characterization technique development.

- Melissa Teague has published a peer-reviewed journal article describing the use of a dual-column FIB for characterization of high burnup oxide fuel. Domestically, this characterization capability is exclusively available at INL. The use of this technique will significantly improve the generation of high-resolution characterization of irradiated nuclear fuels and materials. In addition, two additional peer reviewed publications by L. He et al., document the use of advanced microstructural study of fission gas behavior in $\mathrm{UO}_{2}$. Understanding the behavior of fission gas in the nuclear fuel matrix is fundamental to the understanding of the overall fuel performance of the $\mathrm{UO}_{2}$ system.

- Teague, M., B. Gorman, "Utilization of dual-column focused ion beam and scanning electron microscope for three dimensional characterization of high burn-up mixed oxide fuel," Progress in Nuclear Energy, Vol. 72, 2014, pp. 67-71.

- He, L. F, M. Gupta, C. A. Yablinsky, J. Gan, M. A. Kirk, S. M. Bai, J. Pakarinen, T. R. Allen, "In-situ TEM observation of dislocation evolution in $\mathrm{Kr}$-irradiated $\mathrm{UO}_{2}$ single crystal," Journal of Nuclear Materials, Vol. 443, November 2014, p. 71-77.

- He, L. F., J. Pakarinen, M. A. Kirk, J. Gan, A.T. Nelson, X. Bai, A. El-Azab, T. R. Allen, "Microstructure evolution in Xe-irradiated $\mathrm{UO}_{2}$ at room temperature," Nuclear Instruments and Methods in Physics Research Section B: Beam Interactions with Materials and Atoms, Vol. 330, July 2014, pp. 55-60.

- $\quad$ Supporting the NE fuel cycle program, several test runs of the CCIM Pilot Plant were completed this year. INL has the only CCIM prototype in North America and its integrated test bed is capable of measuring the fate of waste feed components and demonstrating off-gas emissions control.

- Reactivating the RAL to demonstrate highly-enriched uranium recovery for national security uses. The RAL at INTEC was in stand-by mode with no future mission, and possible deactivation in the near future. INL reactivated the facility, under CH2M-WG Idaho, LLC, (CWI) ownership, to perform tests on new technology to recovery domestic-origin, highly-enriched uranium from spent naval nuclear fuel. Testing is currently in progress on samples of irradiate naval fuel to demonstrate a recovery process that generates about 300-400 times less waste than the process used at INTEC in the 1950 s through the 1980s. This work, along with a number of other potential projects will provide a solid base of work to be performed in the RAL in the future. The DOE-NE will make a decision on taking ownership of the RAL from the Office of Environmental Management in 2015.

- The separations demonstration at RAL continued with three chloride volatility tests of irradiated fuel. The three August tests (one with $\mathrm{HCl}$ and two with $\mathrm{Cl}$ ) generated first-of-its-kind separation results on irradiated fuel. A fourth test is planned in mid-September. Results to date have shown reaction rates with irradiated fuel are similar to those with unirradiated zircaloy samples. The separation of the zircaloy from the fuel appears to be functioning well. 
- Three papers were prepared for the International Topical Meeting on High Temperature Reactor Technology that address the significant advances made in post-irradiation examination techniques and safety testing of AGR-1 TRISO fuel.

- "Detection and Analysis of Particles with Breached SiC in AGR-1 Fuel Compacts" discusses the advances made during AGR-1 PIE that have enabled us to detect the specific compact that has TRISO fuel particles with SiC failures, and then identify a single particle with failed SiC using equipment and techniques developed at ORNL. This capability did not exist anywhere worldwide. Historically, the PIE of TRISO fuel has been limited around the world.

- "Irradiation performance of AGR-1 high temperature reactor fuel" the extensive detailed AGR-1 PIE was able to confirm through detailed microstructural characterization of the fuel and fission product mass balances the highly successful results of the AGR-1 TRISO fuel during 620 days of irradiation in ATR with no particle fuel failures. The ability to manufacture TRISO-coated particle fuel to these extremely high standards of quality and performance exceeded previous U.S. and German fuel fabrication efforts. German fuel performance has been the "gold standard" and measurement of true success for past irradiations of TRISO-coated particle fuel.

- "Performance of AGR-1 High-Temperature Reactor Fuel during Post-Irradiation Heating Tests" the successful performance of the AGR-1 TRISO-coated particle fuel under accident conditions up to $1800^{\circ} \mathrm{C}$ is discussed. AGR-1 TRISO-coated fuel has been safety tested in compact form and as loose particles for 300 hours at 1600,1700 , and $1800^{\circ} \mathrm{C}$ while still demonstrating its ability to retain fission products and maintain a high level of safety for the workers, the public, and the environment.

- Research supported through LDRD funding and conducted at ZPPR represented the first-ever integration of experimental trials combining neutron-generator-based active neutron interrogation measurements with source-assisted neutron multiplicity counting. The tests are evaluating a new approach for experimentally determining the multiplication of nuclear assemblies. The results will yield-enabling measurement techniques to support future arms control treaties.

- MFC supported several passive measurements for the NA-40 program in 2014. These measurements were a collaborative effort between LLNL, SNL, and INL. The data from these measurements provides key information to support nuclear nonproliferation and national emergency response assets.

- Notable Outcome 2.4.A Achieved. In accordance with authorization from DOE to start limited operations at IMCL, radioactive specimens were analyzed in FY 2014 at IMCL using the bench-top instruments, which were included in the IMCL Operational Readiness Review (ORR). This completes the requirements of the facility startup plan (PLN-4639). Although research equipment will continue to be installed over the next few years, IMCL is now a fully operational nuclear research facility. Other notable accomplishments for equipment installation include: (1) EPMA/FIB construction activities are nearing completion, (2) turnover of the SSPA to operations has been completed. A management review of the SSPA to support training and equipment development using non-radiological samples has been completed, fulfilling the requirements of a Level 2 milestone, (3) installation and checkout of the FIB has been completed, fulfilling the requirements of a Level 2 milestone,

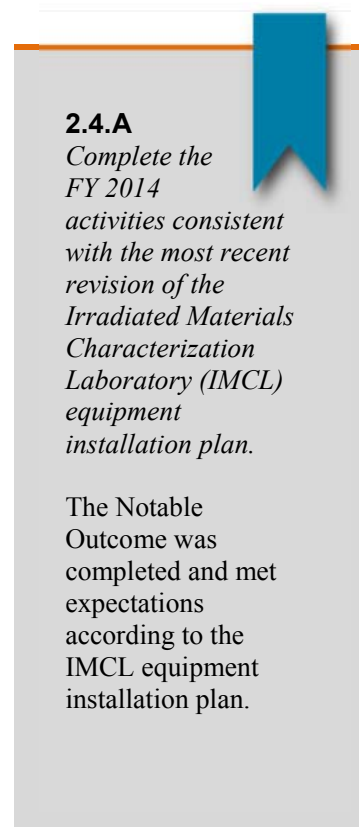


(4) installation and checkout of the EPMA has been completed, also fulfilling the requirements of a Level 2 milestone, (5) Glovebox/Hood design/fabrication specification has been issued for formal solicitation, (6) EPMA/FIB shielding and confinement specification has been issued for formal solicitation, (7) TEM assembly and factory acceptance has been completed and shipped to INL.

\section{Critical Infrastructure Protection and Nuclear Nonproliferation Missions Deployed Solutions and Influenced Science}

Many of INL's facilities offer unique capabilities in the areas of nuclear nonproliferation and energy security. In FY 2014, INL leveraged its scientific expertise and unique power grid infrastructure to become a national leader in full-scale testing designed to resolve uncertainties to significant national security challenges. In providing this national capability, INL continued to exceed expectations by uniquely applying the laboratory's power grid, security systems, and Environment, Safety, and Health $(E S \& H)$ infrastructure to support the U.S. government in obtaining the technical data needed to secure the national power grid. The following represent several of the FY 2014 achievements:

Several wireless test bed programs required investments to establish new capabilities at INL that were used to complete program milestones and deliverables successfully. With each of these successes, the resulting new capabilities or new testing protocols have expanded the breadth of WNUF testing capabilities and testing options that will be available for future WNUF tests. Examples include:

- INL signed an agreement with a U.S. Government organization to accept ownership of the Fillmore Facility as part of completing several years of wireless and power grid testing focused on protecting U.S. military facilities. The transition of this facility to INL will enable the future use of the WTB, Wireless National User Facility, and Power Grid Test Bed by providing options for isolating sensitive projects during overlapping user facility and test bed activities when tests involve export control, proprietary, OPSEC information, etc.

- INL's WTB successfully established a 2nd Generation Global System for Mobile communications (GSM), 3rd Generation Universal Mobile Telecommunications Systems (UMTS), and analog telephone connectivity between the INL cellular network core and DoD's Point Mugu Joint Electronic Warfare Evaluation Laboratory's (JEWEL) Nokia Solutions and Network (NSN) base station equipment. These capabilities are now used by INL researchers to conduct operational tests from INL in support of military system tests of technologies countering improvised explosive devices.

- INL's WTB research team completed a test with the U.S. Special Operations Research, Development, and Acquisition Center to advance the implementation and eventual acquisition of the U.S. SOCOM technologies for broadcasting information during international missions. To successfully complete this test on the INL range, INL personnel established WiMax capabilities at remote sites to enable onsite Internet access and completed site surveys to identify optimized cellular reception sites for coordination of test activities and collection of test results. Research testing was completed on INL's WTB to support testing for Dynexus Technology, LLC, (St. Cloud, Minnesota) in its evaluation of an innovative control system to monitor the operational status and quality of performance of standard cell tower sites. This testing, intended to demonstrate the potential conversion of a cell tower site into a "smart tower site," demonstrated the initial successful use of the INL's Technical Service Agreement work process. 
Threats posed by global terrorism and the vulnerability of U.S. critical infrastructure have continued to evolve in complexity. INL's isolated site, test bed infrastructure, and applied-science focus make INL a major center for national security technology development and demonstration. Therefore, INL continued to provide access to our experts, equipment, facilities, and large-scale infrastructure to deliver experimental results that are achieving DOE strategic objectives for securing our infrastructure and nuclear materials. Examples include:

- $\quad$ DOE-IN, INL Counterintelligence, INL Facility and Site Services (F\&SS), and N\&HS personnel received 2013 Secretarial Honor Awards for establishing the ICS-CERT Control System Operations Center (CSOC) within an INL facility. This award recognized the team of security officers and project leaders who were instrumental in the successful completion of the facility's modification approval, design, construction, and accreditation. With access to these capabilities, DHS, with INL researchers, were able to disseminate more than 250 original peer-reviewed cybersecurity advisories to public and private sector critical infrastructure stakeholders.

- Utilizing satellite communication equipment provided by DHS and INL, the Federal Emergency Management Agency (FEMA) was able to complete an exercise testing audio, video, and data feeds with the Idaho Bureau of Homeland Security and the Idaho National Guard 101st Weapons of Mass Destruction Civil Support Team. INL's Emergency Response Organization and INL's ICS-CERT program personnel

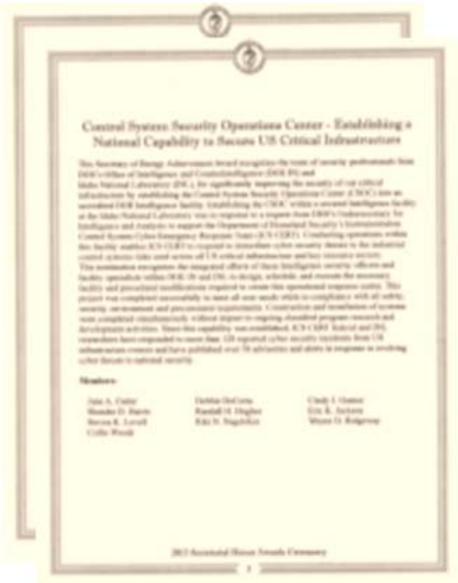

INL and DOE Office of Intelligence and Counterintelligence security officers received a 2013 Secretarial Honor Award for establishing secured ICS-CERT capabilities at INL. received a note of appreciation from DHS for our staff and infrastructure support.

- A new INL facility located at the Critical Infrastructure Test Range Complex (CITRC) hosted several radiological emergency training sessions and exercises for DoD and public safety first responders. Establishing this facility enabled the successful transition of N\&HS's nuclear emergency response training activities from TREAT as part of achieving DOE and INL objectives for the TREAT restart.

- INL completed the cyber security testing of GE's Smart EVSE, which is the first of four Smart EVSEs, funded by a DOE-OE FOA award, to be tested by INL. The GE EVSE is the second EVSE to complete cyber security testing at INL.

- In collaboration with Sandia National Laboratory and the University of New Mexico, N\&HS completed Naval Explosives Ordnance Disposal Team training sessions at Kirtland Air Force Base. This collaboration included demonstration of new capabilities to provide offsite transport and use of INL's unique radiation sources and nuclear/radiological detection system subject matter experts.

- Three significant national security tests on the INL power grid were completed that support national requirements to understand our national capabilities to address vulnerabilities to the electrical power systems servicing DoD and other critical U.S. Government facilities. For these tests, INL's range was selected due to our unique capabilities, technical expertise, and security practices. 


\section{Clean Energy Mission Advanced Science}

INL provides unique capabilities, facilities, and expertise that complement the laboratory's nuclear mission. Non-nuclear strategic research programs are used to provide applied energy engineering research capability to assist the U.S. in achieving environmentally responsible energy security and are grounded in unique Idaho capabilities. Emphasis is placed on advancing deployment of technologies that enhance clean energy development, delivery, security, and use, and address management of energy-related materials and environmental consequences. INL has a robust research program aimed at testing batteries for electric vehicles and biofuels. FY 2014 technical accomplishments are noted below:

- Jon Christophersen completed delivery of the DOE Vehicle Technologies Program Battery Test Manual for Plug-In Hybrid Electric Vehicles (INL/EXT-14-32849). The manual was prepared for the DOE-EERE and VTO as a milestone deliverable. It is based on technical targets for commercial viability established for DOE performance goals for PHEV. The specific procedures defined in this manual support the performance and life characterization of advanced battery devices under development for PHEV's.

- INL's Battery Testing Laboratory provided performance data to industry battery manufacturers at the quarterly review meetings for Saft and Maxwell battery manufacturers. INL is the lead performance test facility for Saft and Maxwell corporations, which are part of the United States Council for Automotive Research, founded by Daimler Chrysler, Ford, and General Motors. Results were also presented to the U.S. Advanced Battery Consortium Technical Advisory Committee for the K2 Energy, Farasis Energy, and Hydro Quebec corporations.

- Based on vehicle battery performance testing, INL posted battery performance test results on the publically available AVTA website for 46 vehicles. The openly communicated data is available and includes the latest test data for each year, make, and model, and can be found at BEVs (http://avt.inl.gov/fsev.shtml), HEVs (http://avt.inl.gov/hev.shtml), and PHEVs (http://avt.inl.gov/evse.shtml).

- Barney Carlson presented INL analysis results of $12-\mathrm{V}$ accessory loads to the USCAR VSATT in Detroit, Michigan. VSATT evaluates the performance of automotive components and subsystems to focus research on areas that maximize potential for fuel efficiency improvements and emissions reduction. Chrysler, GM, and Ford all approached INL to get performance data on 12-V accessory loads from non-electrified vehicles (i.e., normal internal combustion engine vehicles). The automakers requested support from INL in three areas: (1) previous studies that show results for accessory power, idle time, $\mathrm{A} / \mathrm{C}$ operation, parked time, and $\mathrm{MPH} /$ acceleration characteristics; (2) additional vehicles with accessory data collection and analysis including baseline vehicles; and

(3) an increase in collaboration with other groups to try to acquire more accessory data.

- Chris Michelbacher used a 3-D printer to fabricate a unique fixture that would safely support a large format cylindrical battery cell $(\sim 8.5 \mathrm{in} . \mathrm{H} \times \sim 2.25$ in. dia.). This method of producing a test fixture became extremely beneficial by (1) dramatically reducing the cost to produce the fixture compared to conventional methods, and (2) the unique part was able to be created and used within a 24-hour span (just over 9 hours to print). The conventional method would take at least 2 days.

- INL finalized a WFO with Simplot Corporation to conduct a comprehensive review of sensors that could be flown using an UAS to collect information for identifying early stress indicators in crops. 


\section{INL's National User Facilities}

The Laboratory has three working national user facilities (ATR National Scientific User Facility, Wireless National User Facility, and Biomass Feedstock National User Facility); each are in a different stage of development.

- Notable Outcome 2.4.B was achieved. INL submitted the metrics of success approved by each of the three user facilities' stakeholders to DOE-ID on August 21, 2014, (CCN 233814). In addition, the three user facilities provided evidence to DOE-ID that the analysis of the approved metrics had commenced.

\section{ATR National Scientific User Facility}

ATR NSUF has served as a successful and important tool for collaboration between DOE, the nuclear industry, and university researchers for nuclear energy research for several years.

- The ATR NSUF experiment is the EPRI-ZG-D experiment located in the A-16 reactor core position. The EPRI-ZG-D irradiation experiment at INL is a CRADA between BEA and EPRI to obtain data on the anomalous growth of zirconium alloys under certain reactor operating conditions. The EPRI Zirconium Growth experiment will provide data on a postulated hydrogen-assisted irradiation growth rate mechanism that may be operative in zirconium alloys and is associated with BWR channel bowing. Pre- and post-irradiation dimensional measurements will be used to provide information on zirconium growth rates.

Post-irradiation TEM analysis will provide data on the irradiation growth mechanism.

- $\quad$ ATR NSUF University of California Berkeley experiment capsules began disassembly at PNNL. This experiment is designed to examine the feasibility of incorporation of hydride fuels into LWRs. This is the first ATR NSUF irradiation/PIE experiment that utilizes a partner facility (MIT) for irradiation and a partner facility (PNNL) for PIE.

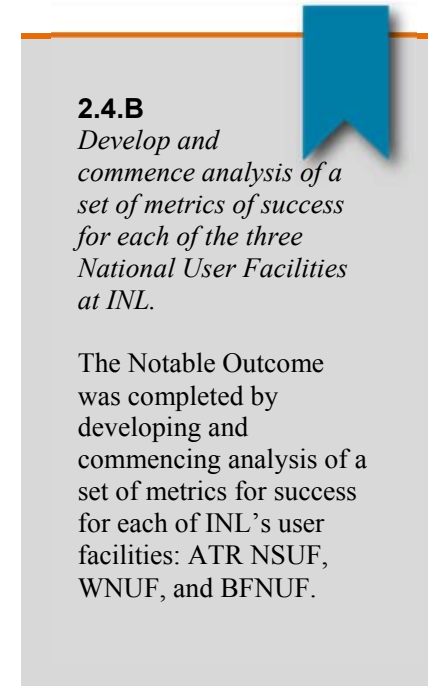

- Wei-Ying Chen, a Ph.D. student from University of Illinois, presented technical results at an INL colloquium on aging and irradiation-induced degradation of cast austenitic steel as a surrogate for in-core LWR welds. Wei-Ying has developed expertise in this area largely as a result of his Ph.D. research conducted through an awarded ATR NSUF Irradiation Experiment.

- The MANTRA NSUF program performed experiments to determine neutron cross sections on a number of elements, from stable isotopes to actinides. The research areas that rely on accurate neutron cross sections are fission reactor design, nuclear fuel cycles, nuclear safety safeguards, reactor monitoring and fluence determinations, waste disposal, and transmutation. The analytical laboratory (AL) at MFC analyzed more than 60 samples in support of the MANTRA 1 and 3 experiments. The parent isotopes $(\mathrm{N})$ through the $\mathrm{N}+5$ isotopes were measured for each of the isotopes in each sample. The major actinide elements irradiated in ATR and measured in the AL include Th, $\mathrm{U}, \mathrm{Np}, \mathrm{Pu}, \mathrm{Am}$, and $\mathrm{Cm}$. For isotopes above mass 241, these were some of the first cross sections measurements undertaken on these elements. The AL was able to meet the instrumental measurement precision requests of $<0.5 \% \mathrm{RSD}$ on the $\mathrm{N} / \mathrm{N}+1$ isotope ratio and $<1 \%$ precision on the $\mathrm{N} / \mathrm{N}+2$ isotope ratio measurements. 
- ATR NSUF awarded three beam line experiments and 25 Rapid Turnaround Experiments to researchers from nine universities and three national laboratories.

- ATR NSUF integrated the standalone solicitation process into the FY 2015 CINR FOA, providing researchers with a "one application" process to apply for NE R\&D funding and ATR NSUF access.

- ATR NSUF worked on an expanded mission, Management of NE Infrastructure, with the objective of having staff expertise and infrastructure data available to support the FY 2015 NE-4 infrastructure FOA reviews.

\section{Wireless National User Facility}

INL's WNUF continues to make progress in providing testing capabilities and results that enable the nation to implement the objectives of the National Broadband Plan through advancements in spectrum sharing technologies R\&D, implementation of an integrated Public Safety network, and deployment of technologies that boost economic growth. FY 2014 accomplishments are advancing INL's strategic objectives for establishing the WNUF as a unique asset that bridges government, industry, and academia, along with obtaining national recognition for large-scale wireless communications experimentation. Examples of these accomplishments include:

- Daniel Devasirvatham was hired as the WNUF director and is participating as an invited technical authority with multiple public policy organizations. These organizations include: DOE-SC Policy Wireless Spectrum R\&D Senior Steering Group; Wireless Innovation Forum Steering Group on Spectrum Sharing; Association of Public Safety Communications Broadband and Standards Development committees; National Public Safety Telecommunications Council Site Hardening document development group; Federal Communications Commission Public Safety and Homeland Security working group; and Oregon's FirstNet working group.

- INL has successfully completed the first two WNUF tests: an industry test with S2 Corporation, and a university test with Stevens Institute of Technology. Both tests evaluated the performance of new technologies intended to solve future challenges with spectrum sharing for government and Public Safety communications.

- WNUF testing results contributed to a decision by Stevens' Lead Researcher, Dr. Chandramouli and Dynamic Spectrum, LLC, to begin a South African trial of SpiderRadio, a long-range high-powered radio in the WiFi bands. The technology, if successful, is intended to provide low-cost, high-speed Internet capability for South Africa's rural and urban needs.

- Test results on the WNUF with the S2 Corporation have supported national recognition of a WNUF test participant as a scientific and engineering leader within the field of communications technology. Dr. Kris Merkel, President and CEO of S2 Corporation, declared the success of this year's WNUF test was a contributing factor in his receipt of the 2014 Association of Old Crows' Jerry Sowell Radio Frequency Award. Also, as a result of the WNUF test, Dr. Merkel has invited INL to participate in the development of a proposal for wideband spread spectrum R\&D.

- As a result of a collaborative proposal to the National Science Foundation (NSF), ISU, and INL successfully co-hosted the National Wireless Research Collaboration Symposium (NWRCS 2014), which reflects achievement of a strategic objective of INL's WNUF to gather academic, industry, and government researchers for technical deployment, policy, and implementation discussions with public safety officials. 
- INL has taken advantage of lessons learned and feedback from these tests to implement processes that will enhance testing capabilities for future users. One of these improvements includes obtaining approval for a process to simplify spectrum access for industry and academia users. This process was approved by the DOE Office of Spectrum Management and coordinated with the Federal Communication Commission.

- Also in response to stakeholder feedback on capabilities needed to support future WNUF testing, INL received commitments for $>\$ 5 \mathrm{M}$ of funding for procuring and installing testing infrastructure enhancements. These enhancements will support RDD\&D testing with wireless technologies spanning 2nd, 3rd, and 4th generation systems for the Smart Grid, Public Safety, Defense, and Intelligence. Included in these infrastructure improvements is an INL investment that addresses an N\&HS Strategic Advisory Committee recommendation to obtain Tier 1 and Tier 2 Long-Term Evolution equipment.

\section{Biomass Feedstock National User Facility}

INL is a critical hub for performing RDD\&D. In FY 2014, INL exceeded expectations in our mission to connect vitally important INL facilities to INL staff as well as national and international industry, university collaborators, and other national laboratories. Aligned with strategic objectives to support academic, industrial, and federal researchers working to understand biomass technologies and refine industrial performance of feedstock supply systems, the following accomplishments are noted for FY 2014:

- BFNUF completed a multi-party project with Forest Concepts, LLC, and Vortex Processing to test the performance of participants' biomass size reduction technologies and compare their performance to the current industry standard hammer milling technology. A final report was completed and delivered to project partners that provided data and analyses for their use to further develop, market, or license their technology. This project is a good example of small business accessing INL facilities and expertise to help accelerate their time to market.

- A BFNUF project supplied Universal Oil Products (UOP), a Honeywell company, feedstock for their pyrolysis pilot plant validation campaign in Kapolei, Hawaii. Five shipping containers, containing 40 tons of feedstocks processed to UOP specification through the BFNUF Process Demonstration Unit, were shipped from INL to Hawaii in August. The feedstocks will be processed through the UOP pilot plant though end of 2014, to produce pyrolysis oils that can be upgraded to gasoline, diesel and jet fuel.

- BFNUF supported an undergraduate intern in a project for TerraPower. With access to INL bioenergy researchers and laboratories, the intern tested the physical properties (durability and grindability) of specialty blended pellets produced for TerraPower by Washington State University (WSU). This project contributes to a feasibility study by TerraPower evaluating technology solutions that couple nuclear energy technologies with biomass technologies to produce renewable fuels and chemicals. A report was prepared and delivered to TerraPower with pellet data to support the study.

- BFNUF participated in an international round-robin study of fast pyrolysis technologies conducted through the International Energy Agency (IEA) Task 34. BFNUF staff supplied and prepared feedstocks to 20 international participants, who will convert the materials to pyrolysis oils. The study will compare the performance of participant fast pyrolysis reactors and methods, measuring pyrolysis oil yield and quality over the range of feedstocks supplied by INL. This first-of-its-kind study will provide necessary data for establishing feedstock specifications for biomass pyrolysis. 
- BFNUF hosted engineers from DuPont Industrial Biosciences throughout the last quarter of FY 2014 in an on-going project involving the scale-up and integration of a process developed by DuPont to produce a cellulosic ethanol co-product. The BFNUF Process Demonstration Unit was reconfigured for this project in proprietary process design that included third-party equipment. DuPont engineers worked with BFNUF engineers throughout the commissioning of this process, overcoming many technical challenges that will translate to DuPont's deployment of this process.

- INL's Bioenergy program and the BFNUF are engaged in an international collaboration sponsored by the BioEnergy Technologies Office and DOE-EERE's International Office. The collaboration is part of a developing 5-year relationship with China's NEA through a joint Memorandum of Understanding between DOE, USDA, and NEA. Through agreement, BFNUF staff is in the initial stages of developing a WFO with Petrochina (the fifth-largest oil and gas company in the world). The work will focus on modeling biomass feedstock supply systems in China to improve its ability to implement bioenergy technologies. The importance of this work is twofold. First, it supports U.S. energy security objectives by offering guidance to the largest growing energy user in the world to help reduce future pressure on energy commodities. Second, it will identify technology options that can readily be deployed to China's large market to help improve U.S. trade.

INL engaged the external technical community to develop teams and deploy critical technologies to pursue similar research goals. In FY 2014, INL maximized the Laboratory's scientific impact by contributing through exceptional R\&D work experiences and partnering with industrial organizations, universities, and other laboratories. Several partnerships pursued in FY 2014 are highlighted below:

- Representatives from Pacific Ethanol, Inc., and Leifmark, LLC, (which represents Inbicon, a cellulosic biofuels technology company in Denmark) visited INL's Biomass Feedstock National User Facility to learn about feedstock supply chain and logistics for cellulosic materials in Idaho, including supply, harvest gathering, storage, transportation, and cost.

- Representative from CEA Pure Vision Technology, Inc, visited the user facility to discuss technical and economic details surrounding wet storage of bioenergy feedstocks, biomass for biofuels, and chemical applications. CEA Pure Vision Technology employees are experts in wet storage of biomass, as well as biomass conversion and logistics. They have conducted assessments for National Renewable Energy Laboratory (NREL), the U.S. Department of Agriculture, and private industry.

- INL BFNUF staff recently hosted representatives from NREL, which has licensed INL to use their near infrared spectroscopic model for predicting corn stover composition. The agreement permits INL to use NREL's model on jointly funded research projects that will allow BFNUF to improve and create new models for corn stover composition and performance prediction.

In FY 2014, INL surpassed expectations in combining intellectual leadership, domain expertise, key facilities, capabilities, and modeling tools to expand our scientific impact and inform the technical community of our clean energy outcomes. A few technical highlights associated with the BFNUF are presented:

- A final report was released summarizing an evaluation of utility-scale biomass co-firing in large pulverized-coal power plants. The purpose of the evaluation was to assess the cost and greenhouse gas reduction benefits of substituting relatively high volumes of biomass for coal. The report is particularly relevant to states and regions in determining how to best meet the new Clean Air Act Section 111(b) and Section 111(d) that curtail and reduce $\mathrm{CO}_{2}$ emissions for new and existing power 
generation. The BFNUF supported key elements of this work, which included collaboration by EPRI, WSU, and a commercial pellet manufacturer.

- Batch acid-precipitation experiments were completed and a report was issued for BETO assessing the potential technical feasibility of selectively precipitating lignin or silica from the liquid phase of alkali-extracted corn stover. The report will provide the basis for a manuscript describing the results of the work.

- A BFNUF report was submitted describing different sludge drying systems that were evaluated for applicability to drying algae paste. In the report, the design for a bench-scale drum drying system was provided that will be built and tested in the next quarter.

- Richard Hess and Kevin Kenney provided invited presentations at Biomass 2014 conference in Washington, D.C. Richard Hess was invited to present during one of the plenary sessions and Kevin was invited to present during one of the breakout sessions. BFNUF also had a booth and communication material.

- $\quad$ "Benefits of Bale Drying Prior to Storage and Preprocessing of Biomass for Lignocellulosic Conversion," was presented at the American Society of Biological and Agricultural Engineers- Canadian Society for BioEngineering Annual International Meeting. This work focused on the 2017 DOE goal to achieve an $\$ 80 /$ ton cost of preprocessed biomass at the "bio-refinery gate."

- Kara Cafferty presented "A Life Cycle Assessment of Hybrid Willow Harvest and Logistics in the Northeastern, U.S." at the NEWBio Annual Meeting. NEWBio is a USDA-supported consortium focused on developing perennial energy crops, especially willow and warm-season grass in the northeastern U.S. for bioenergy (http://www.newbio.psu.edu/). 


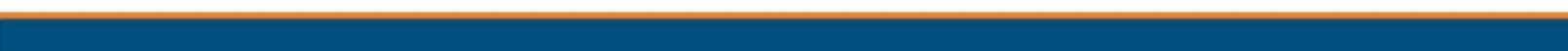




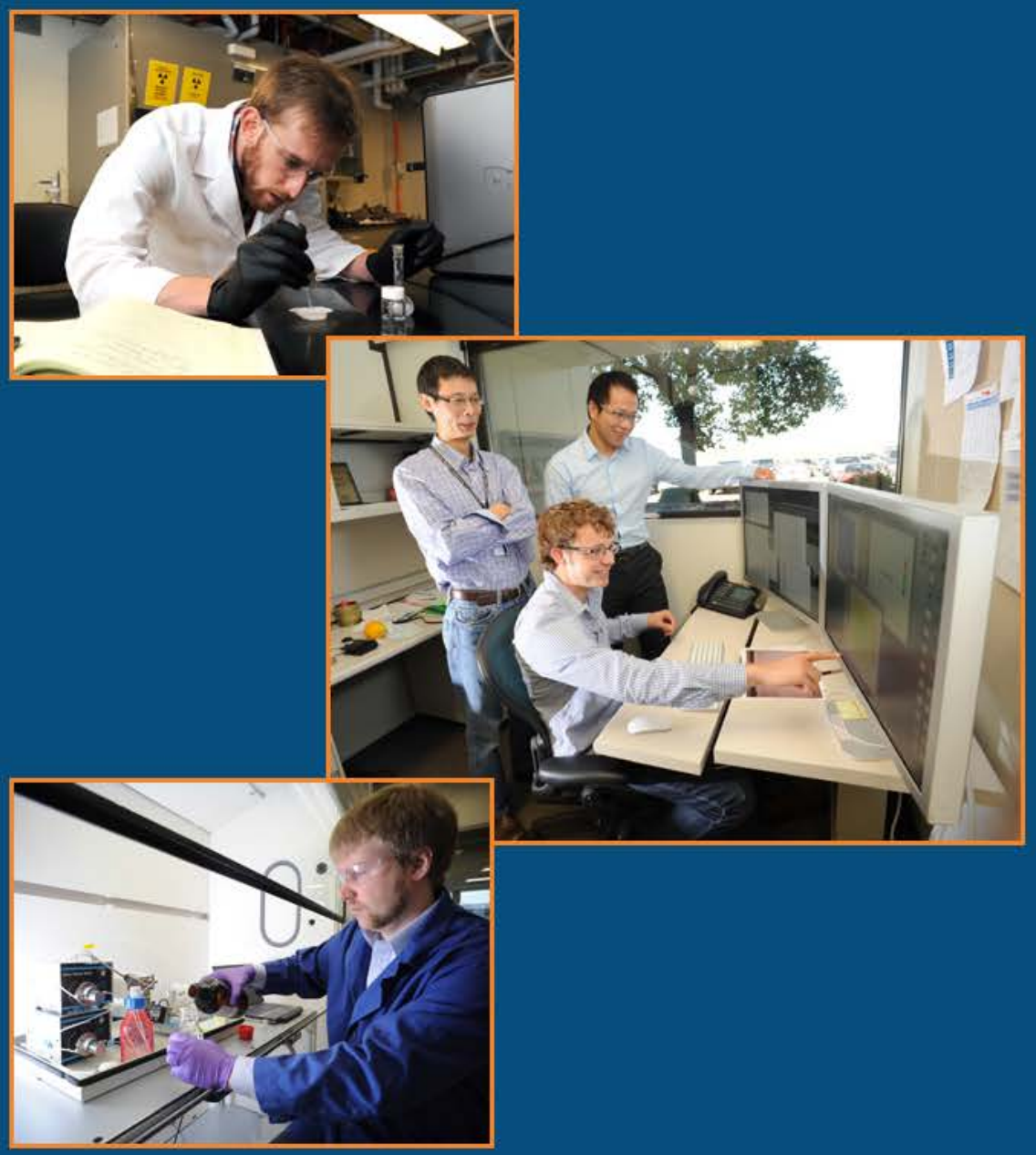

\section{WWWINLGOV}

More information:

Dr. Todd Allen

Deputy Laboratory Director for Science and Technology todd.allen@inl.gov (208) 526-8096 
Battelle Energy Alliance, LLC Contributions to INL Success 


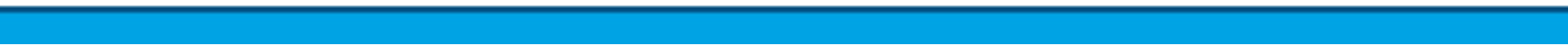




\section{Attachment 3 \\ Battelle Energy Alliance, LLC, Contributions to INL Success}

In FY 2014, BEA drew upon resources and expertise at Battelle, B\&W, URS, EPRI, and partner universities and subcontractors to bring value to INL and DOE as shown in Figure 1, "Corporate and Partner Value Added."

\section{Research and Development}

BEA is supported by a distinguished group of university partners through the NUC and IUC who, together with EPRI, contribute to the science and technology mission of INL. In FY 2014, these partners provided thought leadership to guide INL science strategy, user facility operations, and future research capability development through their participation in the Science and Technology (S\&T) Committee; joint program development and research collaborations; access to leading researchers through university sponsored seminar series, post-doctoral, joint appointments, and faculty exchanges; and access to regional university-sponsored or supported programs. Examples of the value to INL from these partnerships include:

- Established a new national program in Nuclear Hybrid Energy Systems in FY 2014.

INL, in close collaboration with staff from the Massachusetts Institute of Technology (MIT) and collaborators from the National Renewable Energy Laboratory (NREL), established a new nationally funded program to study the efficacy of nuclear hybrid energy systems. This program is anticipated to provide critical knowledge on the expectations on nuclear systems in a 21 st century electrical grid and how nuclear systems, in conjunction with other industrial processes, can be optimized.

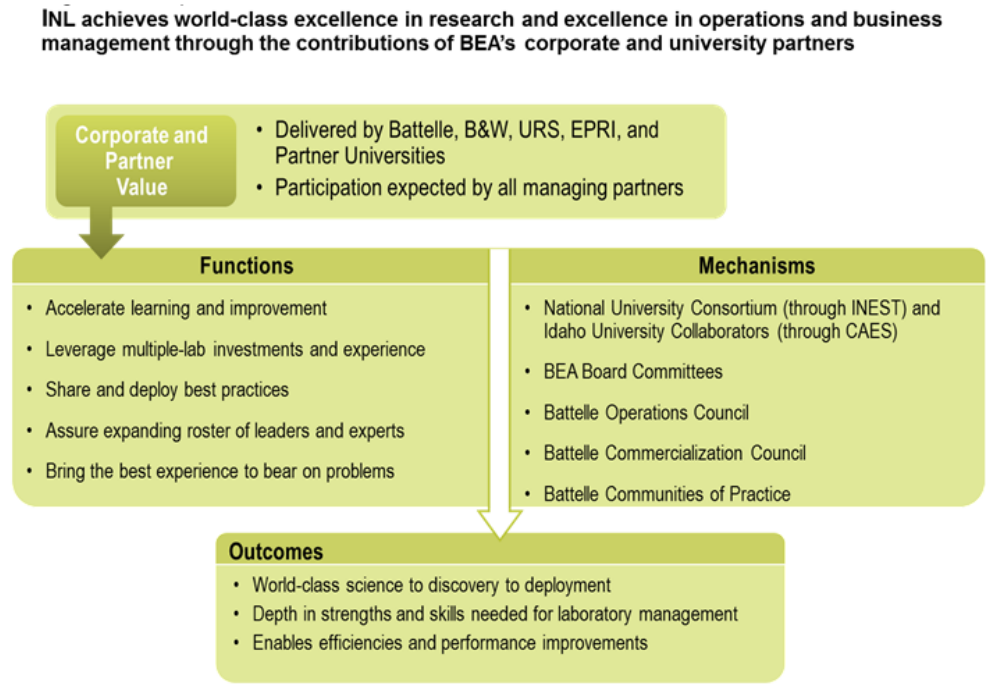

Figure 1. Corporate and Partner Value Added.

- Increased the funding provided to CAES by the state of Idaho by $\$ 1 M$ per year. Due to the ongoing success of the CAES collaboration, the state of Idaho increased the funding to the CAES collaboration by $33 \%$ in FY 2014. The basis of the success included CAES collaborators winning $\$ 9.07 \mathrm{M}$ in new research, equipment, and other funding and producing $225+$ papers, presentations, and proceedings between 2013 and 2014. CAES partners are also a key focus of and provide significant leadership to Governor Otter's LINE 2.0 Commission and continue to be a primary driver for state and regional outreach. 
- Improved INL regional reach through coordinated outreach to western regional states. The CAES partners worked with industry and government leaders in Wyoming to publish two well-publicized reports evaluating hybrid energy system applications in the state. The CAES partners initiated collaborations with the State of Alaska, University of Alaska Fairbanks (UAF), and the Alaska Center for Energy and Power (ACEP). Additionally, the National Governors Association asked INL to present a webinar with select states-Minnesota, Mississippi, Arizona, and Puerto Rico - to discuss INL's role in assisting industry in Wyoming to develop energy solutions.

- Established national visibility for the INL Wireless National User Facility. INL and ISU jointly organized and ran the National Wireless Research Collaboration Symposium. This was funded by an NSF grant of $\$ 50,000$, which was obtained by ISU with INL assistance. The symposium brought together the unlikely combination of Wireless Spectrum Sharing researchers, and leading voices on wireless from NSF, DOD, and national and local public safety officials.

- Developed an understanding of the long-term transient fuel testing needs of LWR fuels through an important partnership with EPRI's Ken Yueh. As INL is getting ready to restart TREAT, it is important to develop plans for addressing the critical testing needs of the industry, as well as the government-sponsored research programs.

- Improved the experimental ability of ATR through CRADAs to irradiate LWR industry relevant materials to understand the effects of neutron exposure on irradiation assisted stress corrosion cracking rates and fracture toughness in BWR repair hardware and to investigate hydrogen-assisted anomalous growth in zirconium alloys. As part of this collaboration, EPRI staff provided consultation on the cause of crud formation in ATR Loop 2A, and put INL in touch with a commercial reactor corrosion expert. While the crud formation and resulting pressure fluctuations for these experiments are not fully resolved, the consultation received is valuable for future test planning and execution.

- Established unique in the world testing capability to understand reactor structural materials stress corrosion cracking response through collaboration with EPRI experts (Raj Pathania, Bob Carter, and Peter Chou) along with an EPRI contracted GE Global Research Company expert (Peter Andresen). The technical oversight, particularly from some of these participants who are globally recognized as leading experts in the field of IASCC, provides immediate validation of this unique new INL capability. The CRADA with EPRI offers the opportunity for INL to provide relevant data toward a database that is universally considered lacking and to develop accepted testing protocol to be used in support of future projects. Through these efforts, as well as external communication by EPRI to stakeholders, INL has become known as one of only a few facilities in the world capable of carrying out IASCC testing that is critical to LWR sustainability. 
- Established experimental programs to understand irradiation growth in LWR cladding materials through collaboration with EPRI program managers (Suresh Yagnik, Rob Daum, and Erik Mader) who provide regular input along with their Nuclear Fuels Industry Research (NFIR) team to INL regarding the progress of a current CRADA that is focused on precision measurement of neutron and hydrogen induced swelling in BWR fuel channels. This includes contribution to the design and validation of a precision measurement system that was installed in the HFEF and successfully used to perform measurements on two sets of irradiated zirconium alloy specimens to date. Additionally, EPRI and INL worked together to coordinate a transmission electron microscopy (TEM) analysis workshop focused on preparation and examination techniques specifically suited to zirconium alloys. A team of international experts convened at CAES and produced a "best practices" document for these specialized techniques. INL scientists and others who perform TEM analyses on irradiated zirconium alloys will utilize these best practices.

- Led the DOE-NE LWRS Program with close collaboration with EPRI. Sherry Bernhoft, the Program Manager for the EPRI Long Term Operations (LTO) Program, works closely with Kathy McCarthy, the director of the LWRS Program Technical Integration Office (TIO), to ensure coordination and collaboration of the two programs. The LWRS Program TIO Director has a standing invitation to present LWRS Program results at the semiannual EPRI Nuclear Power Council (NPC) LTO Technical Advisory Committee meeting. This provides another opportunity to get direct feedback from industry, and in some cases, industry volunteers for collaborations.

- Partnered with EPRI on LWR critical research programs using the INL-developed MOOSE computational framework. Coordination/collaboration with EPRI has resulted in special opportunities such as an invitation to present an overview of the MOOSE framework at the EPRI Safety Technology Week (June 9-13, 2014 in Charlotte, North Carolina). During that meeting, EPRI discussed the direction they will take with their models such as Modular Accident Analysis Program (MAAP) (their severe accident model). They are exploring whether they should continue upgrading in the current manner (which includes Fortran-based models), or make a significant change (the MOOSE framework is an option). These discussions are ongoing. Another example is EPRI's interest in having INL develop a MOOSE-based version of VIPRE (Versatile Internals and Component Program for Reactors; EPRI). VIPRE is used for nuclear reactor thermal-hydraulic analysis applications. That request is still evolving, but it could allow INL to use one or more of the VIPRE closure relationships for subchannel flow in the RELAP-7 model. This would be a significant benefit for the RELAP-7 model.

- Enabled discussions to establish at INL the ability to bring commercial fuel rods in support of the Joint Fuel Cycle Study and other fuel exams. EPRI facilitated discussions with a commercial plant and a fuel vendor on a joint project to bring a substantial quantity of commercial fuel to INL.

- $\quad B \& W$ is playing a significant role in support of a high-priority project to develop a domestic source of enriched uranium for an important national defense program. B\&W Lynchburg has prepared 10 unirradiated fuel elements that have been sized for use in a quarter scale pilot plant. $\mathrm{B} \& \mathrm{~W}$ is also storing the material at their facility at no additional cost until required at INL with shipments scheduled for FY 2015 to support just-in-time testing requirements. B\&W has (1) sectioned the material at an estimated half of the anticipated $\$ 188,900$ cost; (2) provided material storage for over one year at no cost; (3) provided zircaloy coupons at no cost; and (4) facilitated the receipt of oxide-coated zircaloy coupons from Bettis Pittsburgh. B\&W's support facilitated the start of developmental zircaloy testing at Central Facilities Area (CFA), and is providing all of the 
materials needed for the upcoming quarter scale testing. In addition, their willingness to store and provide material as needed has saved the project more than $\$ 500,000$ by eliminating the need for onsite storage and related safety basis, startup, and maintenance costs. The use of B\&W's shipment cask has also avoided over a one year delay to current schedule, which would have been required to repurpose and requalify one of INL's casks. B\&W's support of this project has allowed INL to focus funding and attention directly on laboratory work.

\section{Operations of Major Scientific User Facilities}

BEA and its university partners operate many national science and engineering user facilities and other major research facilities and have built a body of experience represented in people and systems, which spans initial design, through construction, to operations. This experience was made available to INL as it expanded the ATR NSUF and began operations of the BFNUF and WNUF. For example:

- Provided unique reactor-based testing capability to national users through NSUF-based partnerships. MIT provides valuable testing capability to the ATR NSUF through its MIT Reactor (MITR). In FY 2014, two projects at MITR were completed (supporting researchers at MIT and the University of California, Berkeley) and one project started irradiation (supporting researchers from Pennsylvania State University), which will complete in FY 2015.

- Provided access to unique post-irradiation examination capability through close cooperation between INL and the IUC (Boise State University, University of Idaho, and Idaho State University) in managing and operating the Materials and Characterization Suite (MaCS) located in CAES. Researchers, both across the U.S. as well as internationally, have utilized the $\mathrm{MaCS}$ facility to conduct one-of-a-kind atomic scale nuclear fuels and materials investigations. The publication of these important results enhances the reputation of INL, and the application of these results in nuclear materials and fuels development programs strongly contribute to the nuclear science and technology mission of INL. The IUC made the MaCS available six days a week, 12 hours a day to support ATR NSUF research. In FY 2014, ATR NSUF researchers will utilize about $70 \%$ of the available instrument time.

- Used BEA experience with neutron science user facilities to inform the restart of INL's transient testing capability. INL's John Bumgardner and Dan Wachs are working closely with staff from Oak Ridge National Laboratory's (ORNL) Neutron Sciences Directorate to transfer best practices on user facility programs and testing protocols.

\section{Operations and Business Management}

In FY 2014, Battelle and its partners made a set of integrated support mechanisms and activities available to BEA that collectively were designed to help INL excel in operations and business management.

- Through a carefully prepared and jointly agreed-to set of practices and principles titled, "The Safe Conduct of Research," Battelle's expectations for operational excellence were articulated. These practices and principles established a foundation for laboratory operations activities while informing the BEA Board of Managers and Operations Committee of Battelle's expectations for excellence in operations. These set of practices and principles were used to establish INL's approach to Conduct of Research (LWP-20000). 
- Recognizing the key role that front-line supervisors have in understanding and shaping safety culture-poor supervision is often cited as a causal factor in serious events, Battelle began development of an instructional program to provide first-line supervisors with hands-on experience-based training to help internalize the importance of being at the point of work effectively leading, mentoring, and coaching. The first training event is scheduled for October 2014 with four to five INL supervisors attending.

- Through Battelle's Laboratory Operations Leadership Academy (LOLA), emerging senior operational leaders at INL are being provided unique experience-based and operationally focused learning and development opportunities. Three INL leaders completed the two year program in September 2014; another four leaders are scheduled to begin the program in FY 2015.

- Through Communities of Practices (CoPs), Battelle continues to promote innovation and shared learning, the development of human and system capabilities, and rapid assistance across Battelle's affiliated laboratories. The reach-back, provided by Battelle's CoPs, effectively expands INL's organizational capacity and capability. Examples of how INL benefited in FY 2014 include: (1) peer review of Facilities and Site Services to identify strengths and weaknesses in first-line supervision and work planning and control, (2) participation of finance and procurement staff in a "job shadow" program to develop business skills needed at INL, (3) peer review of fitness for duty program to address concerns raised by represented labor, and (4) peer review of INL's revised cost model proposal to validate impacts and points of innovation. Through these peer reviews, BEA reinforces principles and practices for operational excellence, searches for operational issues and blind-spots, and informs Laboratory leadership of potential vulnerabilities.

- BEA's corporate parents committed \$250K of earned fee to a pre-contractual process that helps enable the continued growth of WFO projects at INL. The WFO business volume has averaged about $30 \%$ of the total business volume and is forecasted to remain fairly constant. Many customers have internal constraints and time issues that prohibit them from meeting DOE standard terms and conditions involving the availability of funds before starting the WFO project. These funds close that gap, allowing INL to start work on the project.

- INL received benefits from rates/rebates in travel that are a direct result of our corporate affiliation with Battelle. These included (1) rebates from Avis/Budget of $7 \%$ amounted to $\$ 18,000$ saved over the past year; (2) corporate U.S. Bank travel card refunds for prior year of $\$ 80,000$, which resulted in a 1.4\% savings; and (3) an estimated FY 2014 airfare savings of \$754,000.

- INL also participates in a Battelle-sponsored Purchasing Card rebate program. The rebates we obtain are a direct result of combining the use of the JP Morgan Purchasing Card program with other BEA-managed laboratories. For the second quarter of FY 2014, INL received a rebate in the amount of $\$ 31,708.44$. 


\section{Governance and Corporate Oversight}

Through corporate governance and oversight, Board and Committees, senior managers, scientists, and operations experts assemble to provide oversight of the BEA management team; executive-level policy guidance; corporate support and commitment; and corporate assurance to DOE.

All members of the BEA team, including the NUC and IUC ${ }^{1}$, are represented in this Governance structure; their representatives are responsible for bringing partner resources and knowledge to support INL as necessary. In FY 2014, this structure contributed to INL's success by:

- Delivering on resource commitments with an estimated value of more than $\$ 12,500,000$ in FY 2014. These commitments benefitted INL in a multitude of ways: (1) direct and indirect contributions to improve STEM education and help build a future workforce pipeline; (2) growth of CAES programs and collaborative research with universities; (3) funding to make technical and managerial non-key personnel available to INL that otherwise would not be affordable under contract cost reimbursement; (4) creation of a regional innovation ecosystem through investment in technology-based economic development to support INL's technology deployment mission; and (5) greater industry participation in INL research (e.g., EPRI-funded research, and a CRADA with TerraPower).

- Reviewing and providing critical advice to improve the Laboratory's science and technology strategy and conduct of research. Key recommendations included: (1) improvement of messaging around the future S\&T enterprise to create a compelling and exciting vision for the Laboratory's success (e.g., define and clarify the scientific justification for major initiatives; such as, advanced PIE, TREAT, and a new test reactor). INL applied this advice to present a more compelling vision to U.S. Secretary Dr. Ernest Moniz during his recent visit to INL. (2) Leveraging of ambitious hiring plans to strategically reshape INL. And (3) recognition that integration of research and operations at MFC is a long-term commitment.

- Providing advice on the quality, performance, and direction of the scientific and technical programs including peer reviews of three directorates, ATR NSUF Program, ICIS Signature, and the Center for Materials Sciences of Nuclear Fuels. Recommendations included:

(1) development of a planning basis for the resumption of transient testing experimental capability that integrates funding from infrastructure, advanced fuels, modeling, and university/industry programs; (2) a call for stronger DOE-NE advocacy of INL National and Homeland Security (N\&HS) programs; and (3) affirmation that external peer reviews effectively address the programs' alignment to strategy, value of investments, and performance management.

- Ensuring financial responsibility and effective risk management for BEA, this includes effectiveness of management systems, business controls (e.g., A-123), workplace concerns program, and the independent audit function.

\footnotetext{
${ }^{1}$ The NUC consists of MIT, Oregon State University, NC State, the Ohio State University, and the University of New Mexico. IUC consists of the three large public universities in Idaho: ISU, BSU and University of Idaho.
} 
- Overseeing the quality and performance of the operational and Environment, Safety, Health \& Quality (ESH\&Q) programs, including the effectiveness of the Integrated Safety Management System (ISMS). Recommendations included: (1) development of a comprehensive risk matrix to guide the TREAT restart effort; (2) direction to management to improve accountability for conduct of management observations; (3) need to verify that molten salt event corrective actions were sustainable through measurable program and process improvements; and (4) the need to effectively balance over-reporting of inconsequential events with serious self-reflection of more consequential events and indicators.

- Ensuring INL's senior management team remains staffed with experienced, capable leaders and managers. Battelle recruited from its senior ranks, at a significant corporate expense, a successor Deputy Laboratory Director to replace Riley Chase who retired in May. Battelle provided the INL Laboratory Director with advice and consent on the appointment of a new Environment, Safety, and Health $(E S \& H)$ Director to the Leadership Management Team. The new ES\&H Director was prepared for succession through Battelle investments in leadership development, such as: (1) a two year experience-based and operationally focused learning and development program for emerging senior leaders; (2) direct experience overseeing operations at another national laboratory as a member of PNNL's Operations Committee; and (3) shared learning through Battelle's ES\&H Community of Practice.

- Advocating for INL with a broad range of stakeholders with the aim to secure funding from both public and private sectors. Board members frequently meet with elected officials, senior federal staff, and industry to advocate for INL programs and capabilities. 


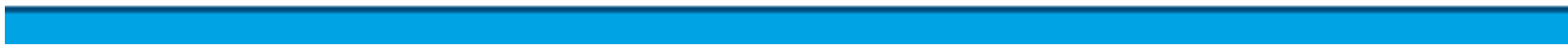




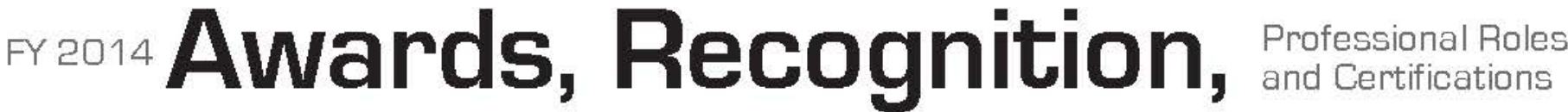

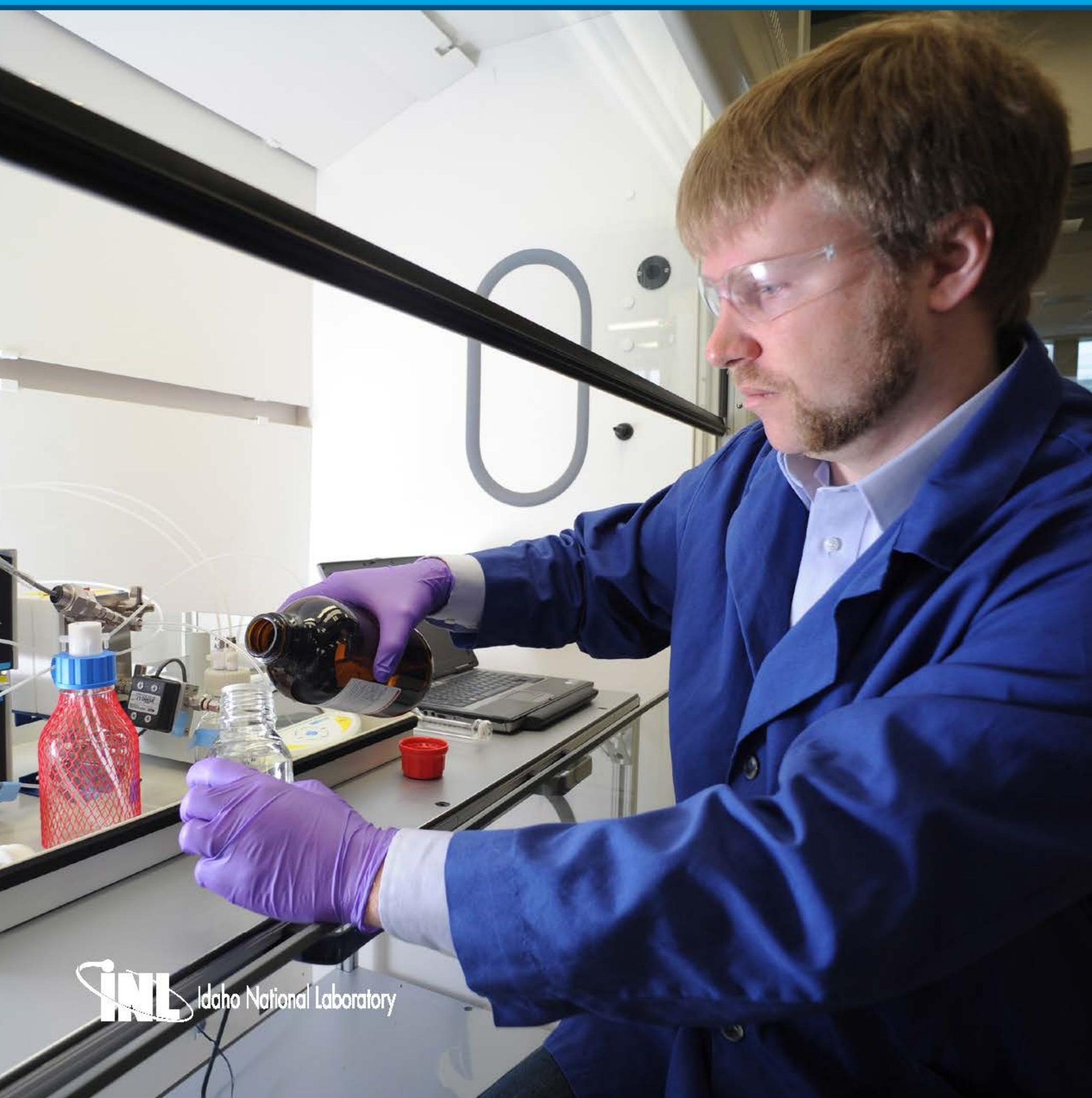




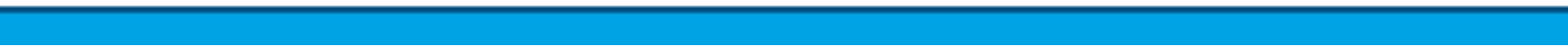




\section{Attachment 4 \\ FY 2014 Awards, Recognition, Professional Roles and Certifications}

\section{AWARDS AND RECOGNITION}

Derek Gaston, Cody Permann, David Andrs, Jason Miller, J. W. Peterson, Andrew Slaughter and Richard Martineau received an $R \& D 100$ Award for the Multiphysics Object Oriented Simulation Environment (MOOSE) which makes it easier for scientists to predict phenomena ranging from nuclear fuel and reactor performance to groundwater and chemical movement. Such simulations can help speed the pace of scientific discovery but traditionally required more computing resources than most scientists and engineers could readily access.

Gary Smith and Derek Gaston received the Federal Laboratory Consortium (FLC) Far West Region, Outstanding Commercialization Success Award, for the deployment of MOOSE.

Bruce Hallbert, Ron Farris, Shawn St. Germain and Arizona Public Service were recipients of the Nuclear Energy Institute, Top Industry Practice (TIP) Award for the Light Water Reactor Sustainability (LWRS) program-developed outage control center technology. This is the first time INL has been honored with Nuclear Energy's top distinction. The award was for an innovative process improvement employed by Arizona Public Service (APS) in collaboration with researchers from INL to manage and provide enhanced collaboration of information and activities associated with PaloVerde's fall 2013 refueling outage.
Kevin Gering received an $R \& D 100$ Award for the Advanced Electrolyte Model (AEM), which is a powerful tool that analyzes and identifies potential electrolytes for battery systems. It offers significant resource savings by optimizing material combinations for new batteries. AEM predicts and reports key properties underlying electrolyte behavior in the electrochemical cell environment.

Kevin Gering received the FLC Far West Region, Outstanding Technology Development Award, for the AEM.

Igor Bolshinsky and Savannah River National Laboratory's John Dewes were selected for Hungary's Golden Cross of Merit, the highest national civilian award, for their participation in the removal of HEU from Hungary. 


\section{AWARDS AND RECOGNITION}

\section{June Cutler, Debbie DeCoria, Cindy Garner, Randall Hughes, Steven Lovell, Riki Nagle-Ker and Wayne Ridgway received the Secretary of Energy's Honor Award for support to the Industrial Control Systems Cyber Emergency Response Team, which significantly improves the security of the nation's critical infrastructure by developing the Cyber Security Operations Center into an accredited DOE Intelligence facility. \\ Melissa Teague and Michael Tonks were nominated for Presidential Early Career Awards in Science and Engineering.}

Michael Tonks, INL Staff Scientist received the 2014 The Minerals, Metals and Materials Society, Structural Materials Division Young Leader Professional Development Award. Tonks is the creator and lead developer of the mesoscale MARMOT code, a finite element-based code that predicts the coevolution of microstructure and properties under applied load, temperature, and radiation damage. MARMOT is the signature mesoscale code for the U.S. DOE's Nuclear Energy Advanced Modeling and Simulation (NEAMS) program. He has also helped to pioneer the application of multiscale modeling to develop physics-based materials models of fuel in the NEAMS program.
Terry Todd, Jack Law and Dean Peterman were honored by Secretary of Energy for their role in the Salt Waste Disposal Technologies Team. The team was a collaboration among DOE program offices and laboratories, industry, and academia for its work to combine fundamental and applied research, technology development, and other elements to develop and deploy new technologies for the safe and cost-effective disposition of large volumes of radioactive salt waste.

Igor Bolshinsky, Ken Allen and Mike Tyacke received the DOE 2013 Secretarial Honor Awards for NNSA's Global Threat Reduction Program.

\section{Cherrie Black, Critical Infrastructure}

Strategist, was inducted into the International Women in Homeland Security and Emergency Management Hall of Fame. Black was selected for her achievements in integrating state, local, tribal, and territorial governments into critical infrastructure protection and resilience programs. Among her many accomplishments is being first female chair elected to the DHS's State, Local, Tribal, and Territorial Government Coordinating Council (SLTTGCC) (USA). During her two terms as chairperson of the SLTTGCC, Ms. Black used her position to fuse the disciplines of infrastructure protection and emergency management, and worked tirelessly to insure that SLTTGCC perspectives were part of the national dialogue on infrastructure protection and resilience. 


\section{AWARDS AND RECOGNITION}

Chang Oh, Lead Engineer, Fellow, and division chairperson with the American Society of Mechanical Engineers, was posthumously awarded the ANS Exceptional Engineering Achievement Award - the highest award given by the Thermal Hydraulics Division of ANS. The award is based on a major contribution to the state-of-the-art, an important publication, a major technical achievement, or a sustained record of accomplishment and technical excellence in the art or science of thermal hydraulics.

INL received the 2013 Secretarial Honor Awards for establishing the DHS's ICS-CERT capability within an IN-accredited facility.
Shannon Bragg-Sitton, INL senior nuclear engineer and deputy national technical director for the DOE's used fuel campaign, received the Partnership for Science and Technology, Nuclear Energy Education Advocate Award. This award is presented to individuals or organizations that were central to a noteworthy achievement in energy, nuclear energy, or an environmental field.

INL received two international awards in recognition of our continued sustainability efforts at the EIL, which is certified as LEED Platinum. First, Engineering News Record, Mountain States announced that EIL won the best 2014 Green Project Award in the Intermountain states of Idaho, Utah, and Montana. EIL's project team earned the award for following stringent international green, sustainable building standards. Second, the International Institute for Sustainable Laboratories (I2SL), selected EIL for the 2014 Go Beyond Award, which recognizes the EIL team's outstanding efforts to minimize the environmental impact of its facility. These awards demonstrate extraordinary leadership, innovation, and achievement in sustainable high-technology facility design and construction. 


\section{AWARDS AND RECOGNITION}

INL was recognized by IAEA's Director of Nuclear Security, Khammar Mrabit, for the valuable contributions it has made in the global nuclear security framework. INL is recognized as a key contributor in cyber security, specifically "IAEA and INL National and Homeland Security Directorate worked together to provide a path forward integrating the disciplines of cyber and physical security within the nuclear security framework. These efforts have been realized through the development of international guidance, the integration and conduct of Computer Security as a component of IPPAS and the development and conduct of international training courses in computer security."

Todd Allen was honored by the ANS Materials Science and Technology Division as the recipient of the Outstanding Achievement Award for his leadership and many contributions to the nuclear materials area.

The Instrumentation, Controls, and Intelligent Systems (ICIS) Distinctive Signature Team led by Craig Rieger received the IEEE Region 6 Northeast Area Directors Special Award for 2014.

Ray Grosshans, Strategy and Integration Development director, CAES, received the Partnership for Science and Technology, Energy Education Advocate Award. The awards are presented to individuals or organizations that were central to a noteworthy achievement in energy, nuclear energy or an environmental field.
INL and Boise State University received the International Association for Science, Technology, Engineering and Mathematics (STEM) Leaders (IASL) "STEM Professional Development Leadership" Award.

Kemal Pasamehmetoglu was honored by the ANS Materials Science and Technology Division as the recipient of its Special Achievement Award. The division's most prestigious award recognizes Kemal's international leadership in establishing a science-based approach to nuclear fuel development and seminal contributions to the nuclear materials area.

Anne Seifert (INL) and Louis Nadelson (Boise State University) received the International Association for STEM Leaders (IASL) recognition for K-12 teacher professional development and i-STEM best practices.

Aaron Wilson, Fred Stewart and Mark Stone received the Idaho Technology Council, 2013 Early Stage Innovation of the Year Award. They were honored for their patent-pending technology, Switchable Polarity Solvent Forward Osmosis (SPS-FO). 


\section{AWARDS AND RECOGNITION}

Bruce Mincher received the Idaho Academy of

Science Achievement Award, Distinguished Scientist/Engineer. Mincher has established himself as an expert in actinide solvent extraction, radiochemical separations, radionuclide behavior in the environment, and radiation chemistry of organic compounds.

Kelly Lively, INL department manager for Radioisotope Power Systems, received Idaho State University's Professional Achievement Award. Since 2003, Lively has been associated with the radioisotope power systems program at MFC.

Heather Chichester, Advanced Fuels Campaign Irradiation Testing Technical Lead, was recognized by the ANS Materials Science and Technology Division, which presented her the Past Chair Award for her dedication to the leadership and advancement of the Materials Science and Technology Division of ANS.

DOE, INL, U.S. Department of Transportation (DOT) and Alliance of Automobile Manufacturers received NFPA's Fire Protection Research Foundation Medal "Best Practices for Emergency Response to Incidents Involving Electric Vehicles Battery Hazards: A Report on Full-Scale Testing Results." The award recognizes a project completed in 2013 that best exemplifies the foundation's fire safety mission and the collaborative approach to execution that is the hallmark of all its projects.
Troy Unruh received the Idaho Academy of Science Achievement Awards, New Investigator Award. Unruh is a research and development engineer at INL's High Temperature Test Laboratory. His efforts have expanded the mission of INL Advanced Test Reactor Critical Facility.

Maria Okuniewski teamed with researchers from the Georgia Institute of Technology and University of California, San Diego, and Los Alamos National Laboratory, and was awarded the ANS Materials Science and Technology Division Student Literary Award for "Atomic Properties of Body-Centered Cubic Uranium, published in the Journal of Physics: Condensed Matter, Number 24, February 2012.

INL's i-STEM program was recognized at the 2014 STEM Innovations Conference: Idaho STEM Education Challenges and Innovative Solutions: "Overcoming STEM Education Barriers in Rural States."

INL received the Federal Electronics Challenge (FEC) Gold Award for efforts to use electronics in an environmentally conscious manner. 


\section{AWARDS AND RECOGNITION}

The Light Water Reactor Sustainability Accomplishments Report for 2012 has won first place honors in the Media Network Idaho communications contest. The contest honors communications products produced in 2013. The report, the first-ever annual review document for the program, focused on research highlights from the program. The report was recognized for its design, ease of reading and professional look. The report now advances to a national competition, with winners announced in September in South Carolina. The first place award was presented to David Combs and Teri Ehresman on April 26, 2014 in Boise, Idaho.

Electronic Warfare Modeling and Simulation research team, led by Mike Snyder received a letter of appreciation from the U.S. Air Force for extraordinary efforts in the development and fielding of the Integrated Many-on-Many (IMOM) software.
Jon Christophersen was contacted by the publishing editor from Sage Publications for the journal Transactions of the Institute of Measurement and Control in late March to inform him that an article he co-authored in 2009, "Comparison of Prognostic Algorithms for Estimating Remaining Useful Life of Batteries," was one of the top-five most-cited articles in the last five years. The paper summarized development of some battery health prognostic tools based on standard electrical impedance spectroscopy measurements under no load conditions. The editor congratulated Dr. Christophersen and encouraged submittal of additional papers to the journal. The article was published in 2009 Volume 31 (3-4), 293-308.

Jonathan Gray received an expression of appreciation from Mark Engels, Dominion Resources Services' Director of Enterprise Technology Security and Compliance, for INL's implementation of the Attack Technology, Analysis, and Characterization (ATAC) and Response Analysis Characterization Tool $(\operatorname{ReACT})$ projects.

Piyush Sabharwall, INL Staff Scientist, received the ANS Young Members Excellence Award, which goes to an early-career nuclear scientist who demonstrates outstanding technical abilities. Sabharwall's research is in developing new technology for very-high-temperature nuclear reactors. 


\section{AWARDS AND RECOGNITION}

\section{Todd Johnson and Dave Griffith were} recognized by NA-70 for delivering high-quality and innovative solutions that will improve NNSA's Classified Matter Protection and Control program. Vicky Sinkler, NA-751 Alternate Security Officer for Defense Nuclear Security, stated "....Mr. Todd Johnson and Mr. Dave Griffith have performed the grueling and time consuming self-assessments for the NA-721 security team. As usual, they performed outstanding and provided exceptional support in preparing the NNSA Program's readiness for sound and organized classified holdings..."

Troy Hiltbrand, Deputy Chief Information Officer, was recognized by Business Intelligence Journal for researching best practices in the area of business intelligence.

INL bus drivers Randy Olaveson, Karen Kinney, and Clayton Nii received the National Safety Council's Million Mile Award for driving a million safe miles.
INL received the 2014 CIO 100 Award, which honors companies that demonstrate excellence and achievement in IT.

Hortense Nelson, Information Management Integration Director, was recognized as Computerworld Magazines Top 100 IT Leaders.

Cathy Riddle, who received her doctorate in radiochemistry from the University of Nevada, Las Vegas, in May, won first place in the "Competition for Students who Attend Universities With Less Than $\$ 600$ Million in 2012 R\&D Expenditures." Her winning paper, "Characterization of Bismuthate Oxidized Americium (V, VI) in Acidic Solution Using X-ray Absorption Fine Structure Spectroscopy," formed one of three research chapters in her dissertation.

Her research focuses on finding a better way to separate americium from the lanthanides, a process that could factor into possible recycling methods for used nuclear fuel. 


\section{Professional Roles}

Kemal Pasamehmetoglu chaired the 2nd International Workshop on Accident Tolerant Fuels organized by OECD/NEA in Paris, France.

Brent Stacey served on the Program Committee for the International Conference Nuclear Security in a Computer World: Prevention, Detection and Resistance to Emerging Cyber Threats - IAEA Office of Nuclear Security.
Robert Podgorney was asked to serve as a technical reviewer for the World Geothermal Congress 2015 for two areas: EGS and Software for Geothermal Applications.

Richard Wright participated in Generation IV International Forum Very High-Temperature Reactor (VHTR) Materials Program Management Board Meeting as U.S. alternate representative and Chair of the High Temperature Metals Working Group.

Terry Todd chaired the GLOBAL (nuclear fuel cycle) Conference.
Harold McFarlane represented the U.S. in an IAEA consultancy on innovations in nuclear energy R\&D collaboration.

April Pope organized the logistics of the Steering Committee Meeting of the International Framework for Nuclear Energy Cooperation (IFNEC) in Abu Dhabi.

Jake Gentle served as a technical expert panelist, supporting "Innovative Dynamic Monitoring Technologies" at TransForum-Texas, which is the utility industry's leading annual transmission and distribution event.

Rangam Subramanian participated in the Telecommunications Industry Association Chief Technology Officer Council December Roundtable to develop and advocate policy recommendations for spectrum sharing.

Steve Aumeier was invited by DOE Office of Nuclear Energy (NE-1) to lead a planning effort for pursuit of hybrid energy systems.
Rob Hoffman served as an international guest lecturer for the IAEA Regional Training Course on "Computer Security at Nuclear Facilities" held in Ghana.

Daniel Devasirvatham served as the technical consultant to both FirstNet and the Oregon Statewide Interoperability Coordinator Office for implementation of the national public safety communications network.

Carl Kutsche received an expression of appreciation from the Dean of the University of Central Florida for his service on their Advisory Board in Undergraduate Optics and Photonics.
Humberto Garcia was invited to present a seminar entitled: "Nuclear Hybrid Energy Systems: Challenges \& Opportunities" at the Organization for Economic Co-operation and Development (OECD) in Paris, France. 


\section{Professional Roles}

Anne Seifert provided an invited presentation at the American Society of Engineering

Education - Conference for Industry and Education Collaboration. Her presentation described the benefits of the INL i-STEM summer institute program and other i-STEM outreach approaches, benefits of enhancing teacher professional development in STEM subjects, and the potential for replicating the program. The event illustrates INL's recognized leadership in STEM education while promoting the national focus on developing a STEM literate workforce and filling the pipelines of industry.

Richard Wyman presented a keynote address focused on the significance of network data security for water utilities at the Smart Water Networks (SWAN) Forum 2014 Conference in Madrid, Spain. SWAN is a worldwide industry forum promoting the integration of data technologies in water networks. The address was delivered to an international audience of vendors from Europe, North America, Asia, New Zealand, and Israel representing major companies including ABB, Itron, 3M, Schneider Electric, and smaller start-up companies. As a result, Mr. Wyman was invited to support two SWAN working groups focused on interoperability and secure network infrastructure.

Amy Lientz and Andy Zach were requested to be part of the Secretarial team organizing a Capitol Hill National Laboratory Day in September 2014. Current actions include proposing a media plan, identifying key research projects to highlight, and building relationships with key congressional stakeholders.
Curtis Smith was invited to a joint EPRI and Electricity de France (EdF) meeting on the topic of probabilistic risk assessment and the work INL is conducting on the RISMC project.
David Petti and Joy Rempe were invited to participate on a committee to assist MIT to consider the future of the MIT nuclear reactor. The committee has been tasked to provide recommendations on how the Nuclear Reactor Laboratory, either in its present form or in a modified or entirely new configuration, contributes most effectively with the Department of Nuclear Science and Engineering to develop a vision for future MIT leadership in nuclear technology R\&D and education.
Steve Aumeier was invited to participate in an Energy Efficiency and Renewable Energy (EERE) National Lab Engagement meeting. The objective of the meeting was to gain Associate/ Deputy Laboratory Director input on specific topics related to "national laboratory engagement" and industry outreach approach prior to review by the Laboratory Policy Council and implementation.
Stephen Johnson, co-chaired a NASA-chartered technical review panel for Nuclear Power Assessment Study (NPAS).
Steve Herring was chosen by DOE to serve on one of the teams that make up the NPAS panel. 


\section{Professional Roles}

Donna Guillen participated in the 2014 Annual ANS as Technical Program Chair for the 2014 International Topical Meeting on Advances in Thermal Hydraulics (ATH'14). Guillen was responsible for organizing ATH'14 and also presented the paper, "Thermal Evaluation of Alternate Shipping Cask for GTRI Experiments," which provides an assessment of the Battelle Research Reactor cask as an alternate to the GE-2000 cask.
Eric Peterson was invited to testify in front of the U.S. House of Representatives Natural Resources Committee's Subcommittee on Energy and Mineral Resources regarding Efficient Use of Critical Materials, which includes recovery, reuse, remanufacturing, and recycling (R4). Dr. Peterson spoke on behalf of the Critical Materials Institute, an Energy Innovation Hub.
INL's Director of State Government Relations, Brian Whitlock, and former Deputy Laboratory Director, Dave Hill were asked by Governor Otter for assistance in meeting with a number of constituents interested in exploring the future of thorium reactors. INL met with the governor and his constituents and provided substantial technical background on current reactor programs, and the science associated with the use of thorium in reactors. Idaho has significant thorium and rare earths deposits, and questions about the viability of utilizing that resource are what prompted the meeting request.

Daniel Devasirvatham participated as a contributing member in the development of the National Public Safety Telecommunications Council's (NPSTC) report "Defining Public Safety Grade Systems and Facilities."

Nuclear Energy Institute's Powered by Our People campaign featured researcher Peter Wells, a Ph.D. candidate at the University of CaliforniaSanta Barbara, who is conducting research at INL through the Advanced Test Reactor National Scientific User Facility. His project relates to safely extending nuclear plant operating licenses to 80 years.
INL's Radiological Assistance Program (RAP) Team, in cooperation with the Department of Homeland Security Domestic Nuclear Detection Office, provided subject matter expertise and radiological sources in support of Radiological Nuclear Detection Seminars and Mobile Detection Deployment Unit Just-in-Time training at Eastern Idaho Technical College and at Gowen Field in Boise. These events provide outreach training for local law enforcement to be aware of RAP and other regional capabilities available during a nuclear/radiological event.

Donna Guillen is serving as a guest editor of Nuclear Technology journal. In this role, Donna invites authors of selected papers to submit manuscripts for publication consideration in two special issues of Nuclear Technology.

The Idaho Public Television asked

Travis McLing to be a subject matter expert to help with a television special that aired December 8, 2013 on groundwater. 


\section{Professional Roles}

Sandra Birk was part of an expert panel discussion at the 29th Institute of Nuclear Materials Management Spent Fuel Conference in Washington, D.C., which examined lessons learned from siting low-level radioactive waste disposal facilities in the U.S.
Richard Boardman provided an invited guest lecture to the Institute of Electrical and Electronics Engineers (IEEE)-Energy Policy Committee on hybridization of nuclear energy with power generation and industrial heat applications as a viable approach to balancing high levels of renewable power generation, while significantly reducing greenhouse gas emissions in both the power generation and industrial manufacturing energy sectors.

Kathryn McCarthy was the Plenary Speaker at the 2014 Region II U.S. Women in Nuclear Conference. Her presentation generated a lot of discussion regarding the INL's Advanced Instrumentation, Information, and Control Systems Technology and Risk-Informed Safety Margin Characterization activities.
Eric Peterson, leader of Academic Outreach and Strategy Development for the Center for Advanced Energy Studies, testified before the House Natural Resources Subcommittee on Energy and Mineral Resources in a hearing titled "American Metals \& Mineral Security: An examination of the domestic critical minerals supply and demand chain." Peterson's testimony focused on INL's Efficient Use and Recycling component of DOE's Critical Materials Institute and the importance of research and development relating to the recycle and reuse of critical materials.

Director Paul Henslee, ATR Life Extension Program, participated in the Third Specialists Meeting on In-vessel Inspection and Repair of the Fast Breeder Reactor Joyo, at the request of the Japan Atomic Energy Agency. The purpose of the meeting was the review of planned activities for the recovery of the Joyo reactor. 


\section{Professional Roles}

The DHS program office participated in two panels at The Infrastructure Security Partnership (TISP) Annual Resilience Symposium. The two panels, "The characteristics of successful regional resilience partnerships" and "The training and education requirements of state and local governments in critical infrastructure protection and resilience," provided leadership, education, and awareness on national cyber initiatives and issues. TISP was established as a non-profit partnership to facilitate a forum for advancing practice and policy for the protection of the nation's critical infrastructure.
Kathryn McCarthy was an invited keynote speaker at the International Symposium on Aging Management Program Development for System Safety of Nuclear Power Plants. The Symposium was organized by the Japan Nuclear Regulatory Authority Project "Japan Aging Management Program on System Safety."

Kelly Beierschmitt serves on the committee of visitors for the DOE Office of Nuclear Physics, the Nuclear Science Advisory Committee isotope subcommittee; the Idaho Higher Education Research Council; the Deans Council for the College of Engineering, Texas Tech University; the Chancellors Council - University of Tennessee; and the Advisory Board of the Japan Proton Accelerator Research Complex Japan.

\begin{tabular}{|l|l|}
\hline INL CERTIFICATIONS, ACCREDITATIONS AND REGISTRATION \\
\hline October & LEED Platinum Certification of REL \\
\hline November & $\begin{array}{l}\text { DOE National Training Center (NTC) Certification to teach the NTCs Job } \\
\text { Analysis course curriculum at INL }\end{array}$ \\
\hline December & DOELAP Radiological Control In-Vitro Bioassay Accreditation \\
\hline January & VPP Star Status \\
\hline February & $\begin{array}{l}\text { Safeguards and Security Training received NTC certification to teach } \\
\text { Curriculum Development at INL }\end{array}$ \\
\hline May & National Board of Boiler and Pressure Vessel Inspectors, "R" Stamp Renewal \\
\hline September & ISO 14001 Triennial Re-Certification \\
\hline
\end{tabular}




\section{LEADERSHIP ROLES}

\begin{abstract}
Denise Stephens currently chairs the National Laboratory Chief Information Officers (NLCIO) Working Group for the National Laboratory Directors Council (NLDC). NLCIO members collaborate to provide input to DOE-HQ's policies and expectations relative to technology security and stewardship. Denise also serves as a member of the DOE's Cyber Council.
\end{abstract}

In June, Juan Alvarez completed his term as vice-chair for the Energy Facility Contractors Group (EFCOG) Board of Directors. EFCOG strives to reduce DOE program costs and increase aggregate contractor performance by identifying issues that can benefit from common solutions, and by providing opportunities for exchanging information on management technical processes, procedures, and programs that have been implemented or evaluated, and positive and negative lessons learned.

Jennifer O'Sullivan chairs the DOE Network Security Monitoring Group.

Greg Christensen chairs the EFCOG Electrical Safety Subcommittee.
Amy Lientz currently chairs the National Laboratory Chief Communications Officers (NLCCO) Working Group Chair for the NLDC. The NLCCO advises on issues related to laboratory-wide communications and providing collective information and awareness of the national laboratory system to a variety of audiences.

Eric Gosswiller is currently the vice-chair of the Emergency Management Issues Special Interest Group (EMI SIG). The EMI SIG coordinates the exchange of expertise, ideas, and resources among DOE and contractor emergency management personnel; identifies common issues and priorities, and pursues activities that address shared needs. The EMI SIG is sponsored by the DOE Office of Emergency Management and Policy (NA-41).

Daren Jensen is currently Vice-Chair for the NQA-1 Subcommittee on Applications.

Patricia Loo participates as a NQA-1 SQA Subcommittee Member, and is the Team Lead for NQA-1 SQA Flow Chart for Implementation in NQA-1, EFCOG Software Quality Assurance Task Team.

Steve McMaster currently chairs the DOE Technology Transfer Working Group.

Marsha Bala chairs the Region IV U.S. Women in Nuclear (U.S. WIN) chapter. U.S. WIN is the premier network of over 6,000 women who work in nuclear- and radiation-related fields around the country. 


\section{LEADERSHIP ROLES}

Nancy Makey is the Director for the Certified Fire Protection Specialist Board of Directors and a member of the NFPA 30, Flammable and Combustible Liquids Code Committee.

Spencer Snow chairs the American Society of Mechanical Engineers (ASME) Boiler and Pressure Vessel Code, Section III, Working Group on Design Methodology, and the ASME B\&PV Code, Section III, Task Group Materials Supporting Division 3 Strain-Based Acceptance Criteria.

Martin Sattison is a member of the ANS/ASME Joint Committee on Nuclear Risk Management.

Craig Rieger started and is the co-lead for the Technical Committee on Resilience and Security for Industrial Applications (ReSia) under IEEE Industrial Electronics Society with a university collaborator.

Carl Kutsche participates on the University of Central Florida, Advisory Board in Undergraduate Optics and Photonics.

Carol Mascarenas chairs the Idaho Department of Environmental Quality Board.

Mike Love is a member of the IAEA Operation and Maintenance Review of Research Reactors, follow up review-National Institute of Standards and Technology (NIST) Centre for Neutron Research (NCNR) under the United States Department of Commerce.
David Young participates as a committee member for NFPA 484, Standard for Combustible Metals, Metal Powders, and Metal Dusts.

Cherrie Black was selected as the Director of TISP Board of Directors to advance the practices and policies of regional and infrastructure resilience and serve as their Vice Chair for Operational and Functional Resilience (OFR). The purpose of the OFR is to enable development of capabilities, policies, and methods for implementing resilience at the regional, state, local, and owner operator levels.

Robert Bratton is a member of ASME subcommittee on graphite core components, subcommittee on design, and working group on editing and design.

Kemal Pasamehmetoglu chairs the International expert group on Accident Tolerant Fuels.

Marsha Bala is currently the vice-chair of the ANS Education, Training, and Workforce Development Division.

Heather Chichester and Terry Todd participate on the ANS Fuel Cycle and Waste Management Division executive committee.

Mike Love is a member of the World Association of Nuclear Operators (WANO) team follow-up evaluation at the Chalk River Research Reactor in Canada and their corporate offices to validate the effectiveness of corrective actions for findings from a previous evaluation. 


\section{LEADERSHIP ROLES}

Mike Love Chaired the EPRI Hoisting, Rigging, and Crane User Group.

Todd Allen participates on the Transatomic Power, Technical Advisory Board.

Donna Guillen serves as an Executive Committee Member of the ANS Thermal Hydraulics

Division.

Jack Law currently chairs the ANS Fuel Cycle \& Waste Management Division.

Paul Humrickhouse performs in the role of secretary/treasurer for the ANS Fusion Energy Division.

John Bess chairs the ANS Aerospace Nuclear Science and Technology Division.

Donna Guillen participates on the ANS Thermal Hydraulics Division executive committee.

Donald Feldman chairs the Energy System Technology and Education Center (ESTEC) at Idaho State University.

Sam Grover chairs the Integrated Contractor Purchasing Team Executive Steering Council.

Appointed by the Governor of Idaho, Steve Aumeier is a member of the LINE 2.0 Commission.
Mike Love is a member of the U.S. International Thermonuclear Experimental Reactor (ITER) Review Team.

Harold McFarlane is a member of the International Nuclear Energy Academy.

Kathryn McCarthy participates on the ANS Human Factors, Instrumentation \& Controls Division executive committee.

David Thompson is a Director at large for the American Institute of Chemical Engineers, Executive Board of the National Programming Committee.

Heather Chichester participates on the ANS Materials Science and Technology Division executive committee.

Richard Martineau participates on the ANS Mathematics and Computation Division executive committee.

Piyush Sabharwall participates on the ANS Young Members Group executive committee.

Kathryn "Kallie" Metzger participates on the ANS Materials and Technology Division executive committee.

Michelle Wiest is a member of the Contractor Supply Chain Council (CSCC). The CSCC is a complex-wide team sponsored by the Director of the Office of Procurement and Assistance Management at DOE-HQ.

Heath Buckland is a member of the Institute of Nuclear Power Operations (INPO) industry working group for Corrective Action Plan (CAP) Performance Level 2 Industry Standards to address cumulative impact effects on the industry. 


\section{LEADERSHIP ROLES}

The Secretary of Energy, Ernie Moniz, appointed Joy Rempe to the Nuclear Energy Advisory Committee (NEAC). The NEAC provides independent advice to NE on complex science and technical issues that arise in the planning, managing, and implementation of DOE's nuclear energy program.
INL led the annual i-STEM Governance and Summer Institute Planning Committee meetings in Boise. STEM leaders representing the state of Idaho government, business, and industry discussed program progress, national recognition, and impact $\mathrm{i}$-STEM is making in Idaho.
Kyle Kofford is co-author of two new versions of American Weld Society Standards.

AWS B2.3/M2.3M:2012, Specification for

Soldering Procedure and Performance

Qualification, and AWS B2.1/B2.1M:2014, Specification for Welding Procedure and Performance Qualification were recently issued. These specifications provide the requirements for qualification of welding and soldering procedure specifications and performers. In his role as the INL Engineering subject matter expert in welding, Kofford participates on the American Weld Society and American Society of Mechanical Engineers codes and standards development committees with relevance to INL activities.

Through coordination with the National Cybersecurity and Communications Integration Center (NCCIC), FEMA requested that DHS and N\&HS and Laboratory Protection employees within the Idaho component of ICS-CERT participate in the Joint Users Interoperability Communications Exercise (JUICE). JUICE is an annual worldwide DOD communications exercise connecting more than 40 diverse organizations under one common operating environment supporting Combatant Commands, as well as intergovernmental, interagency and multi-national partners in a Joint Task Force environment.

INL's nuclear materials management expertise was highlighted during the Institute of Nuclear Materials Management (INMM) 55th Annual Meeting. N\&HS participants provided technical leadership in three forums: Mark Schanfein co-chaired a session on "International Safeguards: Advances in Safeguards Technology and Instrumentation for Pyroprocessing"; Sean Morrell co-chaired a session on "International Safeguards: Interface Among Safety, Security and Safeguards"; and Jeff Sanders chaired a session on "Materials Control and Accountability: Neutron Measurements III." 


\section{LEADERSHIP ROLES}

NNSA Deputy Administrator for Defense Anne Harrington has initiated a NA-20 Cyber Task Force and selected INL's Rob Hoffman

Laboratory Co-Lead for the task force.
INL staff participated in both the Electrochemical Recycling and Safeguards and Security Working Group Meetings of the Joint Fuel Cycle Studies in Seoul, Republic of Korea. These meetings focused on plans for the Integrated Recycle Test (IRT) that will evaluate electrochemical recycling technology, including safeguards at INL.

The DHS Program Office participated in the facilitated workshop conducted in furtherance of the Charlotte-Mecklinburg Municipal Utilities District cyber Regional Resilience Assessment Program, the first of its type. Participants of the workshop included representatives from local jurisdictions, emergency managers, as well as physical and cyber security representatives from the utilities and supporting infrastructure in the area.

DOE's Office of Energy Efficiency and Renewable Energy featured INL's dual-fuel bus conversion process in its spring 2014 issue of Clean Cities Now.
Peaceful Use of Nuclear Energy at Texas A\&M University on April 15-17, 2014. DOE-NE, the TAMU Nuclear Power Institute (NPI), and INL jointly planned the workshop. The official outcome of the workshop was an action plan drafted by DOE and the Nuclear Energy Agency (NEA).

INL and ISU co-hosted a successful international engagement with industry, government, academia, and emergency first responders at the National Wireless Research Collaboration Symposium (NWRCS2014). The Symposium was funded by the National Science Foundation and INL.
Jim Francfort presented and chaired a session at the Defense Energy Summit in Austin, Texas, November 11-13, 2014. The Defense Energy Summit focuses on how to accelerate clean energy and infrastructure solutions for the Department of Defense and Mr. Francfort chaired the session entitled, "Advanced Vehicle Initiatives - Installations to Operations." 
(20) 


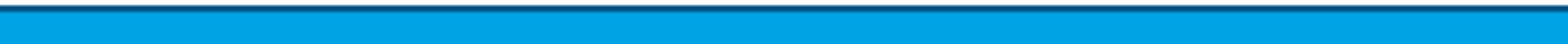




\section{Attachment 5 \\ Performance Issues and Challenges}

INL executes some of the nation's most complex and technologically advanced missions; focusing on issues, such as, R\&D of reliable, affordable, clean energy required to sustain the economy and combat climate change; reliance and security of critical infrastructures (energy, manufacturing, telecom, etc.); development of a science and technology-based workforce and state-of-the-art facilities essential for creating innovation; and collaboration in all stages of the innovation cycle for technology deployment in the 21 st century. These issues present the Laboratory with unique risks and performance challenges. The purpose of this attachment is to identify challenges to the INL's wide-ranging operations as well as problems with specific management processes. The overall goal is to focus attention on key issues, with the objective of aiding BEA and DOE managers in their efforts to enhance the effectiveness of Laboratory programs and operations.

The 2013 Self-Assessment Report defined issues and challenges facing BEA, many of which were addressed and significantly improved upon during FY 2014. Some examples of initiatives in place to sustain systemic improvements include:

- Intellectual Infrastructure Initiatives led by the Chief Scientist and the Laboratory Fellows. Sustaining research excellence (mentoring, development, knowledge transfer).

- Research Excellence Board. Ensuring that research excellence is not only maintained, but is continuously improving (e.g., awareness of initiatives and emerging issues, effective resolution of cross-cutting conduct of research related problems, embracing internal and external lessons learned).

- R\&D Integration Team. Cross section of S\&T thought and opinion leaders that provide valuable and timely feedback, communicate INL research values, and seek a coordinated effort to ensure R\&D excellence.

- Improved Integration Among Operations. ATR, MFC, Nuclear Science \& Technology (NS\&T), Engineering, and Quality are working to improve the experiment process by developing LWP-20700, "Nuclear Materials Execution Process," and coordinating annual strategic operating plans between ATR and MFC.

- Conduct of Research Initiative. Setting standards and expectations for the R\&D community by providing accessible information ("How do I" videos, links to relevant procedures) and greatly simplifying processes while making them easy to access through electronic media.

- Systemic Improvements to Contractor Assurance. Streamlining issues management, establishing screening teams, and conducting Management Review Meetings.

- Quality Process Improvements. Revamped software Quality Assurance (QA) program and streamlined procurement processes for quality items/supplier lists.

- Business Systems Working Group. Ensuring coordinated, efficient, effective tools and processes.

These initiatives and other actions have resulted in a continued decrease in the number and severity of operational incidents and continue to improve safety, efficiency, and productivity. Still, FY 2014 continued to present challenges that remain key factors moving forward. 


\section{Management Challenges}

Based on the results of our completed work, including input from DOE oversight and external entities (OIG, DEQ, DNFSB, etc.) over the past year, in our judgment, the following management challenges represent the best opportunities to strategically improve Laboratory performance (not listed by priority). This is an update from the list provided in FY 2013. These challenges include:

- Human Capital

- Intellectual Infrastructure

- Institutional Policies

- Integration of Research and Operations

- Funding for ATR and MFC

- Infrastructure

- Environmental Legacy

- Cyber Security

- Hazard Identification

- Business Systems and Decision Support

- Work Acceptance.

Human Capital. Significant fiscal challenges in FY 2012 and FY 2013, though improved in FY 2014, limited the ability to establish optimal talent pipelines. BEA took numerous strategic actions to minimize impacts through careful workforce restructuring, yet "single-points-of failure" continue to present efficiency and knowledge transfer risks. This challenge, combined with a significant percentage of the workforce approaching retirement age and a demand for program growth, will require innovation in INL recruitment and retention practices and incentives in FY 2015 as well as close engagement with the mission organizations.

Intellectual Infrastructure. INL's intellectual infrastructure is critical to ensure the Laboratory is well-positioned for achieving long-term mission goals and to sustain the INL's role as a "thought" leader for DOE-NE. This presents the challenge to ensure mentoring and development of incoming researchers through sustainable programs (e.g., formal mentoring, knowledge transfer, and peer reviews).

Institutional Policies. INL's research and operations are diverse, complex, and innovative. The continued challenge facing INL is to establish processes and polices that support, rather than hinder excellence in research. Processes must promote safety, fully address extensive regulatory requirements, be easy to understand and implement, and encompass all interfaces and hand-offs. This must be done in a manner that limits administrative burden and potential for error or non-compliance.

Integration of Research and Operations. BEA has made notable progress in furthering integration between research and operations. However, in FY 2014, there were opportunities for improvement identified (e.g., irradiation experiments were impacted by poor work products resulting from ineffective integration of research, operations, and engineering). Continued progress will require focus on related initiatives (e.g., nuclear experiment process improvements, R\&D Integration Team, Conduct of Research). 
Funding for ATR and MFC. A new cost model was submitted for MFC to provide efficient cost recovery, planning and to ensure sustainability in funding infrastructure upgrades. Similarly, ATR is working with NR and DOE-NE on ATR funding/staffing and the right funding to restore ATR fuel to the agreed to minimum reserve. A team consisting of senior management from ATR, DOE-NE and NR has met throughout the year to discuss the funding levels for ATR. ATR personnel developed an in-depth work break down structure (WBS) that was reviewed by both NR and DOE-NE. ATR is developing a five year implementation plan to close the gaps in base funding.

Infrastructure. Significant multi-year fiscal challenges have resulted in an increase in deferred maintenance and needed upgrades such as roofs, critical infrastructure (electric power grid and information management capability), Decontamination and Decommissioning (D\&D) of non-enduring assets, and space optimization. Without adequate investment in this type of sustainment funding, the ability to enable mission accomplishment is placed at risk.

Environmental Legacy. Managing the disposition of environmental legacy waste and materials and establishing an enduring waste management capability create challenges to effectively address the long-term stewardship of the Laboratory. This includes managing impacts of new cleanup contracts, such as, shared services (e.g., utilities, emergency services, bus service).

Cyber Security. Protecting the Laboratory's networks, information, and services from unintended or unauthorized access, change or destruction is an enduring and increasing risk. Developing staff understanding and commitment to effectively safeguarding cyber systems remains a key challenge.

Hazard Identification. Hazard identification is frequently the most challenging of the ISMS core functions. Assessments continue to find that once identified, hazards are typically effectively mitigated; the greater challenge seems to rest on identifying the hazards, especially related to emerging conditions. Continued focus on understanding the hazards at all phases of research or operations is an exceptionally important and continual challenge.

Business Systems and Decision Support. The ability for INL to perform performance monitoring, decision support, and predictive analytics is hindered by a lack of a mature business systems environment, including a robust business intelligence capability. Business software applications are not well integrated, are approaching end of life, and are not user friendly. Many of the tools are in place (e.g., data warehouse, Microsoft PowerPivot, SAS Visual analytics) yet investment is still needed to coordinate disperse data sources. Funding has been allocated to upgrade Oracle eBusiness Suite in FY 2015.

Work Acceptance. BEA is looking to improve processes for proposing and accepting work at the institutional level. Currently, there is no capability (or system) effectively managing proposal submittals or properly identifying resource capacity and risks, accepting and planning work, and ensuring full-cost recovery. 


\section{Performance Issues}

In FY 2014, BEA is taking action to improve performance challenges (see table below).

\begin{tabular}{|c|c|}
\hline Opportunity & Actions \\
\hline $\begin{array}{l}\text { Ability to run } \\
\text { ATR reliably }\end{array}$ & $\begin{array}{l}\text { Goal } \\
>90 \% \text { availability. } \\
\text { Approach } \\
\text { - Resolve ATR funding needs } \\
\text { - Life-cycle improvements to nuclear experiment process } \\
\text { - Increase equipment reliability. }\end{array}$ \\
\hline $\begin{array}{l}\text { Establish the } \\
\text { fundamental } \\
\text { principle and } \\
\text { standard for } \\
\text { operations that } \\
\text { all uptakes are } \\
\text { preventable }\end{array}$ & $\begin{array}{l}\text { Goal } \\
\text { Drive the chances of high specific activity alpha uptakes to zero to minimize operational } \\
\text { disruptions. This will be accomplished by systematically designing engineering controls } \\
\text { to reduce risk and moving all high specific activity alpha work where an inhalation hazard } \\
\text { exists into full containment. } \\
\text { Approach } \\
\text { - Communicate goals and expectations } \\
\text { - INL-wide response - not just MFC } \\
\text { - Containment is provided and our plan is being worked. }\end{array}$ \\
\hline $\begin{array}{l}\text { Build stronger } \\
\text { partnership with } \\
\text { public affairs }\end{array}$ & $\begin{array}{l}\text { Goal } \\
\text { Good and timely communication among INL, DOE-NE, and DOE-ID so DOE can } \\
\text { effectively respond to internal and external constituencies. } \\
\text { Approach } \\
\text { - Comply with Contracting Officer letter of expectations } \\
\text { - Communicate goals and expectations to staff } \\
\text { - INL-wide response - all programs have to take ownership. }\end{array}$ \\
\hline $\begin{array}{l}\text { Improve radio } \\
\text { coverage }\end{array}$ & $\begin{array}{l}\text { Goal } \\
\text { Emergency responders can effectively communicate and manage risks. } \\
\text { Approach } \\
\text { - Negotiate new contract language for managed service } \\
\text { - Identify coverage gaps for key facilities } \\
\text { - Implement interim solution followed by long-term fix. }\end{array}$ \\
\hline Restart NRAD & $\begin{array}{l}\text { Goal } \\
\text { Resume programmatic use of NRAD. } \\
\text { Approach } \\
\text { - Address vendor nonperformance } \\
\text { - Evaluate alternatives } \\
\text { - Manage program impacts. }\end{array}$ \\
\hline
\end{tabular}




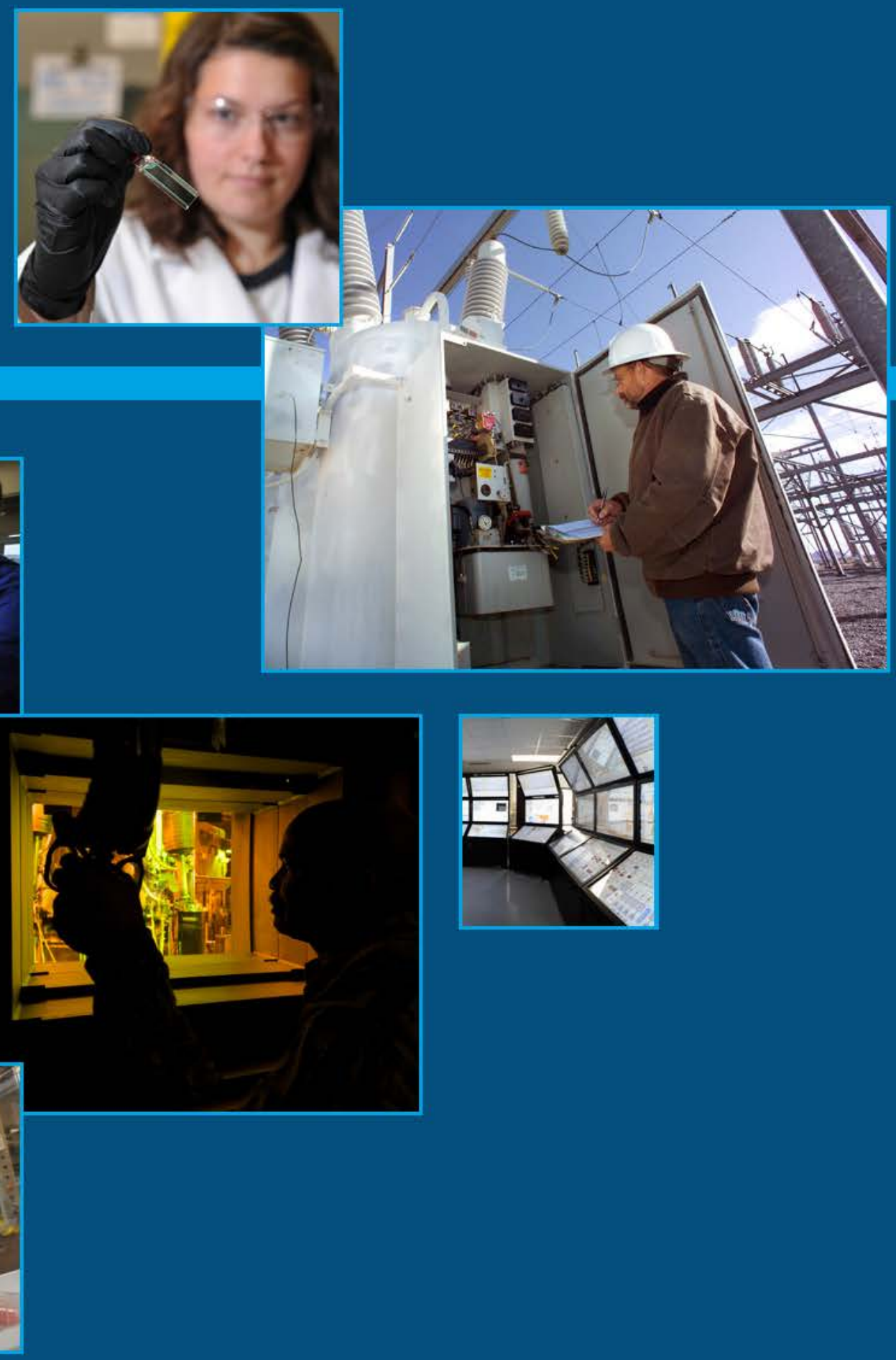

\section{WWW.INL.GOV}

More information:

Juan Alvarez

Deputy Laboratory Director

Management

juan.alvarez@inl.gov

(208) 526-9128 